\title{
The Business Case for Systems Engineering Study: Results of the Systems Engineering Effectiveness Survey
}

\author{
Joseph P. Elm \\ Dennis R. Goldenson
}

November 2012

SPECIAL REPORT

CMU/SEI-2012-SR-009

CERT Program

http://www.sei.cmu.edu

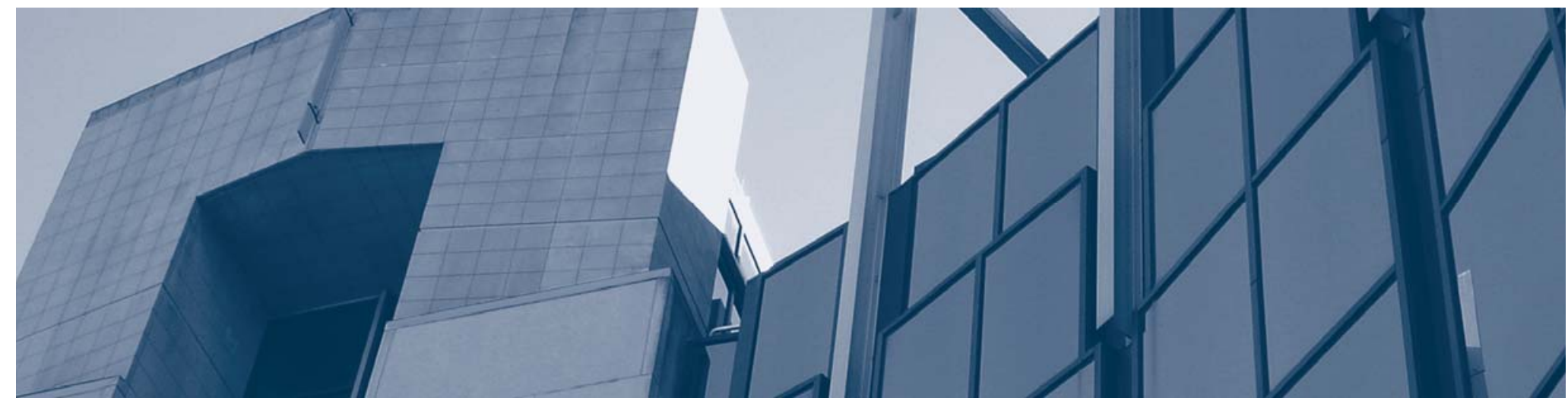


Copyright 2012 Carnegie Mellon University.

This material is based upon work funded and supported by the Department of Defense under Contract No. FA8721-05-C-0003 with Carnegie Mellon University for the operation of the Software Engineering Institute, a federally funded research and development center.

Any opinions, findings and conclusions or recommendations expressed in this material are those of the author(s) and do not necessarily reflect the views of the United States Department of Defense.

This report was prepared for the

SEI Administrative Agent

AFLCMC/PZE

20 Schilling Circle, Bldg 1305, 3rd floor

Hanscom AFB, MA 01731-2125

NO WARRANTY. THIS CARNEGIE MELLON UNIVERSITY AND SOFTWARE ENGINEERING

INSTITUTE MATERIAL IS FURNISHED ON AN “AS-IS” BASIS. CARNEGIE MELLON UNIVERSITY

MAKES NO WARRANTIES OF ANY KIND, EITHER EXPRESSED OR IMPLIED, AS TO ANY MATTER

INCLUDING, BUT NOT LIMITED TO, WARRANTY OF FITNESS FOR PURPOSE OR

MERCHANTABILITY, EXCLUSIVITY, OR RESULTS OBTAINED FROM USE OF THE MATERIAL. CARNEGIE MELLON UNIVERSITY DOES NOT MAKE ANY WARRANTY OF ANY KIND WITH RESPECT TO FREEDOM FROM PATENT, TRADEMARK, OR COPYRIGHT INFRINGEMENT.

This material has been approved for public release and unlimited distribution except as restricted below.

The Government of the United States has a royalty-free government-purpose license to use, duplicate, or disclose the work, in whole or in part and in any manner, and to have or permit others to do so, for government purposes pursuant to the copyright license under the clause at 252.227-7013 and 252.227-7013 Alternate I.

Internal use:* Permission to reproduce this material and to prepare derivative works from this material for internal use is granted, provided the copyright and "No Warranty" statements are included with all reproductions and derivative works.

External use:* This material may be reproduced in its entirety, without modification, and freely distributed in written or electronic form without requesting formal permission. Permission is required for any other external and/or commercial use. Requests for permission should be directed to the Software Engineering Institute at permission@sei.cmu.edu.

* These restrictions do not apply to U.S. government entities.

( $\quad$ Capability Maturity Model, Carnegie Mellon, CERT, CMM, and CMMI are registered in the U.S. Patent and Trademark Office by Carnegie Mellon University.

SM CMM Integration is a service mark of Carnegie Mellon University. 


\section{Table of Contents}

$\begin{array}{lc}\text { Acknowledgments } & \text { ix }\end{array}$

$\begin{array}{lc}\text { Executive Summary } & \text { xi }\end{array}$

$\begin{array}{ll}\text { Abstract } & \text { XV }\end{array}$

1 Introduction $\quad 1$

$\begin{array}{ll}1.1 \text { Background } & 1\end{array}$

1.2 Purpose 1

2 Developing the SE Effectiveness Survey $\quad 3$

2.1 Defining the Survey Population 3

2.2 Developing and Testing the Questionnaire 3

2.2.1 Assessing SE Applied to Projects $\quad 4$

2.2.2 Assessing Project Performance $\quad 5$

2.2.3 Assessing Other Factors $\quad 6$

2.2.4 Testing the Survey Instrument $\quad 6$

$\begin{array}{ll}2.3 & \text { Designing the Solicitation Campaign }\end{array}$

2.3.1 Maximizing Response Rate $\quad 6$

2.3.2 Maximizing Sample Size $\quad 8$

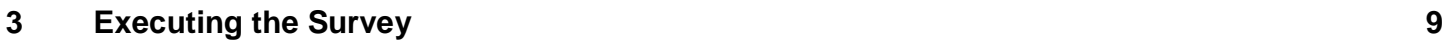

$4 \quad$ Analyzing the Responses $\quad 10$

$\begin{array}{lll}4.1 & \text { Scoring } & 10\end{array}$

4.1.1 Project Performance Analysis 11

4.1.2 Project Challenge $(P C) \quad 12$

4.1.3 Systems Engineering Capability (SEC) 12

$\begin{array}{lll}4.1 .4 & \text { Other Factors } & 14\end{array}$

4.2 Identifying Relationships $\quad 15$

$\begin{array}{lll}\text { 4.2.1 Mosaic Charts } & 15\end{array}$

$\begin{array}{ll}\text { 4.2.2 Statistical Measures } & 17\end{array}$

5 Survey Results $\quad 19$

5.1 Response and Response Rate 19

5.2 Project Performance 22

$\begin{array}{lll}5.3 & \text { Project Challenge } & 25\end{array}$

$\begin{array}{ll}5.4 & \text { Systems Engineering Capabilities }\end{array}$

5.4.1 Total Systems Engineering Capability 27

5.4.2 Requirements Development and Management 29

$\begin{array}{lll}5.4 .3 & \text { Project Planning } & 32\end{array}$

5.4.4 Product Architecture $\quad 34$

$\begin{array}{lll}5.4 .5 & \text { Trade Studies } & 37\end{array}$

5.4.6 Product Integration $\quad 39$

$\begin{array}{lll}5.4 .7 & \text { Verification } & 42\end{array}$

$\begin{array}{lll}5.4 .8 & \text { Validation } & 44\end{array}$

5.4.9 Project Monitoring and Control $\quad 47$

5.4.10 Risk Management $\quad 49$

5.4.11 Configuration Management $\quad 52$

5.4.12 Integrated Product Teams $\quad 54$

$\begin{array}{llr}5.5 & \text { Other Factors } & 57\end{array}$ 
5.5.1 Experience

5.5.2 Contract Type $\quad 59$

$\begin{array}{lll}\text { 5.5.3 SE Organization } & 61\end{array}$

5.5.4 Project Percentage Complete 63

$\begin{array}{lll}\text { 5.5.5 SE Content } & 64\end{array}$

$6 \quad$ Comparison with the Prior Study 66

6.1 Comparison of Study Executions 66

6.1.1 Questionnaire Differences $\quad 66$

$\begin{array}{ll}\text { 6.1.2 Analysis Differences } & 68\end{array}$

6.1.3 Sampling Differences $\quad 68$

6.2 Differences in Study Results 69

$\begin{array}{lll}7 & \text { Summary } & 74\end{array}$

8 Next Steps $\quad \mathbf{8 0}$

$\begin{array}{lll}\text { Appendix A Cross Reference to CMMI } & 83\end{array}$

$\begin{array}{lll}\text { Appendix B } & \text { Questionnaire } & 91\end{array}$

Appendix C Solicitation of an Invitation to Respondents 125

Appendix D Details of the Analysis Process 131

$\begin{array}{ll}\text { Acronyms and Abbreviations } & 151\end{array}$

$\begin{array}{ll}\text { References } & 153\end{array}$ 


\section{List of Figures}

Figure 1: Project Performance vs. Total SE Capability xi

Figure 2: Project Performance vs. SE Capabilities and Drivers xiii

Figure 3: Project Performance vs. Total SE Capability controlled by Project Challenge xiv

Figure 4: Notional Mosaic Chart Key 16

Figure 5: Gamma Calculation 17

Figure 6: Industry 21

Figure 7: System End Users 21

Figure 8: Country of Project Execution 22

Figure 9: Contract Value Response Distribution 22

Figure 10: Perf Response Distribution 23

Figure 11: PerfC Response Distribution 23

Figure 12: PerfS Response Distribution 24

Figure 13: PerfT Response Distribution 24

Figure 14: Perf Cumulative Response Distribution 25

Figure 15: PC Response Distribution 26

Figure 16: PC vs. Perf 26

Figure 17: SEC-Total Response Distribution $\quad 27$

Figure 18: SEC-Total vs. Perf 28

Figure 19: SEC-Total vs. Perf Controlled by PC 29

Figure 20: SEC-REQ Response Distribution 30

Figure 21: SEC-REQ vs. Perf 30

Figure 22: SEC-REQ vs. Perf Controlled by PC 31

Figure 23: SEC-PP Response Distribution 32

Figure 24: SEC-PP vs. Perf 33

Figure 25: SEC-PP vs. Perf Controlled by PC 34

Figure 26: SEC-ARCH Response Distribution 35

Figure 27: SEC-ARCH vs. Perf 35

Figure 28: SEC-ARCH vs. Perf Controlled by PC 36

Figure 29: SEC-TRD Response Distribution 37

Figure 30: SEC-TRD vs. Perf 38

Figure 31: SEC-TRD vs. Perf Controlled by PC 39

Figure 32: SEC-PI Response Distribution 40

Figure 33: SEC-PI vs. Perf 40 
Figure 34: SEC-VER vs. Perf Controlled by PC

Figure 35: SEC-VER Response Distribution

Figure 36: SEC-VER vs. Perf

Figure 37: SEC-VER vs. Perf Controlled by PC

Figure 38: SEC-VAL Response Distribution

Figure 39: SEC-VAL vs. Perf 45

Figure 40: SEC-VAL vs. Perf Controlled by PC 46

Figure 41: SEC-PMC Response Distribution 47

Figure 42: SEC-PMC vs. Perf 48

Figure 43: $\quad$ SEC-PMC vs. Perf Controlled by PC 49

Figure 44: SEC-RSKM Response Distribution $\quad 50$

Figure 45: SEC-RSKM vs. Perf $\quad 50$

Figure 46: SEC-RSKM vs. Perf Controlled by PC 51

Figure 47: SEC-CM Response Distribution $\quad 52$

Figure 48: SEC-CM vs. Perf 53

Figure 49: SEC-CM vs. Perf Controlled by PC 54

Figure 50: SEC-IPT Response Distribution $\quad 55$

Figure 51: SEC-IPT vs. Perf $\quad 55$

Figure 52: SEC-IPT vs. Perf Controlled by PC 56

Figure 53: $\quad$ EXP Response Distribution $\quad 57$

\begin{tabular}{ll} 
Figure 54: & EXP vs. Perf \\
\hline
\end{tabular}

Figure 55: EXP vs. Perf Controlled by PC 59

Figure 56: Contract Type Response Distribution $\quad 60$

$\begin{array}{ll}\text { Figure 57: } & \text { Contract Type vs. Perf }\end{array}$

Figure 58: $\quad$ SE Organization Response Distribution 61

Figure 59: SE-Orgn vs. SEC-Total $\quad 62$

Figure 60: SE-Orgn vs. Perf $\quad 62$

Figure 61: SE Project Percentage Complete Response Distribution 63

Figure 62: Percentage Complete vs. Perf 63

Figure 63: \%SE Response Distribution $\quad 64$

Figure 64: \%SE vs. Perf $\quad 65$

Figure 65: $\quad$ Perf vs. SEC-Total (from 2007 NDIA Study) 69

$\begin{array}{ll}\text { Figure 66: } & \text { Perf vs. SEC-Total }\end{array}$

Figure 67: Comparison of Gamma Values $\quad 71$

$\begin{array}{ll}\text { Figure 68: } & \text { SEC-Total vs. Perf }\end{array}$

Figure 69: $\quad$ SEC-Total vs. Perf Controlled by PC $\quad 75$ 
Figure 70: Summary of Relationships for All Projects

Figure 71: Summary of Relationships for Less Challenging Projects

Figure 72: Summary of Relationships for More Challenging Projects 78

Figure 73: BCSE Process

80 
CMU/SEI-2012-SR-009 | vi 


\section{List of Tables}

Table 1: Summary of Project Performance versus Systems Engineering Capabilities xii

Table 2: Summary of Project Performance versus Other Factors xiii

Table 3: $\quad$ Work Products Used to Assess SE Deployment 4

Table 4: $\quad$ CMMI Process Groups 5

Table 5: $\quad$ Participation Inquiries $\quad 9$

Table 6: $\quad$ SE Process Groups 12

$\begin{array}{lll}\text { Table 7: } & \text { Factors Used to Assess Project Challenge } & 67\end{array}$

Table 8: Comparison of Gamma Values and p-values $\quad 70$

Table 9: Summary of Relationships Between SE Deployment and Project Performance 76

Table 10: Summary of Relationships Between Other Factors and Project Performance 76

Table 11: Cross Reference to CMMI 83

Table 12: Project Performance (Perf) Assessment 131

Table 13: Budget-Based Cost Performance Assessment 133

Table 14: CPI Data Disposition 134

Table 15: CPI-Based Cost Performance 134

Table 16: Customer-Satisfaction-Based Cost Performance Assessment 134

Table 17: Project-Duration-Based Schedule Performance Assessment 135

Table 18: $\quad$ SPI-Based Schedule Performance 135

Table 19: $\quad$ IMS-Based Schedule Performance Assessment 136

Table 20: Customer-Satisfaction-Based Schedule Performance Assessment 136

Table 21: PerfT Assessment 136

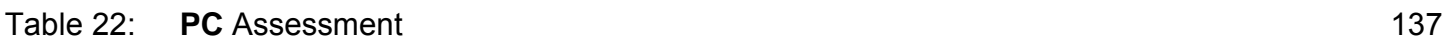

Table 23: $\quad$ SEC-IPT Assessment 139

Table 24: $\quad$ SEC-PP Assessment 139

Table 25: $\quad$ SEC-PMC Assessment Questions 141

Table 26: $\quad$ SEC-RSKM Assessment Questions 142

Table 27: $\quad$ SEC-REQ Assessment Questions 143

Table 28: $\quad$ SEC-TRD Assessment Questions 145

Table 29: $\quad$ SEC-ARCH Assessment Questions 145

Table 30: $\quad$ SEC-PI Assessment Questions 146

Table 31: $\quad$ SEC-VER Assessment Questions 146

$\begin{array}{lll}\text { Table 32: } & \text { SEC-VAL Assessment Questions } & 147\end{array}$

Table 33: $\quad$ SEC-CM Assessment Questions 147 
Table 34: EXP Assessment Questions

Table 35: Contract Type Question

Table 36: SE Organization Question

Table 37: Percentage Complete Question

Table 38: Percentage SE Question 


\section{Acknowledgments}

We created this report based on the collaborative efforts of the National Defense Industrial Association (NDIA) Systems Engineering Division, the Institute of Electrical and Electronic Engineers (IEEE) Aerospace and Electronic Systems Society, the Software Engineering Institute of Carnegie Mellon University, and the Systems Engineering Effectiveness Working Group of the International Council on Systems Engineering (INCOSE).

Primary contributors to this effort include

$\begin{array}{lll}\text { Alan R. Brown } & \text { Julie Cohen } & \text { Geoff Draper } \\ \text { Robert Epps } & \text { Paul Frenz } & \text { Dave Griffith } \\ \text { William F. Lyons } & \text { Jim McCurley } & \text { Judy Scharmann } \\ \text { Derrick Spooner } & \text { Robert Rassa } & \text { Garry Roedler }\end{array}$

Michael J. Zuccher

Members of the NDIA-IEEE-SEI SE Effectiveness Committee include

$\begin{array}{lll}\text { Al Brown } & \text { Dale Blair } & \text { Clyde Chittister } \\ \text { Geoff Draper } & \text { Dan Goddard } & \text { Clarence Gooden } \\ \text { Dave Griffith } & \text { Eric Honour } & \text { Bill Lyons } \\ \text { Bob Lyons } & \text { Marty Meth } & \text { Michael McLendon } \\ \text { Tom McDermott } & \text { Christopher Miller } & \text { Roger Oliva } \\ \text { Ken Ptack } & \text { Bob Rassa } & \text { Annette Reilly } \\ \text { Garry Roedler } & \text { Marina Ruggieri } & \text { Theo Saunders } \\ \text { Steve Teahan } & \text { Hal Wilson } & \end{array}$

Members of the INCOSE SE Effectiveness Committee include

$\begin{array}{lll}\text { John Ackley } & \text { Ron Carson } & \text { Quoc Do } \\ \text { Michael Edwards } & \text { Bruce Elliott } & \text { Joseph Elm } \\ \text { Summer Fowler } & \text { Rick Frazer } & \text { Paul Frenz } \\ \text { Dawn Gilbert } & \text { Heidi Hahn } & \text { Sandra Hammond } \\ \text { Leroy Hanneman } & \text { Eric Honour } & \text { Robert Horner } \\ \text { John Howard } & \text { Carol Hutchinson } & \text { Ebad Jahanger } \\ \text { Steve Mazeika } & \text { Ryan McCullough } & \text { Bill Miller } \\ \text { Paul Miller } & \text { Joan Nolan } & \text { Beth O'Donnell } \\ \text { Chris Orlowski } & \text { Garry Roedler } & \text { Nancy Roseberry } \\ \text { Jean-Claude Roussel } & \text { Frank Sciulli } & \text { Keiko Shimazu } \\ \text { Richard Sidley } & \text { Dale Smith } & \text { Jim Smith } \\ \text { Tim Spencer } & \text { George Walley } & \text { Kevin Weinstein }\end{array}$

We are grateful for the thorough reviews of the report's draft provided by

Elliot Axelband Al Brown Geoff Draper Joan Nolan Garry Roedler Sarah Sheard

We offer our appreciation to the following people for their enduring support of this project:

Clyde Chittister Paul Nielsen Richard D. Pethia William R. Wilson

And finally, we offer our appreciation to our editor, Sandy Shrum, for making our ramblings readable. 
CMU/SEI-2012-SR-009 | x 


\section{Executive Summary}

The National Defense Industrial Association Systems Engineering Division (NDIA-SED) collaborated with the Institute of Electrical and Electronic Engineers Aerospace and Electronic Systems Society (IEEE-AESS) and the Software Engineering Institute (SEI) of Carnegie Mellon ${ }^{\circledR}$ to obtain quantitative evidence of the benefit of systems engineering (SE) best practices on project performance. The team developed and executed this survey of system developers to identify SE best practices used on projects, collect performance data on these projects, and identify relationships between the application of these SE best practices and project performance.

The study found clear and significant relationships between the application of SE best practices to projects and the performance of those projects, as seen in the mosaic chart in Figure 1 and as explained below.

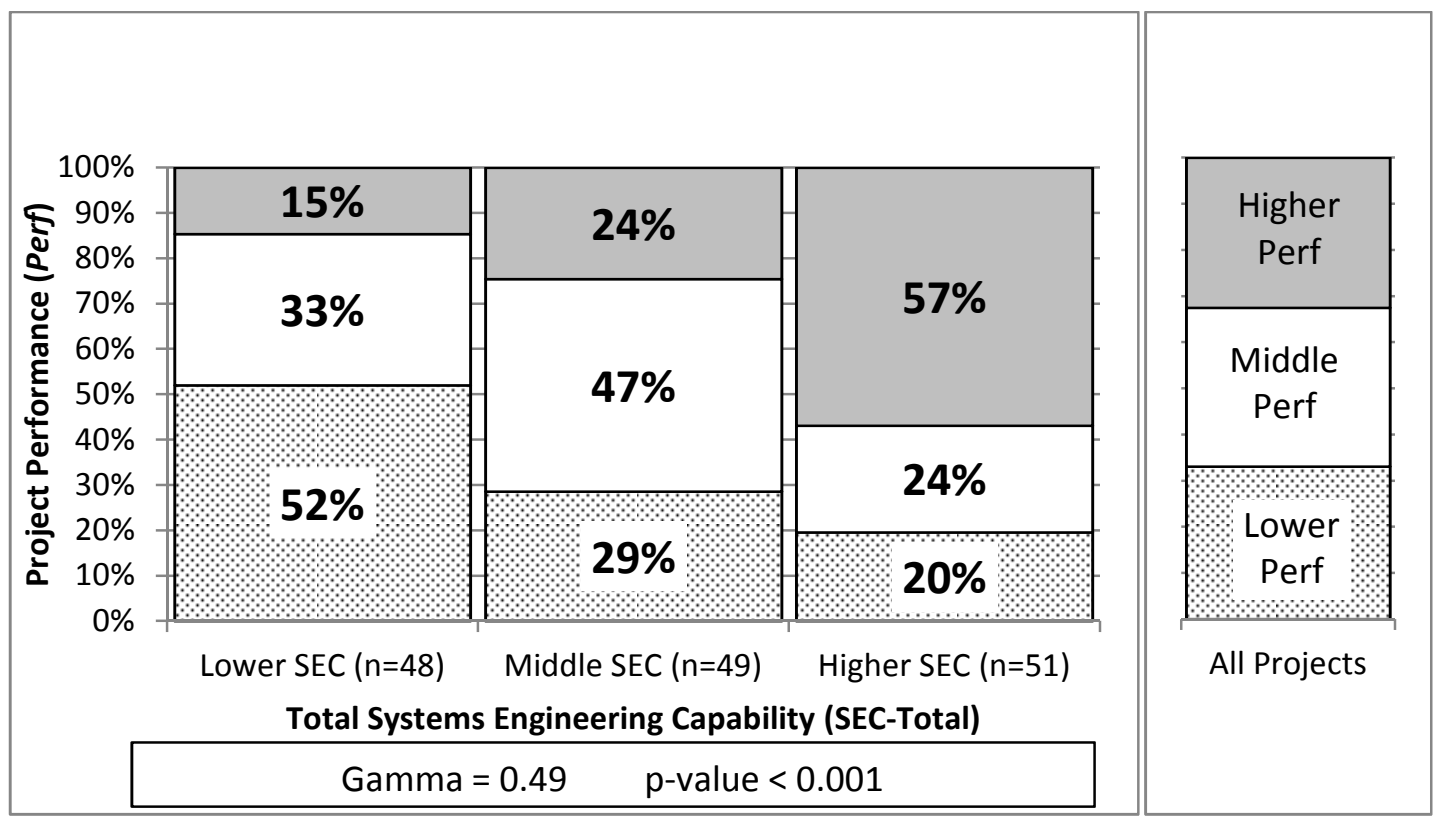

Figure 1: Project Performance vs. Total SE Capability

The left column represents projects deploying lower levels of SE, as measured by assessing the quantity and quality of specific SE work products. Among these projects, only $15 \%$ delivered higher levels of project performance, as measured by satisfaction of budget, schedule, and technical requirements. Within this group, 52\% delivered lower levels of project performance.

The second column represents those projects deploying moderate levels of SE. Among these projects, 24\% delivered higher levels of project performance and 29\% delivered lower levels of performance.

${ }^{\circledR}$ Carnegie Mellon is registered in the U.S. Patent and Trademark Office by Carnegie Mellon University. 
The third column represents projects deploying higher levels of SE. Among these projects, the number delivering higher levels of project performance increased to $57 \%$, while those delivering lower levels decreased to $20 \%$.

In addition to the mosaic chart's graphical representation of the relationship, we also employed statistical measures to characterize it. Goodman and Kruskal's Gamma expresses the strength of the relationship between two ordinal variables. Gamma values near (-1) indicate a very strong opposing relationship; values near 0 indicate a weak or non-existent relationship; values near $(+1)$ indicate a very strong supporting relationship. The gamma value of 0.49 in Figure 1 represents a very strong relationship between SE deployment and project performance.

To further understand the relationship between SE capability and project performance, the questionnaire's assessment of SE capability addressed the project's use of SE best practices in 11 management and technical process groups. Details regarding the contents of these process groups are described in this report. Responses were analyzed to identify relationships between project performance and the project's use of SE best practices in each of the process groups. Table 1and Figure 2 summarize these relationships.

Table 1: $\quad$ Summary of Project Performance versus Systems Engineering Capabilities

\begin{tabular}{|l|l|l|}
\hline \multicolumn{1}{|c|}{ Driver $^{1}$} & \multicolumn{1}{|c|}{ Gamma } & \multicolumn{1}{|c|}{ Section } \\
\hline SEC-Total: total deployed SE & $+0.49 \Rightarrow$ Very strong positive & 5.4 .1 \\
\hline SEC-PP: project planning & $+0.46 \Rightarrow$ Very strong positive & 5.4 .3 \\
\hline SEC-REQ: requirements development and management & $+0.44 \Rightarrow$ Very strong positive & 5.4 .2 \\
\hline SEC-VER: verification & $+0.43 \Rightarrow$ Very strong positive & 5.4 .7 \\
\hline SEC-ARCH: product architecture & $+0.41 \Rightarrow$ Very strong positive & 5.4 .4 \\
\hline SEC-CM: configuration management & $+0.38 \Rightarrow$ Strong positive & 5.4 .11 \\
\hline SEC-TRD: trade studies & $+0.38 \Rightarrow$ Strong positive & 5.4 .5 \\
\hline SEC-PMC: project monitoring and control & $+0.38 \Rightarrow$ Strong positive & 5.4 .9 \\
\hline SEC-PI: product integration & $+0.33 \Rightarrow$ Strong positive & 5.4 .6 \\
\hline SEC-VAL: validation & $+0.33 \Rightarrow$ Strong positive & 5.4 .8 \\
\hline SEC-RSKM: risk management & $+0.21 \Rightarrow$ Moderate positive & 5.4 .10 \\
\hline SEC-IPT: integrated product team utilization & $+0.18 \Rightarrow$ Weak positive & 5.4 .3 \\
\hline
\end{tabular}

1 Avoid overinterpreting the meaning of the Driver categories. For example, the Project Planning category includes elements of project planning, but is not a comprehensive compilation of all project planning activities. The project challenge category (as shown in Figure 2 and Table 2) includes a number of factors that influence the difficulty of a project, but is not a comprehensive assessment of all factors contributing to a project's challenge. To better understand the listed relationships, please refer to the report sections listed in the last column that describe the contents of each category. 


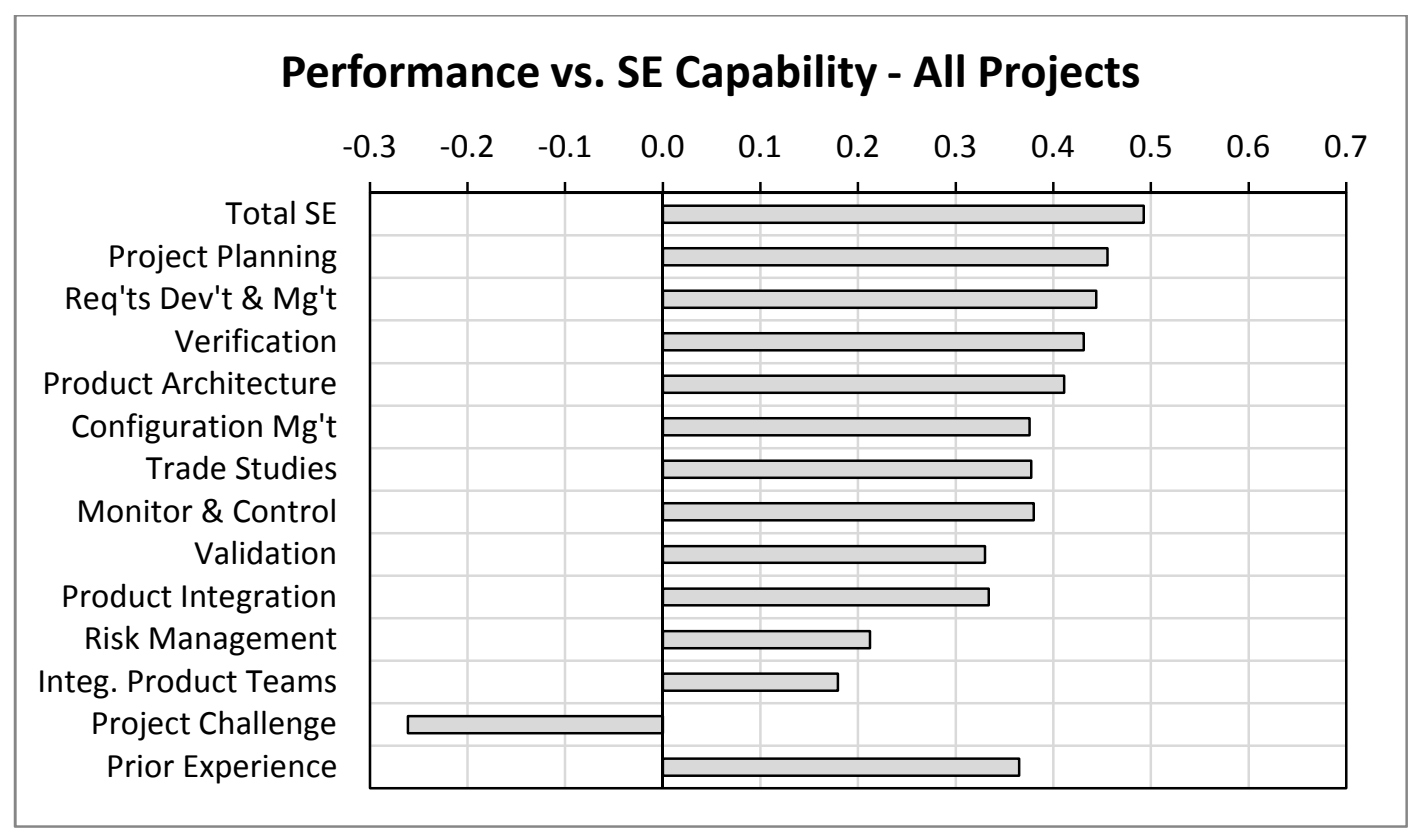

Figure 2: Project Performance vs. SE Capabilities and Drivers

The survey also examined the relationships between project performance and other factors such as project challenge and prior experience. Table 2 summarizes the relationships for these factors.

Table 2: $\quad$ Summary of Project Performance versus Other Factors

\begin{tabular}{|l|l|l|}
\hline \multicolumn{1}{|c|}{ Driver $^{3}$} & \multicolumn{1}{|c|}{ Gamma } & \multicolumn{1}{|c|}{ Section } \\
\hline $\boldsymbol{P C}:$ Project challenge & $-0.26 \Rightarrow$ Moderate negative & 5.3 \\
\hline EXP: Prior experience & $+0.36 \Rightarrow$ Strong positive & 5.5 .1 \\
\hline
\end{tabular}

The importance of implementing systems engineering best practices becomes even more evident when we consider differences in project challenge (PC). Such practices are particularly important for projects that face more difficult challenges in implementing their deliverables (Figure 3).

The chart on the left side of Figure 3 shows the relationship between SEC-Total and Perf for projects with lower PC. It shows a strong supporting relationship between SEC-Total and Perf, with the percentage of projects delivering higher performance changing from $23 \%$ to $23 \%$ to $52 \%$ as SEC-Total increased from lower to middle to higher.

Similarly, the percentage of projects delivering lower performance decreased from $32 \%$ to $19 \%$ to $12 \%$ as $\boldsymbol{S E C}$-Total increased. Thus, for the lower challenge projects, the likelihood of delivering higher performance more than doubled with improved SEC-Total, while those delivering lower performance was reduced to less than half. This relationship is characterized by a Gamma value of +0.34 and a low p-value of 0.029 . 


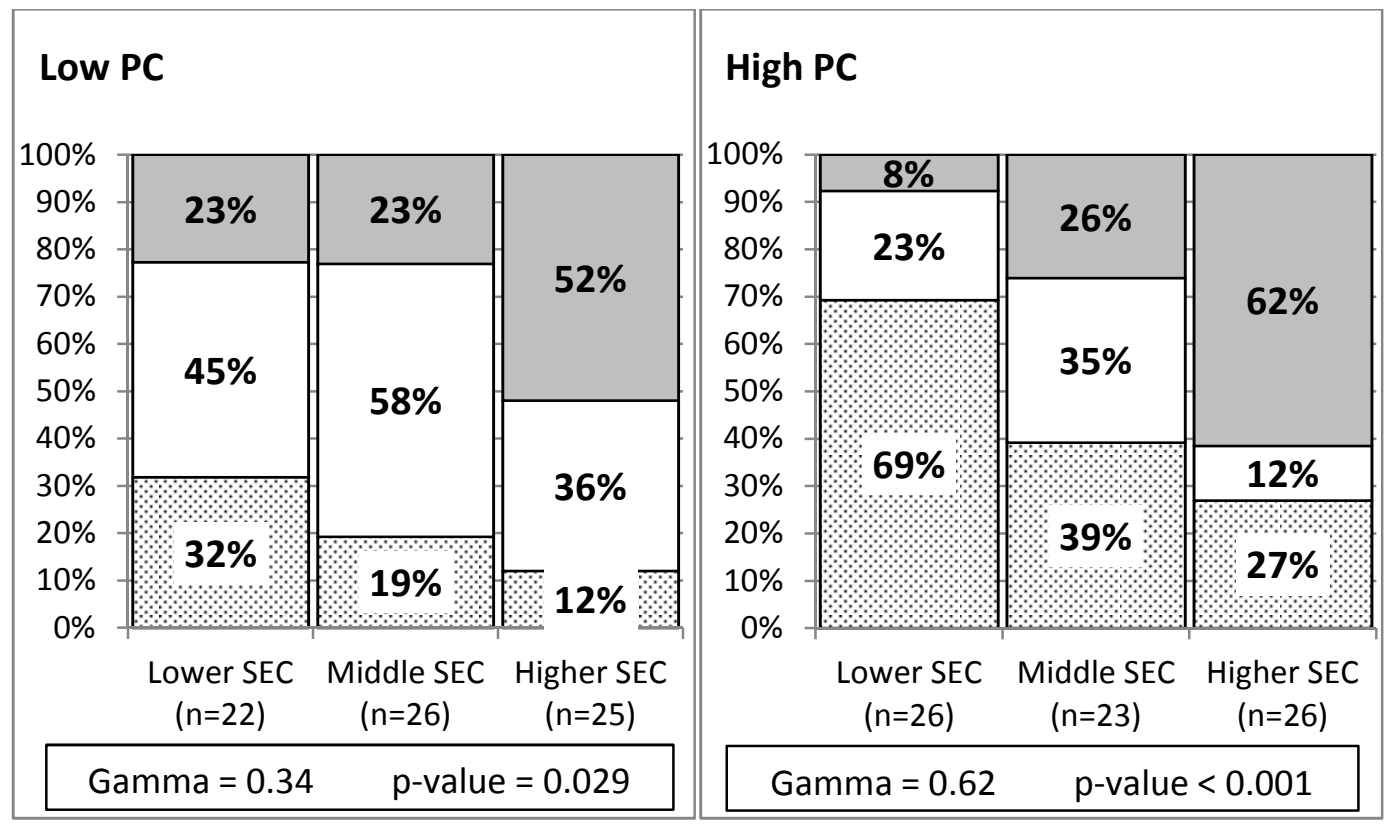

Figure 3: Project Performance vs. Total SE Capability controlled by Project Challenge

The chart on the right side of Figure 3 shows a very strong relationship between SEC-Total and Perf for those projects with higher $\mathbf{P C}$. The percentage of projects delivering higher performance increased from $8 \%$ to $26 \%$ to $62 \%$ as SEC-Total increased from lower to middle to higher. Additionally, the percentage of projects delivering lower performance decreased from $69 \%$ to $39 \%$ to $27 \%$ as $\boldsymbol{S E C}$-Total increased.

Thus, for these higher challenge projects, the likelihood of delivering higher performance increased more than sevenfold and that of delivering lower performance decreased by almost twothirds with improved $\boldsymbol{S E C}$-Total. This relationship is characterized by a Gamma value of +0.62 and a very low p-value less than 0.001 .

The meaning of this information is clear:

Projects that properly apply systems engineering best practices perform better than projects that do not.

This report identifies the SE process groups that have the strongest relationships to project performance. It also shows that more challenging projects tend to perform worse than less challenging projects. However projects that face less challenge still tend to benefit from implementing systems engineering best practices. Moreover the impact of employing systems engineering best practices is even greater for more challenging projects.

With this knowledge, system acquirers and system developers can inform their judgments regarding the application of SE to their projects and improve their SE practices to further enhance project outcomes. 


\section{Abstract}

This report summarizes the results of a survey that had the goal of quantifying the connection between the application of systems engineering (SE) best practices to projects and programs and the performance of those projects and programs. The survey population consisted of projects and programs executed by system developers reached through the National Defense Industrial Association Systems Engineering Division (NDIA-SED), the Institute of Electrical and Electronics Engineers Aerospace and Electronic Systems Society (IEEE-AESS), and the International Council on Systems Engineering (INCOSE). Analysis of survey responses revealed strong statistical relationships between project performance and several categories of specific SE best practices. The survey results show notable differences in the relationship between SE best practices and performance between more challenging and less challenging projects. The statistical relationship with project performance is quite strong for survey data of this kind when both SE capability and project challenge are considered together. 
CMU/SEI-2012-SR-009 | xvi 


\section{Introduction}

\subsection{Background}

An understanding of the value of systems engineering (SE) is necessary to justify a project's investment in SE resources and activities. And yet, quantitative data showing the contributions of SE to project success are sparse. Prior research by Gruhl showed that NASA projects that spent a larger percentage of their efforts in the early phases of the project exhibited smaller cost overruns. $^{2}$ For NASA programs, SE funding is higher as a percentage of the total funds in early phases, than in later phases. Likewise, research by Honour showed that projects that devote $15 \%$ to $20 \%$ of their development budgets on SE exhibit smaller cost and schedule variances [Honour 2004].

Research by Elm and others in 2007 revealed quantitative relationships between the application of specific SE practices to projects, and the performance of those projects as measured by satisfaction of budgets, schedules, and technical requirements [Elm 2008].

While this research produced valuable insights into the role of SE in development projects, these studies were based on a small number of data points. To better understand the contributions of SE to project success, in 2011, the National Defense Industrial Association Systems Engineering Division (NDIA-SED) in collaboration with the Institute of Electrical and Electronics Engineers Aerospace and Electronic Systems Society (IEEE-AESS), and the Software Engineering Institute (SEI) of Carnegie Mellon embarked on the Business Case for Systems Engineering (BCSE) project. Initial results of that project are summarized in this report.

\subsection{Purpose}

The NDIA-SED, the IEEE-AESS, and the SEI are collaborating to expand and extend the 2007 NDIA/SEI Systems Engineering Effectiveness Study [Elm 2008] to develop a business case for systems engineering (BCSE). The mission of this new study is to assist the SE community in achieving a quantifiable and persistent improvement in project performance through the appropriate application of SE principles and practices. The primary steps in the BCSE process are

1. Identify SE principles and practices shown to provide benefit to project performance. This activity is an extension and a confirmation of the prior NDIA survey.

2. Facilitate the adoption of the survey findings through the development of tools, training, and guidance for SE educators, system developers, and system acquirers.

3. Establish an ongoing means of monitoring and tracking the impact of SE to enable continuous improvement of the SE framework and the business case for SE, thereby driving continuous improvement of project results.

2 Gruhl, W. "Lessons Learned, Cost/Schedule Assessment Guide," Internal presentation, NASA Comptroller's office, 1992.,National Avionics and Space Administration (NASA), 1992. 
This report addresses the results of the first item. The remaining items will be addressed by future activities occurring within the NDIA, IEEE, and the International Council on Systems Engineering (INCOSE). 


\section{Developing the SE Effectiveness Survey}

The first step in building a business case for SE is to identify the SE practices that have a measurable impact on project performance. This identification was accomplished via the SE Effectiveness Survey, which surveyed system developers to identify SE principles and practices applied to development projects and the performance achieved by those projects.

The SE Effectiveness Survey was designed to test the hypothesis

The effective performance of SE best practices on a development program yields quantifiable improvements in program execution (e.g., improved cost performance, schedule performance, and technical performance).

Test of this hypothesis requires both a means of assessing the SE activities applied to a project and a means of assessing the performance of that project.

The process used to develop this survey consisted of three steps:

1. Define the survey population and sampling process.

2. Develop and test the questionnaire.

3. Design the solicitation campaign.

\subsection{Defining the Survey Population}

The first step was to choose the population to be included in the survey. We were interested in reaching suppliers of systems (i.e., products composed of hardware and/or software elements). While the 2007 study concentrated solely on U.S. defense contractors, a goal of this survey was to expand the population to include non-defense projects and non-U.S. system developers. As in the 2007 study, this survey focused on system developers as opposed to system acquirers or service suppliers. This focus enabled us to craft questions applicable to the majority of the population.

To reach this population, we used the resources of the NDIA-SED, IEEE-AESS, and INCOSE, as discussed in Section 2.3.

\subsection{Developing and Testing the Questionnaire}

The function of the questionnaire was to assess

- the SE activities applied to individual projects

- the performance of those projects

- factors other than SE that could impact performance, such as

- the degree of challenge posed by the project

- the environment in which the project was executed

- $\quad$ prior experience of the organization and the team executing the project

The survey questions were derived from those used in the 2007 survey [Elm 2008]. 


\subsubsection{Assessing SE Applied to Projects}

To assess the SE activities applied to the project, we questioned the respondents about work products resulting from specific SE activities. In the earlier study, a committee of SE experts chose Capability Maturity Model Integration ${ }^{\circledR}$ (CMMI) as a recognized standard that addresses key areas of SE. The committee reviewed the typical work products cited in the then current CMMISE/SW model [CMMI Product Team 2002] and chose those work products that they believed were the most representative of effective SE practices. We then crafted survey questions asking about the presence and characteristics of these work products. Most questions in this section were structured in the form of an assertion regarding the project being surveyed:

This project has a $<$ work product $>$ with $<$ defined characteristics $>$

where

$<$ work product $>$ references a typical CMMI work product identified for inclusion in the survey

and

$<$ defined characteristics $>$ address the contents of the work product.

Questions were derived from other sources on occasion to assure comprehensiveness.

The respondent was then asked to identify his or her level of agreement with this assertion, choosing one of the following: strongly disagree, disagree, agree, or strongly agree.

For this study, we made only minor revisions to the work product list from the 2007 study. We crafted 82 questions to assess SE deployment on the project. These questions focused on the presence and the quality of the 51 work products listed in Table 3.

Table 3: Work Products Used to Assess SE Deployment

\begin{tabular}{|l|l|l|}
\hline Alternate solutions & Baseline archives & Baseline audit records \\
\hline Change control board & Commitment impacts & Configuration baselines \\
\hline Configuration item list & Concept of operations & Cost and schedule baselines \\
\hline Customer requirements list & Derived requirements list & $\begin{array}{l}\text { Earned Value Management System } \\
\text { (EVMS) data }\end{array}$ \\
\hline EVMS updates & EVMS variance thresholds & Field problem assessments \\
\hline Field problem reports & Integrated master plan & Integrated master schedule \\
\hline Interface control documents & Interface descriptions & Integrated product teams \\
\hline Peer review plan & Product architecture & Product integration process \\
\hline Requirements acceptance criteria & Requirements allocations & Requirements approval process \\
\hline Requirements configuration records & Requirements impact assessments & Requirements management system \\
\hline Requirements provider criteria & Review of action items & Review of issues \\
\hline Review process & Review of selection criteria & Risk list \\
\hline Risk mitigation plans & Risk mitigation status & SE master schedule \\
\hline SE processes & SE tracking records & Systems engineering master plan \\
\hline Technical approach & Trade study records & Use cases \\
\hline Validation criteria & Validation procedures & Verification criteria \\
\hline Verification entry and exit criteria & Verification procedures & Work breakdown structure \\
\hline
\end{tabular}

${ }^{\circledR} \quad$ Capability Maturity Model Integration and CMMI are registered in the U.S. Patent and Trademark Office by Carnegie Mellon University. 
These work products were the result of 42 CMMI standard practices. These practices were collected in the 12 process groups shown in Table 4.

Table 4: $\quad$ CMMI Process Groups

\begin{tabular}{|l|l|}
\hline Requirements Development & Project Planning \\
\hline Product Architecture & Trade Studies \\
\hline Product Integration & Verification \\
\hline Validation & Project Monitoring and Control \\
\hline Risk Management & Requirements Management \\
\hline Configuration Management & Integrated Product Team (IPT) Based Capability \\
\hline
\end{tabular}

A more detailed list of these work products and their relationships to the CMMI-SE/SW model are provided in Appendix A.

\subsubsection{Assessing Project Performance}

We assessed project performance in terms of meeting schedule, meeting budget, and satisfying technical requirements. The relationship between these three aspects of project performance is well known to project managers as the "iron triangle," which reflects the fact that a project manager can often optimize the value of one of these parameters, but only at the expense of the other two. Thus, assessment of project performance demands attention to all three.

Reliable means of assessing project performance are frequently lacking. Many projects employ the Earned Value Management System (EVMS), which may seem to be an ideal means of assessing project performance. However, our earlier study confirmed that the manner in which it is employed is not consistent. EVMS is calculated from variances from a baseline and is therefore highly sensitive to revisions in that baseline. In some organizations, baselines are only revised when responding to contract change orders. In others, baselines may be changed during replanning activities. In yet others, baselines are revised at fixed intervals. These different baselining methods can produce significant variations in the meaning of EVMS data. Furthermore, EVMS assesses the satisfaction of budgetary and schedule needs only. It includes no means of assessing the satisfaction of technical requirements.

We addressed these issues by collecting multiple project performance measures and looking for the degree of agreement between these measures. To maximize the availability of data from the participants, we used measures common to many organizations. Measures of project performance included

- $\quad$ EVMS data (e.g., cost performance index [CPI] and schedule performance index [SPI])

- percent of requirements satisfied

- changes in budget

- changes in schedule

- perception of customer satisfaction

- Respondents are asked to provide available data for all relevant measures.

An in-depth discussion of the collection and analysis of project performance information is found in the report The Business Case for Systems Engineering Study: Assessing Project Performance from Sparse Data [Elm 2012]. 


\subsubsection{Assessing Other Factors}

Not all projects are created equal; some are more challenging than others. Challenge can arise from technical considerations (e.g., lack of precedent, immature technology, extensive interoperability needs, poor definition of requirements and objectives). It may also arise from programmatic considerations (e.g., large size, long duration). Or, it may arise from organizational considerations (e.g., lack of experience, lack of skills). We examine all of these factors to form a measure of project challenge $(\mathbf{P C})$.

We hypothesized that the environment in which the project was executed could also impact performance. To explore this hypothesis, we collected information regarding the structure of SE within the organization, the end user of the product, the industrial sector of the organization, and the country in which the project was executed. These factors were used to better understand the project environment $(\mathbf{P E})$.

Finally, we collected information on the prior experience of the organization and the team executing the project. This information was combined into a weighted summed index measuring experience $(\boldsymbol{E X P}){ }^{3}$

\subsubsection{Testing the Survey Instrument}

We chose to execute the survey online for the respondents' convenience, thereby increasing the likelihood that they would respond. To test the questionnaire, invitations to submit survey responses were sent to members of the SE Effectiveness Committee. They distributed the survey to project members within their organizations who then submitted responses via the online process. In addition to submitting the responses, they also provided feedback on the clarity of the questions and the time required to complete the questionnaire. Most found that they could complete the questionnaire in 30 to 45 minutes - a time commitment that we felt was acceptable for this study.

We collected the feedback from these initial respondents and used it to make minor improvements to the survey instrument. The resulting survey instrument is shown in Appendix B.

\subsection{Designing the Solicitation Campaign}

A primary objective of the survey execution process was to maximize the number of qualified responses. This objective was accomplished in two ways:

- by taking steps to maximize the response rate

- by reaching out to a large population

\subsubsection{Maximizing Response Rate}

We attempted to maximize the response rate by making the process of responding to the survey as convenient as possible, mitigating concerns regarding confidentiality and data security, and offering incentives for responding.

3 A description of the calculation of weighted summed indices can be found in Section 4.1 on page 10. 
We made the process of responding to the survey simple and convenient by providing the survey online. To participate, a respondent merely had to obtain an online account from the survey server, $\log$ in, and complete the survey.

Some organizations were expected to be reluctant to respond due to the survey's request for competition-sensitive information identifying project performance. To mitigate these concerns, we collected all responses anonymously. The survey did not solicit information to identify people, projects, or organizations. All data presented in reports includes only aggregate data and does not include information traceable to any person, project, or organization.

Additionally, we promised that data would be collected and handled by a trusted organizationthe SEI, which is a federally funded research and development center (FFRDC) that does not compete with any of the responding organizations and is known for handling sensitive data. With these processes, we hoped to convince respondents that they could respond fully and honestly to the survey questions without fear of exposing critical information.

To encourage participation, we included an incentive to respond-information. As in the previous study, results of this survey provide a benchmark for SE performance among a broad range of system developers. Organizations could evaluate themselves against this benchmark and develop process improvement plans to obtain a competitive advantage. Early access to this benchmark information was offered as a reward for participating in the survey.

This report, made available to the general public immediately after completion of the survey, contains only summary information of the survey results. It does not contain the distributions and statistical analyses of each survey question. That information is contained in a companion report. The companion report is available to survey participants immediately upon its release; however, it will not be made available to the broader public for one year. Respondents may access this companion report at https://feedback.sei.cmu.edu/2011_SE_EffectivenessSurveyResults.htm using the account name and password that they established for submission of their survey responses.

An additional incentive was also made available. Each submitted response was identified by a randomly assigned account name and a user-defined password. Other identifying information (e.g., respondent name, organization, project) was unknown to the researchers. However, if the organization submitting project responses elected to subsequently provide to the SEI the account names and passwords of the responses submitted by its employees, the SEI could extract those records from the survey database and perform an analysis similar to that presented here but limited to the participating organization's own projects. This analysis would be provided only to the requesting organization, and would serve as an organization-specific baseline that could then be compared against the industry-wide baseline derived from the entire database. Such a comparison would enable the requesting organization to identify its relative strengths and weaknesses, and create process improvement activities to enhance its future performance. 


\subsubsection{Maximizing Sample Size}

Sample size was maximized by using both a targeted and broadcast approach to reach potential respondents.

The targeted approach relied on networking through the NDIA-SED, IEEE-AESS, and INCOSE. Members of the SE Effectiveness Committee are active in all of these organizations. Furthermore, the memberships of these organizations often include senior and mid-level managers from major system design organizations worldwide. By reaching out through the NDIA-SED, IEEE-AESS, and INCOSE, we successfully enlisted the leaders of many companies in the SE Effectiveness Committee. These committee members sponsored and promoted participation in the survey within their organizations, soliciting respondents, distributing invitations, and expediting responses.

The targeted approach was effective in reaching our intended audience of the large organizations that are well represented within the societies supporting this study. However, we also wished to reach the smaller organizations participating in these societies. To do this, we adopted a "broadcast" approach using the resources of the NDIA-SED, IEEE-AESS, and INCOSE to reach their respective memberships. The multi-domain, multi-national constituency of both the INCOSE and IEEE-AESS supported the goals of reaching beyond the defense industry and beyond the collection of U.S. companies surveyed in the 2007 study.

Both the IEEE-AESS and INCOSE provided copies of their membership rosters, enabling us to contact their members via email. The NDIA-SED chose to contact its members directly and provide us with their responses.

We had some concerns about reaching out to the members of these organizations and asking them to respond to the survey. The questionnaire solicits information regarding projects executed within their employing organizations. We did not wish to place these individuals in a potential conflict by asking them to release information that was not sanctioned by their companies. Hence, our initial contact via email, as shown in Appendix C, did not ask them to participate in the survey, but merely asked them to identify one or more individuals in their organization who could authorize the organization's participation in the survey. Those individuals were subsequently invited to participate in the survey. 


\section{Executing the Survey}

In October 2011, following the targeted solicitation approach discussed in Section 2.3, members of the SE Effectiveness Committee approached their organizations to invite respondents to participate. In some cases, the committee members provided names and contact information to the SEI, who then sent the invitations. In other cases, the committee members distributed the invitations themselves within their organizations. This approach resulted in the distribution of approximately 81 invitations to participate.

Also in October, the SEI began to broadcast participation inquires (see Appendix C) to the memberships of the INCOSE and IEEE-AESS. The NDIA-SED encountered some delays and did not broadcast the inquiries to its members until February 2012. Results of this process are shown in Table 5. Some members of these professional organizations may be from the companies contacted via the targeted solicitation approach.

Additionally, some may be members of multiple professional organizations. We cannot tell how many such duplicates exist since we took pains to keep competition-sensitive information anonymous. No effort was made to eliminate these duplicative contacts. If anything the $55 \%$ response rate described in Section 5.1 may be an underestimate.

Table 5: Participation Inquiries

\begin{tabular}{|lrrrr|} 
& IEEE-AESS & INCOSE & NDIA & \multicolumn{2}{c|}{ TOTAL } \\
\hline Participation inquiries sent & 3,555 & 7,756 & --- & 11,311 \\
\hline Participation inquiries delivered & 3,341 & 6,865 & --- & 10,206 \\
\hline Responses received & & & & \\
\hline Referrals to others & 11 & 85 & 6 & 102 \\
\hline Self-referral & 15 & 68 & 4 & 87 \\
\hline Invitations sent & 26 & 153 & 10 & 189 \\
\hline
\end{tabular}

The invitation email contained a link to the SEI's survey web server. When logging on, the respondent received a unique and randomly generated URL that he or she could use to access a copy of the questionnaire. Access to this secure site required both knowledge of the URL and a user-defined password. In this manner, only the respondent could access his or her assigned website. The respondent could then complete the questionnaire online, saving his or her results incrementally. At any time, the respondent could exit the website without losing the data saved. In this manner, the respondent could complete the questionnaire over multiple sessions. As the respondent completed the questionnaire, he or she notified the survey server by clicking the Submit button.

Data for the survey were collected over a time period extending from October 2011 to March 2012.

In January, February, and March, reminder emails were sent to invitees encouraging them to complete their submissions in a timely fashion. 


\section{Analyzing the Responses}

The primary survey hypothesis as defined in Section 2 is that SE best practices have a quantifiable positive impact on project performance. We also postulated that the degree of challenge imposed by the project and the environment in which the project was executed could also impact performance. Mathematically, we can state this hypothesis as

$\begin{array}{lll}\text { Perf }=f(P C, P E, E X P, S E C) & \\ \text { where } & \text { Project challenge } & P C \\ & \text { Project environment } & P E \\ & \text { Prior experience } & E X P \\ & \text { Systems engineering capability } & S E C \\ & \text { Project performance } & \text { Perf }\end{array}$

Our goal is to identify the impact of $\boldsymbol{P C}, \boldsymbol{P E}, \boldsymbol{E X P}$, and $\boldsymbol{S E C}$ on Perf. We do this by first scoring each parameter, and then by identifying the relationships among them.

\subsection{Scoring}

Measures for Perf, PC, EXP, SEC, and $\boldsymbol{P E}$ are derived by combining the responses for a set of conceptually related questions into weighted, summed indices used as composite measures. There are several reasons to combine the component questions into single composite indices. Of course, reducing the number simplifies visual interpretation. While it may seem counterintuitive, combining the components also follows a basic reliability principle. Noise always exists in survey data (actually in measured data of any kind). Respondents can be uncertain about their answers concerning the details of a specific question, or the lack of clarity in the wording of a specific question may cause different respondents to attribute different meanings to the same question. Other things being equal, the unreliability can be averaged such that the composite index is more reliable than many or all of its individual components [Guilford 1954, Coleman 1964, Hill 2006].

Many of the response categories range ordinally from "disagree strongly" to "agree strongly." The projects' answers are scored as 1 through 4 respectively and then summed. Since the number of component items varies for each composite measure, the scores are normalized to allow consistent interpretation of their meaning. Much like student grade point averages, the composite scores are divided by the number of questions answered. The composite scores are therefore constrained to range between 1 and $4 .{ }^{4}$ Calculating the composite scores this way provided sufficient variation to enable meaningful statistical comparisons. Moreover, the values on the extremes of the weighted summed indices require consistency of replies across all of their respective component questions.

4 Such a normalization procedure is appropriate for ordinal data since the component items fall in the same constrained range. Since the fractional differences cannot be interpreted additively, the composite scores are split into two or three groupings as appropriate for the data analysis. (e.g., "Lower," "Middle," and "Higher" groupings). 
See Appendix D for details of the scoring process.

The project environment $(\boldsymbol{P E})$ measures address factors other than project challenge and SE capability that could influence project performance. These factors include the organization's industry classification, percentage of project completion, SE organizational structure, contract type, and so forth. The impact on project performance of each of the $\boldsymbol{P E}$ elements is evaluated as is the impact of some of them on the relationships between $\boldsymbol{S E C}$ and Perf.

\subsubsection{Project Performance Analysis}

Project performance (Perf) can be measured and decomposed into

$$
\begin{array}{ll}
\text { Cost performance } & (\text { PerfC }) \\
\text { Schedule performance } & (\text { PerfS }) \\
\text { Technical performance } & (\text { PerfT })
\end{array}
$$

As noted previously, these three factors are interrelated, reflecting the fact that project managers can often optimize the value of one of these parameters, but only at the expense of the other two. For example, a project manager's election to reduce project cost can have adverse impacts on the project schedule and the achieved technical performance of the project. As such, while looking for relationships between SEC and the individual components of Perf (i.e., PerfC, PerfS, PerfT) may be useful, a more complete picture is obtained by looking for relationships between $\boldsymbol{S E C}$ and a composite project performance variable combining all three of these components.

PerfC is assessed based on evaluations of three factors:

1. estimated cost at completion (ECAC) vs. project budget

2. Earned Value Management System (EVMS) Cost Performance Index (CPI)

3. perception of customer satisfaction with the cost performance of the project

Additional factors such as project scope changes resulting from contract amendments and EVMS baseline management practices are also considered in this evaluation.

PerfS is assessed based on the evaluation of four factors:

1. estimated project duration vs. initial planned duration

2. EVMS Schedule Performance Index (SPI)

3. deviation from approved schedule

4. perception of customer satisfaction with the schedule performance of the project

Additional factors such as project scope changes resulting from contract amendments and EVMS baseline management practices are also considered in this evaluation. 
PerfT is assessed based on the evaluation of two factors:

1. satisfaction of system requirements

2. perception of customer satisfaction with the technical performance of the project

PerfC, PerfS, and PerfT are each assessed on a scale ranging from 1 (very poor performance) to 5 (very good performance). A measure of overall project performance, Perf, is calculated as a weighted summed index of these more specific measures. Details of the development of Perf, PerfC, PerfS, and PerfT are provided in Appendix D and in the report The Business Case for Systems Engineering Study: Assessing Project Performance from Sparse Data [Elm 2012].

\subsubsection{Project Challenge $(P C)$}

The project challenge (PC) questions address a number of diverse issues contributing to the difficulty of a project: issues such as project size, project complexity, technology precedents, and others. All of these factors are combined into a single $\boldsymbol{P C}$ measure, with the intent of examining the impact of project difficulty on Perf and the relationships between SEC and Perf. The survey estimated the degree of challenge posed by the project through a combination of factors including

- $\quad$ sources of technical challenge

- lack of well-defined customer requirements

- incomplete requirements

- large contract value

- long contract duration

- large project budget
- lack of similar prior experience

- lack of SE direction from the customer

- excessive contract change orders

- large change of contract value

- large change in contract duration

- large change in project budget

All factors were assessed and the results were combined into a weighted summed index to create an overall assessment of $\boldsymbol{P C}$ scaled from 1 (not very challenging) to 4 (very challenging). Details of the development of $\boldsymbol{P C}$ can be found in Appendix D.

\subsubsection{Systems Engineering Capability (SEC)}

SEC is a measure of the SE activities applied to each project. In addition to assessing the total SE activities (SEC-Total) applied to the project, the questionnaire is designed to permit the decomposition of SEC-Total into 11 measures of SE capability in the identified process groups, as shown in Table 6.

\section{Table 6: SE Process Groups}

\begin{tabular}{|ll|}
\hline Requirements Development and Management & $($ SEC-REQ) \\
\hline Project Planning & $($ SEC-PP) \\
\hline Product Architecture & $($ SEC-ARCH $)$ \\
\hline Trade Studies & $($ SEC-TRD $)$ \\
\hline Product Integration & $($ SEC-PI) \\
\hline Verification & $($ SEC-VER $)$ \\
\hline Validation & $($ SEC-VAL) \\
\hline Project Monitoring and Control & $($ SEC-PMC) \\
\hline Risk Management & $($ SEC-RSKM) \\
\hline Configuration Management & $($ SEC-CM) \\
\hline Integrated Product Team (IPT) Based Capability & $($ SEC-IPT) \\
\hline
\end{tabular}


With this decomposition, it is possible to look at more specific correlations between these systems engineering capability factors and project performance. Each of these factors was assessed over the range of 1 (low capability) to 4 (high capability).

SEC-REQ assessed the requirements development and requirements management activities applied to the project. Assessment factors included the existence and characteristics of requirements lists; requirements allocation documentation; operational installation, maintenance, and support concept documentation; use cases; requirements provider authorization criteria; and requirements impact analyses.

SEC-PP assessed the planning activities applied to the project. Assessment factors included the existence and characteristics of SE planning processes, a work breakdown structure (WBS), a project technical approach, integrated master plan (IMP), an integrated master schedule (IMS), and a systems engineering master plan (SEMP).

SEC-ARCH assessed the product architecture activities applied to the project. Assessment factors included the existence and characteristics of product interfaces and high-level, multi-view product structure documentation.

SEC-TRD assessed the trade study activities applied to the project. Assessment factors included involvement of stakeholders in trade studies, and the existence and characteristics of selection criteria for alternative and trade study findings.

SEC-PI assessed the product integration activities applied to the project. Assessment factors included the existence and characteristics of product integration processes, plans, and criteria.

SEC-VER assessed the verification activities applied to the project. Assessment factors included the existence and characteristics of verification procedures; acceptance criteria; review processes; review training; action item tracking; baseline reviews; and non-advocate reviews.

SEC-VAL assessed the validation activities applied to the project. Assessment factors included the existence and characteristics of validation procedures and acceptance criteria.

SEC-PMC assessed the project monitoring and control activities applied to the project. Assessment factors included the existence and characteristics of review processes, cost and schedule baselines, EVMS data, SE budgets, and field problem reports.

SEC-RSKM assessed the risk management activities applied to the project. Assessment factors included the existence and characteristics of the risk management process and risk mitigation plans. The integration of the risk management process with project cost projections, project schedule, and project decision making was also assessed.

SEC-CM assessed the configuration management activities applied to the project. Assessment factors included the configuration management practices for requirements and baselines; the process for managing changes to controlled items; and the archiving of prior versions.

SEC-IPT assessed the use of integrated product teams on the project. Assessment factors included the presence of IPTs on the project, acquirer and supplier participation in IPTs, the existence of an SE-focused IPT, and SE staff participation on other IPTs. 
All of the SE capabilities listed were also combined into a weighted summed index measuring total systems engineering capability (SEC-Total). This index measure also resulted in an assessed value within the range of 1 (low capability) to 4 (high capability).

Details of the development of all of these SE capability assessments are provided in Appendix D.

\subsubsection{Other Factors}

Other factors with the potential to impact project performance were also assessed, including prior experience, contract type, SE organization, percentage complete, and SE content, as summarized in the following sections. Details of the development of all of these assessments are provided in Appendix D.

\subsubsection{Prior Experience (EXP)}

We hypothesized that prior experience with similar projects within an organization and within a project team could impact the performance of the project. To test this hypothesis, we collected data on prior experiences to form an $\boldsymbol{E X P}$ score.

\subsubsection{Contract Type}

We theorized that the type of contract governing the project could impact project performance. While many contract types may be encountered, we chose to categorize them as either

fixed price - The total contract value is primarily determined by the initial contract (e.g., firm fixed price, fixed price with incentive fee, firm fixed price—level of effort).

cost-reimbursable - The total contract value is primarily determined by the cost of executing the contract (e.g., cost plus fixed fee, cost plus award fee, cost plus incentive fee).

other-The contract is a type that does not fit the prior two categories.

This categorization was then used to examine the impact of these contract types on project performance.

\subsubsection{SE Organization}

Some organizations concentrate the SE function in a separate department. Others distribute SE functions throughout the organization. We collected data to assess the SE organizational structure and used it to examine the impact of this structure on both SE deployment and project performance.

\subsubsection{Percentage Complete}

We collected data to assess the degree of project completion with the intent of evaluating when SE activities were performed. Additionally, we wished to use this information to assess confidence in the project performance assessments.

\subsubsection{SE Content}

We collected data to assess the magnitude of the SE effort as a percentage of the total nonrecurring engineering effort with the intent of identifying how the magnitude of this effort related to project performance. 


\subsection{Identifying Relationships}

Once the scores of all parameters are calculated as discussed in Section 4.1, we can begin identifying relationships between the scores. The primary objective of this survey is to identify correlations between $\boldsymbol{S E C}$ and Perf; however, we are also interested in the impacts of $\boldsymbol{P C}$ and $\boldsymbol{P E}$ variables.

Relationships are evaluated and presented in two ways: (1) via mosaic charts and (2) via nonparametric statistical analysis. These analytic methods process the data differently. Using multiple methods provides the opportunity to identify subtleties in the relationships and to evaluate corroboration between the methods.

\subsubsection{Mosaic Charts}

Mosaic charts provide an intuitive and visual means of examining the relationship between a dependent variable (e.g., Perf depicted on the vertical axis) and an independent variable (e.g., SECTotal or SEC-PP depicted on the horizontal axis).

Development of a mosaic chart starts with the weighted summed indices of the independent variable (i.e., the score for a process group such as SEC-PP or SEC-RSKM) and the weighted summed indices of the dependent variable (i.e., Perf). ${ }^{5}$ For each of the projects, the indices are then categorized as lower, middle, or higher, based on the establishment of breakpoints that distribute the projects evenly between these categories. The categorized scores are then tallied and displayed on the mosaic chart showing the relationship between pairs of scores (e.g., $\boldsymbol{S E C}$-PP vs. Perf, SEC-RSKM vs. Perf).

As an example, consider the notional mosaic chart examining SEC-PP vs. Perf in Figure 4. To develop this chart, we first examined each project's Perf score to assign it to one of three binsone for lower scores, one for middle scores, and one for higher scores. The boundaries for these bins are chosen such that the number of projects in each bin is approximately one-third of the total sample.

Next we establish three similar groups based on the project's $\boldsymbol{S E C - P P}$ score and assign each project to one of three bins representing the lower, middle, and upper levels of $\boldsymbol{S E C - P P}$ capability. Again, the boundaries for these bins are chosen so that the number of projects in each bin is approximately one-third of the total sample. These three bins are identified across the horizontal axis of the chart. Finally, we examine the projects in each of the $\boldsymbol{S E C - P P}$ bins to determine the number of projects that would fall into each of the three Perf bins. These values are displayed in the columns for each of the $\boldsymbol{S E C - P P}$ bins.

5 A description of the calculation of weighted summed indices can be found in Section 4.1 on page 10. 


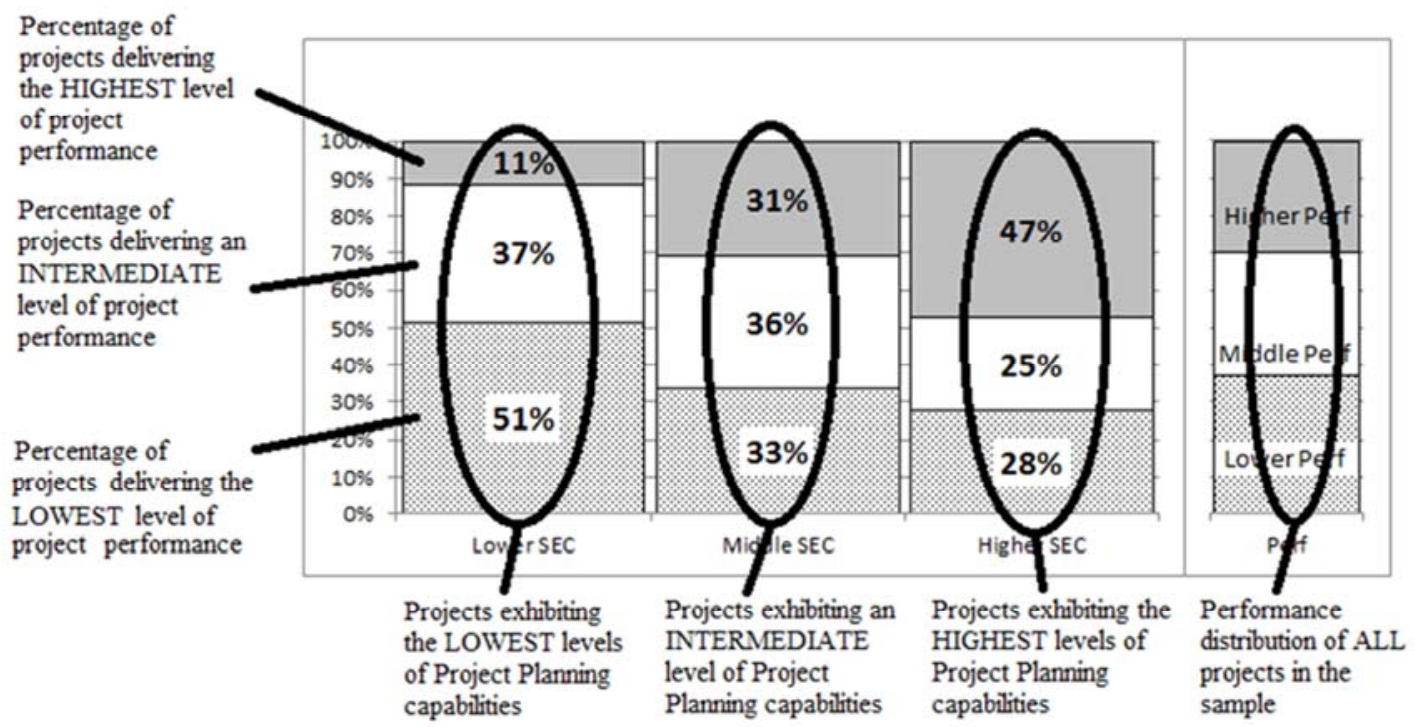

Figure 4: Notional Mosaic Chart Key

The resulting chart is shown in Figure $4:^{6}$

- Of the projects performing the fewest project planning activities

- only $11 \%$ delivered the higher project performance

- $\quad 37 \%$ delivered intermediate project performance

- $51 \%$ delivered the lower project performance

- Of the projects performing an intermediate amount of project planning activities

- $31 \%$ delivered the higher project performance

- $36 \%$ delivered intermediate project performance

- $\quad 33 \%$ delivered the lower project performance

- Of the projects performing the most project planning activities

- $\quad 47 \%$ delivered the higher project performance

- $25 \%$ delivered intermediate project performance

- $\quad 28 \%$ delivered the lower project performance

In this hypothetical case, it is evident that better project planning capability is related to better project performance.

The mosaic charts describe relative rather than absolute differences. The project performance categories on the vertical axis do not range from worst possible performance score to the best possible performance score. Instead, they range from the lowest performance score achieved by any of projects in the survey sample to the highest performance score that was achieved. Thus, on an absolute scale of 1 (worst possible performance) to 4 (best possible performance), if all of the respondents indicate that their projects were performing relatively well and fell into the range from

$6 \quad$ The numbers in the chart are notional only. The actual results for the relationship between project planning SEC-PP and project performance Perf may be seen in Figure 23 on page 33. 
2 to 4, the mosaic chart might consider those scoring from 2 to 2.7 as "Lower Performance," those scoring from 2.8 to 3.2 as "Middle Performance," and those scoring from 3.3 to 4 as "Higher Performance." The same is true for the capability measure of the horizontal axis. It also is relative in nature, ranging from the lowest capability reported to the highest.

\subsubsection{Statistical Measures}

We also use nonparametric statistical analysis methods to examine these same relationships. Many of the questions in the questionnaire are in the form of Likert questions, structured as an assertion to which the respondent provides his degree of agreement (i.e., strongly disagree, disagree, agree, strongly agree). Such responses are ordinal in nature because they contain information regarding rank, but not magnitude. In other words, we know "strongly agree" is better than "agree," but we do not know how much better. Because the majority of the data are ordinal, we need to use nonparametric methods to analyze them.

For this study, the relationships between the variables (e.g., SEC-Total vs. Perf, PC vs. Perf) are summarized using Goodman and Kruskal's Gamma, a measure of association that expresses the strength of relationship between two ordinal variables. A clear, simple description of Goodman and Kruskal's Gamma appears in the book Elementary Applied Statistics by Linton Freeman [Freeman 1965]. Gamma is calculated by comparing pairs of the independent variable with pairs of the dependent variable, as illustrated in Figure 5.

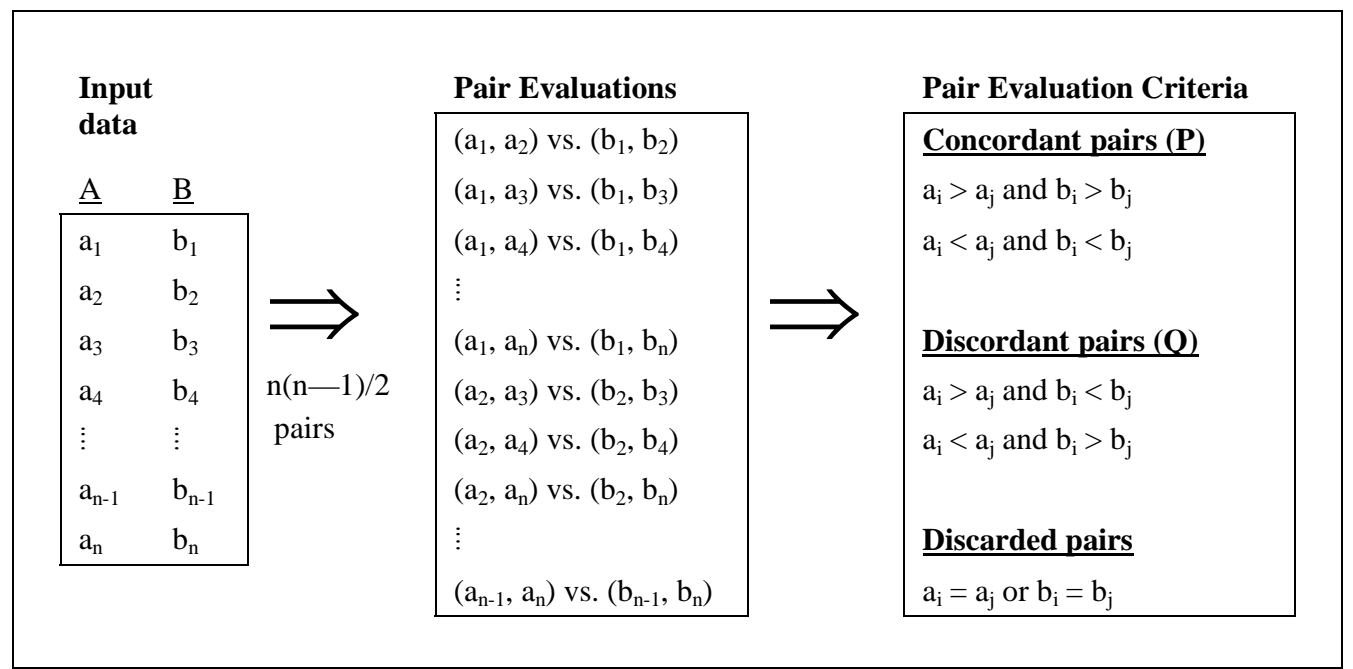

Figure 5: Gamma Calculation

Gamma is computed as $(\mathrm{P}-\mathrm{Q}) /(\mathrm{P}+\mathrm{Q})$; in other words, the excess of concordant pairs as a percentage of all pairs, ignoring ties. Similar to Pearson's product moment correlation coefficient $(\boldsymbol{r})$, Gamma varies from $(+1)$ to $(-1)$, with

- values near -1 indicating a strong opposing relationship

- values near 0 indicating a weak or no relationship (statistical independence)

- $\quad$ values near +1 indicating a strong supporting relationship

Gamma is a proportional reduction in error (PRE) statistic, so understanding its value is intuitively straightforward. Conceptually similar to Pearson's $\boldsymbol{r}^{2}$ for interval or ratio data, the value of gamma is the proportion of paired comparisons where knowing the rank order of one variable 
reduces the proportionate error in predicting the rank order of the other variable. For example, if gamma is 0.65 then knowing the rank of the independent variable reduces the error in predicting the rank of the dependent variable by 65 percent. In this sense, gamma is a measure of relative accuracy.

The calculation of Gamma is not performed using the raw indices for the independent and dependent variables. Instead, it is performed using the indices after categorization as lower, middle, or higher, as used in the mosaic charts. The Gamma calculation simply pairs the responses of the categorized indices and counts the concordant and discordant pairs.

Notionally, Gamma values may be interpreted as

$$
\begin{array}{rll}
0 \leq \mid \text { Gamma } \mid<0.2 & \Rightarrow & \text { Weak relationship } \\
0.2 \leq \mid \text { Gamma } \mid<0.3 & \Rightarrow & \text { Moderate relationship } \\
0.3 \leq \mid \text { Gamma } \mid<0.4 & \Rightarrow & \text { Strong relationship } \\
0.4 \leq \mid \text { Gamma } \mid & \Rightarrow & \text { Very strong relationship }
\end{array}
$$

The mosaics that appear beginning in Section 5.3 also display p-values from statistical tests associated with each Gamma statistic. No statistical relationship can ever be fully corroborated. However we can estimate the probability that an observed relationship is likely to occur by chance alone. The lower the p-value, the less likely the magnitude of the relationship is to be a chance occurrence. By convention, values of $\boldsymbol{p}<\mathbf{0 . 0 5}$ or $\boldsymbol{p}<\mathbf{0 . 0 1}$ typically are used as a basis for rejecting the null hypothesis (i.e., having confidence that the relationship is not specious).

Because of the small number of cases in the present survey, the p-values for some of the weaker relationships are greater than 0.05 . However, the mosaic charts and related Gamma values themselves are more meaningful for understanding the results than are the p-values per se.

Given the way in which the sample was drawn, we cannot generalize our univariate findings to the larger population of DoD programs. The distribution of scores for any single variable may differ from other such programs; however, there is sufficient variation to analyze the relationships among the variables. It is those relationships that allow us to address the validity of assertions about the effects systems engineering activities have on program performance under varying circumstances. 


\section{Survey Results}

This section examines the results of the analysis of survey responses. It contains only summaries of aggregated information derived from survey results.

Detailed information showing the distributions and statistical analyses of each survey question are contained in a companion report, The Business Case for Systems Engineering Study: Detailed Response Data [Elm 2013]. This detailed information is useful in defining a benchmark against which system developers can compare their SE capabilities to manage SE process improvements. As a reward for their participation, the companion report is also available with the publication of this report to all those who submitted useable responses to the SE Effectiveness Survey. ${ }^{7}$ The companion report will be made available to the general public one year later.

\subsection{Response and Response Rate}

Invitations were delivered to 270 potential participants - 81 resulting from targeting specific organizations and 189 from inquiries broadcast through the NDIA, IEEE, and INCOSE. There most probably were duplicates between the invitations sent as a result of the inquiries and the 81 sent through the auspices of the SE Effectiveness Committee members. We cannot tell how many such duplicates exist since we took pains to keep competition-sensitive information anonymous. Thus it is likely that the number of invitees is less than 270 .

These invitations resulted in the receipt of 148 responses that were sufficiently complete to support analysis. ${ }^{8}$ This number of responses amounts to an effective response rate of at least $55 \%$.

Selection biases are a concern in any survey when the sample is not based on random, known probability of selection criteria. Due to the means available to us for soliciting respondents, we could not ensure that the participation inquiries were selected by random criteria. However, we did take steps to:

- Ensure anonymity to all of the survey respondents to maximize the likelihood of truthfulness

- Stress the need to provide candid responses to make the results useful to themselves as well as others.

- Provide detailed instructions with criteria to help corporate management from the targeted organizations randomize their selections.

Survey participants can use the URL and password that they used to submit their response to the SE Effectiveness Survey to access the SEI website at

https://feedback.sei.cmu.edu/2011_SE_EffectivenessSurveyResults.htm and download the companion report.

8 As you may notice beginning in Section 5.4, a few of the respondents did not answer all of the questions. 
In the absence of required, auditable benchmarks we cannot generalize elsewhere the distributions of scores on our individual measures of program performance or implementation of systems engineering practices when each of them is considered alone. However there is sufficient covariation in the relationships between program performance and the systems engineering measures to draw useful conclusions about the impact of those practices on program outcomes.

Despite our efforts to reach out to non-defense and non-U.S. system developers, the majority of the responses came from U.S. defense industry organizations that were executing contracts within the U.S. for the U.S. DoD. However, as shown in Figure 6, 21\% of survey participants are not defense manufacturing or service providers. ${ }^{9}$ As shown in Figure 7, 22\% of projects' end users are not from the defense industry. ${ }^{10}$ As shown in Figure 8, 88\% of the development engineering was or will be done in the United States.

$9 \quad$ The categories in Figure 5 are Standard Industrial Classification (SIC) codes.

10 The categories in Figure 6 were established after considerable discussion by members of the Systems Engineering Effectiveness working group. 


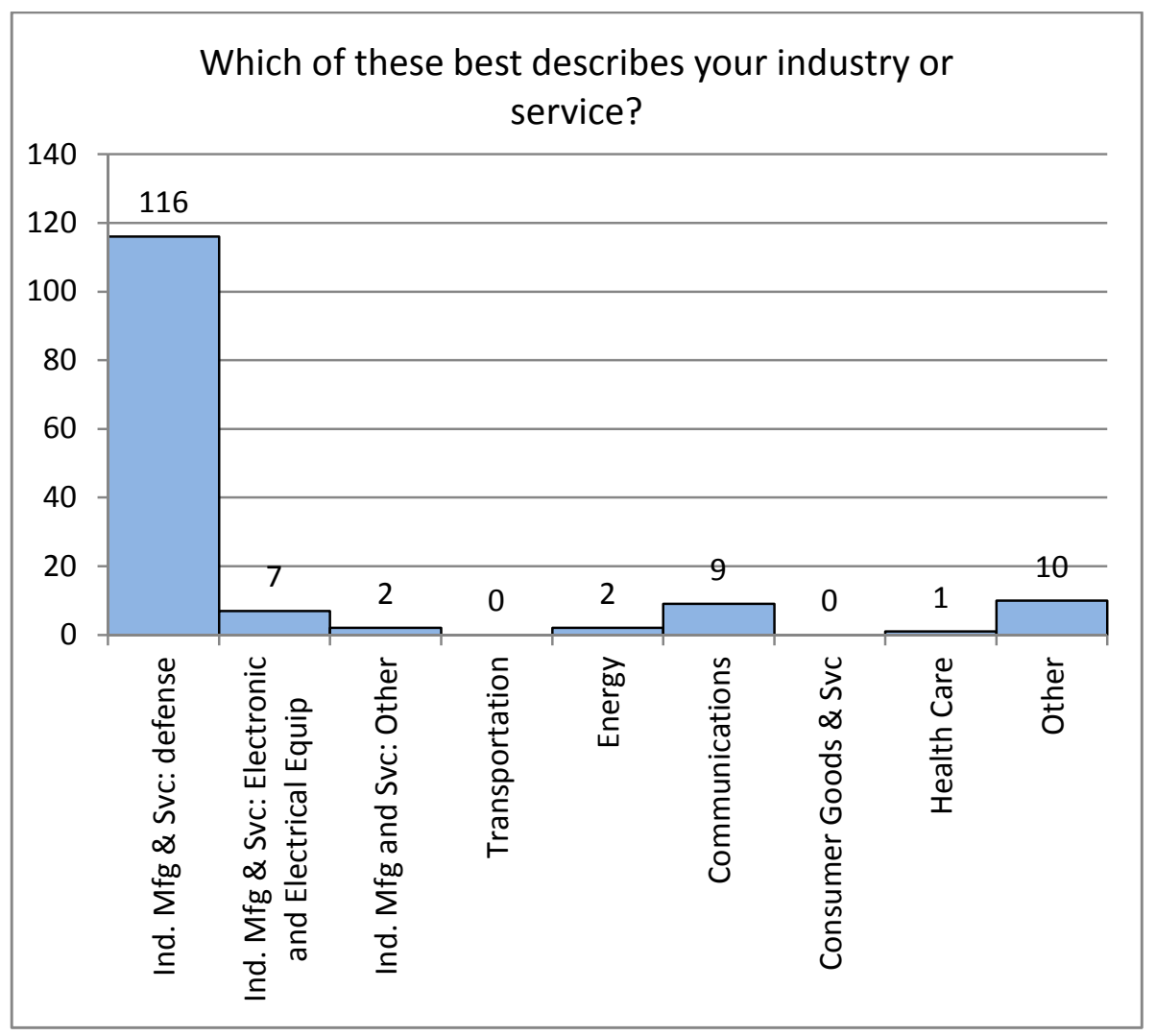

Figure 6: Industry

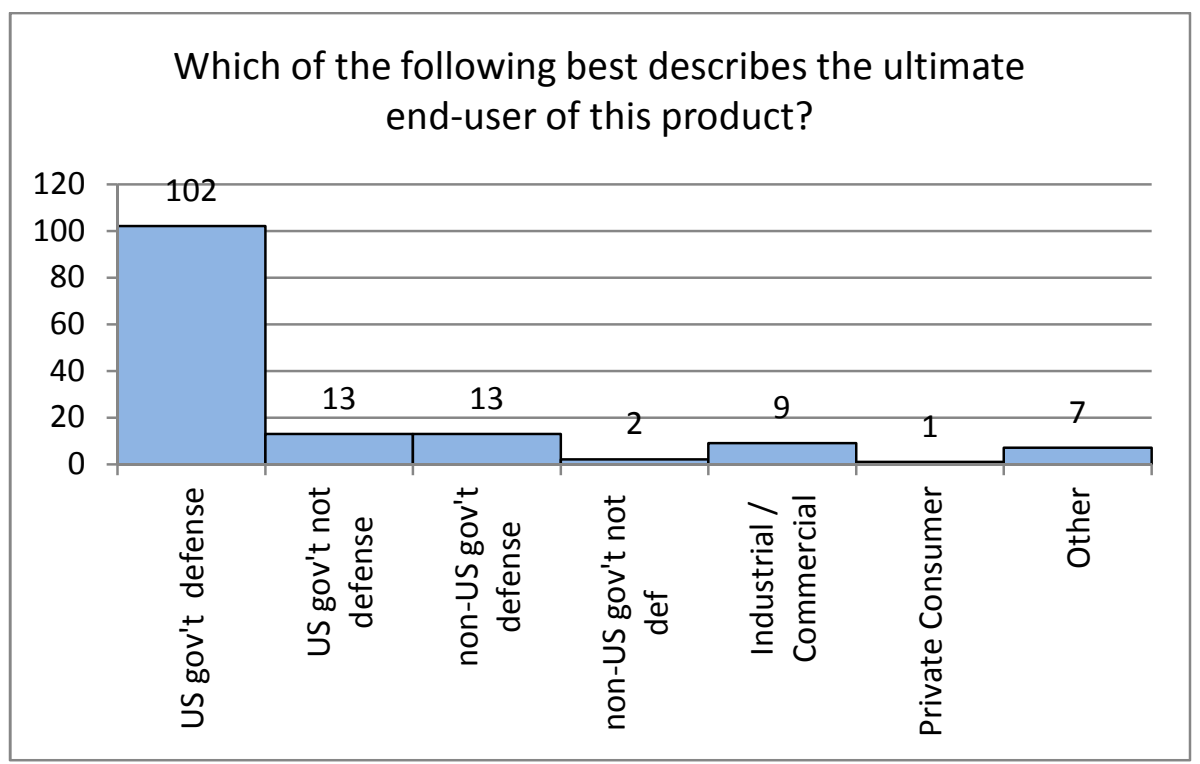

Figure 7: System End Users 


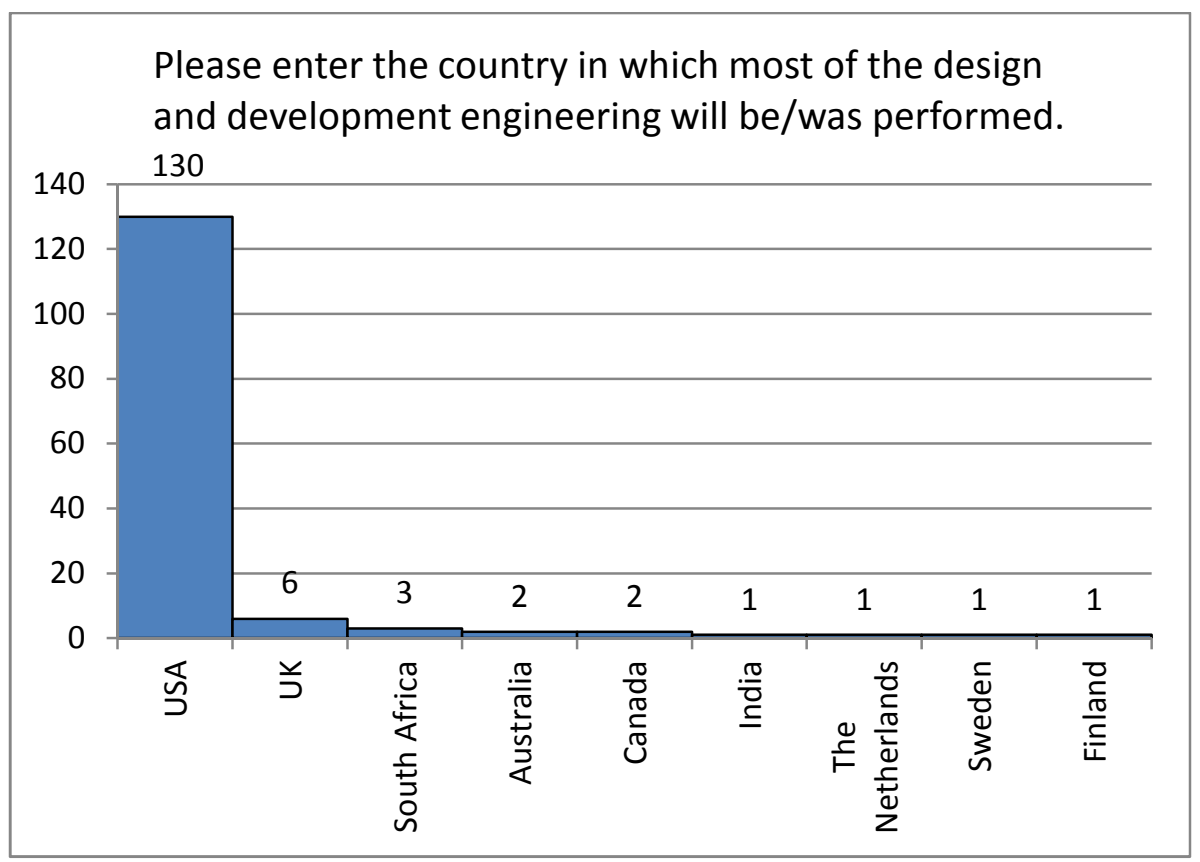

Figure 8: Country of Project Execution

We also collected information regarding the size of the responding projects, as measured by their contract value (Figure 9). The contract values are expressed exponentially on the horizontal axis because of the extremely wide variation across the projects. The median contract value is $\$ 50.5$ million. The arithmetic mean is much larger (\$488 million) because of the extremely high contract values above the median.

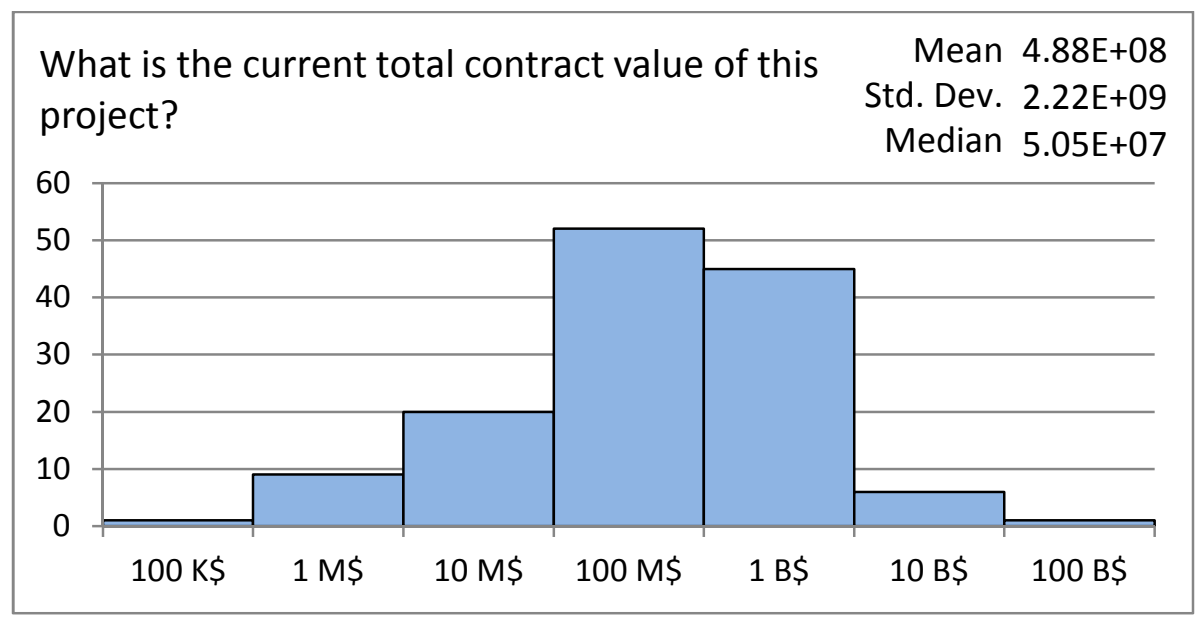

Figure 9: Contract Value Response Distribution

\subsection{Project Performance}

As noted in Section 4.1.1, total project performance (Perf) comprises cost performance (PerfC), schedule performance (PerfS), and technical performance (PerfT).

Distribution of Perf for the surveyed sample is shown in Figure 10. 


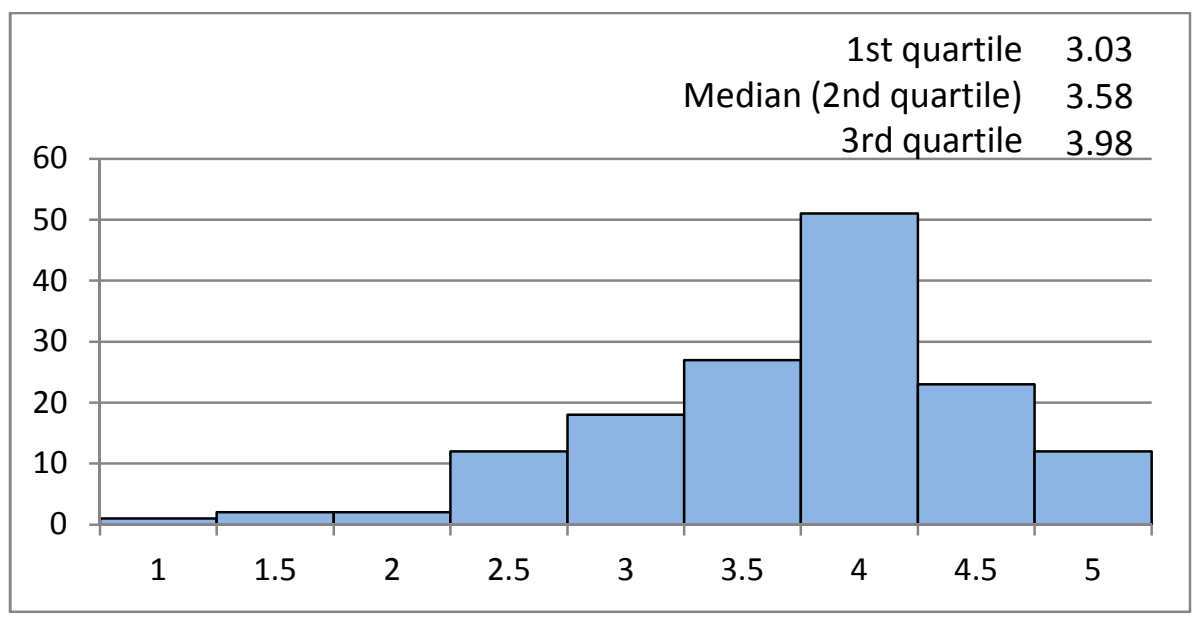

Figure 10: Perf Response Distribution

A Perf value of 3.00 may be interpreted as a project that is on schedule, on budget, and satisfying technical requirements. Values greater than three indicate superior performance (e.g., under budget, ahead of schedule, and/or exceeding technical requirements), while values less than three represent inferior performance.

The median value of 3.58 indicates that the sample of projects surveyed, in the aggregate, exceeded performance expectations in terms of cost, schedule, and/or technical performance.

The high Perf scores reported here in Section 5.2 cannot be generalized from this sample to all DoD programs. However, it is the relationships between Perf and the other variables discussed throughout all of Section 5 that allow us to judge the extent to which systems engineering activities can affect program performance. Whether or not the sample is biased does not matter as long as any such bias is consistent across the projects and programs surveyed, regardless of their values on the independent variables.

Distribution of the cost performance (PerfC) for the surveyed sample is shown in Figure 11.

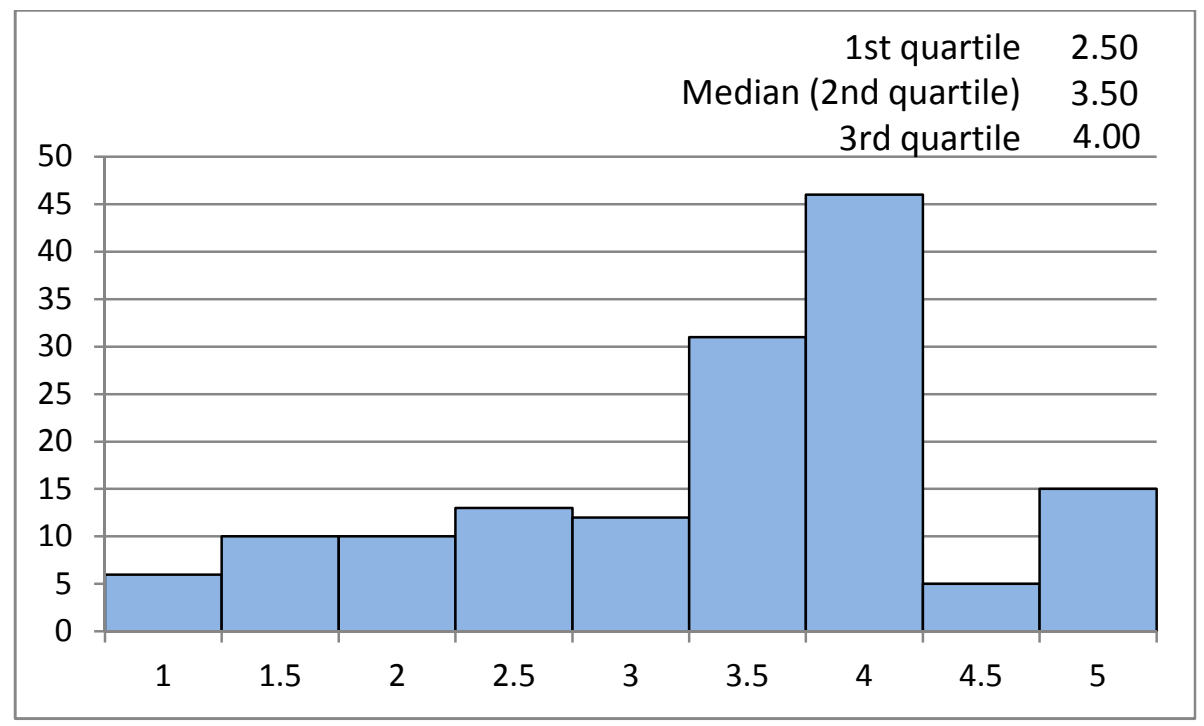

Figure 11: PerfC Response Distribution 
Again, a PerfC value of 3.00 may be interpreted as a project that is expected to execute within \pm $5 \%$ of budget. Values greater than 3 indicate under-budget performance while values less than 3 represent over-budget performance.

The median value of 3.50 indicates that the sample of projects surveyed, in the aggregate, exceeded cost performance expectations.

Distribution of schedule performance (PerfS) for the surveyed sample is shown in Figure 12.

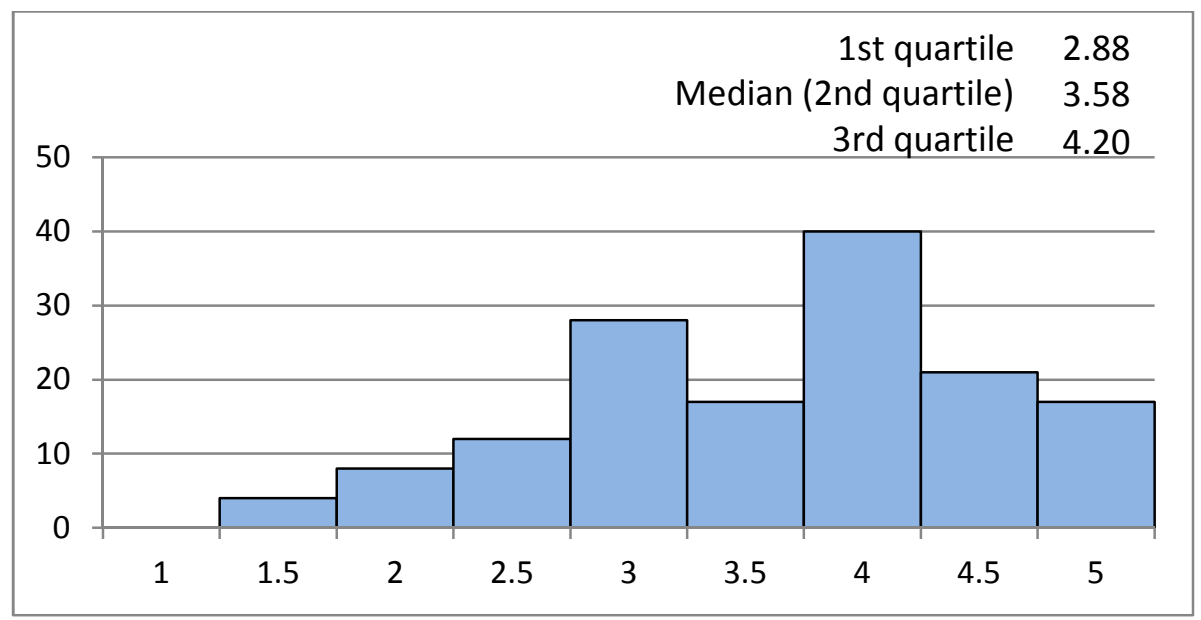

Figure 12: PerfS Response Distribution

Again, a PerfS value of 3.00 may be interpreted as a project that is expected to execute within \pm $5 \%$ of the planned duration. Values greater than 3 indicate accelerated performance, while values less than 3 represent delayed performance.

The median value of 3.58 indicates that the sample of projects surveyed, in the aggregate, exceeded schedule performance expectations.

Distribution of the technical performance ( $\underline{\text { PerfT }})$ for the surveyed sample is shown in Figure 13.

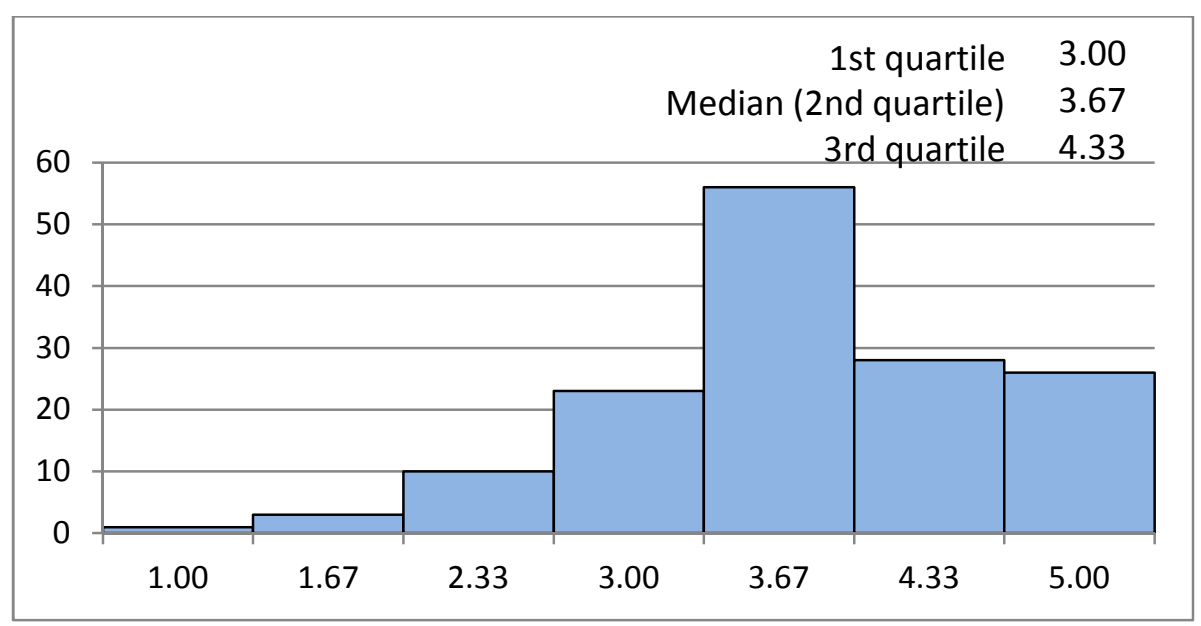

Figure 13: PerfT Response Distribution 
Again, a PerfT value of 3.00 may be interpreted as a project that is on track to meet most of its technical requirements. Values greater than 3 indicate technical performance exceeding expectations while values less than 3 represent technical performance falling short of expectations.

The median value of 3.67 indicates that the sample of projects surveyed, in the aggregate, exceeded technical expectations.

An examination of the spread of these performance measures is also instructive. Among the three components of performance, PerfT has the narrowest distribution, indicating that projects meet their technical expectations (as measured by this survey) with good consistency. PerfS has a wider distribution, indicating that projects are less consistent at controlling schedule performance. PerfC has the widest distribution, revealing the least consistency in managing project costs.

Perf is used as the primary variable for comparison with $\boldsymbol{S E C}$ variables. As discussed in Section 4.2.1, the first step in preparing the mosaic charts showing these relationships is to divide the responses into three groups based on Perf. This activity is done by examining the cumulative distribution function of Perf (Figure 14) to identify two breakpoints that distribute the projects evenly into three bins. ${ }^{11}$

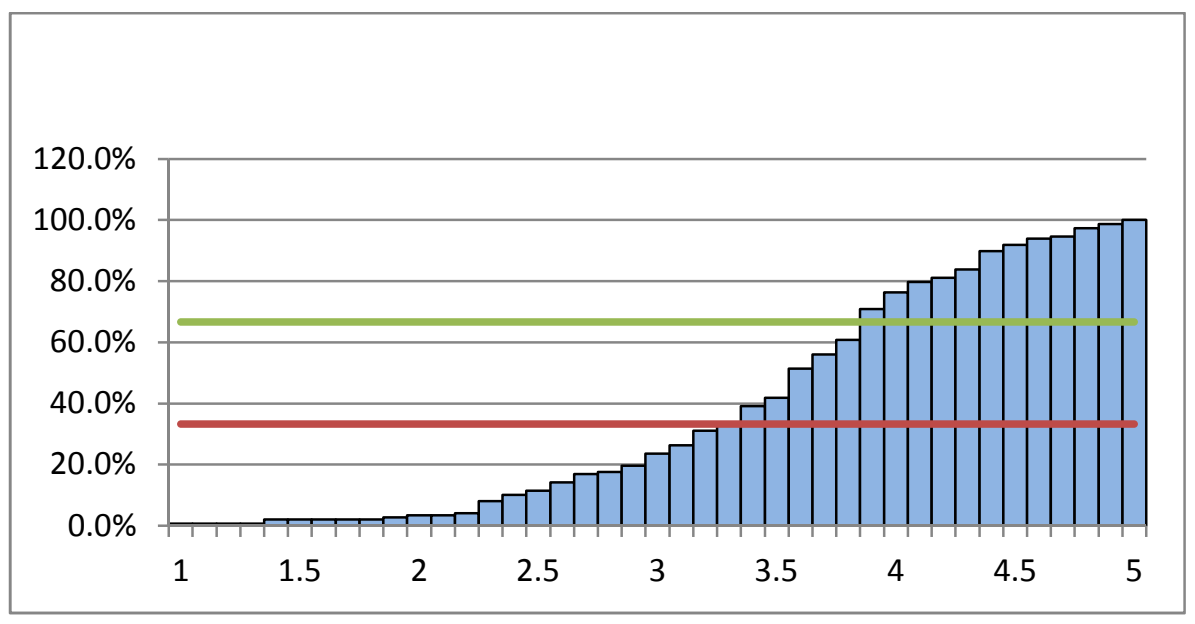

Figure 14: Perf Cumulative Response Distribution

Examining the data, we can identify these breakpoints at 3.10 and 3.59. Thus, for all future analysis, we categorize projects as follows:

$1 \leq \boldsymbol{P e r f} \leq 3.30 \Rightarrow$ Lower project performance

$3.30<$ Perf $\leq 3.85 \Rightarrow$ Middle project performance

$3.85<$ Perf $\quad \Rightarrow \quad$ Higher project performance

\subsection{Project Challenge}

The distribution of the responses that assessed project challenge $(\boldsymbol{P C})$ is shown in Figure 15 with the value of 1 representing very low challenge and 4 representing very high challenge.

11 More detail about establishing the cutting points can be found in The Business Case for Systems Engineering Study: Assessing Project Performance from Sparse Data [Elm 2012]. 


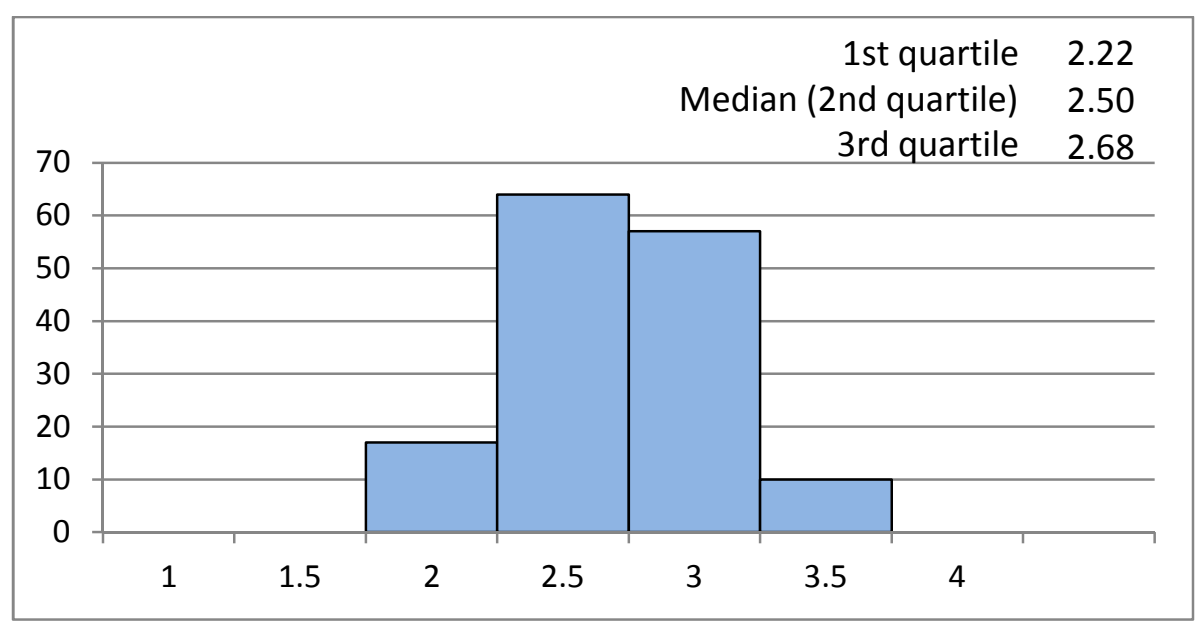

Figure 15: PC Response Distribution

The median of 2.50 indicates that the sampled projects were nearly in the middle of the continuum of project challenge.

As part of preparing the mosaic chart showing the relationship between $\boldsymbol{P C}$ and Perf, three groups for $\boldsymbol{P C}$ were established with breakpoints at 2.33 and 2.65. These breakpoints resulted in 47 projects categorized as presenting lower challenge, 54 as presenting middle challenge, and 47 as presenting higher challenge. The resulting mosaic chart is shown in Figure 16.

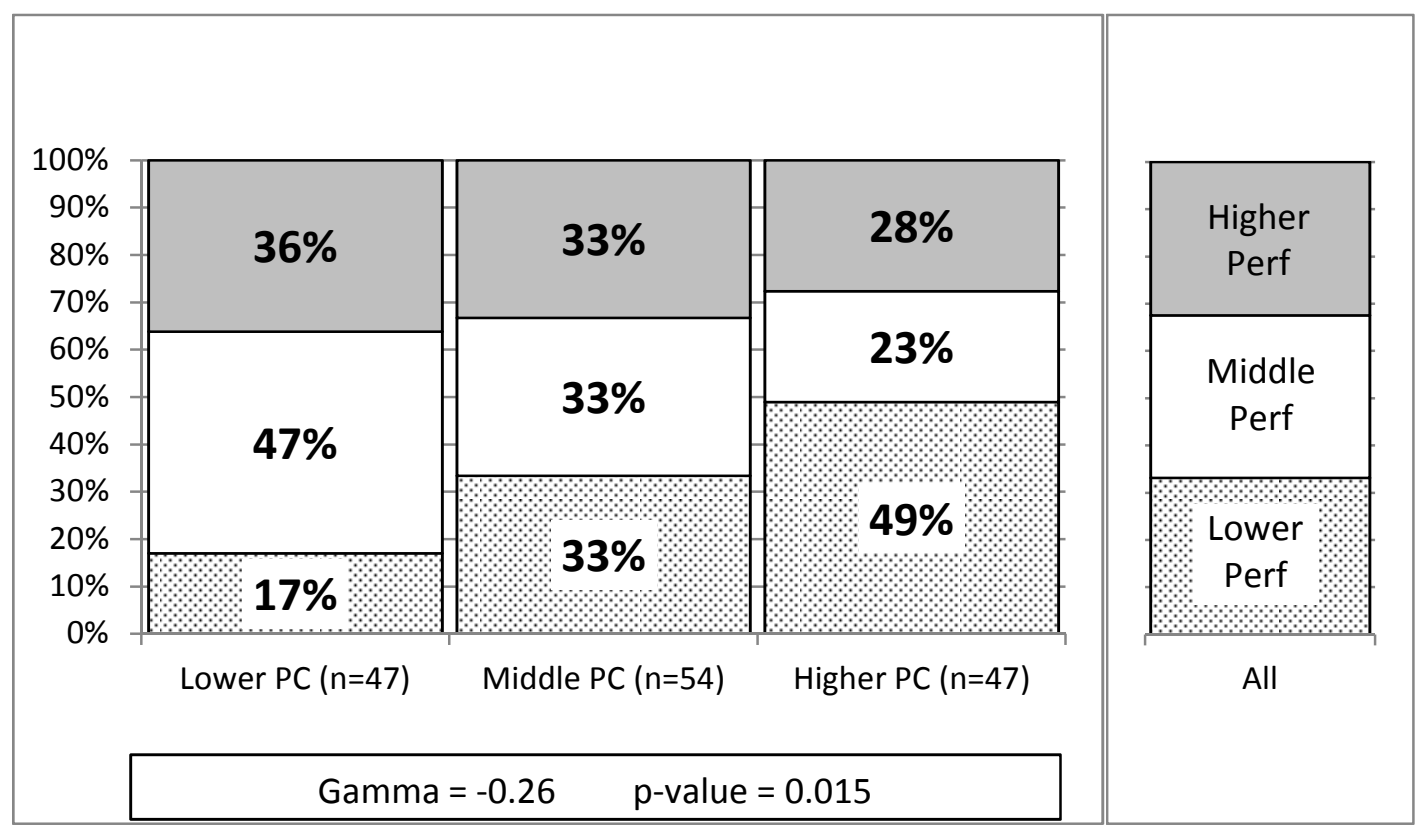

Figure 16: PC vs. Perf

Examining this chart reveals a moderately negative relationship between PC and Perf. This relationship is consistent with intuition-you would expect more challenging projects to have greater difficulty achieving performance expectations. The percentage of projects delivering higher performance decreased from $36 \%$ to $33 \%$ to $28 \%$ as $\mathbf{P C}$ increased from lower to middle to higher. 
Additionally, the percentage of projects delivering lower performance increased from $17 \%$ to $33 \%$ to $49 \%$ as $\boldsymbol{P C}$ increased. This relationship is characterized by a moderate Gamma value of -0.26 and a p-value of 0.015 .

\subsection{Systems Engineering Capabilities}

The following 12 sections discuss the results of the survey for systems engineering capabilities.

\subsubsection{Total Systems Engineering Capability}

As discussed previously, the total systems engineering capability (SEC-Total) applied to a project is assessed as the amalgam of SE capabilities applied in the following process groups:

Requirements development and management (SEC-REQ)

Project planning (SEC-PP)

Product architecture (SEC-ARCH)

Trade studies (SEC-TRD)

Product integration (SEC-PI)

Verification (SEC-VER)

Validation (SEC-VAL)

Project monitoring and control (SEC-PMC)

Risk management (SEC-RSKM)

Configuration management (SEC-CM)

Integrated product team based capability (SEC-IPT)

The distribution of $\boldsymbol{S E C - T o t a l}$ is shown in Figure 17, with a value of 1 representing very poor SE deployment and 4 representing very good SE deployment.

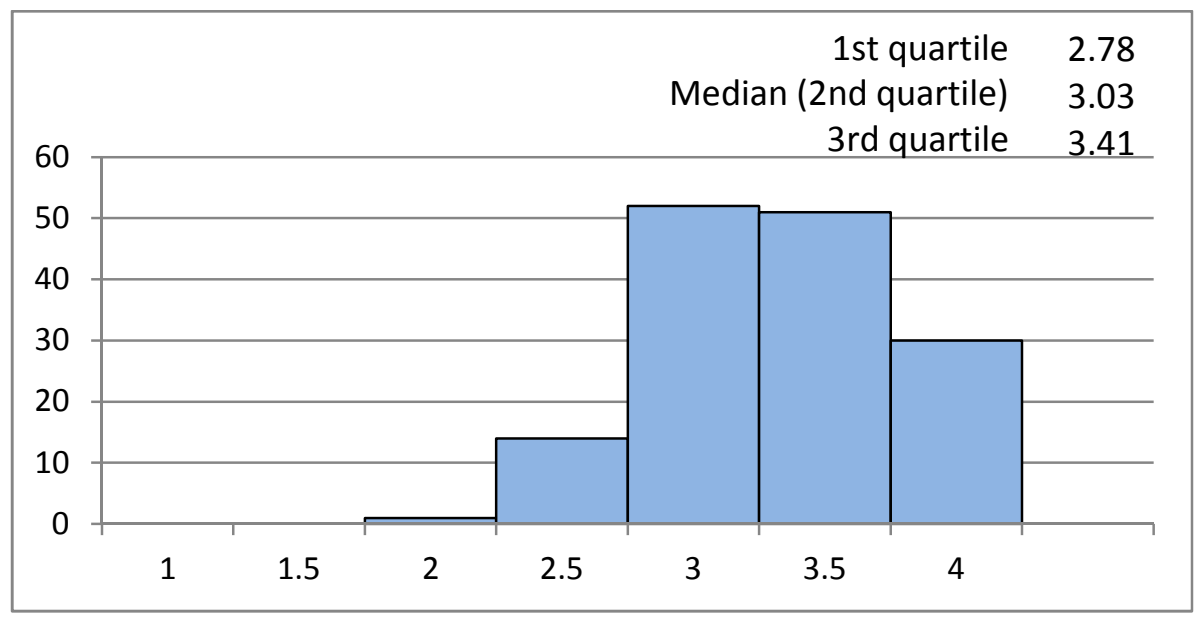

Figure 17: SEC-Total Response Distribution

The median of 3.03 indicates that the typical project in the sample offers good deployment of SE, with some room for improvement. 
In preparing the mosaic chart showing the relationship between $\mathbf{S E C}$-Total and Perf, three groups for $\boldsymbol{S E C - T o t a l}$ were established with breakpoints at 2.85 and 3.27. This resulted in 48 projects categorized as having lower $\boldsymbol{S E C}$-Total capability, 49 as having middle $\boldsymbol{S E C}$-Total capability, and 51 as having higher $\boldsymbol{S E C}$-Total capability. These breakpoints result in the mosaic chart shown in Figure 18.

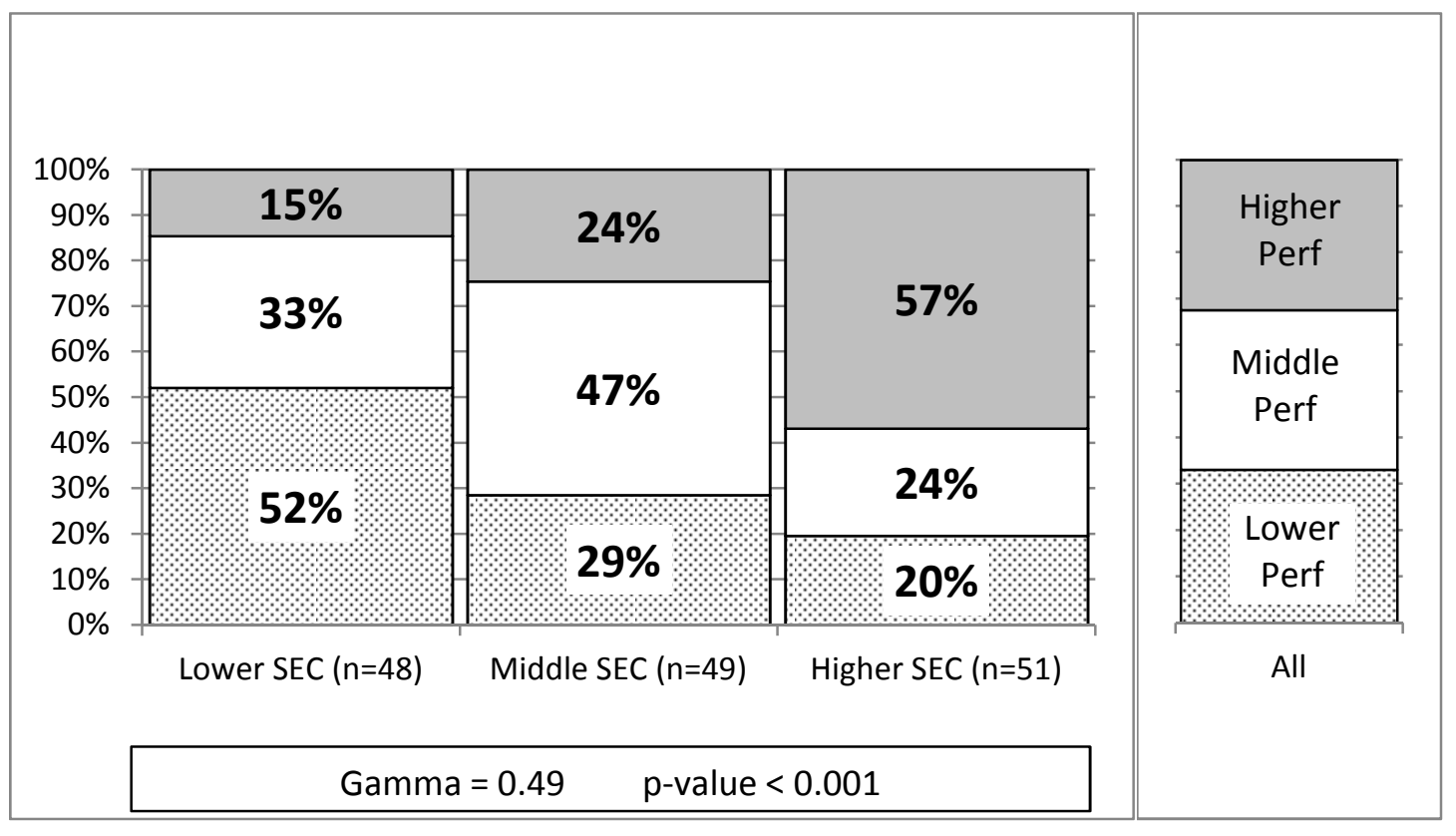

Figure 18: SEC-Total vs. Perf

Examination of this chart reveals a very strong supporting relationship between SEC-Total and Perf. The percentage of projects delivering higher performance increased from $15 \%$ to $24 \%$ to $57 \%$ as $\boldsymbol{S E C - T o t a l}$ increased from lower to middle to higher.

Additionally, the percentage of projects delivering lower performance decreased from $52 \%$ to $29 \%$ to $20 \%$ as $\boldsymbol{S E C}$-Total increased. This relationship is characterized by a Gamma value of +0.49 and a very low p-value less than 0.001 .

We further examined this relationship by incorporating the impact of project challenge (PC). The chart on the left side of Figure 19 shows the relationship between $\boldsymbol{S E C}$-Total and Perf for those projects with lower $\boldsymbol{P C}(\boldsymbol{P C}<2.45)$. This set contains 73 projects. Of these, 22 were assessed as deploying lower $\boldsymbol{S E C}$-Total capabilities, 26 deploying middle $\boldsymbol{S E C}$-Total capabilities, and 25 deploying higher $\boldsymbol{S E C}$-Total capabilities.

The chart shows a strong supporting relationship between SEC-Total and Perf, with the percentage of projects delivering higher performance changing from $23 \%$ to $23 \%$ to $52 \%$ as SEC-Total increased from lower to middle to higher. Similarly, the percentage of projects delivering lower performance decreased from $32 \%$ to $19 \%$ to $12 \%$ as $\boldsymbol{S E C}$-Total increased. 
Thus, for the lower challenge projects, the likelihood of delivering higher performance more than doubled with improved $\boldsymbol{S E C}$-Total, while those delivering lower performance was reduced to less than half. This relationship is characterized by a Gamma value of +0.34 and a low p-value of 0.029 .
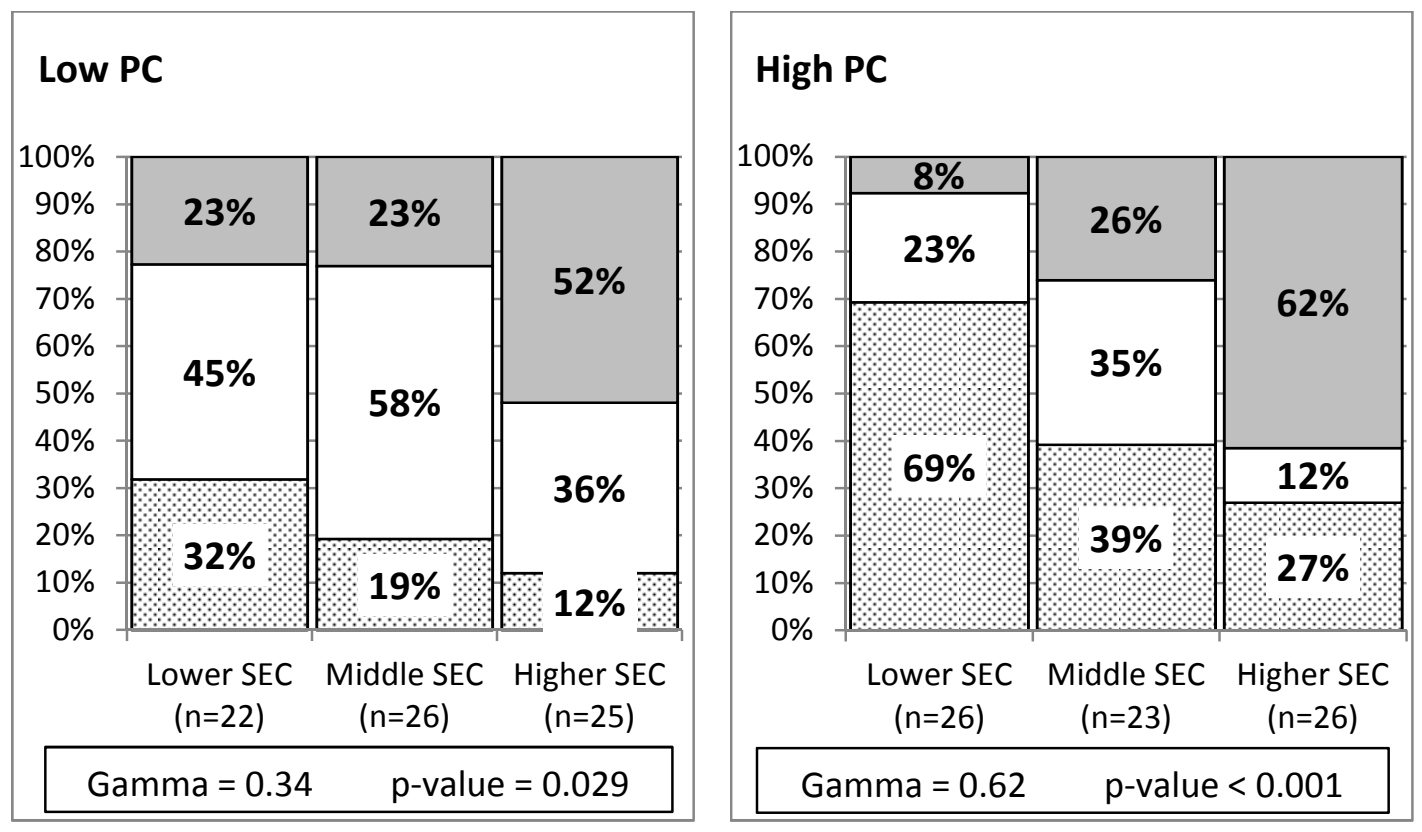

Figure 19: SEC-Total vs. Perf Controlled by PC

The chart on the right side of Figure 19 shows the relationship between $\boldsymbol{S E C}$-Total and Perf for those projects with higher $\boldsymbol{P C}(\boldsymbol{P C} \geq 2.45)$. This set contains 75 projects. Of these, 26 were assessed as deploying lower $\boldsymbol{S E C}$-Total capabilities, 23 deploying middle $\boldsymbol{S E C}$-Total capabilities, and 26 deploying higher $\boldsymbol{S E C}$-Total capabilities.

The chart shows a very strong supporting relationship between SEC-Total and Perf, with the percentage of projects delivering higher performance increasing from $8 \%$ to $26 \%$ to $62 \%$ as $\boldsymbol{S E C}$ Total increased from lower to middle to higher.

Additionally, the percentage of projects delivering lower performance decreased from $69 \%$ to $39 \%$ to $27 \%$ as $\boldsymbol{S E C}$-Total increased. Thus, for these higher challenge projects, the likelihood of delivering higher performance increased more than sevenfold and that of delivering lower performance decreased by almost two-thirds with improved SEC-Total. This relationship is characterized by a Gamma value of +0.62 and a very low p-value less than 0.001 .

These findings support the concept that projects of all complexity benefit from stronger systems engineering practices, but the impacts are even greater for challenging projects.

\subsubsection{Requirements Development and Management}

The distribution of the responses assessing the requirements development and management activities (SEC-REQ) of the projects is shown in Figure 20, with a value of 1 representing very poor requirements development and management and 4 representing very good requirements development and management. 


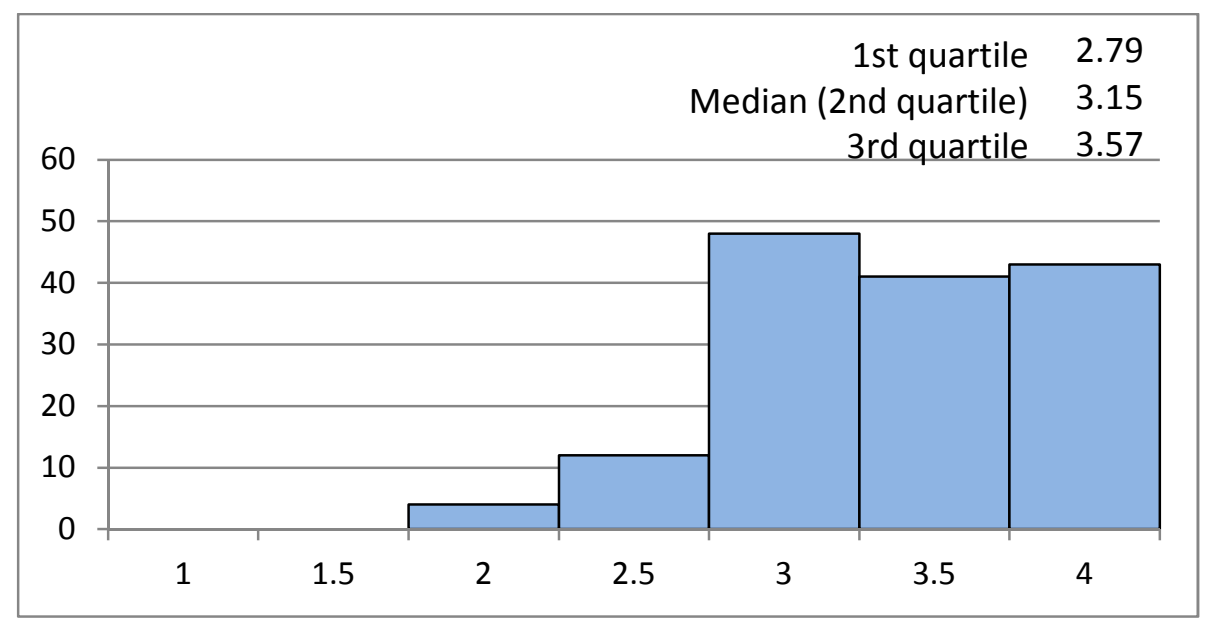

Figure 20: SEC-REQ Response Distribution

The median of 3.15 indicates good application of requirements development and management best practices, relative to the survey questions, but still with some room for improvement.

In preparing the mosaic chart showing the relationship between SEC-REQ and Perf, three groups for $\boldsymbol{S E C - R E Q}$ were established with breakpoints at 2.90 and 3.45. These breakpoints resulted in 48 projects categorized as having lower $\boldsymbol{S E C - R E Q}$ capability, 50 as having middle $\boldsymbol{S E C - R E Q}$ capability, and 50 as having higher $\boldsymbol{S E C - R E Q}$ capability. The resulting mosaic chart is shown in Figure 21.

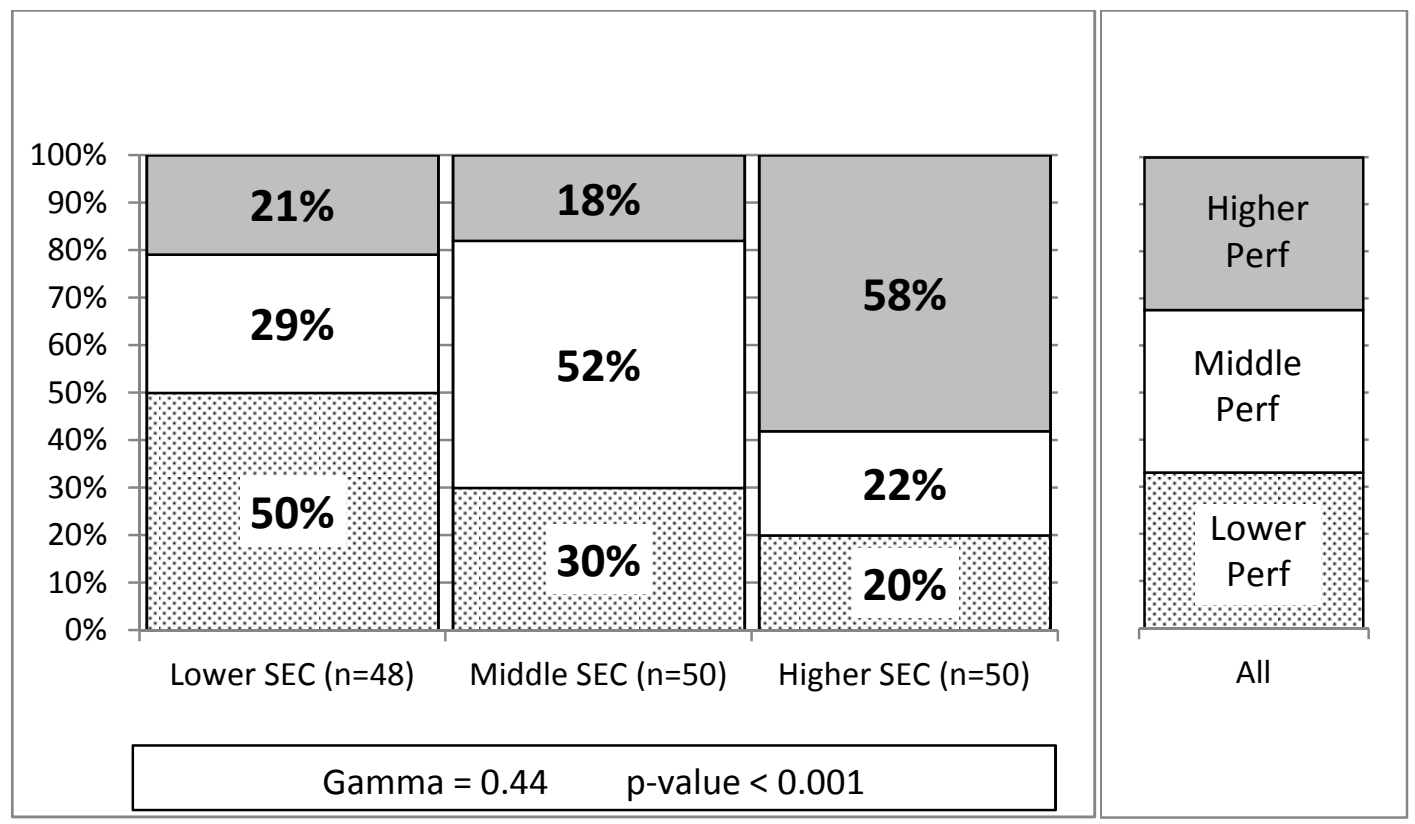

Figure 21: SEC-REQ vs. Perf

Examination of this chart reveals a very strong supporting relationship between SEC-REQ and Perf. The percentage of projects delivering higher performance changed from $21 \%$ to $18 \%$ to $58 \%$ as $\boldsymbol{S E C - R E Q}$ increased from lower to middle to higher. 
Additionally, the percentage of projects delivering lower performance decreased from $50 \%$ to $30 \%$ to $20 \%$ as $\boldsymbol{S E C - R E Q}$ increased. This relationship is characterized by a very strong Gamma value of +0.44 and a very low p-value less than 0.001 .

We further examined this relationship by incorporating the impact of $\boldsymbol{P C}$. The chart on the left side of Figure 22 shows the relationship between $\boldsymbol{S E C - R E Q}$ and Perf for those projects with lower $\boldsymbol{P C}(\boldsymbol{P C}<2.45)$. This set contains 73 projects. Of these, 20 were assessed as deploying lower SEC-REQ capabilities, 26 deploying middle SEC-REQ capabilities, and 27 deploying higher SEC-REQ capabilities.

The chart shows a strong supporting relationship between SEC-REQ and Perf, with the percentage of projects delivering higher performance changing from $25 \%$ to $15 \%$ to $56 \%$ as $\boldsymbol{S E C - R E Q}$ increased from lower to middle to higher.

Additionally, the percentage of projects delivering lower performance changed from 35\% to $15 \%$ to $15 \%$ as $\boldsymbol{S E C - R E Q}$ increased. Thus, for these lower challenge projects, the likelihood of delivering higher performance more than doubled with improved $\boldsymbol{S E C - R E Q}$, and that of delivering lower performance was reduced by $57 \%$. This relationship is characterized by a strong Gamma value of +0.36 and a low p-value of 0.017 .

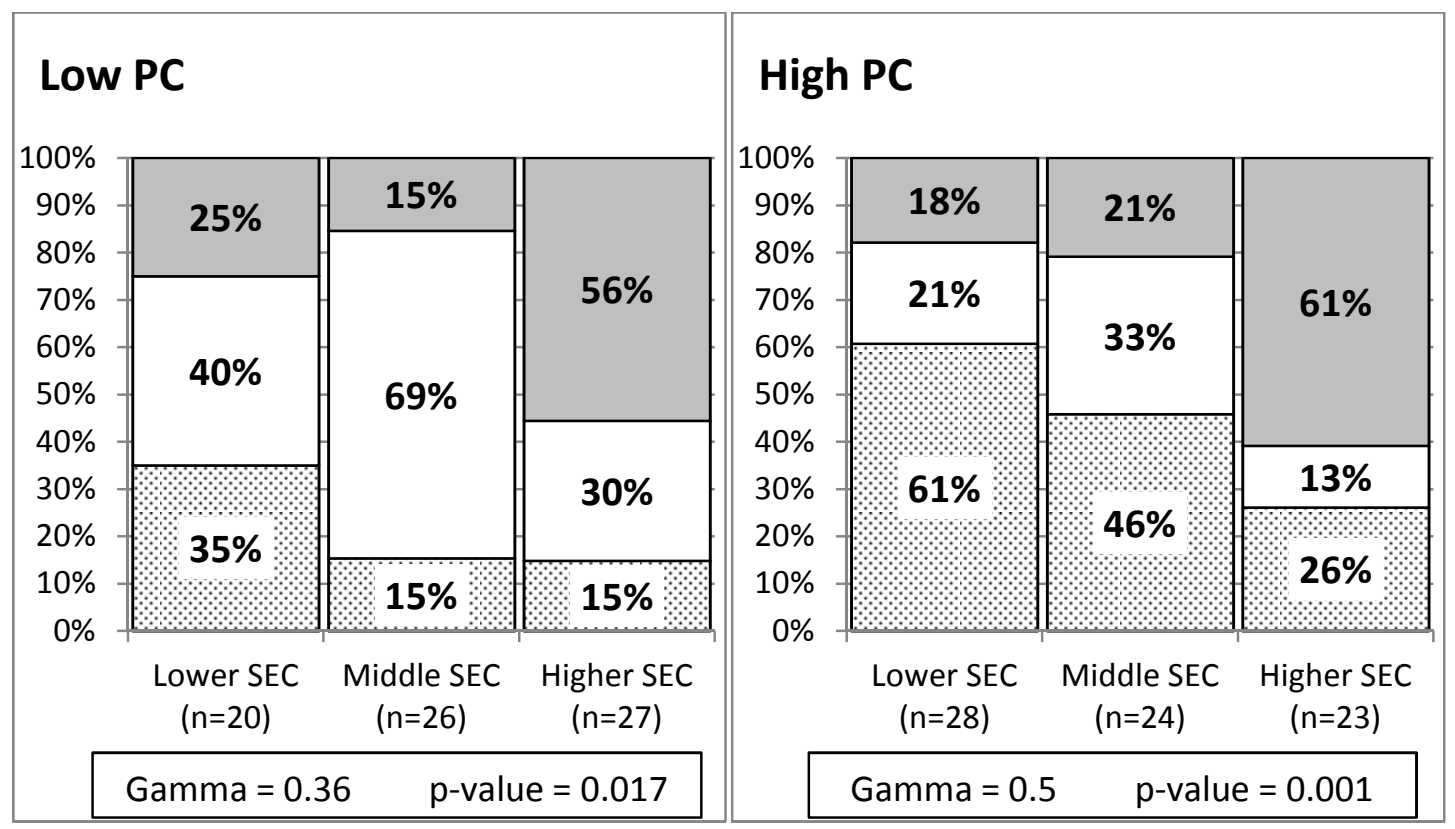

Figure 22: SEC-REQ vs. Perf Controlled by PC

The chart on the right side of Figure 22 shows the relationship between SEC-REQ and Perf for those projects with higher $\boldsymbol{P C}(\boldsymbol{P C} \geq 2.45)$. This set contains 75 projects. Of these, 28 were assessed as deploying lower $\boldsymbol{S E C}$ - $\boldsymbol{R E} \boldsymbol{Q}$ capabilities, 24 deploying middle $\boldsymbol{S E C - R E Q}$ capabilities, and 23 deploying higher $\boldsymbol{S E C - R E Q}$ capabilities.

The chart shows a very strong supporting relationship between SEC-REQ and Perf, with the percentage of projects delivering higher performance changing from $18 \%$ to $21 \%$ to $61 \%$ as $\boldsymbol{S E C}$ $\boldsymbol{R E Q}$ increased from lower to middle to higher. 
Additionally, the percentage of projects delivering lower performance decreased from $61 \%$ to $46 \%$ to $26 \%$ as $\boldsymbol{S E C}-\boldsymbol{R E Q}$ increased. Thus, for these higher challenge projects, the likelihood of delivering higher performance more than tripled, and that of delivering lower performance was reduced by $57 \%$ with improved $\boldsymbol{S E C - R E Q}$. This relationship is characterized by a very strong Gamma value of +0.50 and a very low p-value of 0.001 .

We infer that a higher requirements development and management capability is strongly associated with better program performance, particularly on challenging projects. This relationship supports our intuitive impressions that projects have a better chance of success if they are able to effectively manage the project scope and changes to the requirements baseline.

\subsubsection{Project Planning}

The distribution of the responses assessing project planning activities (SEC-PP) of the projects is shown in Figure 23, with a value of 1 representing very poor project planning and 4 representing very good project planning.

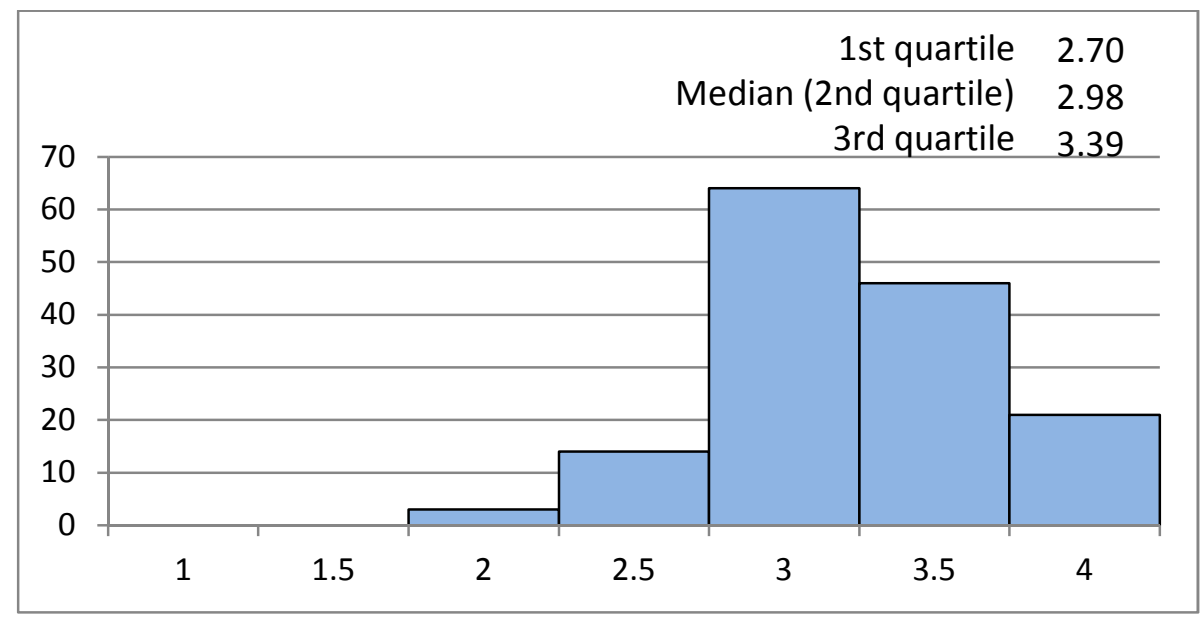

Figure 23: SEC-PP Response Distribution

The median of 2.98 indicates moderate application of project planning best practices, with room for improvement.

In preparing the mosaic chart showing the relationship between $\mathbf{S E C - P P}$ and Perf, three groups for $\boldsymbol{S E C - P P}$ were established with breakpoints at 2.82 and 3.25. These breakpoints resulted in 48 projects categorized as having lower $\boldsymbol{S E C - P P}$ capability, 50 as having middle $\boldsymbol{S E C - P P}$ capability, and 50 as having higher $\boldsymbol{S E C - P P}$ capability. The resulting mosaic chart is shown in Figure 25. 


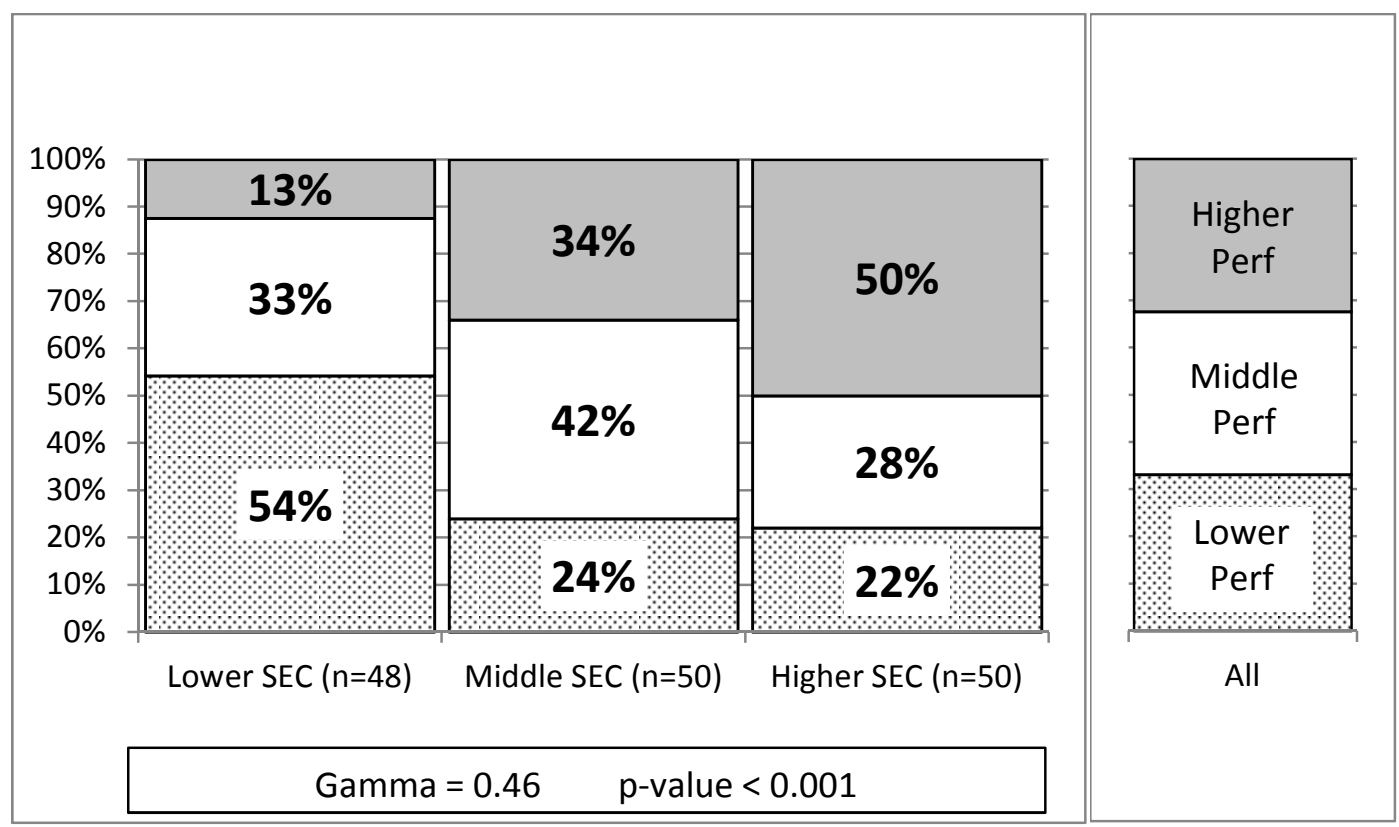

Figure 24: SEC-PP vS. Perf

Examination of this chart reveals a very strong supporting relationship between $\mathbf{S E C - P P}$ and Perf. The percentage of projects delivering higher performance increased from $13 \%$ to $34 \%$ to $50 \%$ as $\boldsymbol{S E C - P P}$ increased from lower to middle to higher.

Additionally, the percentage of projects delivering lower performance decreased from $54 \%$ to $24 \%$ to $22 \%$ as $\boldsymbol{S E C - P P}$ increased. This relationship is characterized by a very strong Gamma value of +0.46 and a very low p-value less than 0.001 , suggesting high confidence in the relationship between $\boldsymbol{S E C - P P}$ and Perf.

We further examined this relationship by incorporating the impact of $\boldsymbol{P C}$. The chart on the left side of Figure 25 shows the relationship between $\boldsymbol{S E C - P P}$ and Perf for those projects with lower $\boldsymbol{P C}(\boldsymbol{P C}<2.45)$. This set contains 73 projects. Of these, 17 were assessed as deploying lower SEC-PP capabilities, 27 deploying middle $\boldsymbol{S E C - P P}$ capabilities, and 29 deploying higher $\boldsymbol{S E C}$ $\boldsymbol{P P}$ capabilities.

The chart shows a weak supporting relationship between SEC-PP and Perf, with the percentage of projects delivering higher performance increasing from $18 \%$ to $37 \%$ to $38 \%$ as $\boldsymbol{S E C - P P}$ increased from lower to middle to higher.

Similarly, the percentage of projects delivering lower performance changed from $24 \%$ to $19 \%$ to $21 \%$ as $\boldsymbol{S E C - P P}$ increased. Thus, for these lower challenge projects, the likelihood of delivering higher performance more than doubled with improved $\boldsymbol{S E C - P P}$, while the likelihood of delivering lower performance remained substantially unchanged.

This relationship is characterized by a weak Gamma value of +0.16 and a high p-value of 0.313 , indicating that it is difficult to draw any reliable conclusions from this sample. SEC-PP does not appear to have a significant correlation with the performance of less challenging projects. 


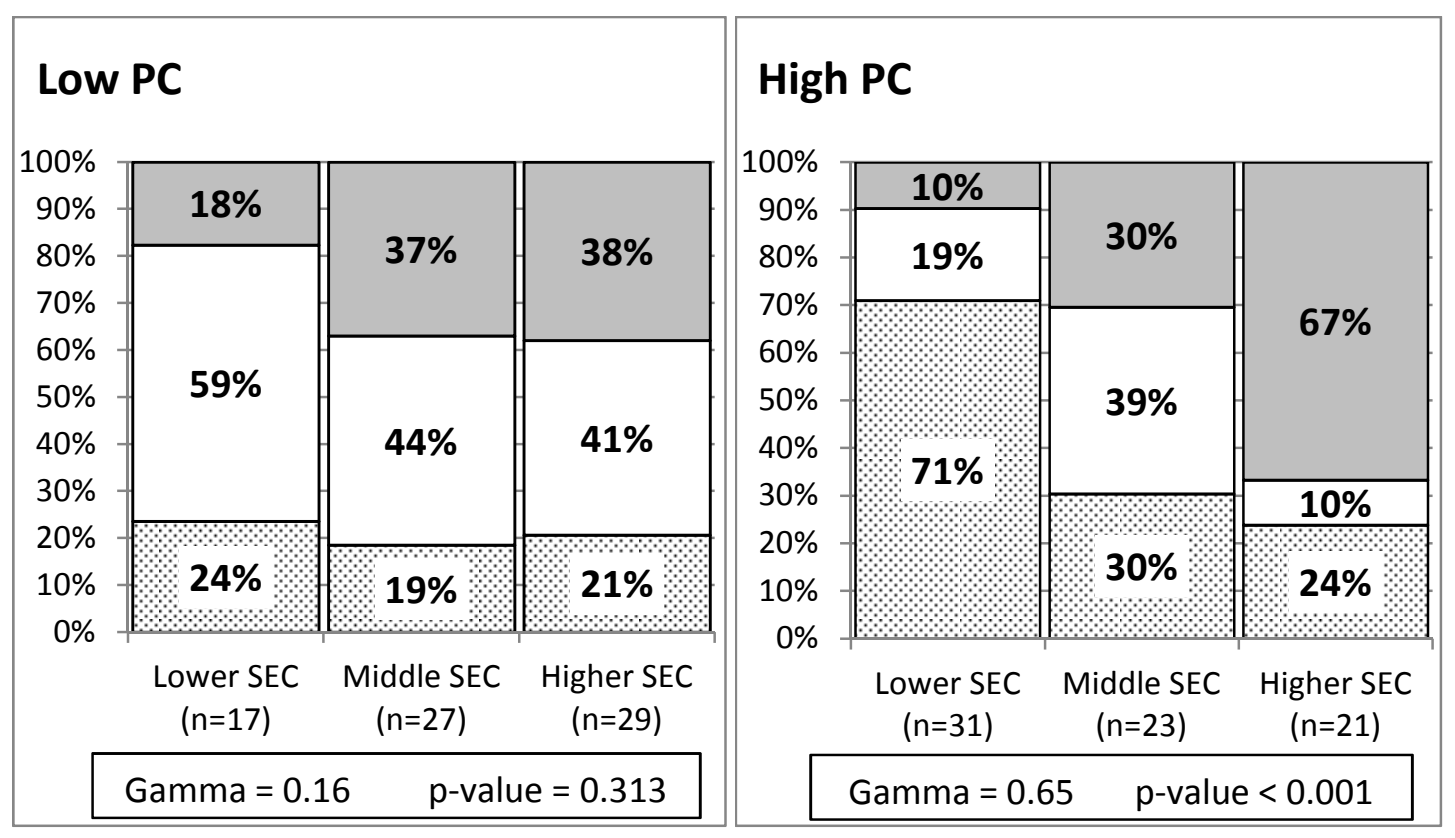

Figure 25: SEC-PP vs. Perf Controlled by PC

The chart on the right side of Figure 25 shows the relationship between $\mathbf{S E C}-\boldsymbol{P P}$ and Perf for those projects with higher $\boldsymbol{P C}(\boldsymbol{P C} \geq 2.45)$. This set contains 75 projects. Of these, 31 were assessed as deploying lower $\boldsymbol{S E C - P P}$ capabilities, 23 deploying middle $\boldsymbol{S E C}$-PP capabilities, and 21 deploying higher $\boldsymbol{S E C - P P}$ capabilities.

The chart shows a very strong supporting relationship between SEC-PP and Perf, with the percentage of projects delivering higher performance increasing from $10 \%$ to $30 \%$ to $67 \%$ as $\boldsymbol{S E C}$ $\boldsymbol{P P}$ increased from lower to middle to higher.

Additionally, the percentage of projects delivering lower performance decreased from $71 \%$ to $30 \%$ to $24 \%$ as $\boldsymbol{S E C - P P}$ increased. Thus, for these higher challenge projects, the likelihood of delivering higher performance increased almost sevenfold, and that of delivering lower performance decreased by nearly two-thirds with improved $\boldsymbol{S E C - P P}$. This relationship is characterized by a very strong Gamma value of +0.65 and a very low p-value less than 0.001 .

We can infer that higher $\boldsymbol{S E C - P P}$ capability is strongly correlated with project performance on challenging projects where planning may be even a more critical need due to project size and complexity.

\subsubsection{Product Architecture}

The distribution of the responses assessing product architecture activities (SEC-ARCH) of the projects is shown in Figure 26 with a value of 1 representing very poor product architecture work and 4 representing very good product architecture work. 


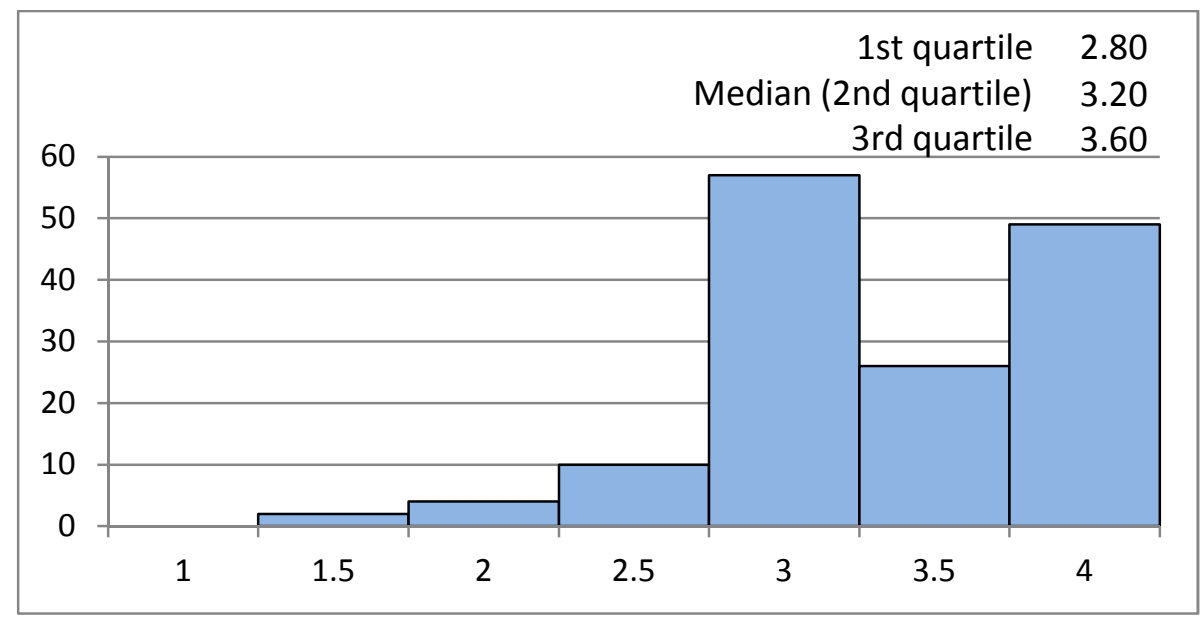

Figure 26: SEC-ARCH Response Distribution

The median of 3.20 indicates good application of product architecture best practices, but still with some room for improvement.

In preparing the mosaic chart showing the relationship between SEC-ARCH and Perf, three groups for $\boldsymbol{S E C}$-ARCH were established with breakpoints at 2.90 and 3.40. These breakpoints resulted in 45 projects categorized as having lower $\boldsymbol{S E C}$ - $\boldsymbol{A R C H}$ capability, 54 as having middle SEC-ARCH capability, and 49 as having higher SEC-ARCH capability. The resulting mosaic chart is shown in Figure 27.

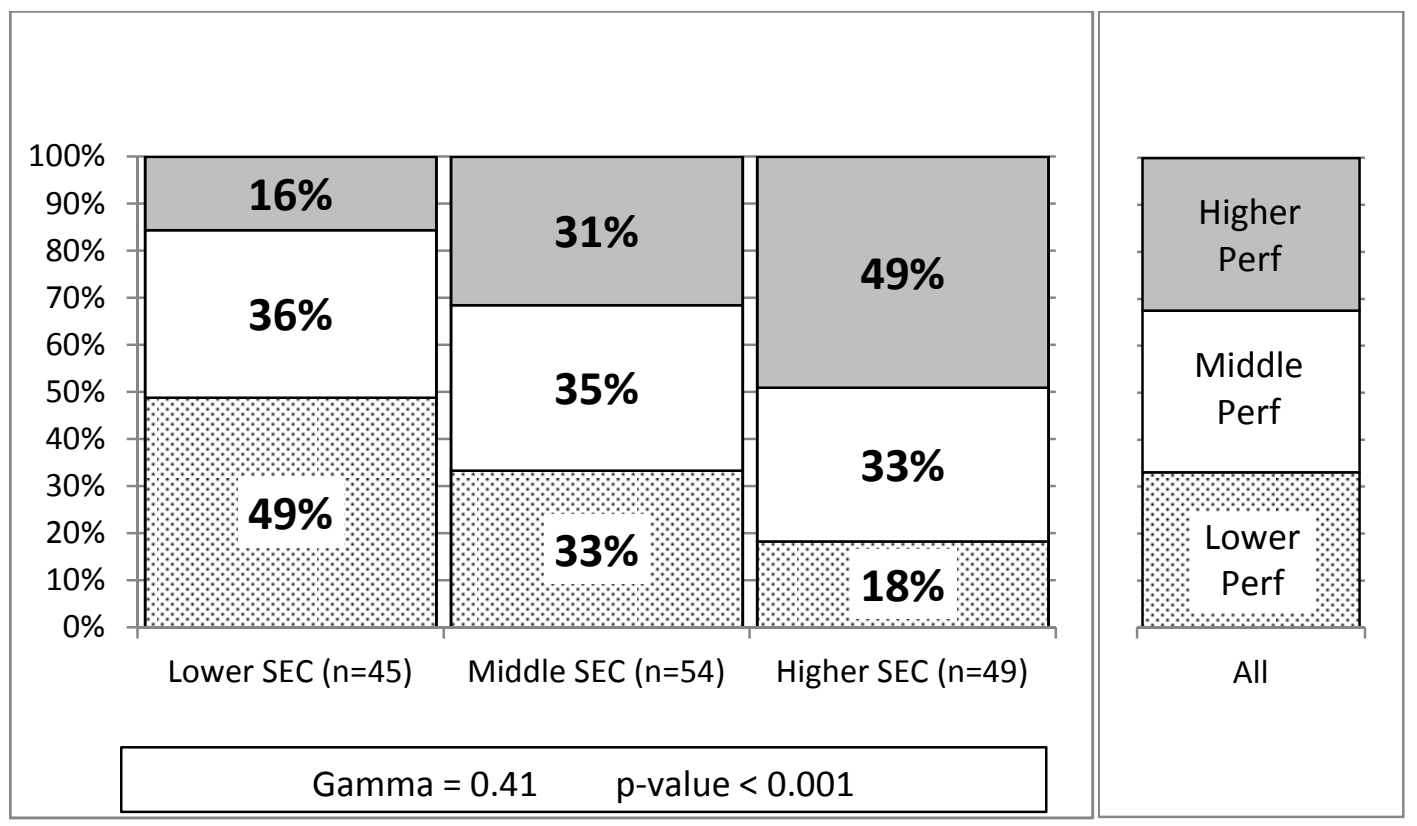

Figure 27: SEC-ARCH vs. Perf

Examination of this chart reveals a very strong supporting relationship between SEC-ARCH and Perf. The percentage of projects delivering higher performance increased from $16 \%$ to $31 \%$ to $\mathbf{4 9 \%}$ as $\boldsymbol{S E C}-\boldsymbol{A R} \boldsymbol{C H}$ increased from lower to middle to higher. 
Additionally, the percentage of projects delivering lower performance decreased from $49 \%$ to $33 \%$ to $18 \%$ as $\boldsymbol{S E C}$ - $\boldsymbol{A R C H}$ increased. This relationship is characterized by a very strong Gamma value of +0.41 and a very low p-value less than 0.001 .

We further examined this relationship by incorporating the impact of $\boldsymbol{P C}$. The chart on the left side of Figure 28 shows the relationship between SEC-ARCH and Perf for those projects with lower $\boldsymbol{P C}(\boldsymbol{P C}<2.45)$. This set contains 73 projects. Of these, 21 were assessed as deploying lower $\boldsymbol{S E C}$-ARCH capabilities, 28 deploying middle $\boldsymbol{S E C - A R C H}$ capabilities, and 24 deploying higher $\boldsymbol{S E C}$-ARCH capabilities.

The chart shows a strong supporting relationship between SEC-ARCH and Perf, with the percentage of projects delivering higher performance changing from $24 \%$ to $29 \%$ to $46 \%$ as $\boldsymbol{S E C}$ $A R C H$ increased from lower to middle to higher.

Additionally, the percentage of projects delivering lower performance decreased from $33 \%$ to $21 \%$ to $8 \%$ as $\boldsymbol{S E C - A R C H}$ increased. Thus, for these lower challenge projects, the likelihood of delivering higher performance nearly doubled with improved $\boldsymbol{S E C - A R C H}$, and that of delivering lower performance was reduced by over $75 \%$. This relationship is characterized by a strong Gamma value of +0.31 and a p-value of 0.051 .

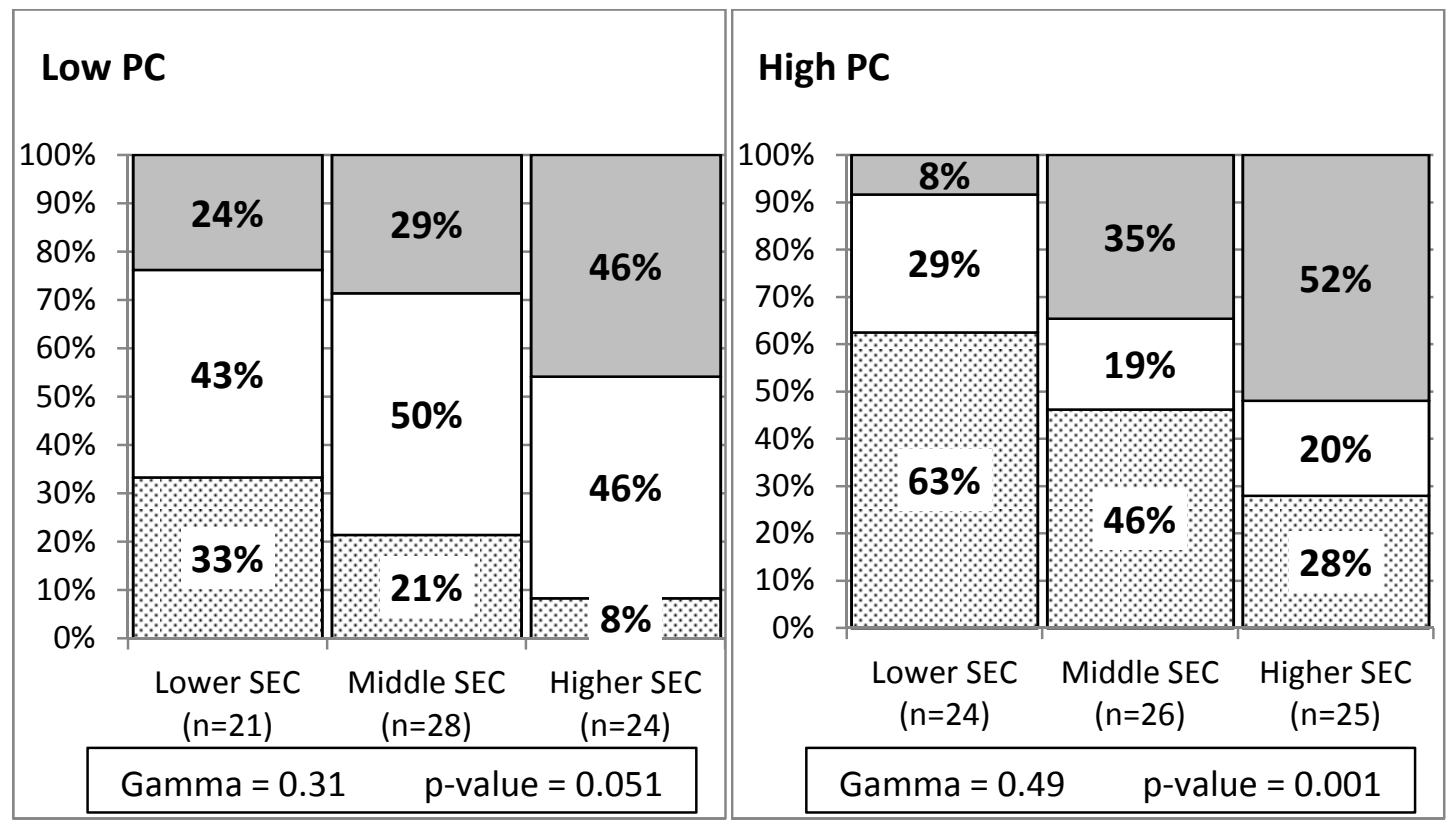

Figure 28: SEC-ARCH vs. Perf Controlled by PC

The chart on the right side of Figure 28 shows the relationship between SEC-ARCH and Perf for those projects with higher $\boldsymbol{P C}(\boldsymbol{P C} \geq 2.45)$. This set contains 75 projects. Of these, 24 were assessed as deploying lower $\boldsymbol{S E C}$ - $\boldsymbol{A R C H}$ capabilities, 26 deploying middle $\boldsymbol{S E C}$ - $\boldsymbol{A R C H}$ capabilities, and 25 deploying higher $\boldsymbol{S E C}$ - $\boldsymbol{A R C H}$ capabilities.

The chart shows a very strong supporting relationship between SEC-ARCH and Perf, with the percentage of projects delivering higher performance increasing from $8 \%$ to $35 \%$ to $52 \%$ as $\boldsymbol{S E C}$ $\boldsymbol{A R C H}$ increased from lower to middle to higher. 
Additionally, the percentage of projects delivering lower performance decreased from $63 \%$ to $46 \%$ to $28 \%$ as $\boldsymbol{S E C}$ - $\boldsymbol{A R C H}$ increased. Thus, for these higher challenge projects, the likelihood of delivering higher performance increased over sixfold, and that of delivering lower performance was reduced by more than half with improved SEC-ARCH. This relationship is characterized by a very strong Gamma value of +0.49 and a very low p-value of 0.001 .

We infer that stronger product architecture capability is associated with better performance on projects of all types, but the benefits are particularly evident on challenging projects where size and rework of architectural problems could be significant issues.

\subsubsection{Trade Studies}

The distribution of the responses assessing trade study activities (SEC-TRD) of the projects is shown in Figure 29 with a value of 1 representing very poor trade study work and 4 representing very good trade study work.

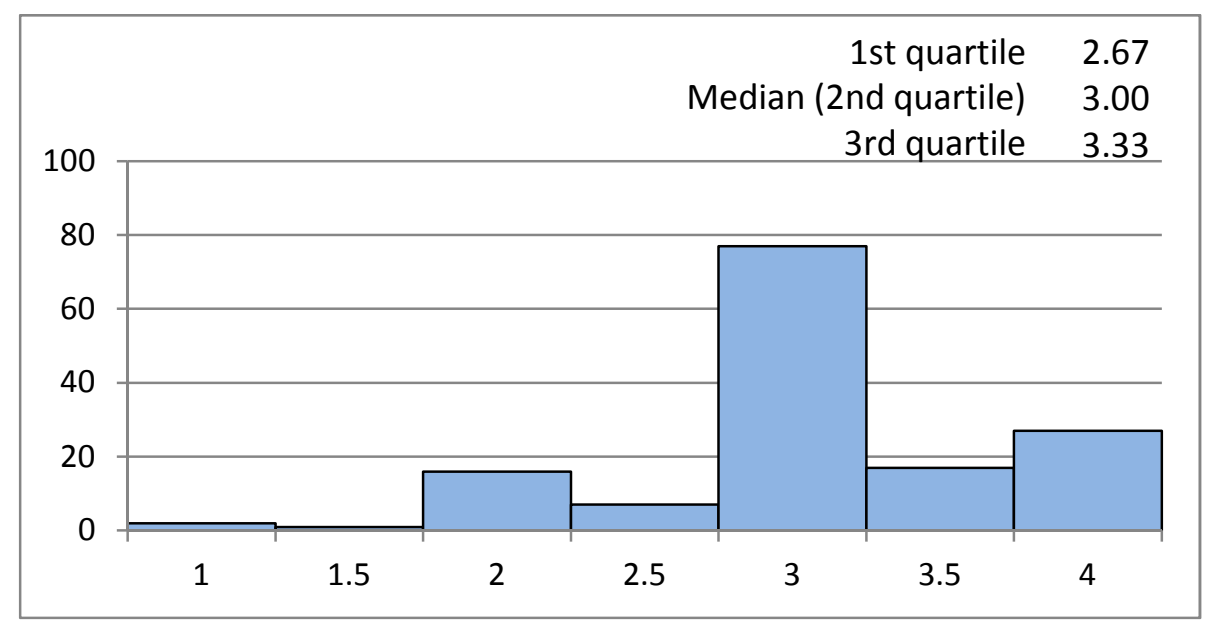

Figure 29: SEC-TRD Response Distribution

The median of 3.00 indicates moderate application of trade study best practices, with room for improvement.

In preparing the mosaic chart showing the relationship between $\boldsymbol{S E C - T R D}$ and Perf, three groups for $\boldsymbol{S E C - T R D}$ were established with breakpoints at 2.80 and 3.20. These breakpoints resulted in 46 projects categorized as having lower $\boldsymbol{S E C - T R D}$ capability, 58 as having middle $\boldsymbol{S E C - T R D}$ capability, and 44 as having higher $\boldsymbol{S E C - T R D}$ capability. The resulting mosaic chart is shown in Figure 30. 


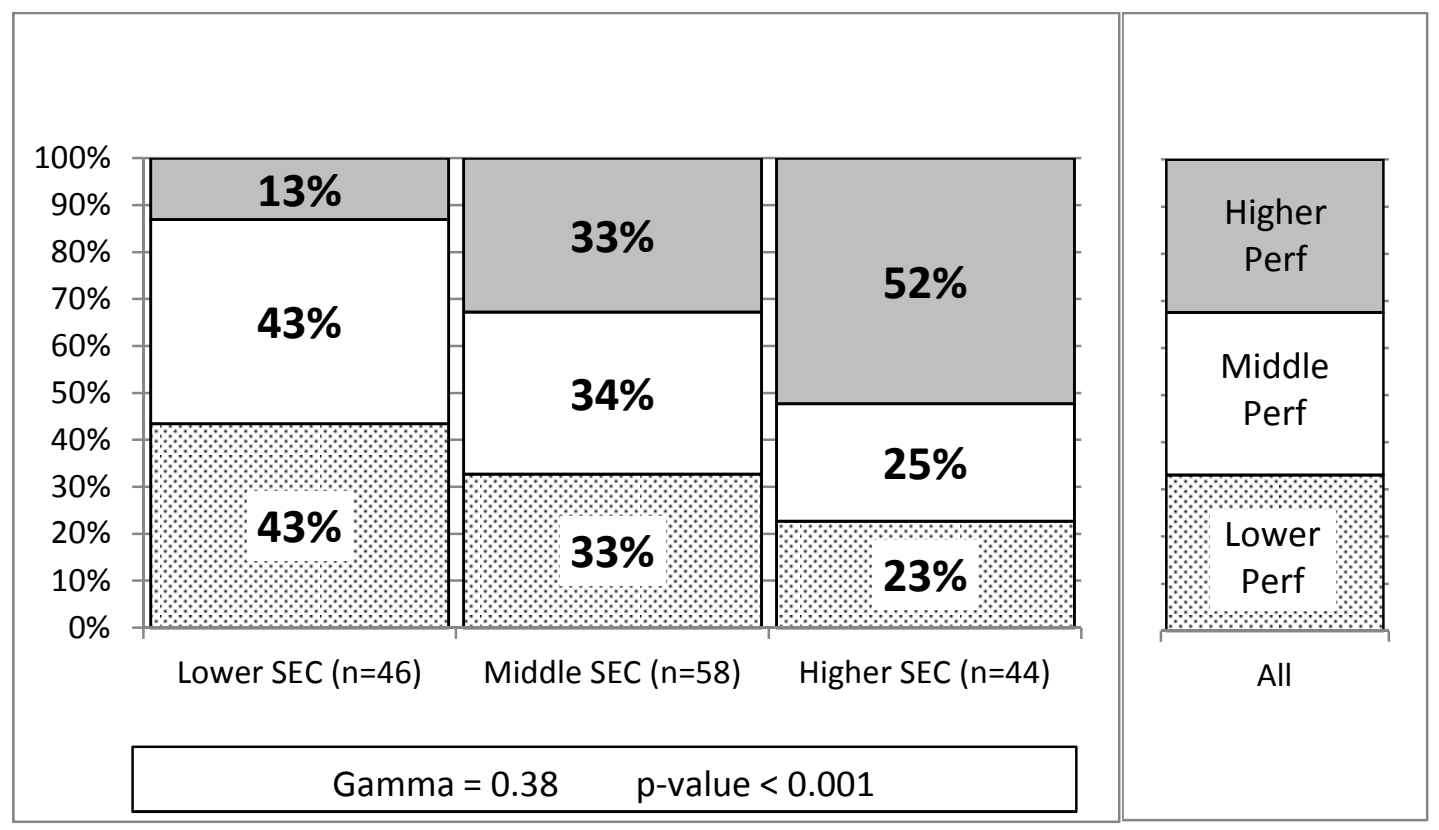

Figure 30: SEC-TRD vs. Perf

Examination of this chart reveals a strong supporting relationship between SEC-TRD and Perf. The percentage of projects delivering higher performance changed from $13 \%$ to $33 \%$ to $52 \%$ as SEC-TRD increased from lower to middle to higher.

Additionally, the percentage of projects delivering lower performance decreased from $43 \%$ to

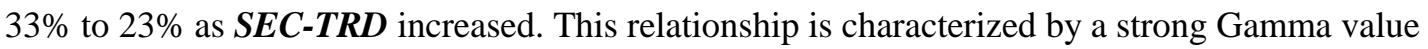
of +0.38 and a very low p-value less than 0.001 .

We further examined this relationship by incorporating the impact of $\boldsymbol{P C}$. The chart on the left side of Figure 31 shows the relationship between SEC-TRD and Perf for those projects with lower $\boldsymbol{P C}(\boldsymbol{P C}<2.45)$. This set contains 73 projects. Of these, 19 were assessed as deploying lower SEC-TRD capabilities, 30 deploying middle $\boldsymbol{S E C - T R D}$ capabilities, and 24 deploying higher SEC-TRD capabilities.

The chart shows a moderate supporting relationship between SEC-TRD and Perf, with the percentage of projects delivering higher performance increasing from $11 \%$ to $33 \%$ to $50 \%$ as $\boldsymbol{S E C}$ TRD increased from lower to middle to higher.

Additionally, the percentage of projects delivering lower performance changed from $26 \%$ to $17 \%$ to $21 \%$ as $\boldsymbol{S E C - T R D}$ increased. Thus, for these lower challenge projects, the likelihood of delivering higher performance increased more than fourfold with improved $\boldsymbol{S E C}$-TRD, while that of delivering lower performance did not change consistently. This relationship is characterized by a moderate Gamma value of +0.29 and a marginally low p-value of 0.062 . 


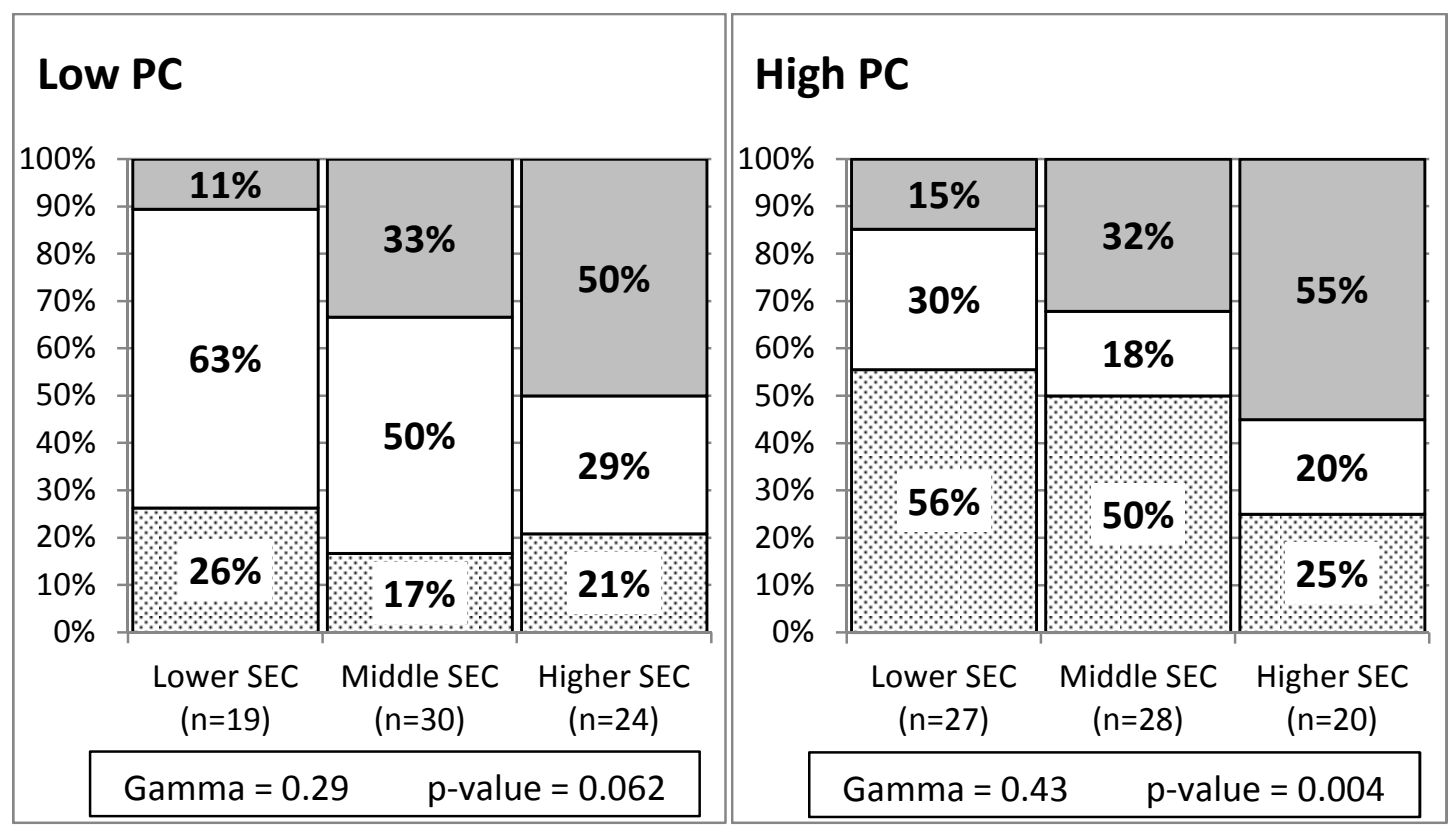

Figure 31: SEC-TRD vs. Perf Controlled by PC

The chart on the right side of Figure 31 shows the relationship between $\boldsymbol{S E C - T R D}$ and Perf for those projects with higher $\boldsymbol{P C}(\boldsymbol{P C} \geq 2.45)$. This set contains 75 projects. Of these, 27 were assessed as deploying lower $\boldsymbol{S E C}$-TRD capabilities, 28 deploying middle $\boldsymbol{S E C - T R D}$ capabilities, and 20 deploying higher $\boldsymbol{S E C - T R D}$ capabilities.

The chart shows a very strong supporting relationship between SEC-TRD and Perf, with the percentage of projects delivering higher performance increasing from $15 \%$ to $32 \%$ to $55 \%$ as $\boldsymbol{S E C}$ TRD increased from lower to middle to higher.

Additionally, the percentage of projects delivering lower performance decreased from $56 \%$ to $50 \%$ to $25 \%$ as $\boldsymbol{S E C - T R D}$ increased. Thus, for these higher challenge projects, the likelihood of delivering higher performance increased nearly fourfold, and that of delivering lower performance was reduced to less than half with improved $\boldsymbol{S E C - T R D . ~ T h i s ~ r e l a t i o n s h i p ~ i s ~ c h a r a c t e r i z e d ~ b y ~ a ~}$ very strong Gamma value of +0.43 and a very low p-value of 0.004 .

We infer that trade studies are most strongly associated with better performance on challenging projects, which may depend on sound trade studies to evaluate best alternatives in support of decision making for difficult or complex issues and to reduce potential rework.

\subsubsection{Product Integration}

The distribution of the responses assessing product integration activities (SEC-PI) of the projects is shown in Figure 32 with a value of 1 representing very poor product integration and 4 representing very good product integration. 


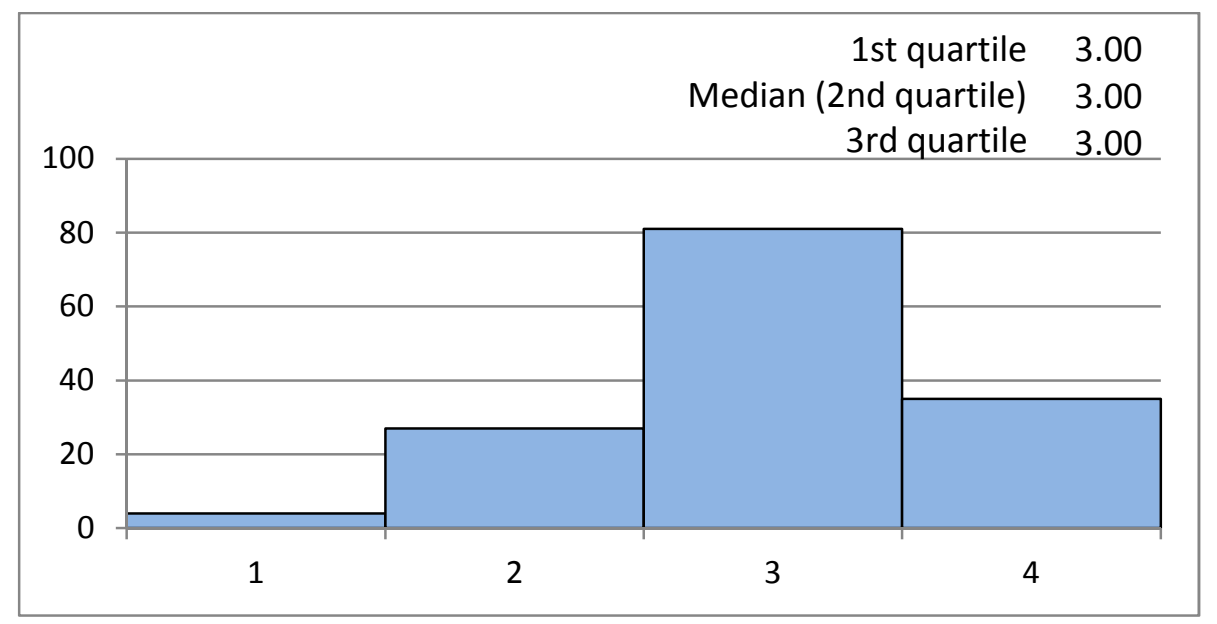

Figure 32: SEC-PI Response Distribution

The median of 3.00 indicates moderate application of product integration best practices, with room for improvement. The quartiles are all listed as 3.0 since there is only one question about product integration, and over half of the survey respondents chose the third option (agree) in answering the question.

Hence we could not use the usual categorizing criterion in this one instance to prepare the mosaic chart showing the relationship between SEC-PI and Perf. Instead the lower group includes the projects where the survey respondents chose the "strongly disagree" or "disagree" option. The middle group includes the projects where the respondents chose the "agree" category, and the higher group includes the projects whose respondents chose "strongly agree" in answering the question. These breakpoints resulted in 32 projects categorized as having lower $\boldsymbol{S E C - P I}$ capability, 81 as having middle $\boldsymbol{S E C - P I}$ capability, and 35 as having higher $\boldsymbol{S E C - P I}$ capability. The resulting mosaic chart is shown in Figure 33.

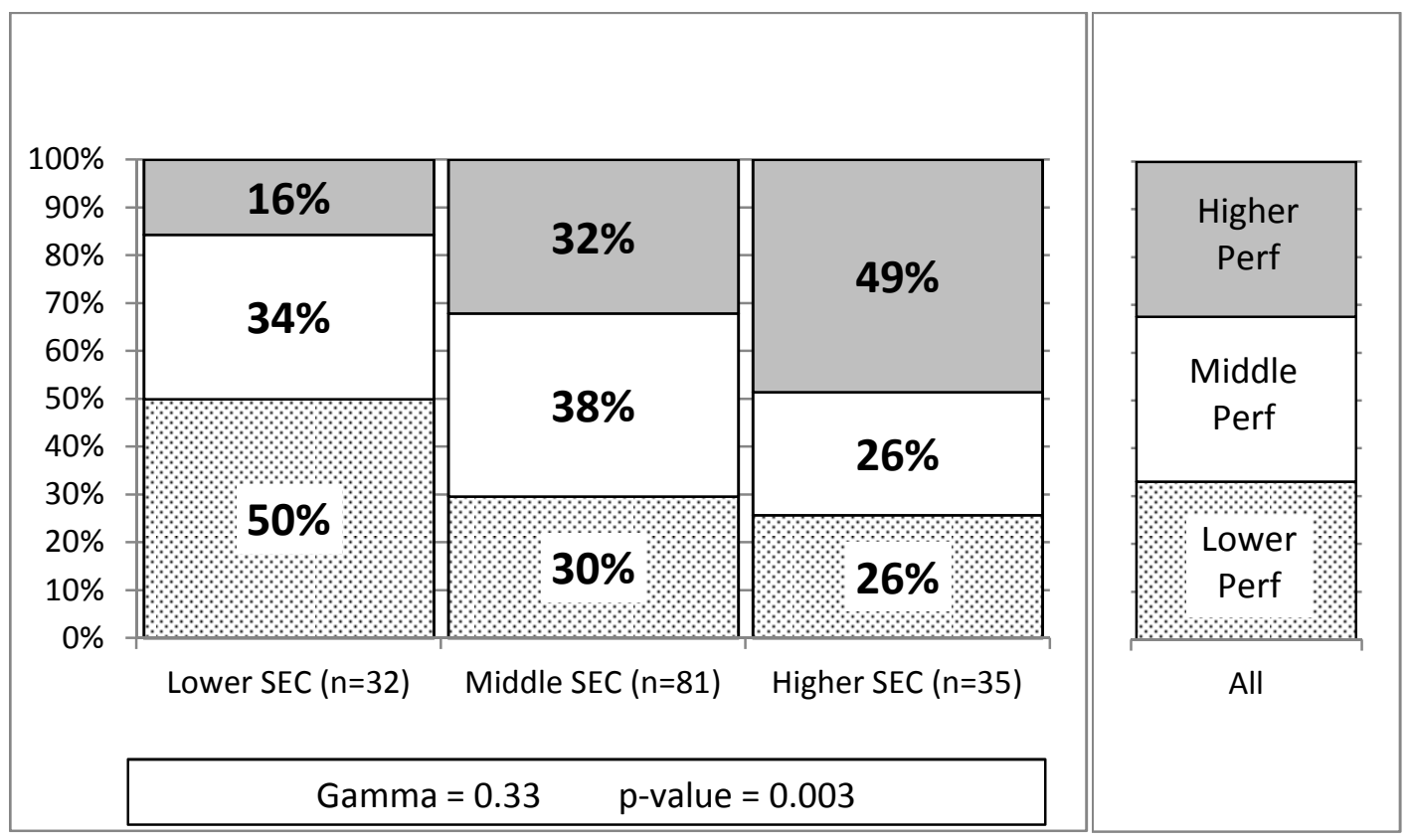

Figure 33: SEC-PI vs. Perf 
Examination of this chart reveals a strong supporting relationship between SEC-PI and Perf. The percentage of projects delivering higher performance increased from $16 \%$ to $32 \%$ to $49 \%$ as $\boldsymbol{S E C}$ $\boldsymbol{P I}$ increased from lower to middle to higher.

Additionally, the percentage of projects delivering lower performance changed from $50 \%$ to $30 \%$ to $26 \%$ as $\boldsymbol{S E C - P I}$ increased. This relationship is characterized by a strong Gamma value of +0.33 and a very low p-value of 0.003 .

We further examined this relationship by incorporating the impact of $\boldsymbol{P C}$. The chart on the left side of Figure 34 shows the relationship between SEC-PI and Perf for those projects with lower $\boldsymbol{P C}(\boldsymbol{P C}<2.45)$. This set contains 73 projects. Of these, 15 were assessed as deploying lower SEC-PI capabilities, 41 deploying middle $\boldsymbol{S E C - P I}$ capabilities, and 17 deploying higher $\boldsymbol{S E C - P I}$ capabilities.

The chart shows a moderate supporting relationship between SEC-PI and Perf, with the percentage of projects delivering higher performance changing from $20 \%$ to $32 \%$ to $47 \%$ as $\boldsymbol{S E C - P I}$ increased from lower to middle to higher.

Additionally, the percentage of projects delivering lower performance changed from $33 \%$ to $17 \%$ to $18 \%$ as $\boldsymbol{S E C - P I}$ increased. Thus, for these lower challenge projects, the likelihood of delivering higher performance more than doubled with improved SEC-PI, while that of delivering lower performance was reduced by nearly half. This relationship is characterized by a moderate Gamma value of +0.23 and a marginal $p$-value of 0.153 .

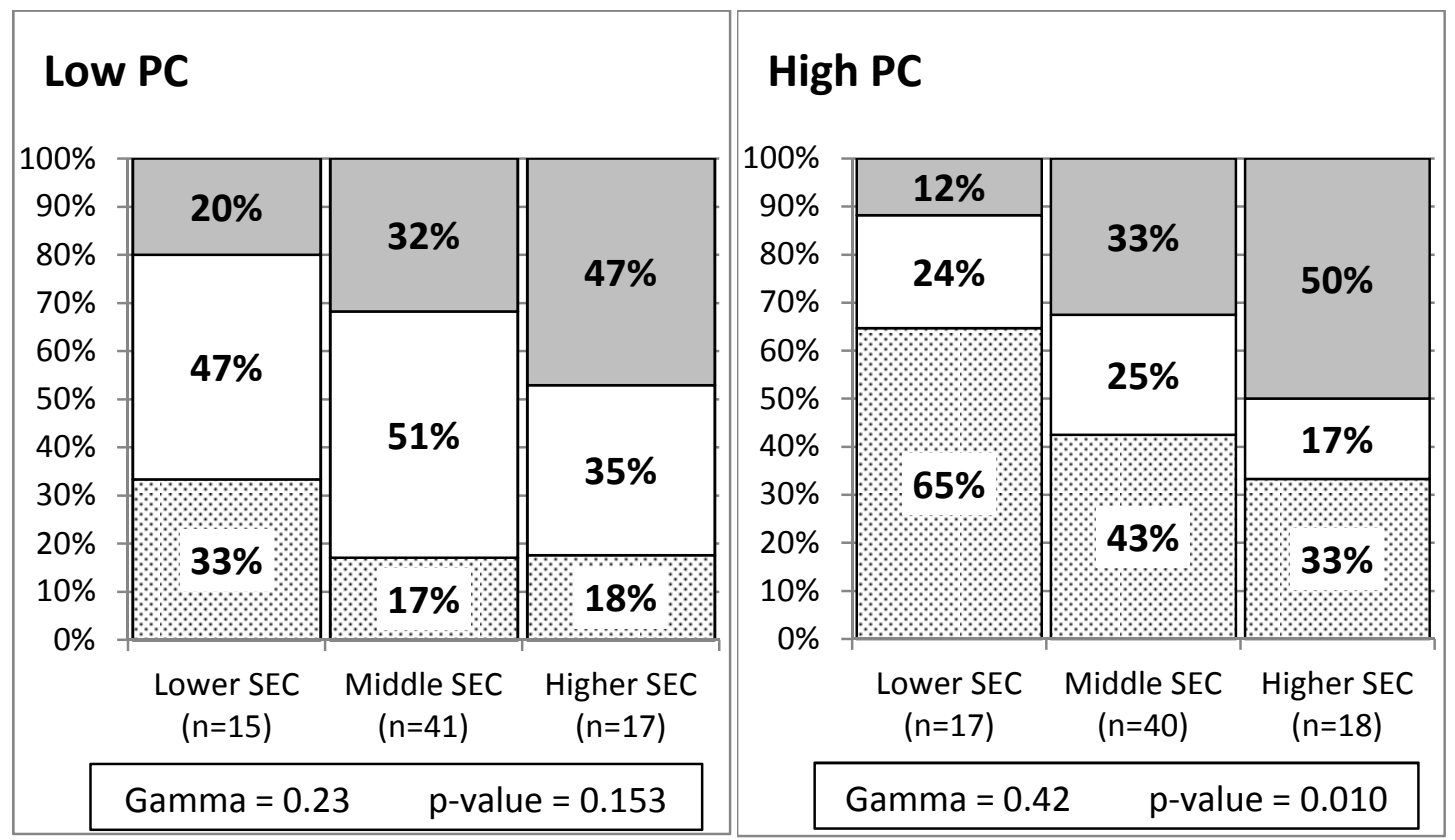

Figure 34: SEC-VER vs. Perf Controlled by PC

The chart on the right side of Figure 34 shows the relationship between SEC-PI and Perf for those projects with higher $\boldsymbol{P C}(\boldsymbol{P C} \geq 2.4)$. This set contains 75 projects. Of these, 17 were assessed as deploying lower $\boldsymbol{S E C - P I}$ capabilities, 40 deploying middle $\boldsymbol{S E C - P I}$ capabilities, and 18 deploying higher $\boldsymbol{S E C - P I}$ capabilities. 
The chart shows a very strong supporting relationship between SEC-PI and Perf, with the percentage of projects delivering higher performance increasing from $12 \%$ to $33 \%$ to $50 \%$ as $\boldsymbol{S E C - P I}$ increased from lower to middle to higher.

Additionally, the percentage of projects delivering lower performance decreased from $65 \%$ to 43\% to 33\% as $\boldsymbol{S E C - P I}$ increased. Thus, for these higher challenge projects, the likelihood of delivering higher performance increased fourfold, and that of delivering lower performance was reduced by almost half with improved $\boldsymbol{S E C - P I}$. This relationship is characterized by a very strong Gamma value of +0.42 and a low p-value of 0.010 .

We conclude that integration best practices are strongly associated with the performance of challenging projects in particular. This conclusion seems intuitive- that stronger integration capabilities are necessary to achieve the best performance on projects that are large or complex. Challenging projects that lack a strong integration capability are less likely to achieve top levels of performance.

\subsubsection{Verification}

The distribution of the responses assessing verification activities (SEC-VER) of the projects is shown in Figure 35 with a value of 1 representing very poor verification work and 4 representing very good verification work.

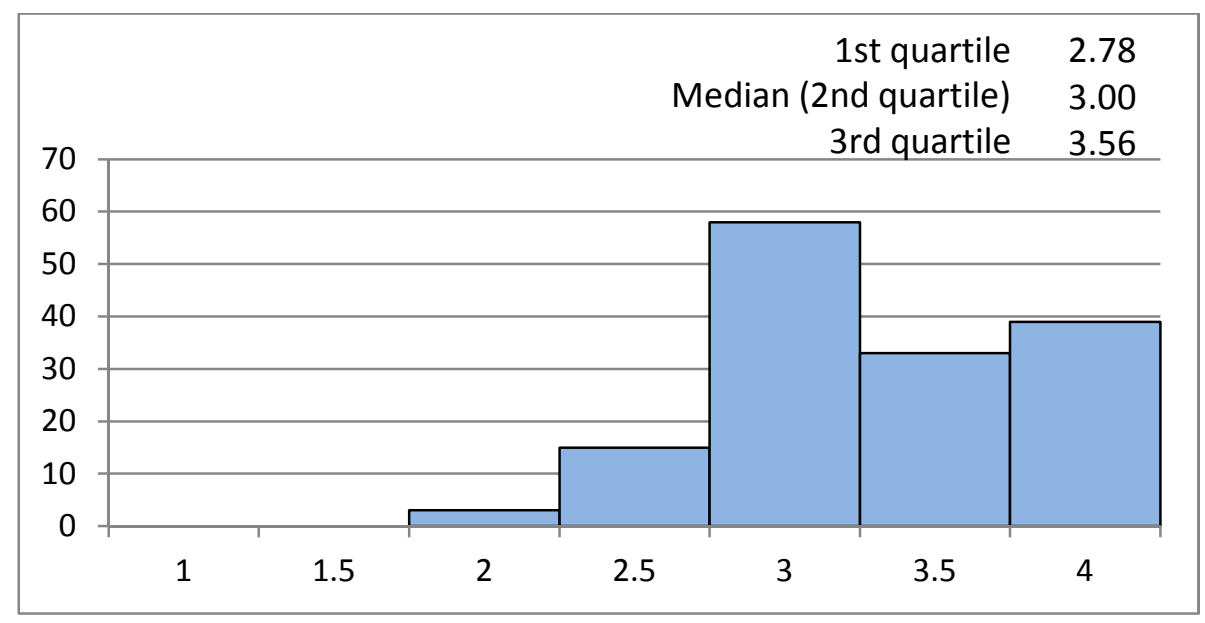

Figure 35: SEC-VER Response Distribution

The median of 3.00 indicates moderate application of verification best practices, with room for improvement.

In preparing the mosaic chart showing the relationship between $\boldsymbol{S E C}-\boldsymbol{V E R}$ and Perf, three groups for $\boldsymbol{S E C - V E R}$ were established with breakpoints at 2.80 and 3.33. These breakpoints resulted in 44 projects categorized as having lower $\boldsymbol{S E C - V E R}$ capability, 50 as having middle $\boldsymbol{S E C - V E R}$ capability, and 54 as having higher $\boldsymbol{S E C - V E R}$ capability. The resulting mosaic chart is shown in Figure 36 . 


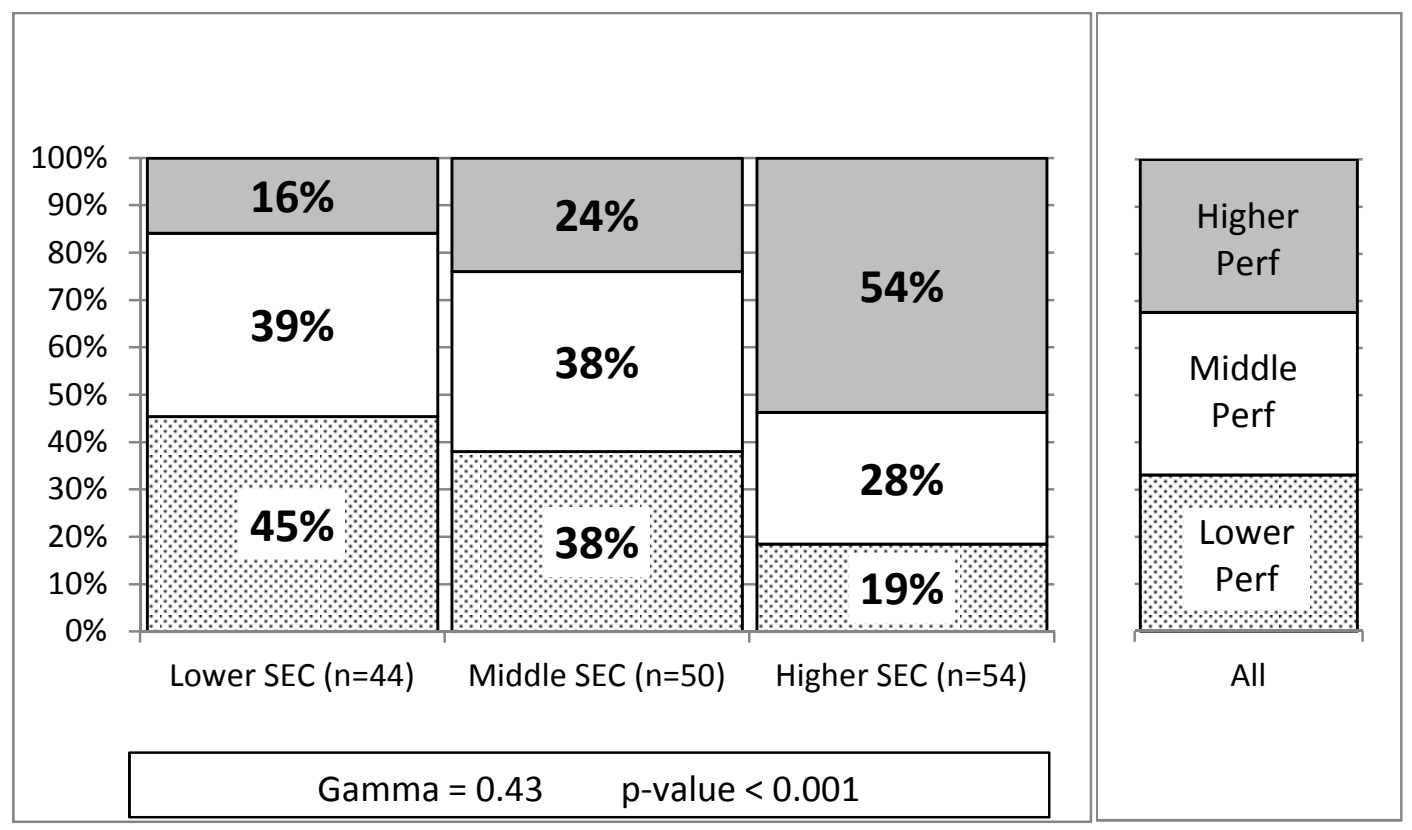

Figure 36: SEC-VER vS. Perf

Examination of this chart reveals a very strong supporting relationship between $\boldsymbol{S E C}$-VER and Perf. The percentage of projects delivering higher performance increased from $16 \%$ to $24 \%$ to 54\% as $\boldsymbol{S E C - V E R}$ increased from lower to middle to higher.

Additionally, the percentage of projects delivering lower performance decreased from $45 \%$ to $38 \%$ to $19 \%$ as $\boldsymbol{S E C}$-VER increased. This relationship is characterized by a very strong Gamma value of +0.43 and a very low $p$-value less than 0.001 .

We further examined this relationship by incorporating the impact of $\boldsymbol{P C}$. The chart on the left side of Figure 37 shows the relationship between SEC-VER and Perf for those projects with lower $\boldsymbol{P C}(\boldsymbol{P C}<2.45)$. This set contains 73 projects. Of these, 23 were assessed as deploying lower $\boldsymbol{S E C}$-VER capabilities, 23 deploying middle $\boldsymbol{S E C}$-VER capabilities, and 27 deploying higher SEC-VER capabilities.

The chart shows a moderate supporting relationship between SEC-VER and Perf, with the percentage of projects delivering higher performance changing from $22 \%$ to $22 \%$ to $52 \%$ as $\boldsymbol{S E C}$ $\boldsymbol{V E R}$ increased from lower to middle to higher.

Additionally, the percentage of projects delivering lower performance changed from $22 \%$ to $26 \%$

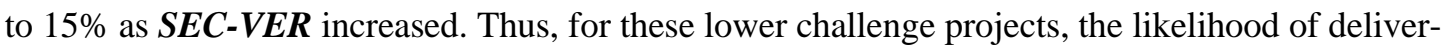
ing higher performance more than doubled with improved SEC-VER, while that of delivering lower performance did not change consistently. This relationship is characterized by a moderate Gamma value of +0.27 and a marginally low p-value of 0.084 . 


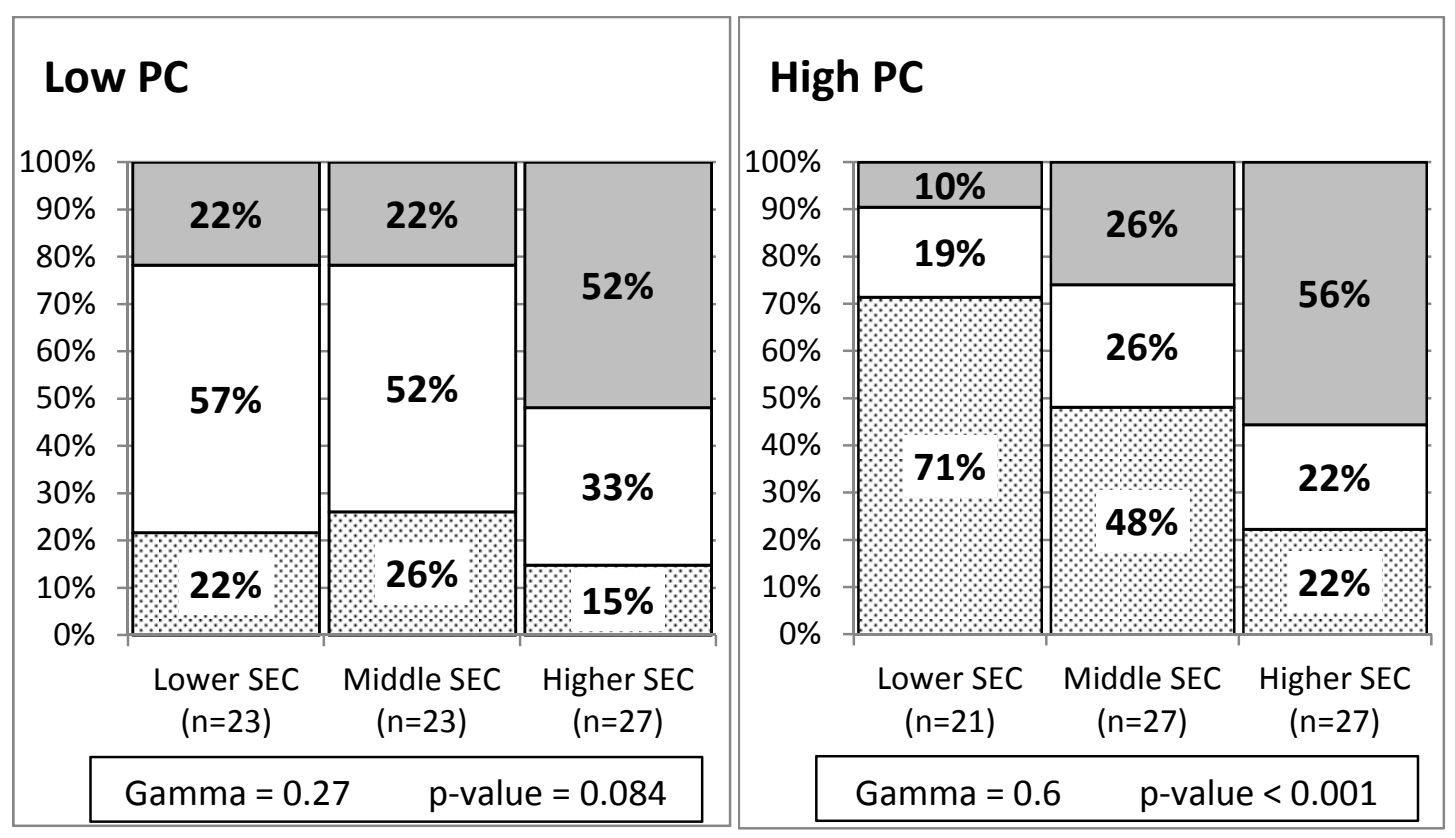

Figure 37: SEC-VER vs. Perf Controlled by PC

The chart on the right side of Figure 37 shows the relationship between SEC-VER and Perf for those projects with higher $\boldsymbol{P C}(\boldsymbol{P C} \geq 2.4)$. This set contains 75 projects. Of these, 21 were as-

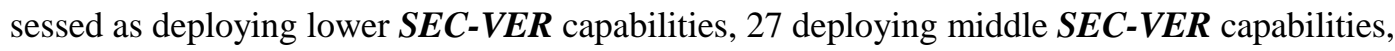
and 27 deploying higher $\boldsymbol{S E C - V E R}$ capabilities.

The chart shows a very strong supporting relationship between SEC-VER and Perf, with the percentage of projects delivering higher performance increasing from $10 \%$ to $26 \%$ to $56 \%$ as $\boldsymbol{S E C}$ $\boldsymbol{V E R}$ increased from lower to middle to higher.

Additionally, the percentage of projects delivering lower performance decreased from $71 \%$ to $48 \%$ to $22 \%$ as $\boldsymbol{S E C - V E R}$ increased. Thus, for these higher challenge projects, the likelihood of delivering higher performance increased over fivefold and that of delivering lower performance was reduced by almost 70\% with improved SEC-VER . This relationship is characterized by a very strong Gamma value of +0.60 and a very low p-value less than 0.001 .

We conclude that verification best practices are strongly associated with the performance of challenging projects in particular. This conclusion seems intuitive-that stronger verification capabilities are necessary to achieve the best performance on projects that are large or complex. Challenging projects that lack a strong verification capability rarely achieve top levels of performance.

\subsubsection{Validation}

The distribution of the responses assessing validation activities (SEC-VAL) of the projects is shown in Figure 38 with a value of 1 representing very poor validation work and 4 representing very good validation work. 


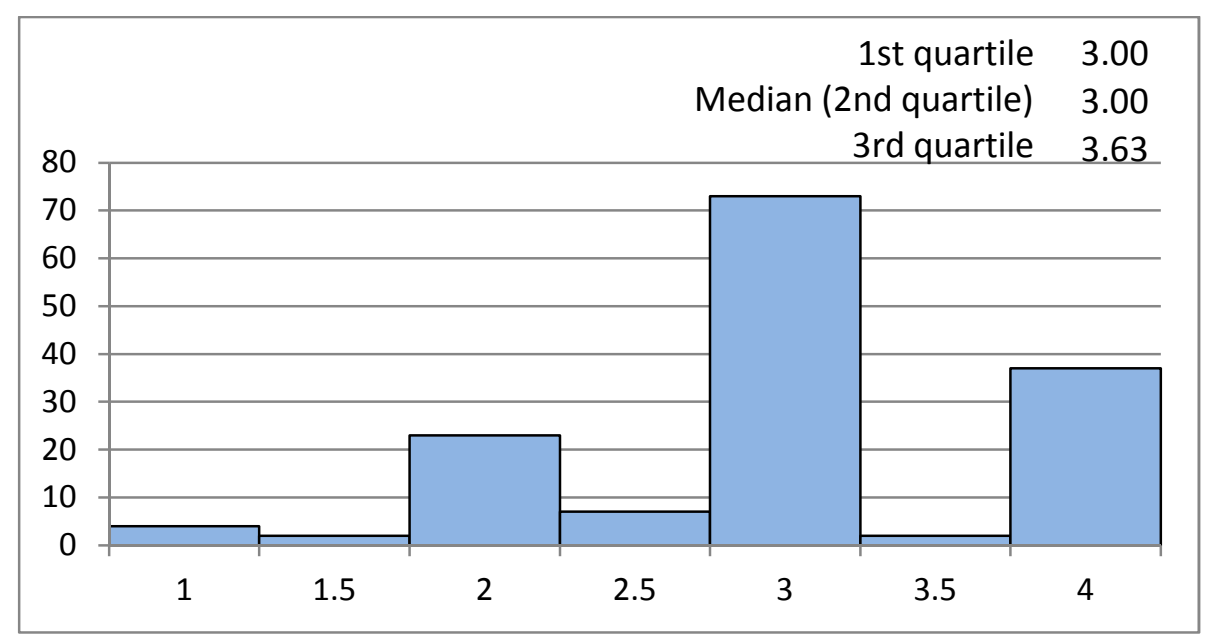

Figure 38: SEC-VAL Response Distribution

The median of 3.00 indicates moderate application of validation best practices, with room for improvement.

In preparing the mosaic chart showing the relationship between $\boldsymbol{S E C}-\boldsymbol{V A L}$ and Perf, three groups for $\boldsymbol{S E C - V A L}$ were established with breakpoints at 2.70 and 3.30. These breakpoints resulted in 36 projects categorized as having lower $\boldsymbol{S E C - V A L}$ capability, 73 as having middle $\boldsymbol{S E C - V A \boldsymbol { L }}$ capability, and 39 as having higher $\boldsymbol{S E C - V A L}$ capability. The resulting mosaic chart is shown in Figure 39.

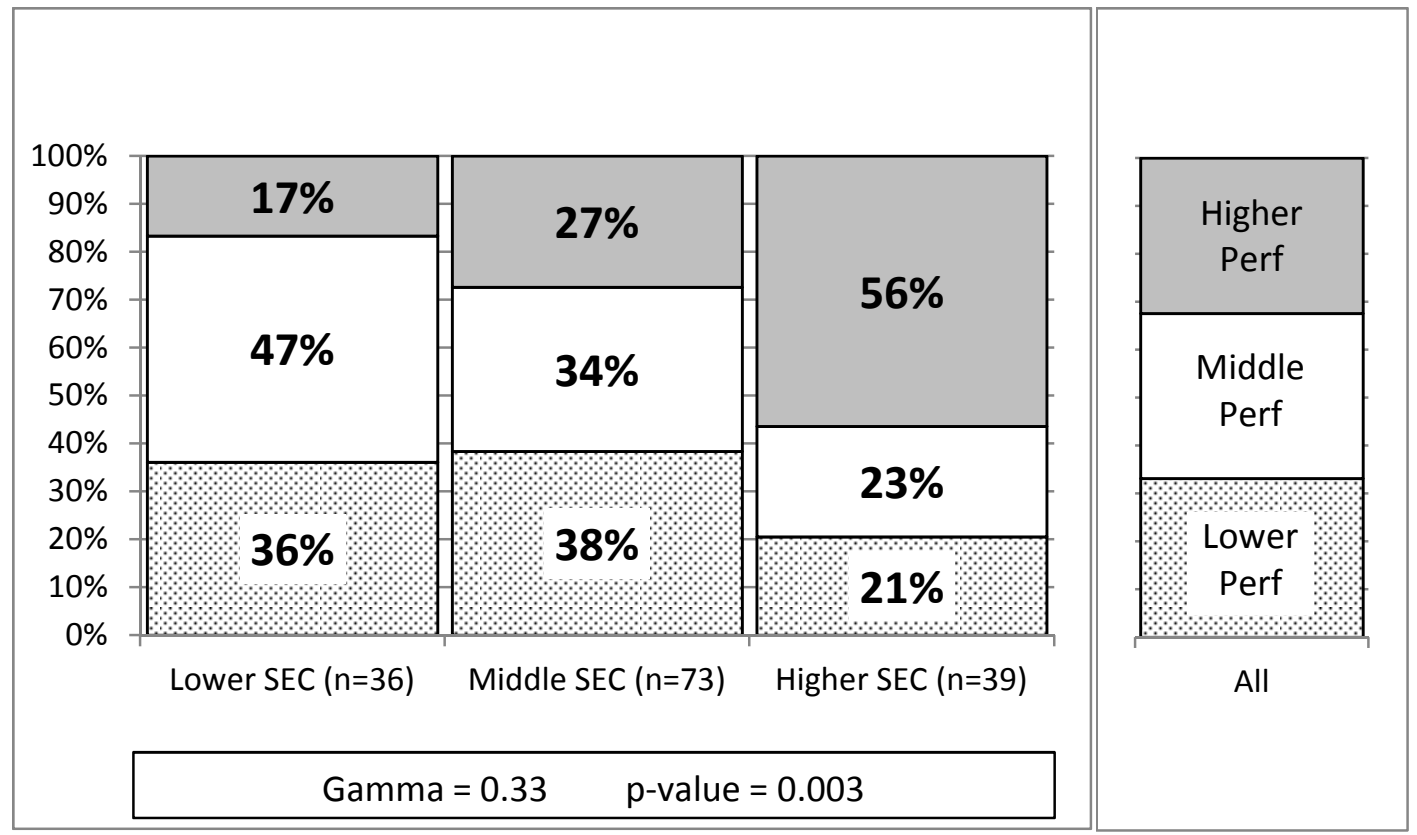

Figure 39: SEC-VAL vs. Perf

Examination of this chart reveals a strong supporting relationship between SEC-VAL and Perf. The percentage of projects delivering higher performance changed from $17 \%$ to $27 \%$ to $56 \%$ as SEC-VAL increased from lower to middle to higher 
Additionally, the percentage of projects delivering lower performance changed from 36\% to 38\%

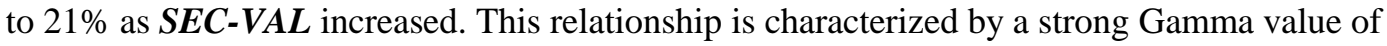
+0.33 and a very low p-value of 0.003 .

We further examined this relationship by incorporating the impact of $\boldsymbol{P C}$. The chart on the left side of Figure 40 shows the relationship between SEC VAL and Perf for those projects with lower $\boldsymbol{P C}(\boldsymbol{P C}<2.45)$. This set contains 73 projects. Of these, 22 were assessed as deploying lower $\boldsymbol{S E C}$-VAL capabilities, 34 deploying middle $\boldsymbol{S E C}$ - $\boldsymbol{V A L}$ capabilities, and 17 deploying higher SEC-VAL capabilities.

The chart shows a moderate supporting relationship between SEC-VAL and Perf, with the percentage of projects delivering higher performance changing from $22 \%$ to $24 \%$ to $59 \%$ as $\boldsymbol{S E C}$ $V A L$ increased from lower to middle to higher.

Additionally, the percentage of projects delivering lower performance changed from $18 \%$ to $26 \%$

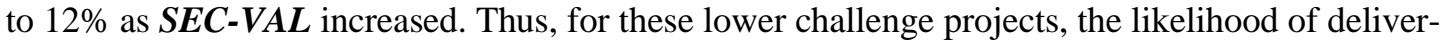
ing higher performance more than doubled with improved $\boldsymbol{S E C - V A L}$, while that of delivering lower performance did not change consistently. This relationship is characterized by a moderate Gamma value of +0.23 but with a moderately high p-value of 0.127 .

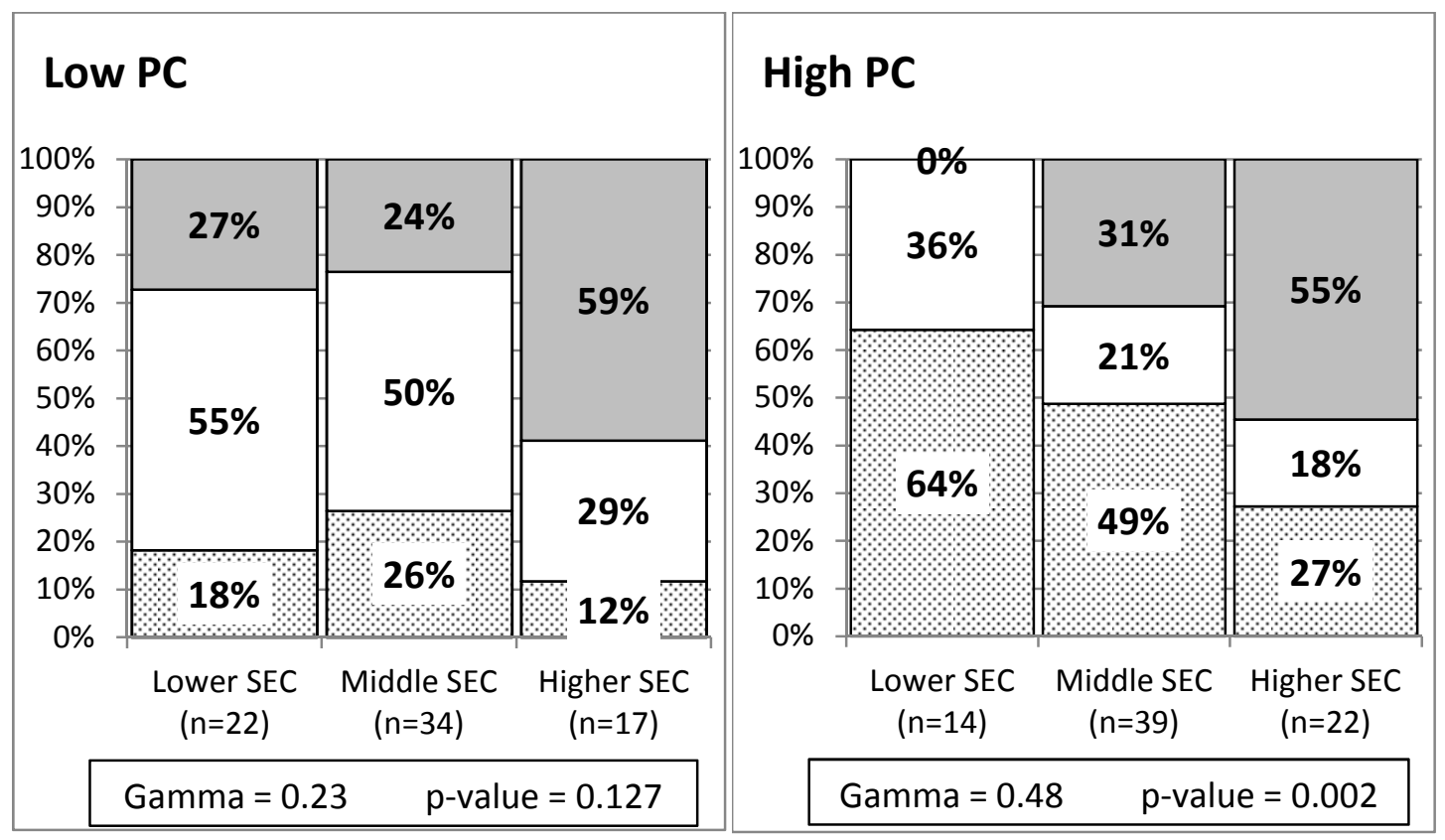

Figure 40: SEC-VAL vs. Perf Controlled by PC

The chart on the right side of Figure 40 shows the relationship between SEC-VAL and Perf for those projects with higher $\boldsymbol{P C}(\boldsymbol{P C} \geq 2.4)$. This set contains 75 projects. Of these, 14 were assessed as deploying lower $\boldsymbol{S E C}$-VAL capabilities, 39 deploying middle $\boldsymbol{S E C} \boldsymbol{V} \boldsymbol{A} \boldsymbol{L}$ capabilities, and 22 deploying higher $\boldsymbol{S E C}$ - $\boldsymbol{V A L}$ capabilities.

The chart shows a very strong supporting relationship between SEC-VAL and Perf, with the percentage of projects delivering higher performance increasing from $0 \%$ to $31 \%$ to $55 \%$ as $\boldsymbol{S E C}$ $V A L$ increased from lower to middle to higher. 
Additionally, the percentage of projects delivering lower performance decreased from $64 \%$ to $49 \%$ to $27 \%$ as $\boldsymbol{S E C}$ - VAL increased. Thus, for these higher challenge projects, the likelihood of delivering higher performance increased from $0 \%$ to over $50 \%$, and that of delivering lower performance was reduced by almost $60 \%$ with improved $\boldsymbol{S E C - V A L}$. This relationship is characterized by a very strong Gamma value of +0.48 and a very low p-value of 0.002 .

We conclude that validation best practices are strongly associated with the performance of challenging projects in particular. This conclusion seems intuitive- that greater involvement with end users and validation of project performance in an operational environment would be most critical on large or complex projects, and such projects that do not have strong validation practices are unlikely to achieve the best levels of project performance.

\subsubsection{Project Monitoring and Control}

The distribution of the responses assessing project monitoring and control activities (SEC-PMC) of the projects is shown in Figure 41 with a value of 1 representing very poor project monitoring and control and 4 representing very good project monitoring and control.

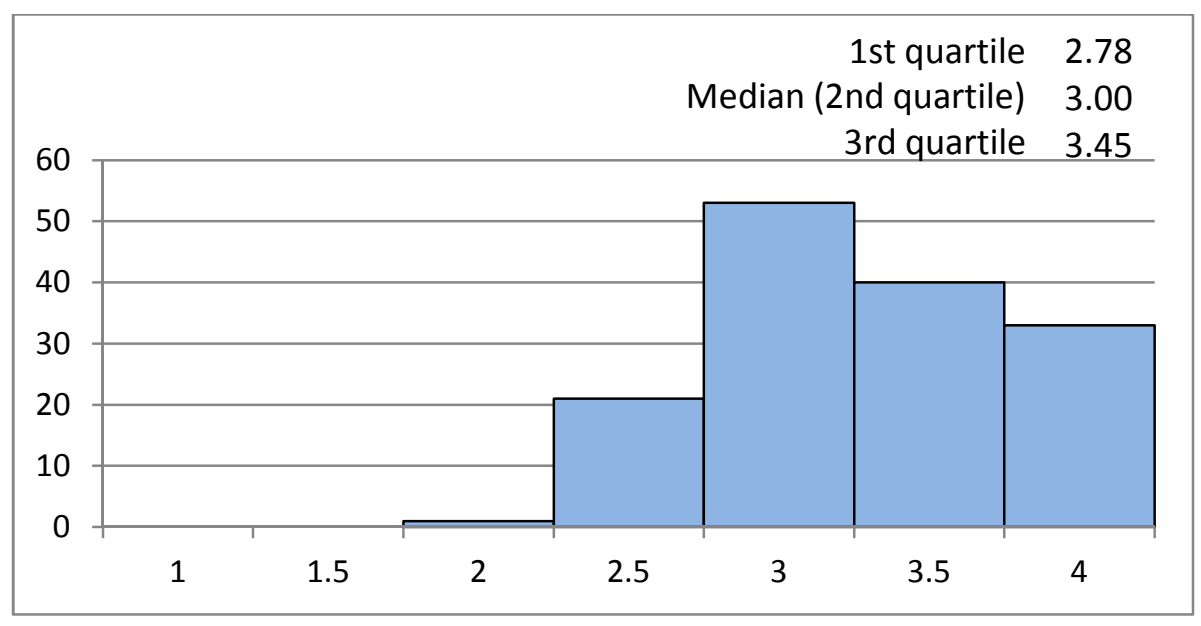

Figure 41: SEC-PMC Response Distribution

The median of 3.00 indicates moderate application of project monitoring and control best practices, with room for improvement.

In preparing the mosaic chart showing the relationship between SEC-PMC and Perf, three groups for $\boldsymbol{S E C - T R D}$ were established with breakpoints at 2.90 and 3.30. These breakpoints resulted in 48 projects categorized as having lower $\boldsymbol{S E C - P M C}$ capability, 52 as having middle $\boldsymbol{S E C - P M C}$ capability, and 48 as having higher $\boldsymbol{S E C - P M C}$ capability. The resulting mosaic chart is shown in Figure 42. 


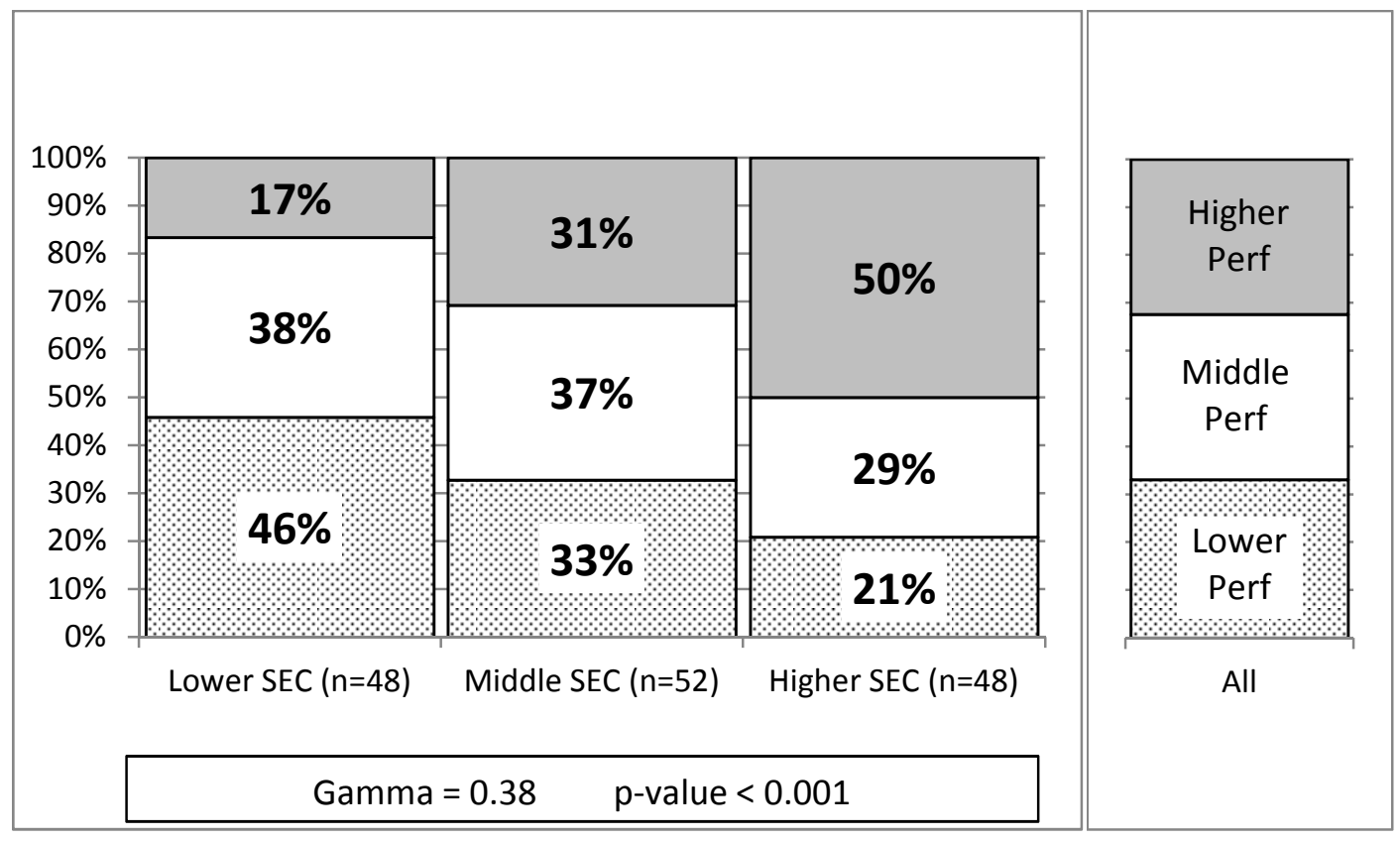

Figure 42: SEC-PMC vs. Perf

Examination of this chart reveals a strong supporting relationship between SEC-PMC and Perf. The percentage of projects delivering higher performance changed from $17 \%$ to $31 \%$ to $50 \%$ as SEC-PMC increased from lower to middle to higher.

Additionally, the percentage of projects delivering lower performance changed from $46 \%$ to $33 \%$ to $21 \%$ as $\boldsymbol{S E C - P M C}$ increased. This relationship is characterized by a strong Gamma value of +0.38 and a very low p-value less than 0.001 .

We further examined this relationship by incorporating the impact of $\boldsymbol{P C}$. The chart on the left side of Figure 43 shows the relationship between SEC-PMC and Perf for those projects with lower $\boldsymbol{P C}(\boldsymbol{P C}<2.45)$. This set contains 73 projects. Of these, 26 were assessed as deploying lower SEC-PMC capabilities, 25 deploying middle $\boldsymbol{S E C}$-PMC capabilities, and 22 deploying higher SEC-PMC capabilities.

The chart shows a moderate supporting relationship between SEC-PMC and Perf, with the percentage of projects delivering higher performance changing from $19 \%$ to $36 \%$ to $45 \%$ as $\boldsymbol{S E C}$ $\boldsymbol{P M C}$ increased from lower to middle to higher.

Additionally, the percentage of projects delivering lower performance changed from $27 \%$ to $20 \%$ to $14 \%$ as $\boldsymbol{S E C - P M C}$ increased. Thus, for these lower challenge projects, the likelihood of delivering higher performance more than doubled with improved SEC-PMC, while that of delivering lower performance was reduced by nearly half. This relationship is characterized by a moderate Gamma value of +0.27 with a marginally low p-value of 0.092 . 


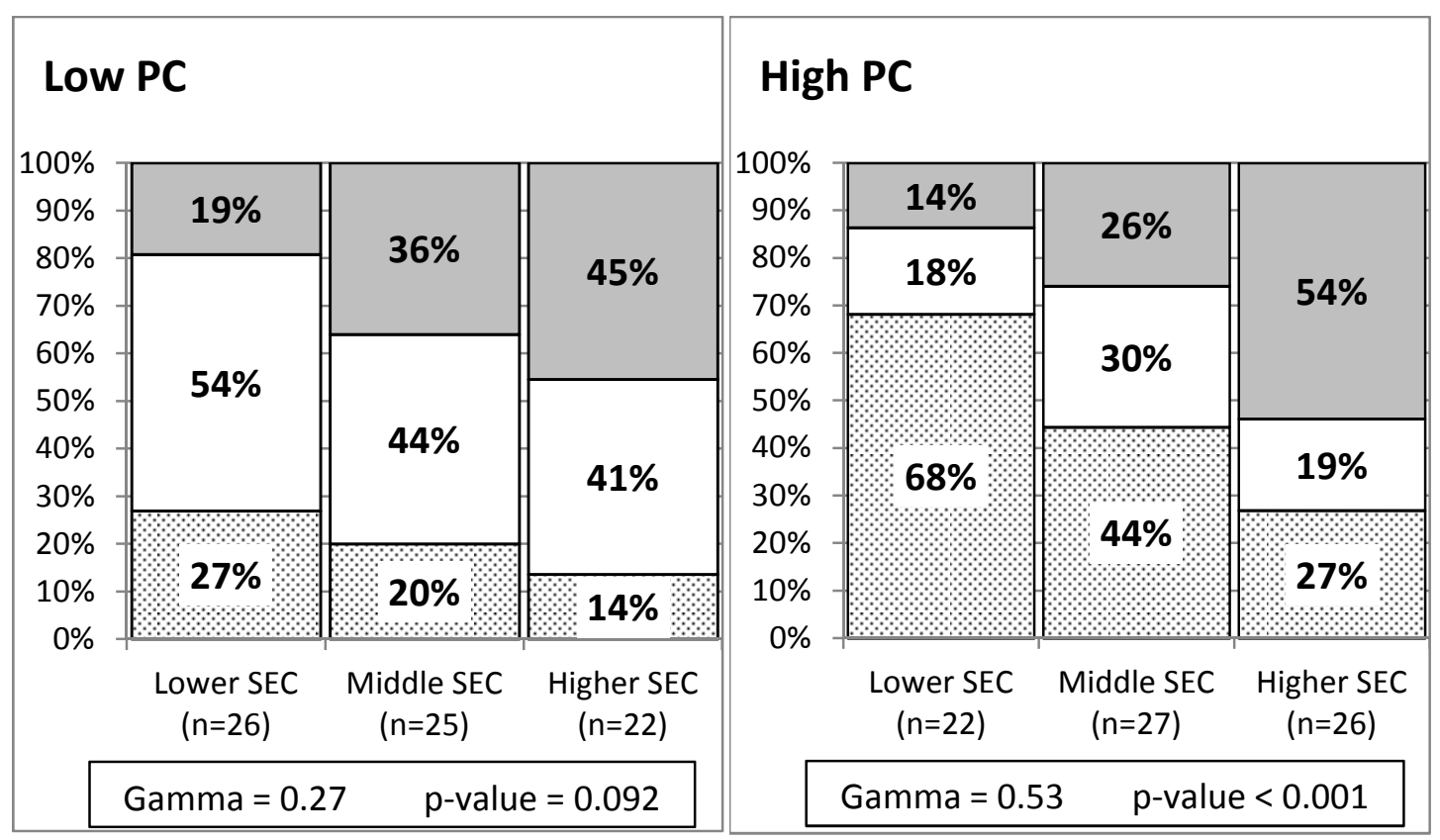

Figure 43: SEC-PMC vs. Perf Controlled by PC

The chart on the right side of Figure 43 shows the relationship between $\boldsymbol{S E C - P M C}$ and Perf for those projects with higher $\boldsymbol{P C}(\boldsymbol{P C} \geq 2.4)$. This set contains 75 projects. Of these, 22 were assessed as deploying lower $\boldsymbol{S E C - P M C}$ capabilities, 27 deploying middle $\boldsymbol{S E C - P M C}$ capabilities, and 26 deploying higher $\boldsymbol{S E C - P M C}$ capabilities.

The chart shows a very strong supporting relationship between SEC-PMC and Perf, with the percentage of projects delivering higher performance increasing from $14 \%$ to $26 \%$ to $54 \%$ as $\boldsymbol{S E C}$ PMC increased from lower to middle to higher.

Additionally, the percentage of projects delivering lower performance decreased from $68 \%$ to $44 \%$ to $27 \%$ as $\boldsymbol{S E C - P M C}$ increased. Thus, for these higher challenge projects, the likelihood of delivering higher performance increased nearly fourfold, and that of delivering lower performance was reduced by more than half with improved $\boldsymbol{S E C - P M C}$. This relationship is characterized by a very strong Gamma value of +0.53 and a very low p-value less than 0.001 .

We conclude that a strong project monitoring and control capability is associated with higher performance, particularly on the most challenging projects. This conclusion seems intuitive- that the largest and most complex projects depend on effective project monitoring and control practices to achieve the best levels of project performance.

\subsubsection{Risk Management}

The distribution of the responses assessing risk management activities (SEC-RSKM) of the projects is shown in Figure 44, with a value of 1 representing very poor risk management and 4 representing very good risk management. 


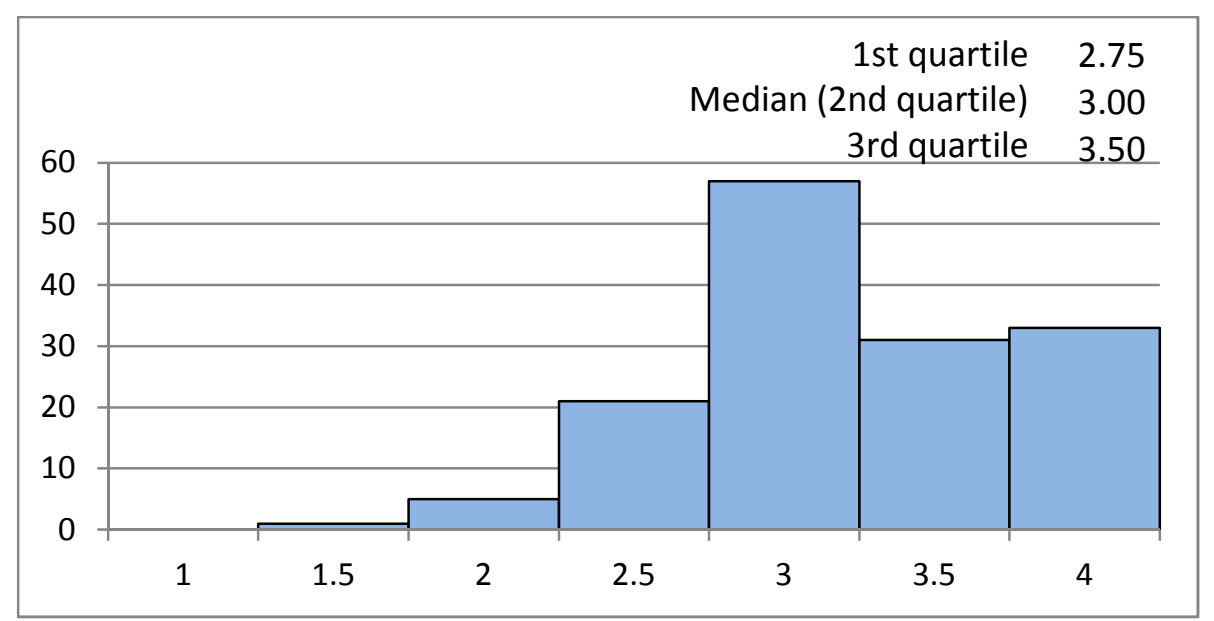

Figure 44: SEC-RSKM Response Distribution

The median of 3.00 indicates moderate application of risk management best practices, with room for improvement.

In preparing the mosaic chart showing the relationship between SEC-RSKM and Perf, three groups for $\boldsymbol{S E C - R S K M}$ were established with breakpoints at 2.80 and 3.36. These breakpoints resulted in 50 projects categorized as having lower $\boldsymbol{S E C - R S K M}$ capability, 45 as having middle SEC-RSKM capability, and 53 as having higher $\boldsymbol{S E C - R S K M}$ capability. The resulting mosaic chart is shown in Figure 45.

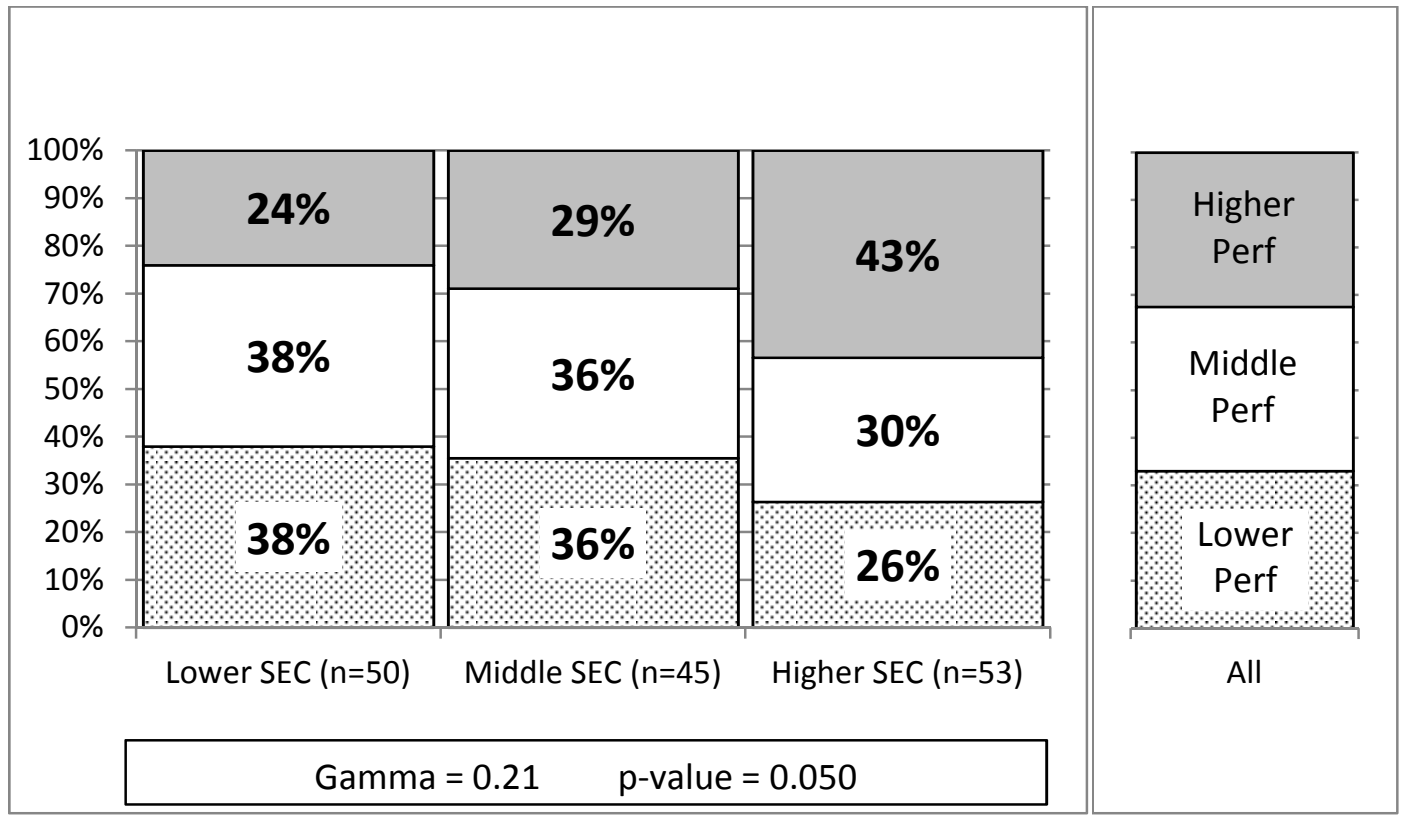

Figure 45: SEC-RSKM vs. Perf

Examination of this chart reveals a moderate supporting relationship between SEC-RSKM and Perf. The percentage of projects delivering higher performance increased from $24 \%$ to $29 \%$ to 43\% as $\boldsymbol{S E C - R S K M}$ increased from lower to middle to higher. 
Additionally, the percentage of projects delivering lower performance decreased from $38 \%$ to $36 \%$ to $26 \%$ as $\boldsymbol{S E C}$ - $\mathbf{S S K M}$ increased. This relationship is characterized by a moderate Gamma value of +0.21 and a low p-value of 0.050 .

We further examined this relationship by incorporating the impact of $\boldsymbol{P C}$. The chart on the left side of Figure 46 shows the relationship between SEC-RSKM and Perf for those projects with lower $\boldsymbol{P C}(\boldsymbol{P C}<2.45)$. This set contains 73 projects. Of these, 21 were assessed as deploying lower SEC-RSKM, 27 deploying middle SEC-RSKM, and 25 deploying higher SEC-RSKM.

The chart shows a weak supporting relationship between SEC-RSKM and Perf, with the percentage of projects delivering higher performance increasing from $19 \%$ to $33 \%$ to $44 \%$ as $\boldsymbol{S E C}$ $\boldsymbol{R S K M}$ increased from lower to middle to higher.

Additionally, the percentage of projects delivering lower performance changed from $14 \%$ to $33 \%$ to $12 \%$ as $\boldsymbol{S E C - R S K M}$ increased. Thus, for these lower challenge projects, the likelihood of delivering higher performance more than doubled with improved $\boldsymbol{S E C - R S K M}$, but that of delivering lower performance was not consistently reduced. The lack of a consistent decrease in lower performing projects as $\boldsymbol{S E C - R S K M}$ increased may reflect the influence of other factors impacting project performance. This relationship is characterized by a weak Gamma value of +0.18 and a high p-value of 0.256 .

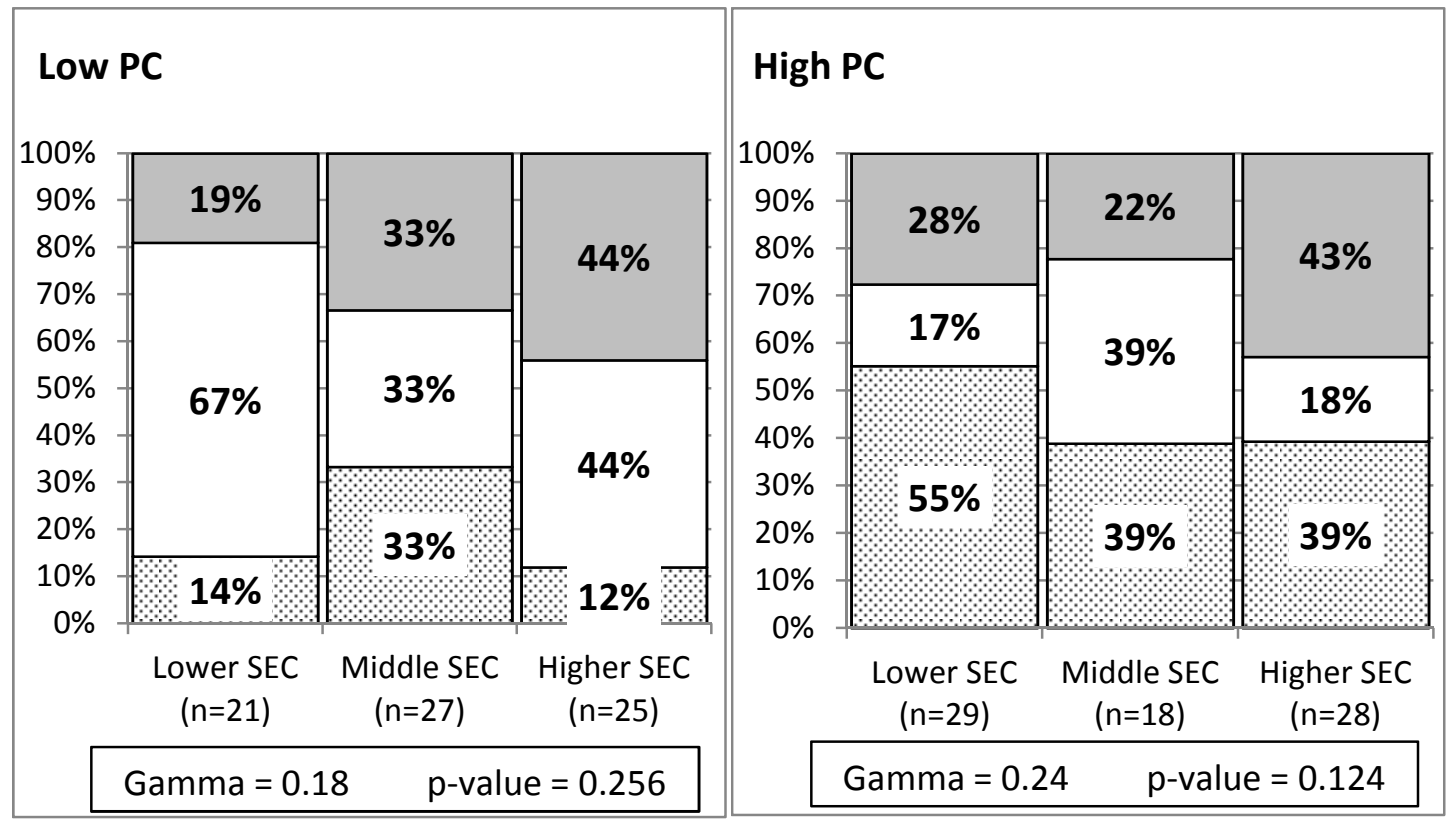

Figure 46: SEC-RSKM vS. Perf Controlled by PC

The chart on the right side of Figure 46 shows the relationship between SEC-RSKM and Perf for those projects with higher $\boldsymbol{P C}(\boldsymbol{P C} \geq 2.45)$. This set contains 75 projects. Of these, 29 were assessed as deploying lower $\boldsymbol{S E C - R S K M}, 18$ deploying middle $\boldsymbol{S E C - R S K M}$, and 28 deploying higher SEC-RSKM.

The chart shows a moderate supporting relationship between SEC-RSKM and Perf, with the percentage of projects delivering higher performance changing from $28 \%$ to $22 \%$ to $43 \%$ as $\boldsymbol{S E C}$ $\boldsymbol{R S K M}$ increased from lower to middle to higher. 
Additionally, the percentage of projects delivering lower performance changed from 55\% to 39\% to 39\% as $\boldsymbol{S E C - R S K M}$ increased. Thus, for these higher challenge projects, the likelihood of delivering higher performance increased by over $50 \%$, and that of delivering lower performance was reduced by nearly 30\% with improved SEC-RSKM. This relationship is characterized by a moderate Gamma value of +0.24 and a moderately high p-value of 0.124 .

Overall, higher $\boldsymbol{S E C - R S K M}$ capability appears associated with better project performance, but to a lesser degree than most other factors. This association may be due in part to a response distribution that is more heavily weighted toward higher risk management capability scores, which may suggest generally mature risk management processes with less variation among higher and lower performing projects.

\subsubsection{Configuration Management}

The distribution of the responses assessing configuration management activities (SEC-CM) of the projects is shown in Figure 47 with a value of 1 representing very poor configuration management and 4 representing very good configuration management.

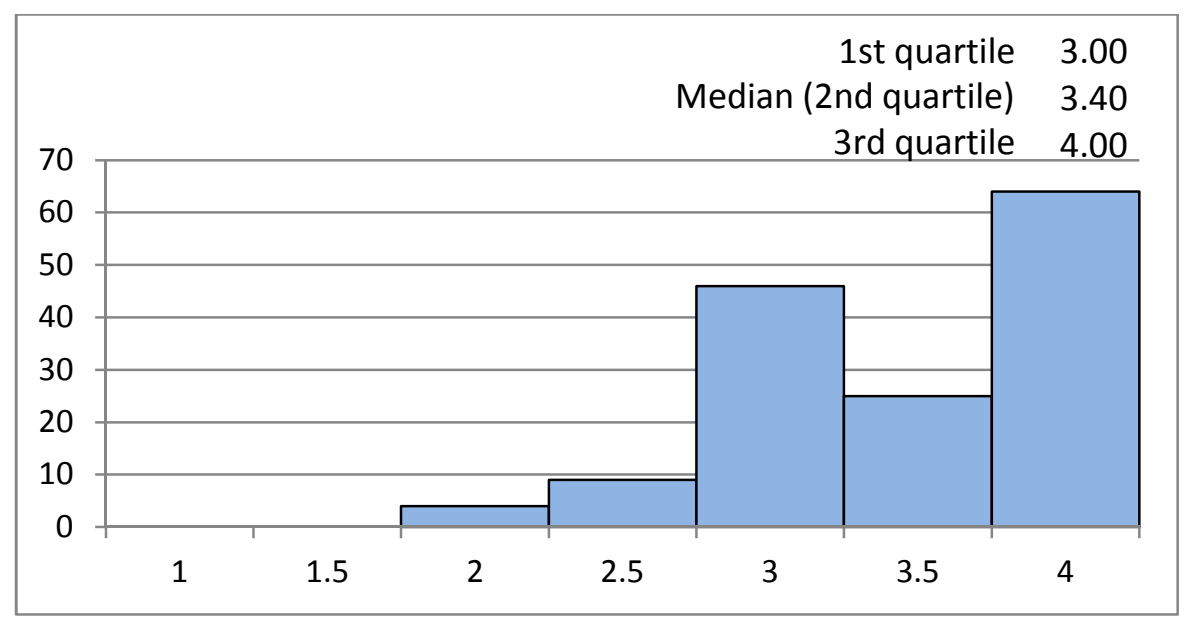

Figure 47: SEC-CM Response Distribution

The median of 3.40 indicates strong application of configuration management best practices, with a little room for improvement.

In preparing the mosaic chart showing the relationship between $\boldsymbol{S E C - C M}$ and Perf, three groups for $\boldsymbol{S E C - T R D}$ were established with breakpoints at 3.10 and 3.80. These breakpoints resulted in 59 projects categorized as having lower $\boldsymbol{S E C} \boldsymbol{C M}$ capability, 51 as having middle $\boldsymbol{S E C - C M}$ capability, and 38 as having higher $\boldsymbol{S E C - C M}$ capability. The resulting mosaic chart is shown in Figure 48. 


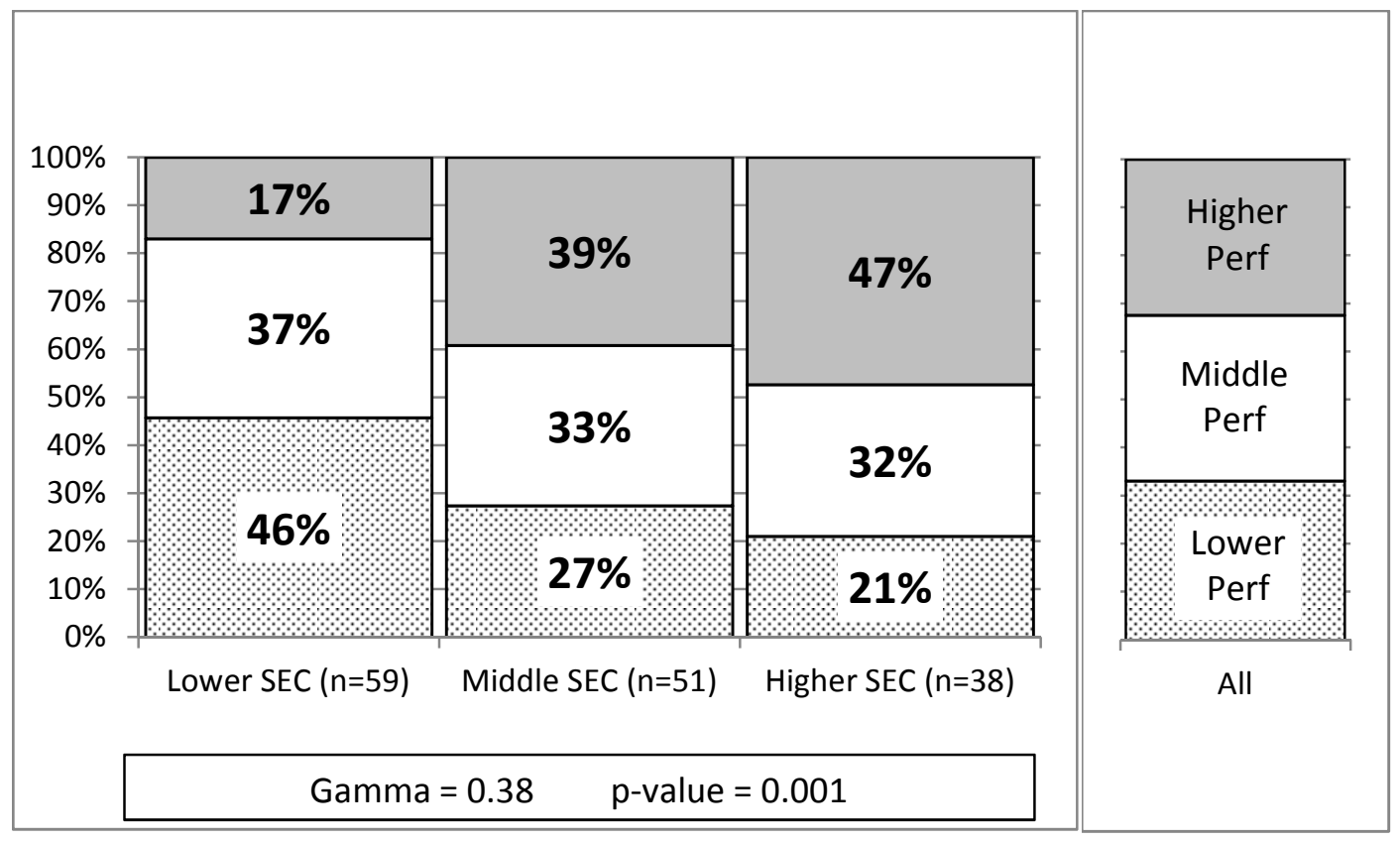

Figure 48: SEC-CM vS. Perf

Examination of this chart reveals a strong supporting relationship between SEC-CM and Perf. The percentage of projects delivering higher performance changed from $17 \%$ to $39 \%$ to $47 \%$ as SEC-CM increased from lower to middle to higher.

Additionally, the percentage of projects delivering lower performance changed from $46 \%$ to $27 \%$ to $21 \%$ as $\boldsymbol{S E C - C M}$ increased. This relationship is characterized by a strong Gamma value of +0.38 and a very low p-value of 0.001 .

We further examined this relationship by incorporating the impact of $\boldsymbol{P C}$. The chart on the left side of Figure 49 shows the relationship between SEC-CM and Perf for those projects with lower $\boldsymbol{P C}(\boldsymbol{P C}<2.45)$. This set contains 73 projects. Of these, 15 were assessed as deploying lower $\boldsymbol{S E C}$ - $\boldsymbol{C M}$ capabilities, 41 deploying middle $\boldsymbol{S E C}$ - $\boldsymbol{C M}$ capabilities, and 17 deploying higher $\boldsymbol{S E C}$ CM capabilities.

The chart shows a moderate supporting relationship between $\boldsymbol{S E C - C M}$ and Perf, with the percentage of projects delivering higher performance changing from $20 \%$ to $44 \%$ to $39 \%$ as $\boldsymbol{S E C}$ $\boldsymbol{C M}$ increased from lower to middle to higher.

Additionally, the percentage of projects delivering lower performance changed from $27 \%$ to $16 \%$ to $17 \%$ as $\boldsymbol{S E C}$ - $\boldsymbol{C M}$ increased. Thus, for these lower challenge projects, the likelihood of delivering higher performance nearly doubled with improved $\boldsymbol{S E C - C M}$, while that of delivering lower performance was reduced by more than one-third. This relationship is characterized by a moderate Gamma value of +0.22 but with a moderately high p-value of 0.203 . 


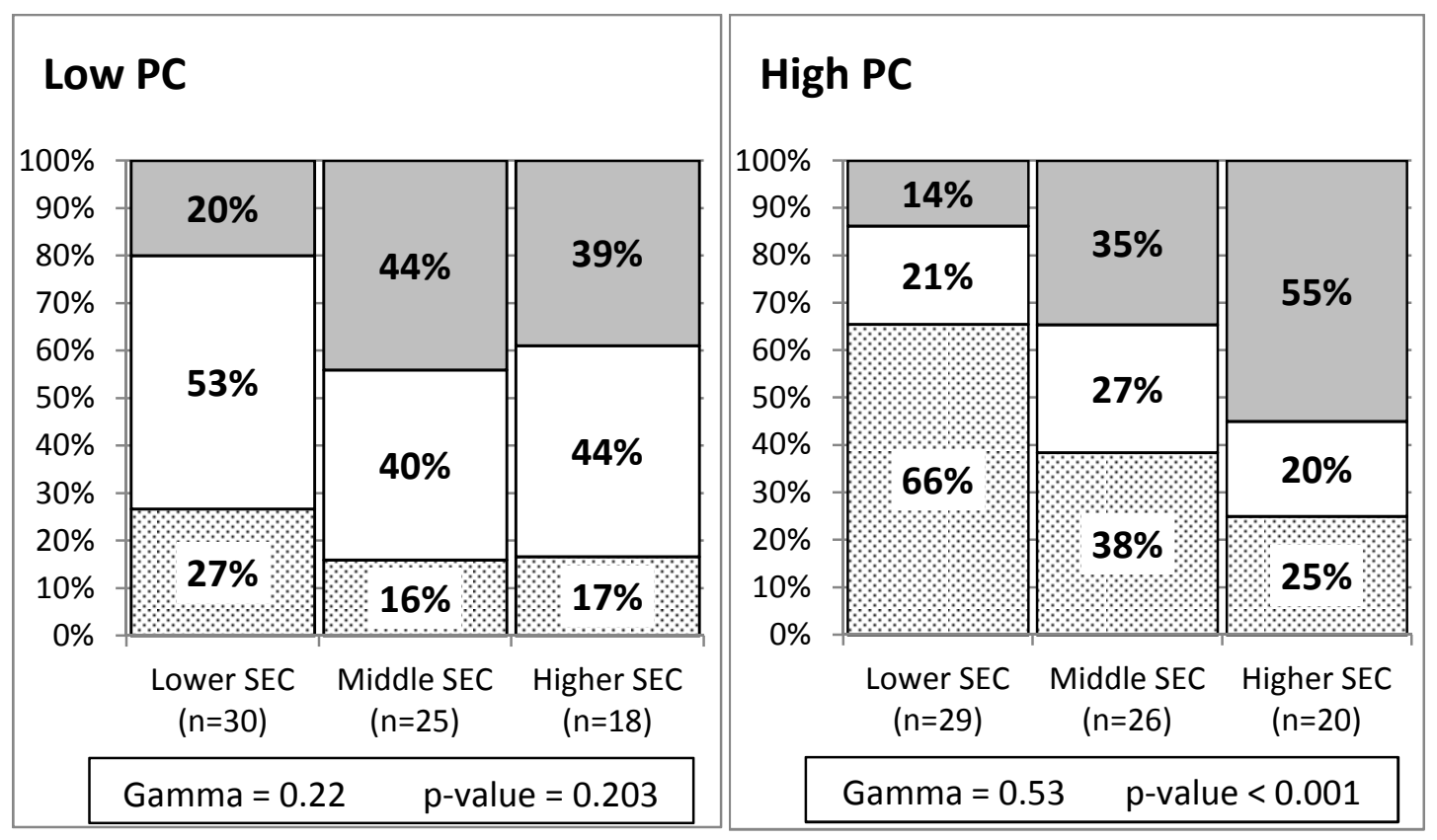

Figure 49: SEC-CM vs. Perf Controlled by PC

The chart on the right side of Figure 49 shows the relationship between SEC-CM and Perf for those projects with higher $\boldsymbol{P C}(\boldsymbol{P C} \geq 2.4)$. This set contains 75 projects. Of these, 29 were assessed as deploying lower $\boldsymbol{S E C - C M}$ capabilities, 26 deploying middle $\boldsymbol{S E C - C M}$ capabilities, and 20 deploying higher $\boldsymbol{S E C}-\boldsymbol{C M}$ capabilities.

The chart shows a very strong supporting relationship between $\boldsymbol{S E C - C M}$ and Perf, with the percentage of projects delivering higher performance increasing from $14 \%$ to $35 \%$ to $55 \%$ as $\boldsymbol{S E C}$ $\boldsymbol{C M}$ increased from lower to middle to higher.

Additionally, the percentage of projects delivering lower performance decreased from $65 \%$ to $38 \%$ to $25 \%$ as $\boldsymbol{S E C}$ - $\boldsymbol{C M}$ increased. Thus, for these higher challenge projects, the likelihood of delivering higher performance increased nearly fourfold, and that of delivering lower performance was reduced by more than half with improved $\boldsymbol{S E C}$ - $\boldsymbol{C M}$. This relationship is characterized by a very strong Gamma value of +0.53 and a very low p-value less than 0.001 .

We conclude that a strong configuration management capability is strongly associated with higher performance on the most challenging projects. This conclusion seems intuitive- that the largest and most complex projects depend most heavily on best practices for configuration management, and such projects lacking effective configuration management activities are unlikely to achieve the best levels of project performance.

\subsubsection{Integrated Product Teams}

The distribution of the responses assessing the use of integrated product teams (SEC-IPT) is shown in Figure 50, with a value of 1 representing very poor use and 4 representing very good use. 


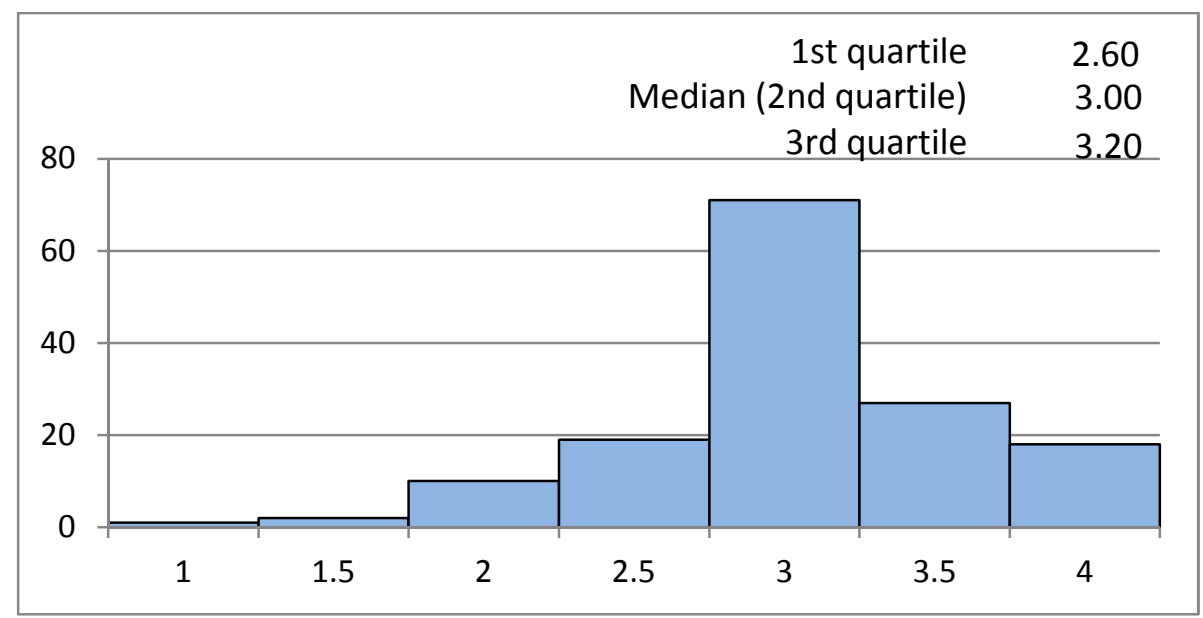

Figure 50: SEC-IPT Response Distribution

The median of 3.00 indicates moderate use of IPTs, with room for improvement.

In preparing the mosaic chart showing the relationship between $\boldsymbol{S E C - I P T}$ and Perf, three groups for $\boldsymbol{S E C - I P T}$ were established with breakpoints at 2.60 and 3.00. These breakpoints resulted in 51 projects categorized as having lower $\boldsymbol{S E C}$-IPT capability, 52 as having middle $\boldsymbol{S E C - I P T}$ capability, and 45 as having higher SEC-IPT capability. The resulting mosaic chart is shown in Figure 51.

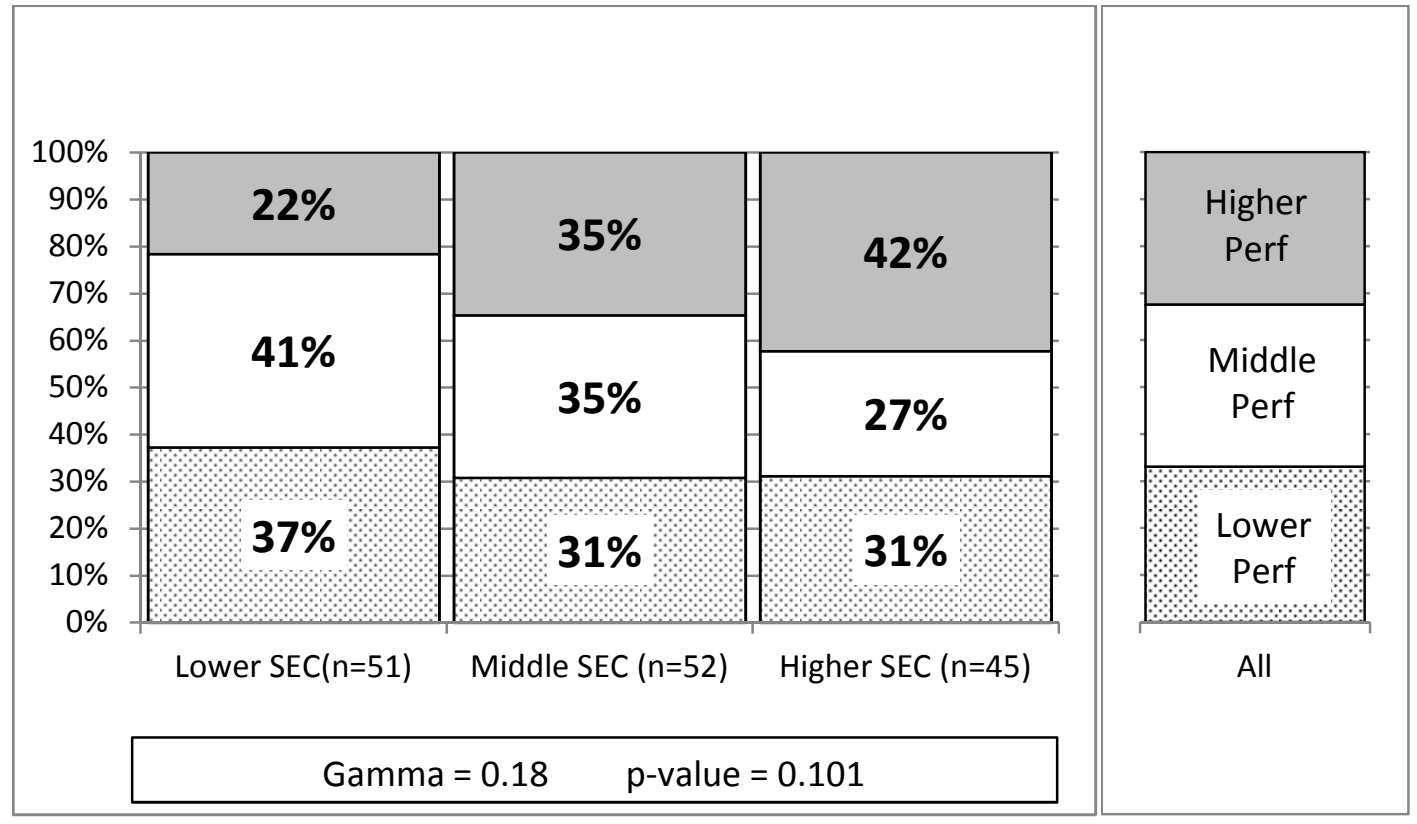

Figure 51: SEC-IPT vS. Perf

Examination of this chart reveals only a weak supporting relationship between SEC-IPT and Perf. The percentage of projects delivering higher performance increased only from $22 \%$ to $35 \%$ to $42 \%$ as $\boldsymbol{S E C - I P T}$ increased from lower to middle to higher. Similarly, the percentage of projects delivering lower performance changed from $37 \%$ to $31 \%$ to $31 \%$ as SEC-IPT increased from lower to middle to higher. This relationship is characterized by a weak Gamma value of +0.18 with a moderately high p-value of 0.101 . 
We further examined this relationship by incorporating the impact of $\boldsymbol{P C}$. The chart on the left side of Figure 52 shows the relationship between SEC-IPT and Perf for those projects with lower $\boldsymbol{P C}(\boldsymbol{P C}<2.45)$. This set contains 73 projects. Of these, 23 were assessed as deploying lower SEC-IPT capabilities, 26 deploying middle $\boldsymbol{S E C}$-IPT capabilities, and 24 deploying higher $\boldsymbol{S E C}$ IPT capabilities.

The chart shows a weak opposing relationship between SEC-IPT and Perf, with the percentage of projects delivering higher performance changing from 30\% to 38\% to $29 \%$ as $\boldsymbol{S E C - I P T}$ increased from lower to middle to higher.

Additionally, the percentage of projects delivering lower performance increased from $13 \%$ to $23 \%$ to $25 \%$ as $\boldsymbol{S E C - I P T}$ increased. Thus, for these lower challenge projects, the likelihood of delivering higher performance did not change appreciably with improved SEC-IPT, while those delivering lower performance almost doubled. This relationship is characterized by a weak Gamma value of +0.12 and a high p-value of 0.463 , indicating it is difficult to draw any reliable conclusions from this sample. SEC-IPT does not appear to have a significant correlation with the performance of less challenging projects.

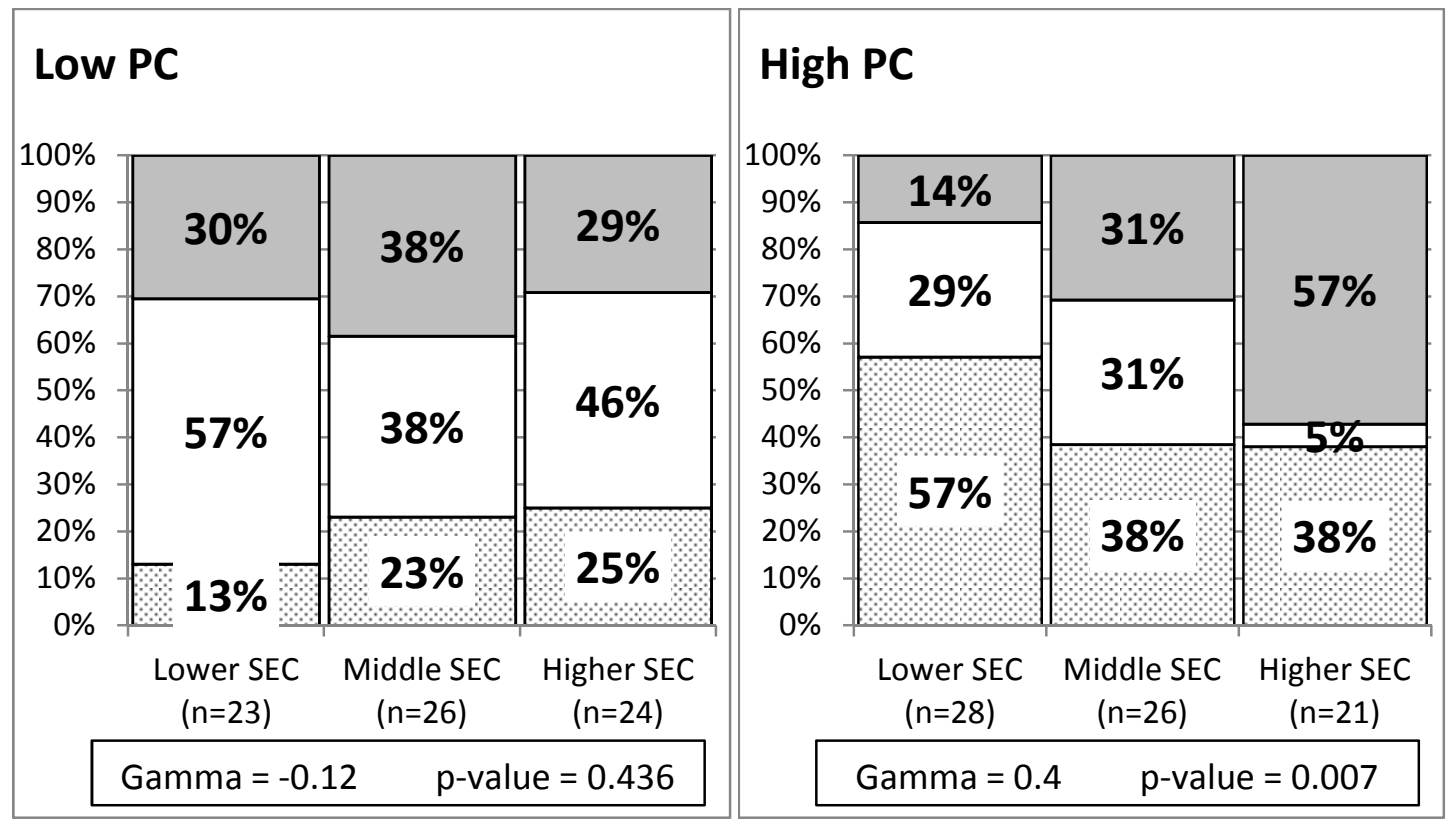

Figure 52: SEC-IPT vS. Perf Controlled by PC

The chart on the right side of Figure 52 shows the relationship between SEC-IPT and Perf for those projects with higher $\boldsymbol{P C}(\boldsymbol{P C} \geq 2.45)$. This set contains 75 projects. Of these, 28 were assessed as deploying lower $\boldsymbol{S E C}$-IPT capabilities, 26 deploying middle $\boldsymbol{S E C - I P T}$ capabilities, and 21 deploying higher $\boldsymbol{S E C - I P T}$ capabilities.

The chart shows a very strong supporting relationship between SEC-IPT and Perf, with the percentage of projects delivering higher performance increasing from $14 \%$ to $31 \%$ to $57 \%$ as $\boldsymbol{S E C}$ IPT increased from lower to middle to higher. 
Additionally, the percentage of projects delivering lower performance changed from $57 \%$ to $38 \%$ to $38 \%$ as $\boldsymbol{S E C - I P T}$ increased. Thus, for these higher challenge projects, the likelihood of delivering higher performance increased more than fourfold and that of delivering lower performance decreased by one-third with improved SEC-IPT. This relationship is characterized by a very strong Gamma value of +0.40 and a low p-value of 0.007 .

These findings suggest higher $\boldsymbol{S E C}$-IPT capability has a greater effect on more challenging projects, which might be expected to depend more heavily on integrated cross-functional involvement to successfully solve the most complex problems, interfaces, or larger projects.

\subsection{Other Factors}

The following five sections discuss the results of the survey for these other factors: experience, contract type, SE organization, project percentage complete, and SE content.

\subsubsection{Experience}

The distribution of the responses assessing prior experience $(\boldsymbol{E X P})$ with similar projects is shown in Figure 53 with a value of 1 representing very little prior experience and 4 representing a lot of prior experience.

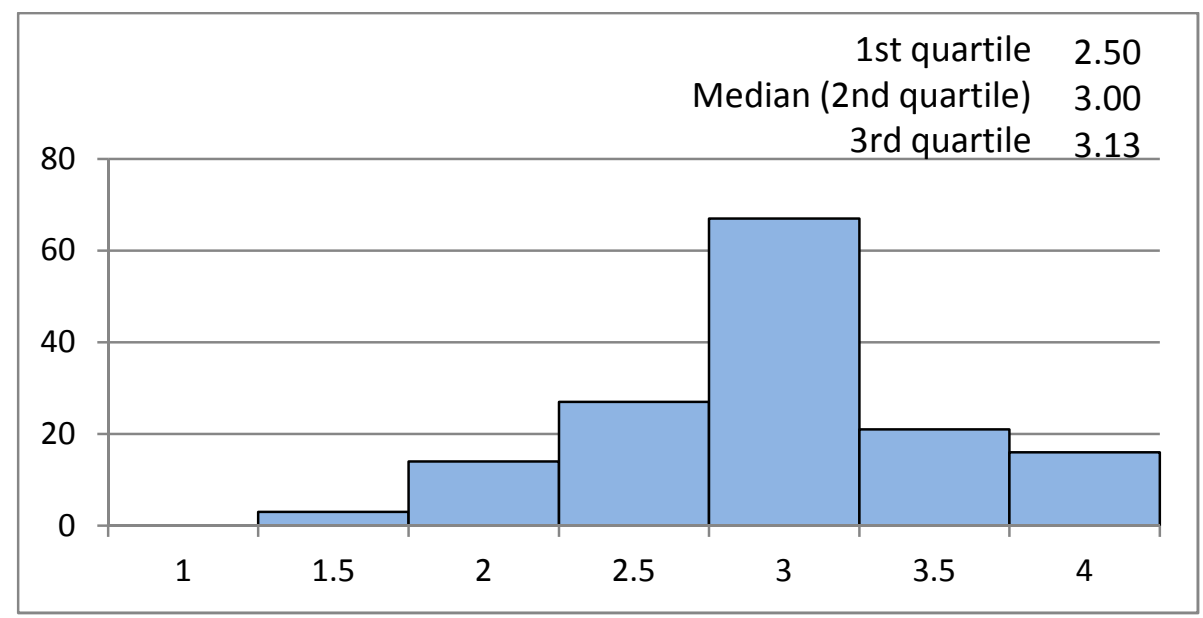

Figure 53: EXP Response Distribution

The median of 3.00 indicates that the sampled projects were just above the middle of the continuum of prior experience.

In preparing the mosaic chart showing the relationship between $\boldsymbol{E X P}$ and Perf, three groups for $\boldsymbol{E X P}$ were established with breakpoints at 2.60 and 3.40. These breakpoints resulted in 44 projects categorized as having lower $\boldsymbol{E X P}, 67$ as having middle $\boldsymbol{E X P}$, and 37 as having higher $\boldsymbol{E X P}$. The resulting mosaic chart is shown in Figure 54. 


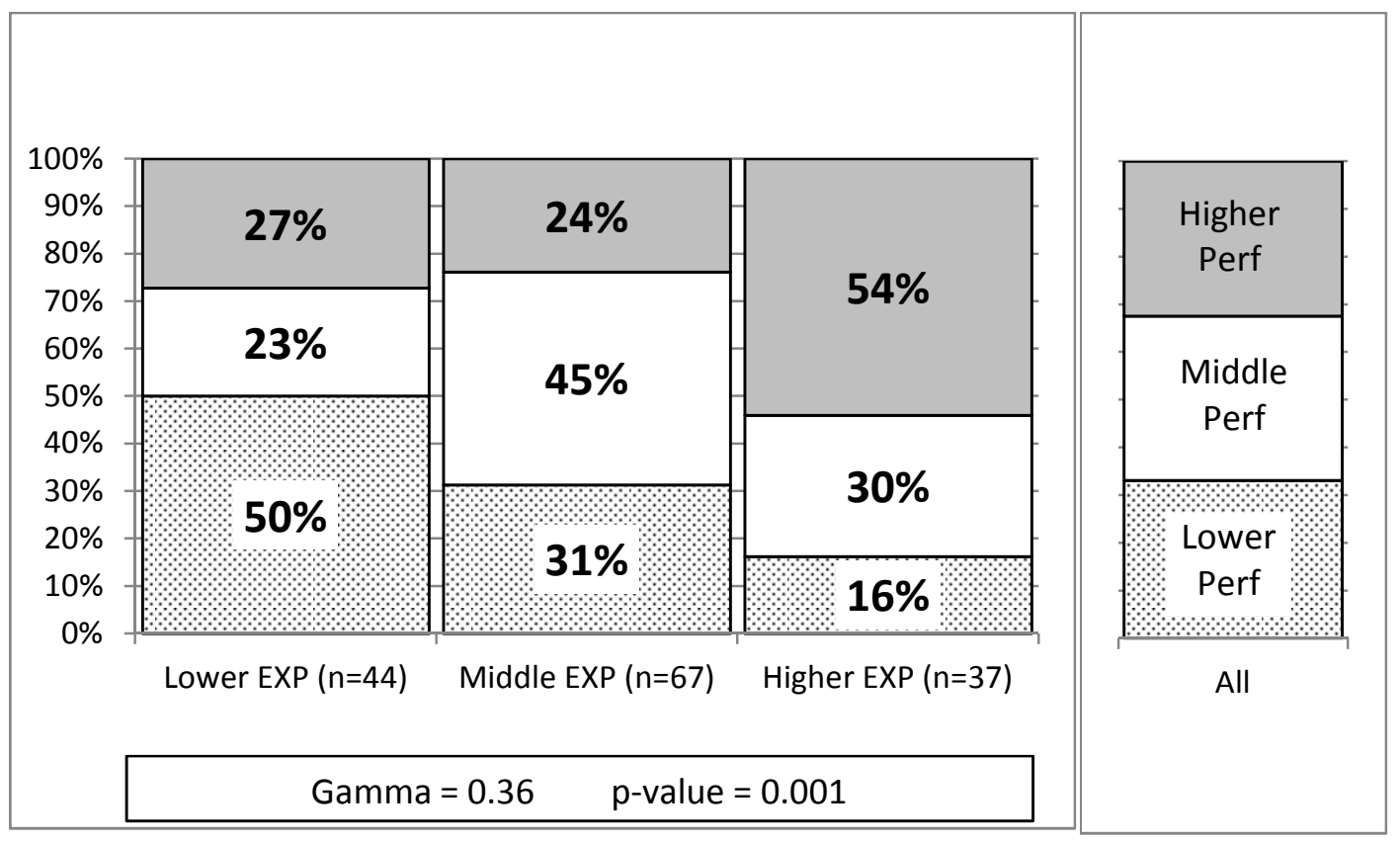

Figure 54: EXP vs. Perf

Examination of this chart reveals a strong supporting relationship between $\boldsymbol{E X P}$ and Perf. The percentage of projects delivering higher performance changed from $27 \%$ to $24 \%$ to $54 \%$ as $\boldsymbol{E X P}$ increased from lower to middle to higher.

Additionally, the percentage of projects delivering lower performance decreased from $50 \%$ to $31 \%$ to $16 \%$ as $\boldsymbol{E X P}$ increased. This relationship is characterized by a strong Gamma value of +0.36 and a very low p-value of 0.001 .

We further examined this relationship by incorporating the impact of $\boldsymbol{P C}$. The chart on the left side of Figure 55 shows the relationship between $\boldsymbol{E X P}$ and Perf for those projects with lower $\boldsymbol{P C}$ $(\boldsymbol{P C}<2.45)$. This set contains 73 projects. Of these, 18 were assessed as deploying lower $\boldsymbol{E X P}, 27$ deploying middle $\boldsymbol{E} \boldsymbol{X P}$, and 28 deploying higher $\boldsymbol{E X P}$.

The chart shows a very strong supporting relationship between $\boldsymbol{E X P}$ and Perf, with the percentage of projects delivering higher performance changing from $19 \%$ to $36 \%$ to $45 \%$ as $\boldsymbol{E X P}$ increased from lower to middle to higher.

Additionally, the percentage of projects delivering lower performance changed from $27 \%$ to $20 \%$ to $14 \%$ as $\boldsymbol{E X P}$ increased. Thus, for these lower challenge projects, the likelihood of delivering higher performance more than doubled with improved $\boldsymbol{E X P}$, while that of delivering lower performance was reduced by nearly half. This relationship is characterized by a very strong Gamma value of +0.51 and a very low p-value of 0.001 . 


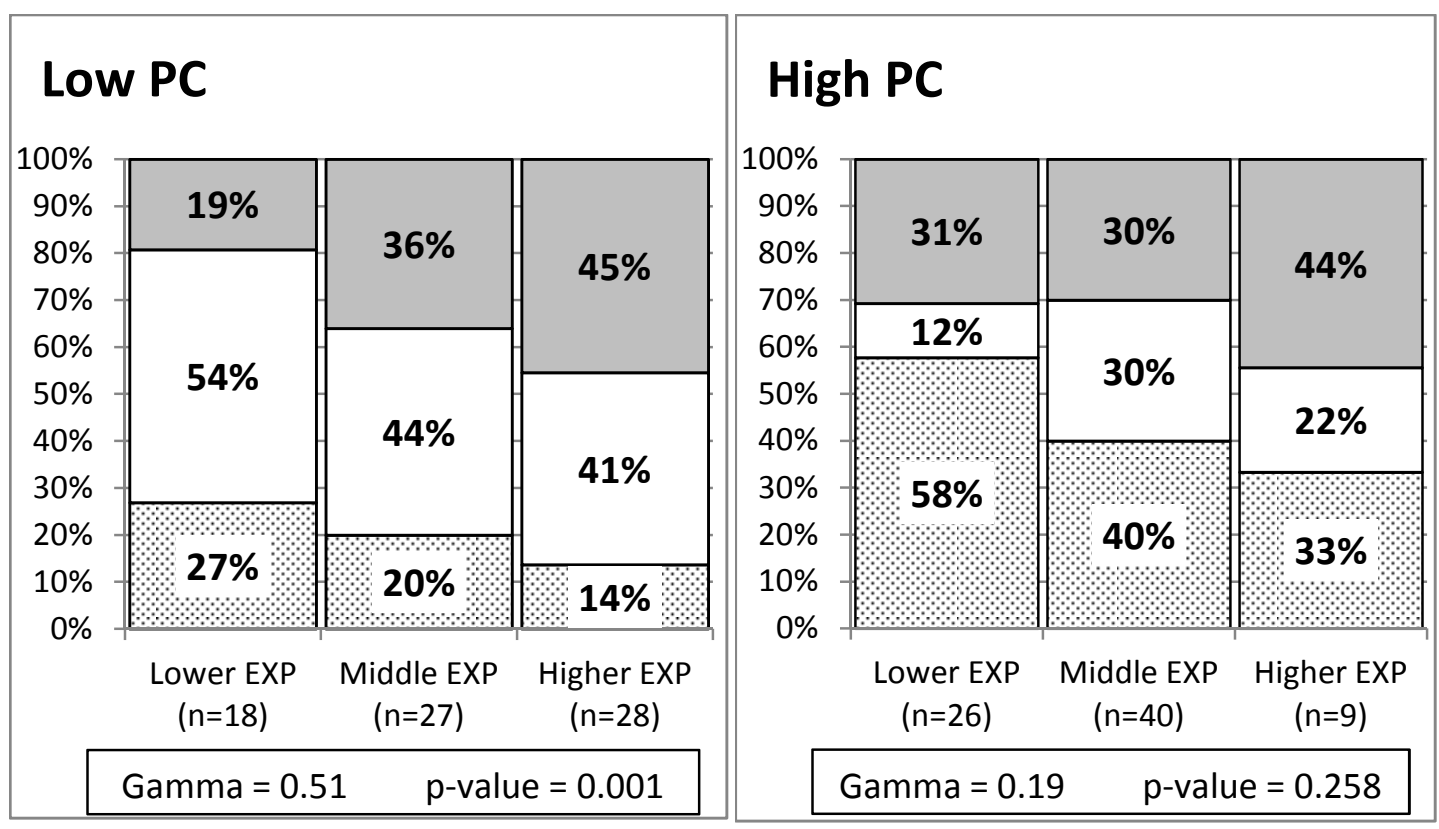

Figure 55: EXP vs. Perf Controlled by PC

The chart on the right side of Figure 55 shows the relationship between $\mathbf{E X P}$ and Perf for those projects with higher $\boldsymbol{P C}(\boldsymbol{P C} \geq 2.4)$. This set contains 75 projects. Of these, 26 were assessed as deploying lower $\boldsymbol{E X P}, 40$ deploying middle $\boldsymbol{E X P}$, and 9 deploying higher $\boldsymbol{E X P}$.

The chart shows a weak supporting relationship between $\boldsymbol{E X P}$ and Perf, with the percentage of projects delivering higher performance increasing from $31 \%$ to $30 \%$ to $44 \%$ as $\boldsymbol{E X P}$ increased from lower to middle to higher.

Additionally, the percentage of projects delivering lower performance decreased from $58 \%$ to 40\% to 33\% as $\boldsymbol{E X P}$ increased. Thus, for these higher challenge projects, the likelihood of delivering higher performance increased by more than one-third, and that of delivering lower performance was reduced by more than one-third with improved $\boldsymbol{E X P}$. This relationship is characterized by a weak Gamma value of +0.19 and a high p-value of 0.258 .

These findings seem consistent with our intuition. Projects are considered challenging or not largely based on our past experience with similar applications. There is a strong direct relationship between this past experience and the likely success of future projects. Projects that include dealing with complexity, incorporating innovation, or pushing the boundaries of "state of the art" while having little prior experience, are challenging projects. When we have little relevant experience to fall back on, project success is likely to depend on other critical factors such as the use of strong systems engineering practices.

\subsubsection{Contract Type}

The survey explored the type of contract governing the projects. Respondents were asked to choose between the following contract types:

fixed-price - The total contract value is primarily determined by the initial contract (e.g., firm fixed price [FFP], fixed price incentive fee [FPIF], firm fixed price-level of effort [FFP-LOE]). 
cost-reimbursable- The total contract value is primarily determined by the buyer's cost of executing the contract (e.g., cost plus fixed fee [CPFF], cost plus award fee [CPAF], cost plus incentive fee [CPIF]).

other - The contract is a type that does not fit the prior two categories.

If they chose "other contract type,” respondents were asked to describe the contract type. Typical responses included

- a mix of FFP and CPFF

- task-order contract

The distribution of responses assessing contract type is shown in Figure 56.

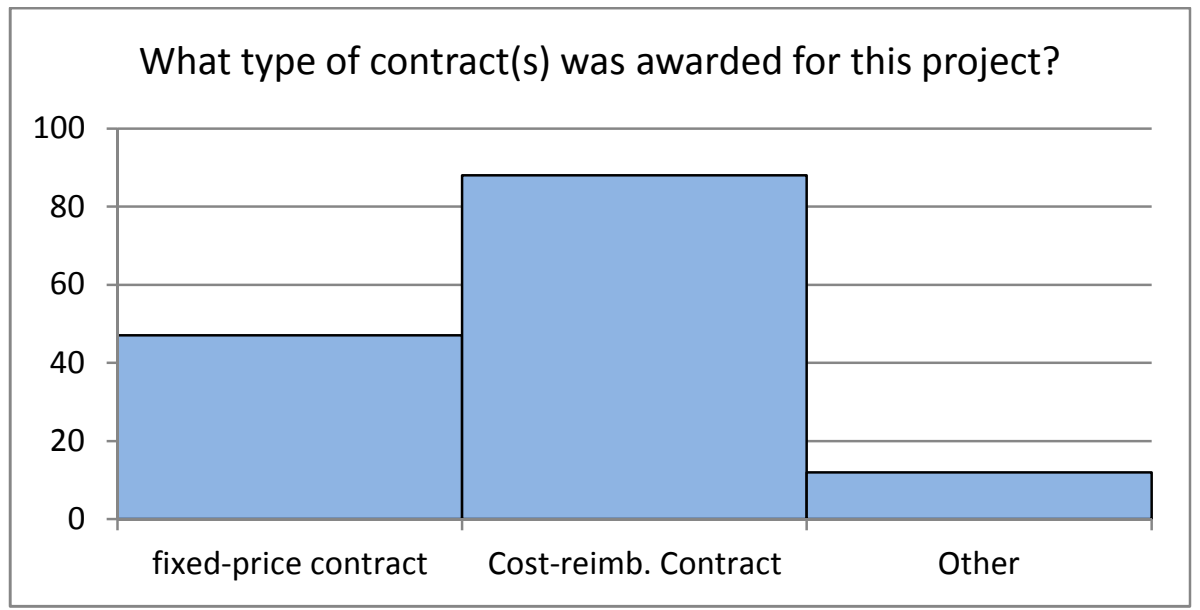

Figure 56: Contract Type Response Distribution

The mosaic chart showing the performance distribution for each of these contract types is shown in Figure 57.

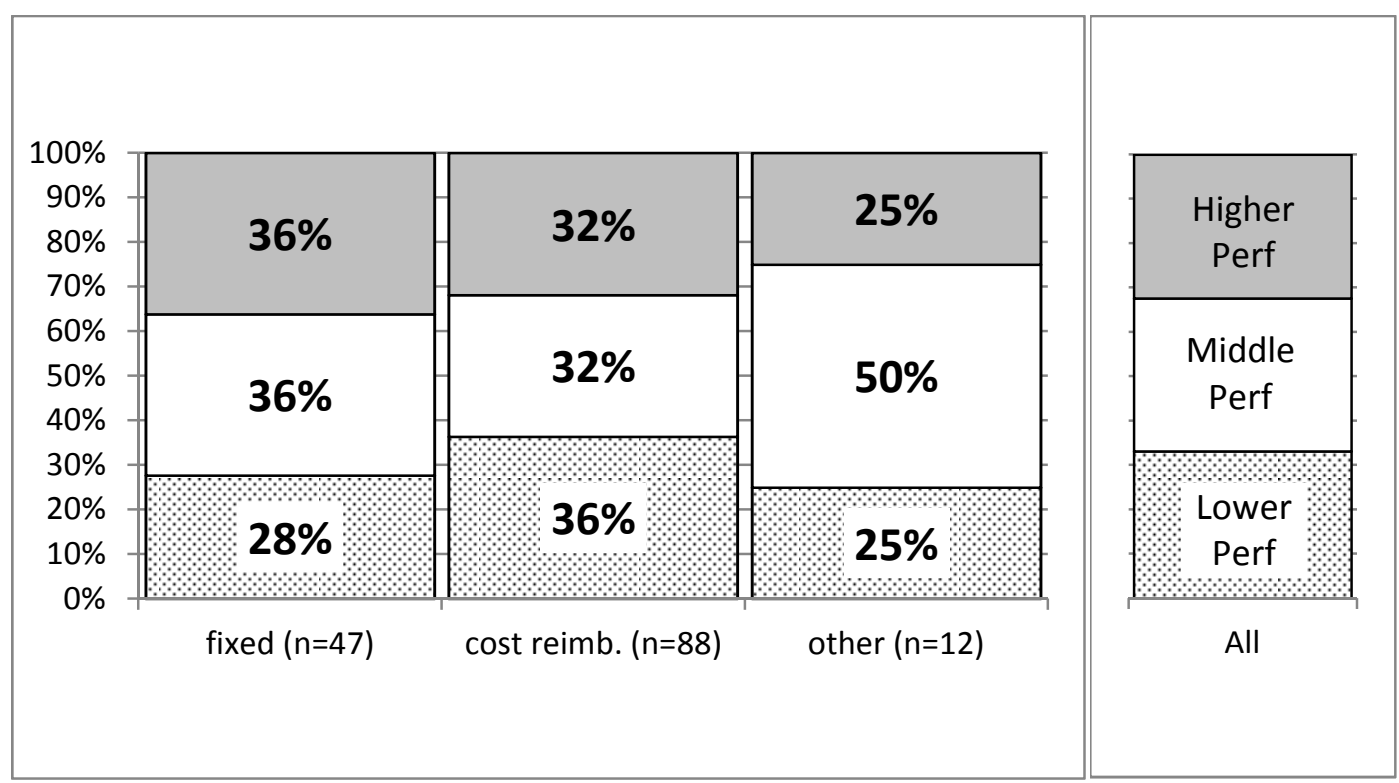

Figure 57: Contract Type vs. Perf 
This chart shows that cost-reimbursable contracts perform slightly worse than fixed price contracts, with the percentage of projects delivering higher performance dropping from $36 \%$ to $32 \%$, and the percentage of projects delivering lower performance increasing from $28 \%$ to $36 \%$. This result is consistent with intuition, in that cost-reimbursable contracts are typically used for riskier projects; hence lower project performance is not unexpected.

Performance differences between contract types do not appear to be significant. Additional tests of data relationships factoring in the impact of project challenge did not add additional insight.

\subsubsection{SE Organization}

The survey explored the impact of the structure of the SE organization within the company executing the project. SE may be either centralized in an SE department or distributed throughout other departments within the company. Respondents were asked to choose between the following statements:

- Systems engineering skills and responsibilities are contained in a separate department.

- Systems engineering skills and responsibilities are distributed throughout other departments.

The distribution of the responses assessing the SE organization is shown in Figure 58.

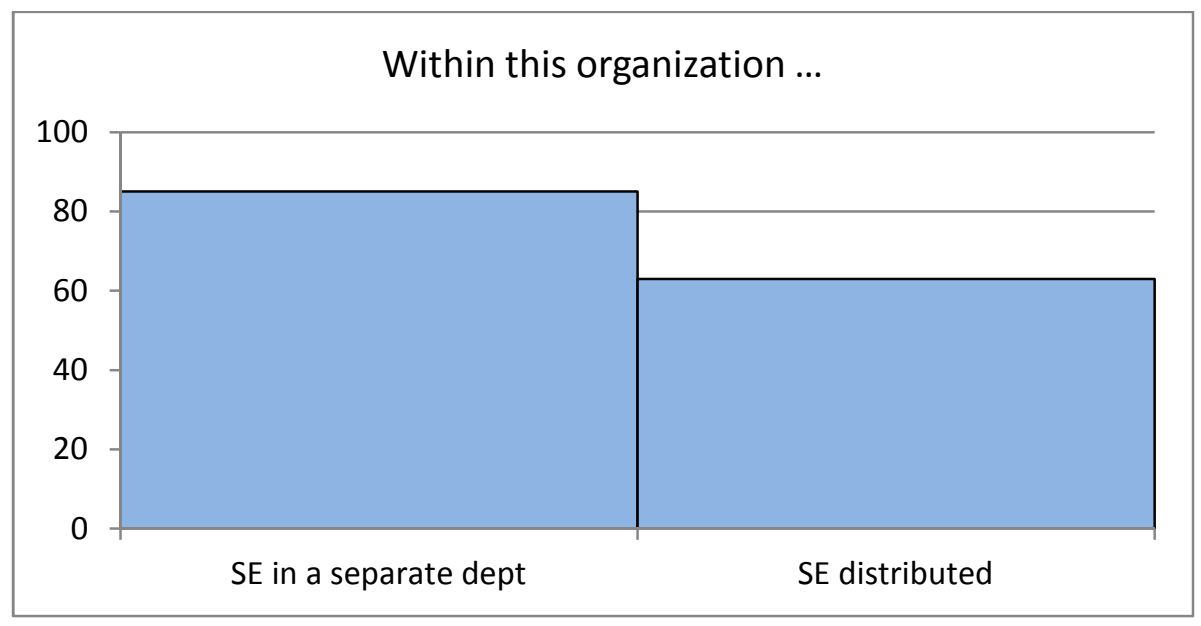

Figure 58: SE Organization Response Distribution

Responses were nearly evenly divided between the two alternatives.

We first explored the relationship between $\mathbf{S E - O r g n}$ and the deployment of SE best practices, as measured by $\boldsymbol{S E C}$-Total. We divided the responding projects into those with centralized SE (85 projects) and those with distributed SE (63 projects). We then examined the distribution of SE deployment, as measured by $\boldsymbol{S E C - T o t a l , ~ i n ~ e a c h ~ o f ~ t h e s e ~ g r o u p s . ~ I n ~ b r e a k i n g ~} \boldsymbol{S E C - T o t a l}$ into three groups, we used the previously established breakpoints of 2.85 and 3.27 as discussed in Section 5.4.1. The resulting mosaic chart is shown in Figure 59. 


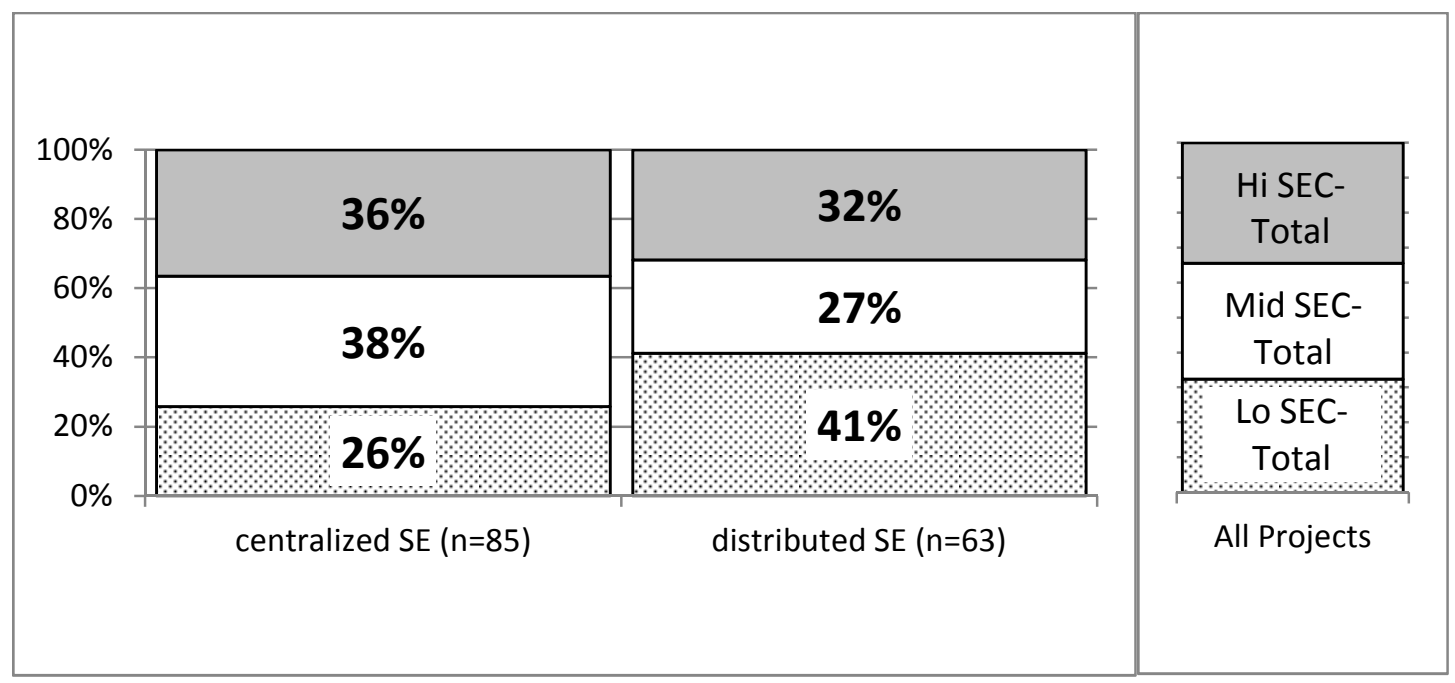

Figure 59: SE-Orgn vS. SEC-Total

This chart shows that organizations with centralized SE are somewhat more effective at deploying SE best practices when compared to organizations with distributed SE. The obvious question to ask is, "Does this more effective deployment of SE best practices influence project performance?" To explore this question, we examined the relationship between $\boldsymbol{S E - O r g n}$ and Perf via the mosaic chart of Figure 60.

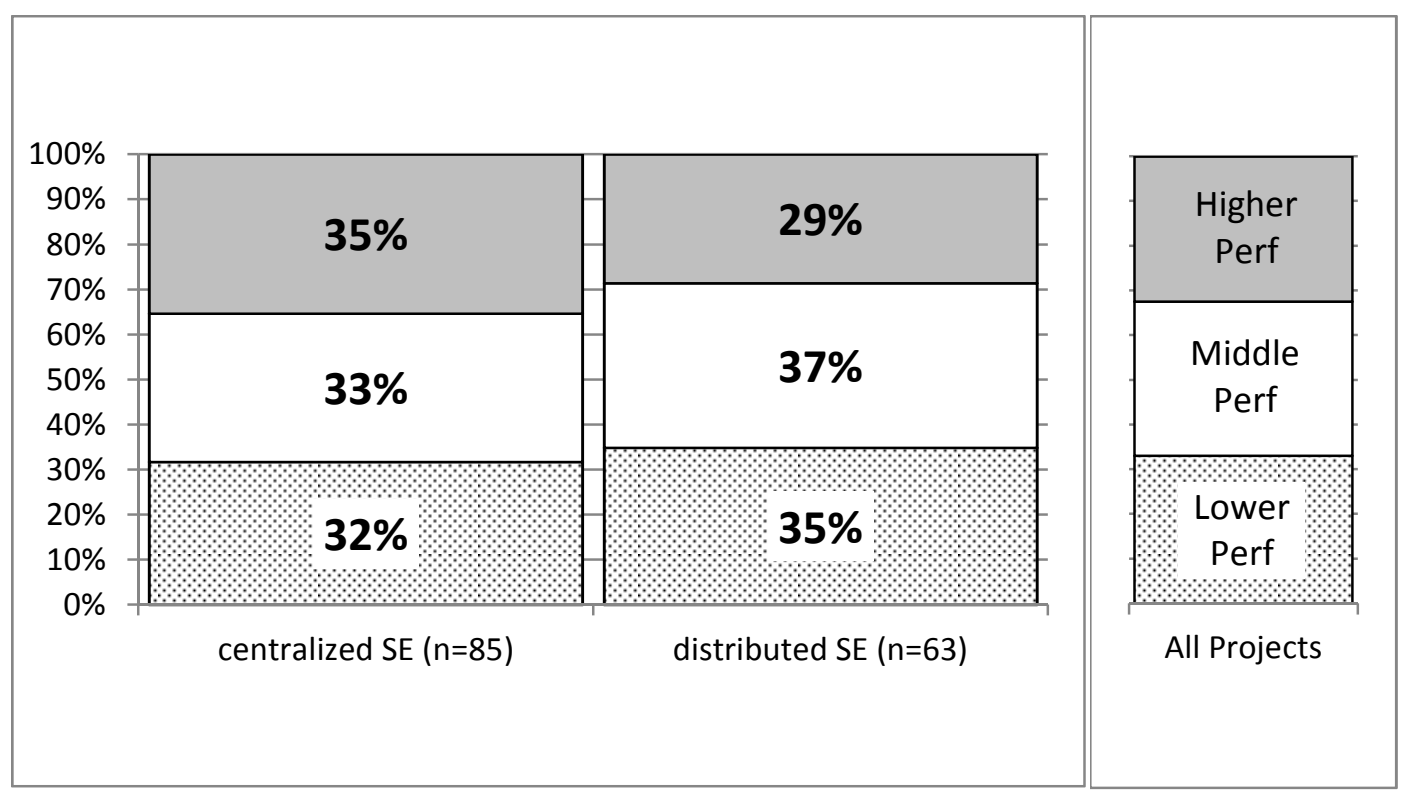

Figure 60: SE-Orgn vs. Perf

We see virtually no difference in performance between organizations with centralized SE versus those with distributed SE. How do we reconcile this result with the fact that Figure 19 shows that better deployment of SE is related to better performance, and Figure 60 shows that organizations with centralized SE provide somewhat better deployment of SE? One hypothesis is that while centralized SE is more effective at performing SE tasks and producing the SE artifacts assessed in this survey, those efforts and artifacts are less integrated with the work of the project and therefore have less impact on project performance. This hypothesis is worthy of additional study. 


\subsubsection{Project Percentage Complete}

Nearly all projects start out on budget and on schedule. It is only as project execution progresses that departures from the plan occur. Thus, you might expect that projects in the early phases of execution would predict performance at completion to be very close to the initial plan, while projects in the later phases of execution would be more likely to recognize and predict deviations.

The survey tested this hypothesis by capturing data regarding the percentage complete of the project. Distribution of these responses is shown in Figure 61.

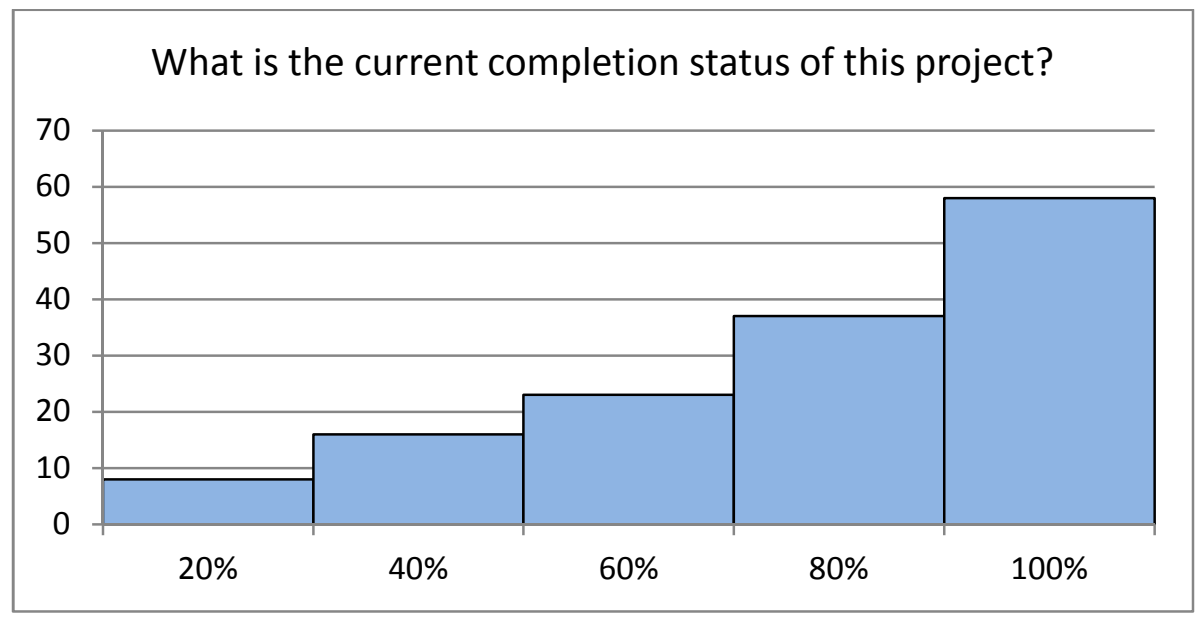

Figure 61: SE Project Percentage Complete Response Distribution

Half of the projects responding to the survey were $71 \%$ complete (Figure 60 ). This is a sufficient degree of completion to reflect the production of the SE artifacts queried in the survey and also a sufficient degree of completion to develop some confidence in performance projections.

We used the scatter plot in Figure 62 to examine the relationship between percentage complete and Perf.

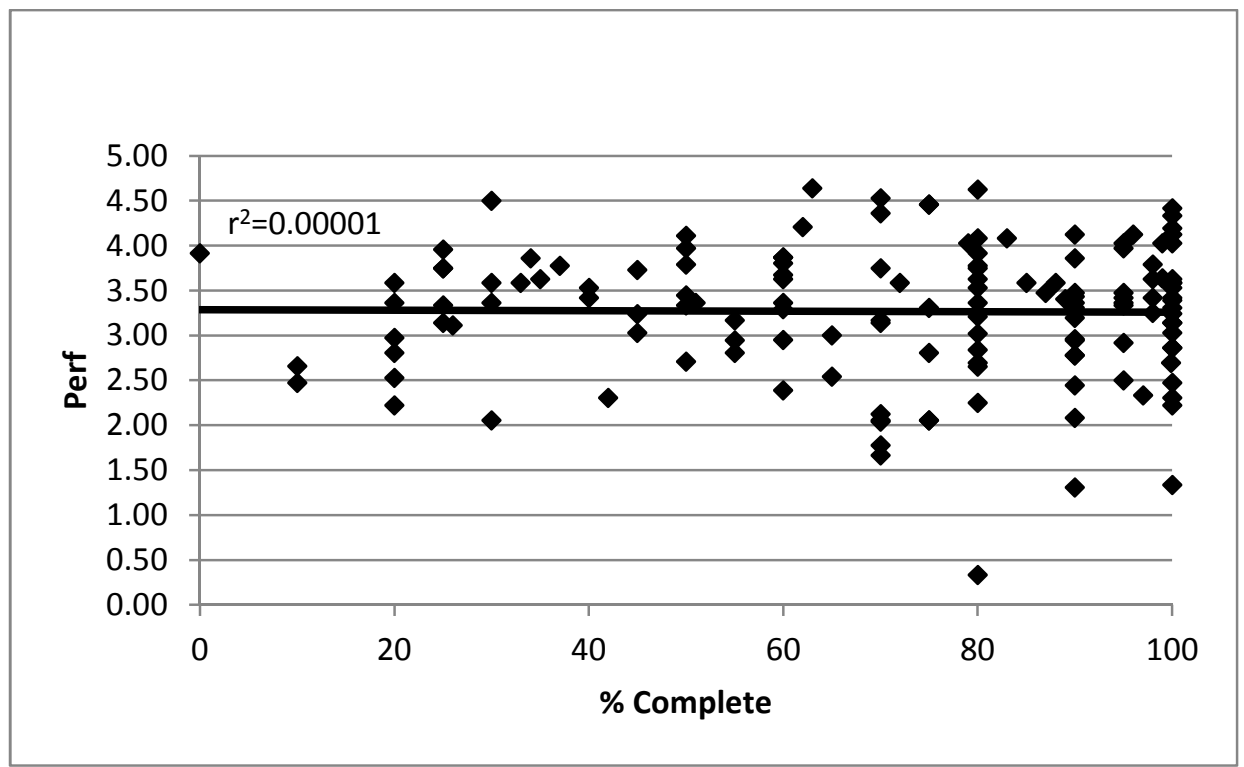

Figure 62: Percentage Complete vs. Perf 
The solid line represents a linear fit of the data. Examination of this chart does not support the hypothesis postulated earlier in this section and shows that neither project performance nor the variance in project performance shows much relationship to the percentage of project completion.

\subsubsection{SE Content}

The survey captured data regarding the amount of SE effort contained in the project with the question.

Approximately what percentage of non-recurring engineering (NRE) does Systems Engineering represent?

Distribution of these responses is shown in Figure 63.

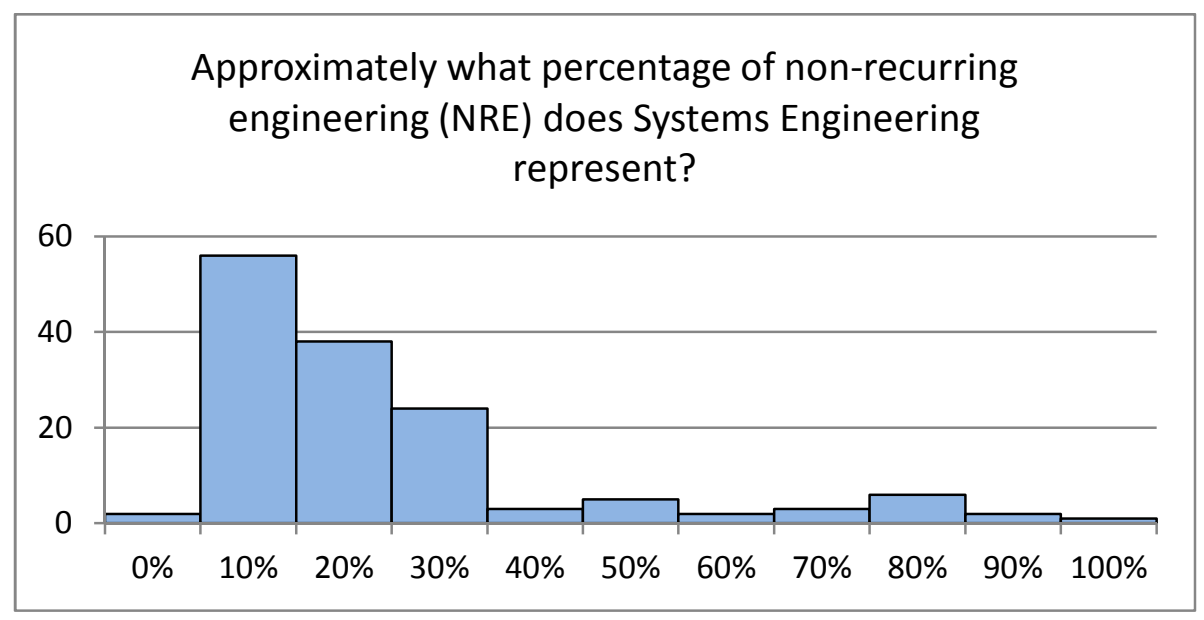

Figure 63: \%SE Response Distribution

The mean and median values for all projects were 22\% and 15\% respectively. Projects with very high percentages of SE effort may indicate projects that are not traditional development projects (e.g., study contracts). We examine the relationship between $\% \mathbf{S E}$ and Perf using the scatter plot in Figure 64. 


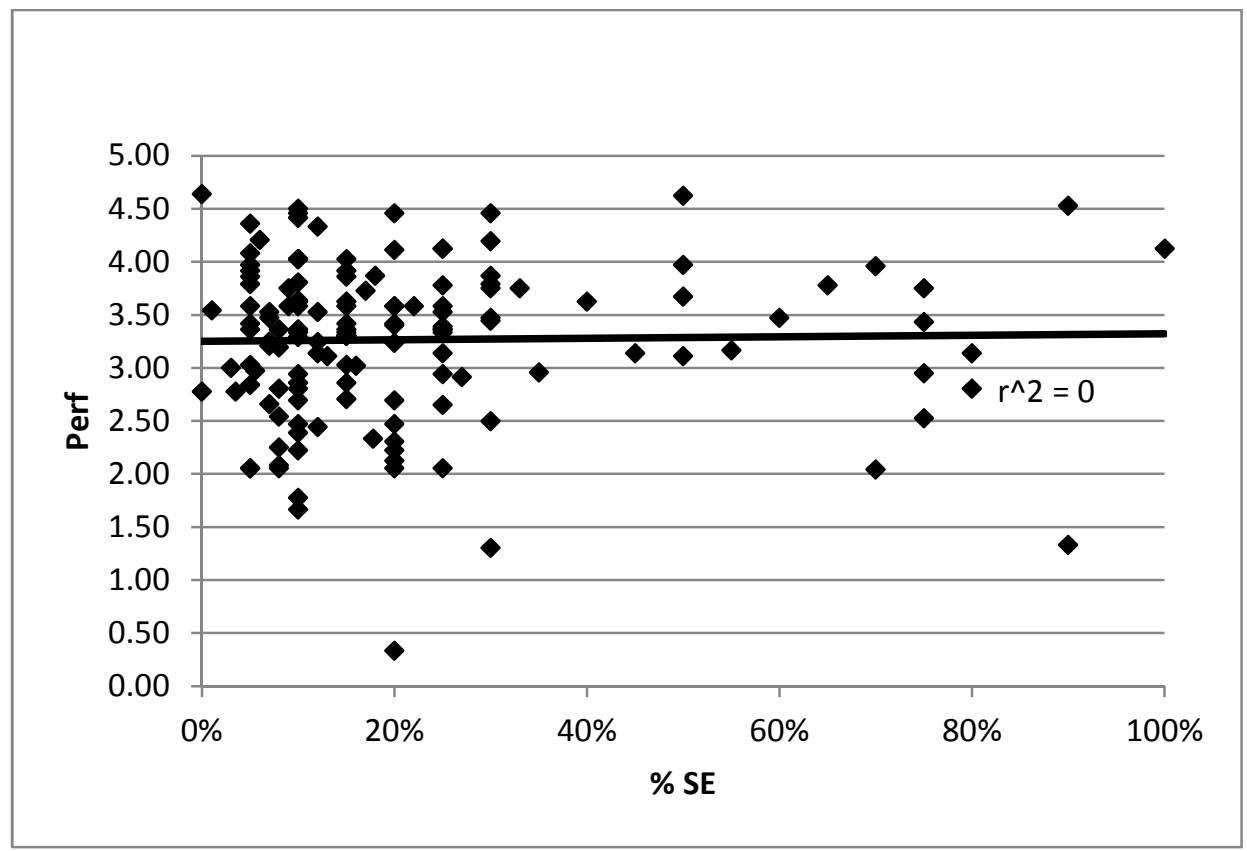

Figure 64: \%SE vs. Perf

The solid line represents a linear fit of the data. Examination of these data does not show a significant relationship between project performance and the amount of SE applied to the project as a percentage of total NRE. 


\section{Comparison with the Prior Study}

This study is similar to one conducted in 2007 [Elm 2008]. However, this study was conducted with some differences from the first and the results also varied from the first.

\subsection{Comparison of Study Executions}

The following sections describe the differences between the questionnaire, analysis, and sampling used in the prior study to those used in this study.

\subsubsection{Questionnaire Differences}

While the tools and methods used in this study are very similar to those used in the 2007 NDIA study [Elm 2008], some changes were made based on lessons learned from that study. Primary complaints about the prior study centered on the length of the questionnaire and the difficulties in answering some of the questions. In response to these complaints, we modified the questionnaire in the following areas:

1. Elimination of questions addressing acquirer capabilities - In the 2007 study, we hypothesized the capabilities of the acquirer were a factor affecting the overall performance of the project. To test this hypothesis, the 2007 study included five questions intended to assess acquirer capabilities. Analysis of the responses showed a moderately strong negative relationship between the acquirer's capabilities and project performance-a puzzling result. While we believe that this result requires further study, we also determined that such investigation would require an expansion of the questionnaire to probe more deeply into acquirer capabilities. Since this was not the primary focus of this study (i.e., assessing the effectiveness of SE practices), we chose to eliminate this area of study.

2. Simplification of the process of assessing project challenge - In both studies, project challenge (PC) was assessed using the factors in Table 7. Notice that the 2007 study used more factors than the 2012 study. 
Table 7: Factors Used to Assess Project Challenge

\begin{tabular}{|c|c|c|}
\hline PC Assessment Factor & 2007 & 2012 \\
\hline Included lifecycle phases & $\cdot$ & \\
\hline Sources of technical challenge & • & • \\
\hline Inter-organizational complexity & $\cdot$ & \\
\hline Contract duration & • & $\bullet$ \\
\hline Contract stability & • & \\
\hline Change in contract duration & • & \\
\hline Lifecycle phases currently in execution & • & \\
\hline Total project effort & • & • \\
\hline Contract value & • & • \\
\hline Requirements completeness and stability & • & • \\
\hline Percentage change of contract value & - & - \\
\hline Dollar change of contract value & • & \\
\hline Percentage change in contract duration & & $\bullet$ \\
\hline
\end{tabular}

3. Reduction of the assessment of project environment factors - The 2007 study investigated a number of environmental factors that were hypothesized to have an impact on project performance. These factors included

- customer type

- end user

- system deployment environment

- $\quad$ percent of effort subcontracted

- $\quad$ process improvement efforts
- acquiring organization

- contract type

- CMMI-related capabilities

- prior experience

- position in the systems hierarchy (e.g., SoS [system of systems], system, subsystem)

Results from the analysis of some of these data were not particularly useful. Furthermore, since this study was targeting a broader and more diverse population (global system developers from all industries rather than just U.S. defense contractors), some of the factors were no longer relevant. To simplify the questionnaire, the environmental factors assessed were reduced to

- customer type

- end user

- contract type

- prior experience

4. Simplification of the assessment process for project monitoring and control - The 2007 study included 11 questions assessing SEC-PMC. These were reduced to eight questions, eliminating the inquiries about operational hazard risk assessments, materiel readiness assessments, and system upgrade planning.

5. Improvement of the assessment process for risk management - The 2007 study included five questions assessing $\boldsymbol{S E C - R S K M}$. This study added three more, assessing the integration of risk management with cost and schedule management and with supplier risk management. 
6. Reduction of the assessment process for product architecture - The 2007 study included six questions assessing SEC-ARCH. These were reduced to five questions, eliminating the inquiry about the management of commercial off-the-shelf (COTS) products.

\subsubsection{Analysis Differences}

In addition to the modifications to the questionnaire, we also made improvements to the analysis process-particularly the analysis of project performance. The 2007 study assessed project performance by examining factors addressing cost performance (five questions), schedule performance (seven questions), and technical performance (one question). These factors were then combined into a weighted summed index to create an overall performance assessment. ${ }^{12}$ This process gave undue weight to the single question assessing technical performance, making it as significant as all of the questions assessing schedule or cost performance taken together. In this study, we improved the assessment process for performance by using ten questions to assess cost performance, eight questions to assess schedule performance, and two questions to assess technical performance.

Furthermore, we increased the rigor applied to the performance assessment process. In the 2007 study, some human interpretation of the survey responses was needed to develop the performance assessment. This interpretation was done by the researchers and validated by independent experts in project management. In this study, we were able to improve the questionnaire and codify the analysis process in a manner that used no additional human judgment. The analysis process is documented in the report The Business Case for Systems Engineering Study: Assessing Project Performance from Sparse Data [Elm 2012]. The process was reviewed and validated by independent experts in project management.

\subsubsection{Sampling Differences}

In the 2007 study, participants were solicited through the NDIA-SED membership. Obviously, this method limited the sample to members of the U.S. defense industrial sector. For this study, we reached out not only to the NDIA members, but also to the members of the IEEE-AESS and INCOSE. Both of these organizations are international and cover a multitude of industrial sectors beyond U.S. defense.

We also chose multiple methods of soliciting respondents. In addition to broadly soliciting the memberships of the NDIA, IEEE, and INCOSE, we also targeted a number of organizations represented within these groups. Within each of the targeted organizations, we identified a sponsor who would recruit respondents and manage their participation in the survey. The organizations targeted were typically those that were familiar with the 2007 study and had found it useful. Since the 2007 study was centered on U.S. defense contractors and published through the NDIA and SEI, most of the organizations familiar with it were U.S. defense contractors; thus most of the organizations targeted for this study were also U.S. defense contractors. As shown in Figures 6, 7, and 8 , the majority of the responses come from U.S. defense contractors.

12 A description of the calculation of weighted summed indices can be found in Section 4.1 on page 10. 


\subsection{Differences in Study Results}

The results of this study reinforce those of the 2007 study; however, some differences are apparent. Figure 65 shows the mosaic chart from the 2007 study detailing the relationship between project performance and the total deployment of SE as assessed by the questionnaire.

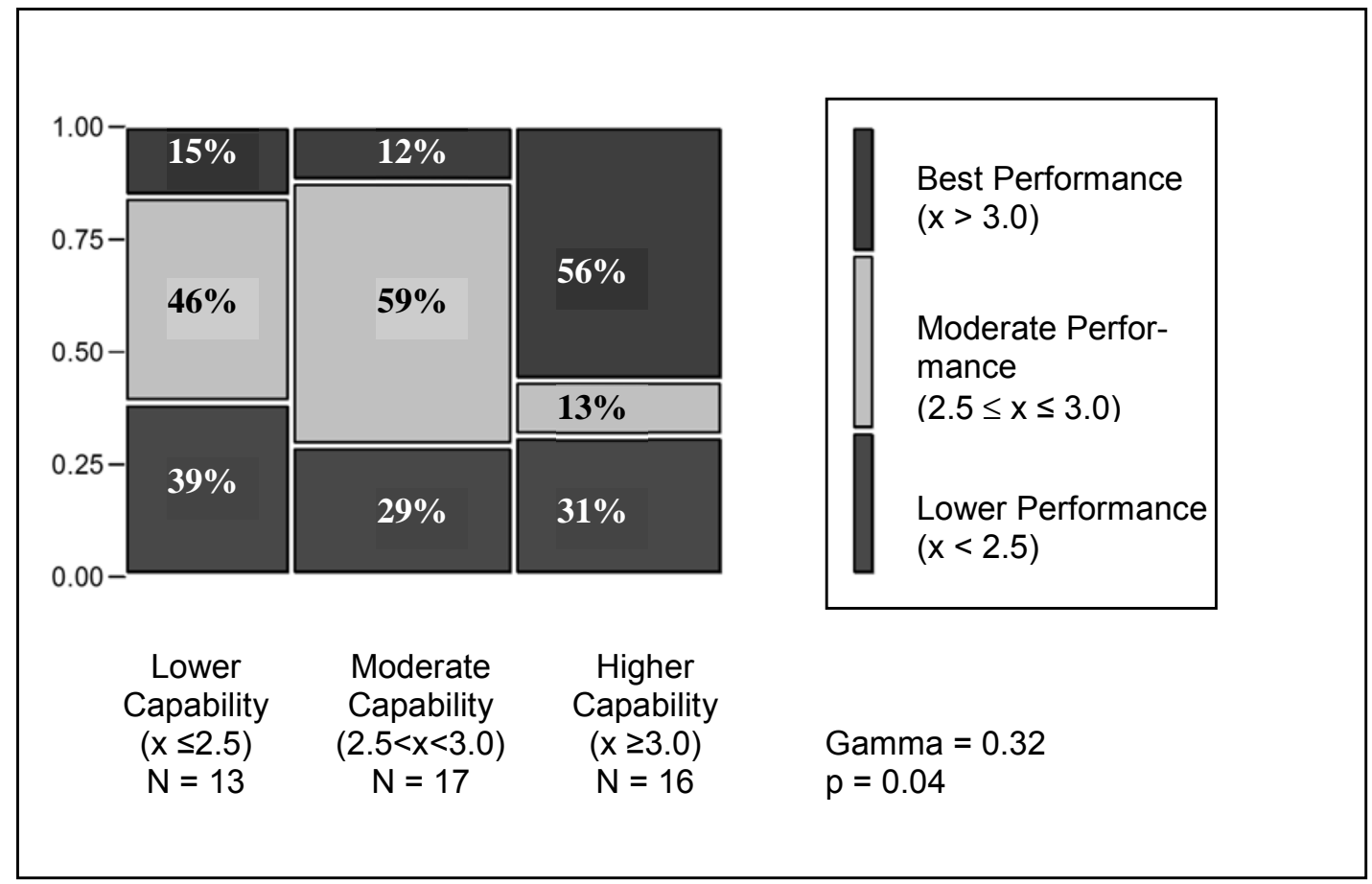

Figure 65: Perf vs. SEC-Total (from 2007 NDIA Study)

The chart in Figure 65 from the 2007 study is remarkably similar to the chart produced by this study, shown in Figure 66. Both studies showed an increase in projects delivering higher performance, and a decrease in projects delivering lower performance as SE deployment increases. 


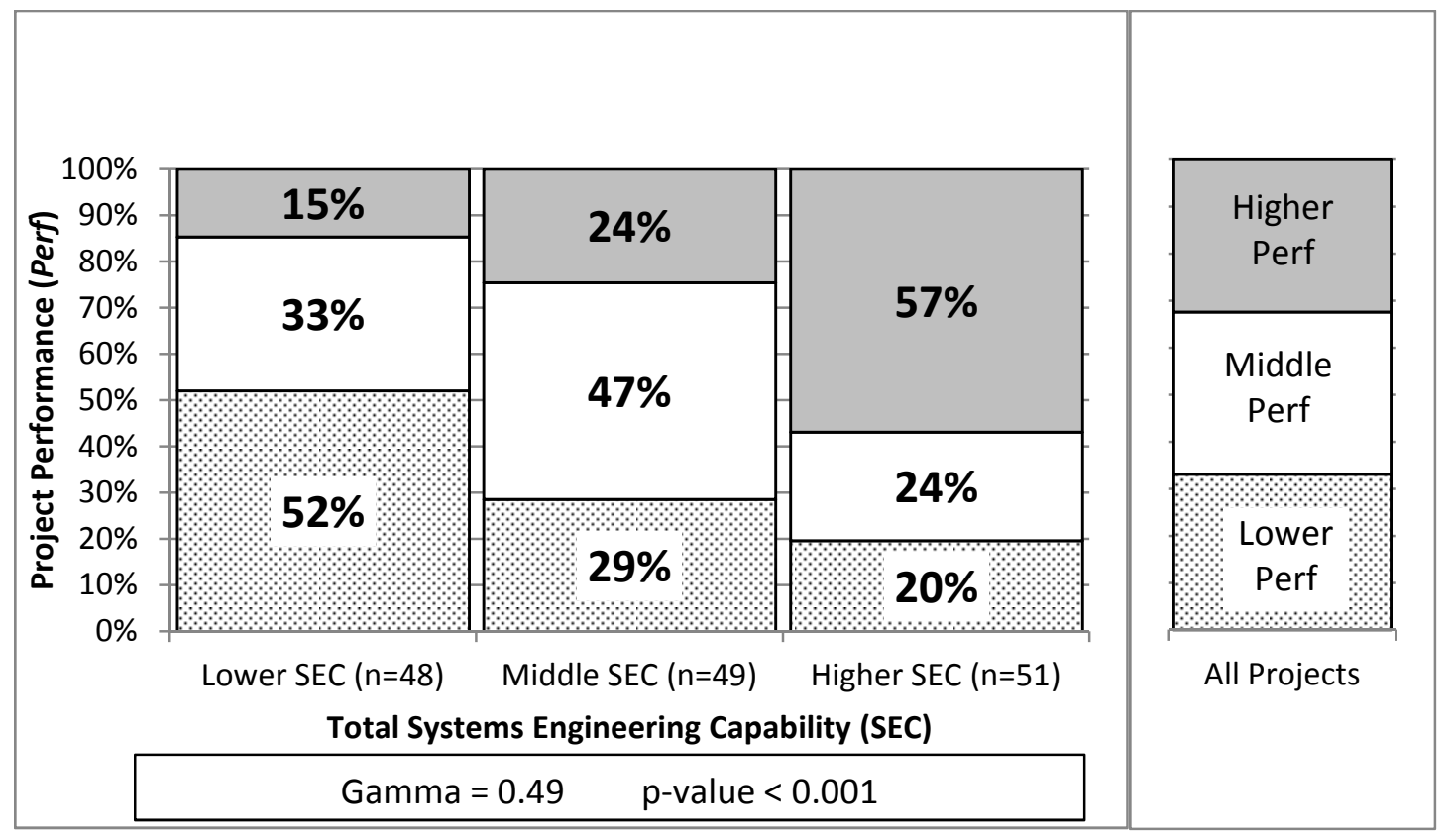

Figure 66: Perf vs. SEC-Total

In the 2007 research study, we also examined the relationships between project performance and specific SE process groups, just as we did in this study. For each process group, Table 8 shows the Gamma value and $\boldsymbol{p}$-value of its relationship to project performance for both the 2007 and the 2012 studies.

Table 8: Comparison of Gamma Values and p-values

\begin{tabular}{|l|c|c|c|c|}
\hline \multirow{2}{*}{ SE Process Area } & \multicolumn{2}{|c|}{ Gamma } & \multicolumn{2}{c|}{$p$-value } \\
\cline { 2 - 5 } & 2007 & 2012 & 2007 & 2012 \\
\hline SEC-Total & +0.32 & +0.49 & 0.040 & $<0.001$ \\
\hline SEC-PP & +0.13 & +0.46 & 0.250 & $<0.001$ \\
\hline SEC-REQ & +0.33 & +0.44 & 0.040 & $<0.001$ \\
\hline SEC-VER & +0.25 & +0.43 & 0.090 & $<0.001$ \\
\hline SEC-ARCH & +0.40 & +0.41 & 0.002 & $<0.001$ \\
\hline SEC-CM & +0.13 & +0.38 & 0.260 & 0.001 \\
\hline SEC-TRD & +0.37 & +0.38 & 0.030 & $<0.001$ \\
\hline SEC-PMC & -0.13 & +0.38 & 0.250 & $<0.001$ \\
\hline SEC-VAL & +0.28 & +0.33 & 0.070 & 0.003 \\
\hline SEC-PI & +0.21 & +0.33 & 0.160 & 0.003 \\
\hline SEC-RSKM & +0.28 & +0.21 & 0.061 & 0.050 \\
\hline SEC-IPT & +0.34 & +0.18 & 0.040 & 0.101 \\
\hline
\end{tabular}


A summary of this comparison is shown in Figure 67.

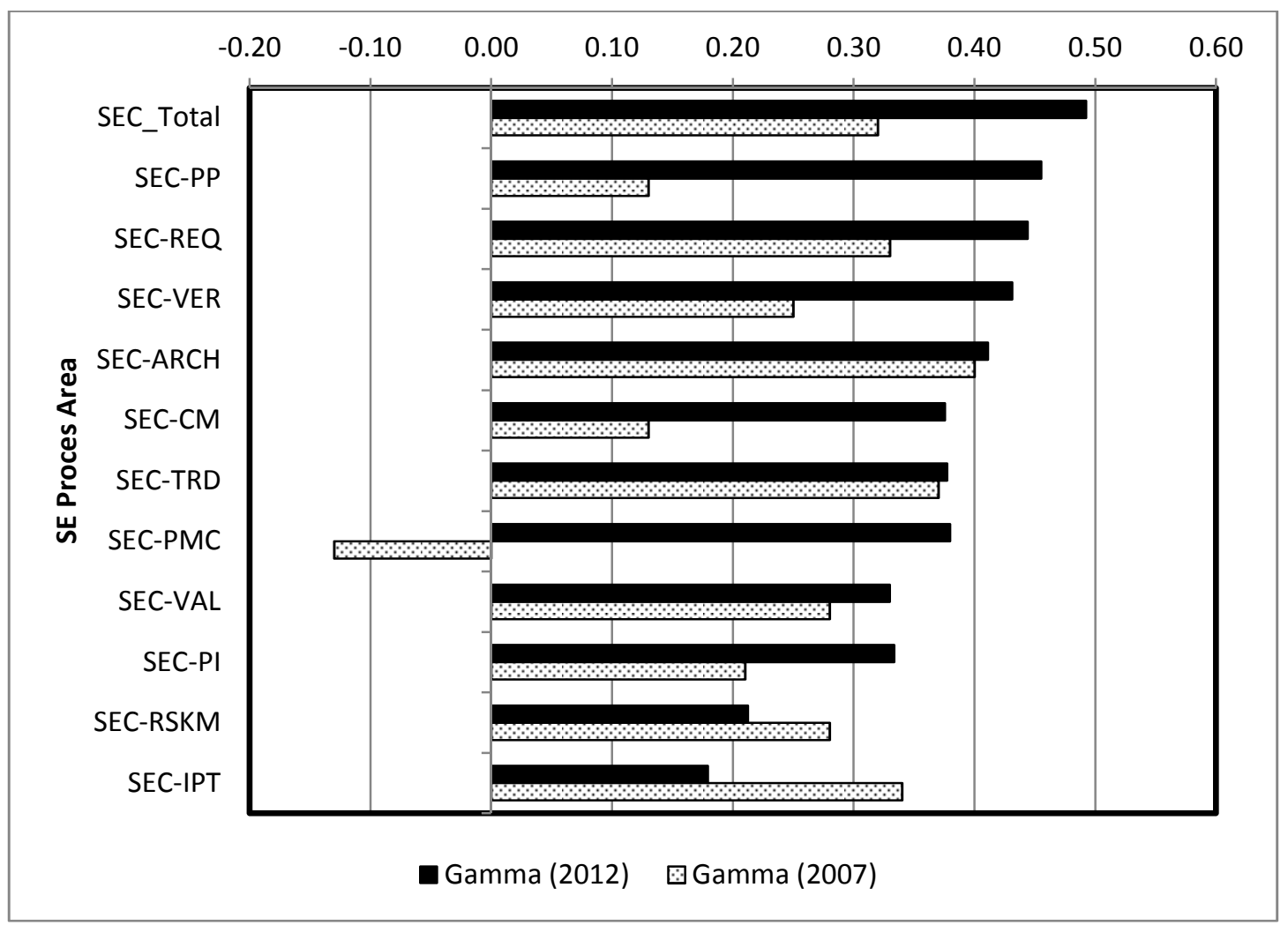

Figure 67: Comparison of Gamma Values

Most results from the two studies are generally in agreement, which is reasonable for data of this nature. Notable differences in the results of the two studies exist for the relationships between project performance (Perf) and four systems engineering capabilities.

1. $\quad \boldsymbol{S E C - P P}$ - In the 2007 study, this relationship was evaluated at Gamma $=+0.13$. Now it is evaluated at Gamma $=+0.46$, which is a considerable increase from what was a weak relationship to a very strong one.

As noted in Section 6.1.1, the questions assessing SEC-PP did not change appreciably between the two studies. As noted in Section 6.1.2, improvements were made in the questions and process for assessing Perf.

It is conceivable that these changes account for the observed differences in results. To assess this possibility, we reverted to an analysis process more similar to the one used in 2007. While it was not practical to use the less rigorous assessment process of the 2007 study, we could eliminate some of the Perf questions added for this study. Once we eliminated those questions, we found that 47 of the 148 responses used in the analysis were rendered unusable due to insufficient data to evaluate Perf, reducing the number of useable cases to 101.

Examining the relationship between SEC-PP and Perf for these 101 cases did not produce a result more consistent with the 2007 study. Hence, it is reasonable to claim that the changes in the assessment of Perf do not account for the observed relationship difference. However the explanation may lie in differences between the two survey samples. 
2. $\quad \boldsymbol{S E C}-\boldsymbol{C M}-$ In the 2007 study, this relationship was evaluated at Gamma $=+0.13$. Now, it is evaluated at Gamma $=+0.38$, which also is a considerable increase from what was a weak relationship to a strong one.

Similar to $\boldsymbol{S E C - P P}$, the questions assessing $\boldsymbol{S E C}$ - $\boldsymbol{C M}$ did not change appreciably between the two studies; however the questions and process for assessing Perf did. To assess the impact of this change, we repeated the analysis eliminating the additional Perf questions and found that the analysis of the relationship between $\boldsymbol{S E C - P P}$ and Perf did not produce a result more consistent with the 2007 study.

Hence, it is reasonable to claim that the changes in the assessment of Perf do not account for the observed relationship difference. However the explanation may lie in differences between the two survey samples.

3. $\boldsymbol{S E C - P M C}$ - In the 2007 study, this relationship was evaluated at Gamma $=-0.13$. Now, it is evaluated at Gamma $=+0.38$. That is, of course, a very large difference in magnitude that also is a change from a weak negative relationship to a strong positive one.

As noted in Section 6.1.1, this study deleted several questions that were used to assess $\boldsymbol{S E C}$ $\boldsymbol{P M C}$ in the 2007 study. These questions centered on the use of engineering analyses to support operational hazard risk assessments, materiel readiness assessments, and system upgrade planning. These topics tend to be specialty subjects "beyond the mainstream" fundamentals of project monitoring and control that may not apply to the set of sampled projects at large, and thus SEC-PMC may have been scored lower as a consequence.

It is conceivable that the inclusion of these questions in the 2007 study resulted in a difference in the overall assessment of $\boldsymbol{S E C - P M C}$ creating the observed relationship difference. Unfortunately, we cannot redo the 2007 analysis since those data were collected under a promise of restricted use after which they would be discarded.

4. $\quad \boldsymbol{S E C}-\mathbf{I P T}-$ In the 2007 study, this relationship was evaluated at Gamma $=+0.34$. Now, it is evaluated at Gamma $=+0.18$, which is a considerable decrease from what was a moderately strong relationship to a weak one.

Similar to $\boldsymbol{S E C - P P}$, the questions assessing $\boldsymbol{S E C - I P T}$ did not change appreciably between the two studies; however the questions and process for assessing Perf did. To assess the impact of this change, we repeated the analysis eliminating the additional questions and found that the analysis of the relationship between SEC-PP and Perf did not produce a result substantially more consistent with the 2007 study. Hence, it is reasonable to claim that the changes in the assessment of Perf do not account for the observed relationship difference. However the explanation may lie in differences between the two survey samples.

Overall, there are many more commonalities than differences in the results of the two surveys. For example, we examined the impact of $\boldsymbol{P C}$ on the relationships between various areas of $\boldsymbol{S E}$ and Perf in the 2007 study. The relationships were stronger in the 2007 study for the more challenging projects.

In the 2012 study, we examined this impact to a greater extent and found the effect to hold true in all cases. Thus, even for the four cases discussed above, we see that project challenge amplifies the strength of the relationships between systems engineering and project performance (Figure 25, Figure 43, Figure 49 and Figure 52). 
Those four relationships with process performance are notably stronger for projects that are confronted by more difficult challenges (higher PC). It is the projects with lower PC where the relationships remain weaker. That is an encouraging finding about the validity of the current results.

All statistical measures have noise, about which we can only conjecture based on our existing data. For example, in our experience, the targeted organizations that were solicited for the current survey tend to have more programs that regularly use advanced measurement practices to inform their SE practices. Other studies show that such practices often are accompanied by better project performance and product quality outcomes [Goldenson 2008, Stoddard 2010, McCurley 2010].

However, further analysis of the existing data may clarify the differences discussed in this section. Such analysis may also augment the results that are summarized in the current report as a whole, for example

Some of the differences in the strength of the relationships between the SE variables and Perf may be due to the extent to which the distributions of the $\boldsymbol{S E C}$ variables differ between the two samples with respect to higher versus lower SE capability.

If the samples differ, more variability on the $\boldsymbol{S E C}$ variables may lead to stronger relationships with Perf.

Less variability on some of the weighted summed indices also may confound the results. Relationships may be lower if there is too little variability in one or both of the variables in a statistical relationship.

While most of the survey participants are working on U.S. DoD programs, $21 \%$ of them do not. That too may affect the differences between the two surveys' results.

The larger number of cases in the current survey also may account for some of the differences in the strength of relationships between the two studies. A few outliers can account for more of an apparent relationship in a small sample. That is one reason why statistical significance (p-values) tends to be lower with large samples.

The research team will continue investigating these and other possible reasons for any differences in the results of the two surveys. The team will make public the results of those investigations later rather than delay the publication of the noteworthy results described in this report. 


\section{Summary}

The impetus for this survey was a desire to answer these questions:

What will the application of systems engineering practices cost me?

What benefits will I gain from the application of these practices?

To address these questions, we assessed the impact of the deployment of SE practices and several other factors on project performance. The analysis of the collected data shows that there are identifiable and significant relationships between many of these driving factors and project performance. Figure 68 shows that for projects deploying the least SE, only 15\% delivered higher project performance, while for those projects deploying the most SE, 57\% delivered higher project performance.

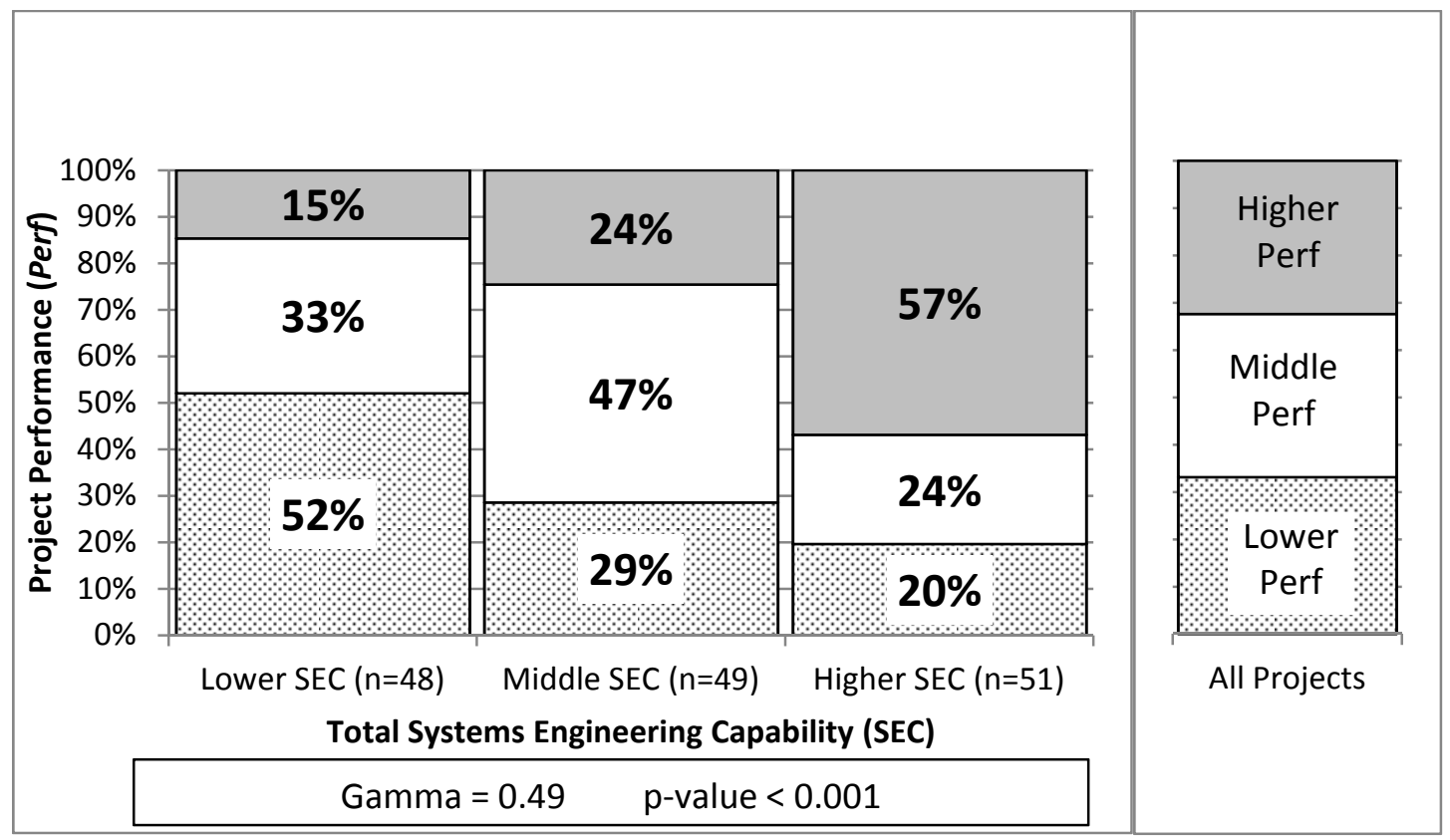

Figure 68: SEC-Total vs. Perf

The impact of SE is even more apparent if we consider the degree of challenge posed by the project. The chart on the left side of Figure 69 shows the relationship between SEC-Total and Perf for those projects presenting a lower degree of challenge. For these projects, the likelihood of delivering higher project performance with the least amount of SE is a reasonable $23 \%$. However, the deployment of effective SE more than doubles this likelihood to $52 \%$.

Contrast this finding with the chart on the right side of Figure 69, which shows the relationship between SEC-Total and Perf for those projects presenting a higher degree of challenge. Here, the likelihood of delivering higher project performance without the deployment of effective SE is only 8\%. With the deployment of effective SE, this likelihood increases almost eightfold to $62 \%$. A Gamma of 0.62 is very strong for survey data such as these. As shown in Section 5.4 and later in Section 7, similarly strong relationships also exist for other $\boldsymbol{S E C}$ variables when project challenge $(\boldsymbol{P C})$ is high. 

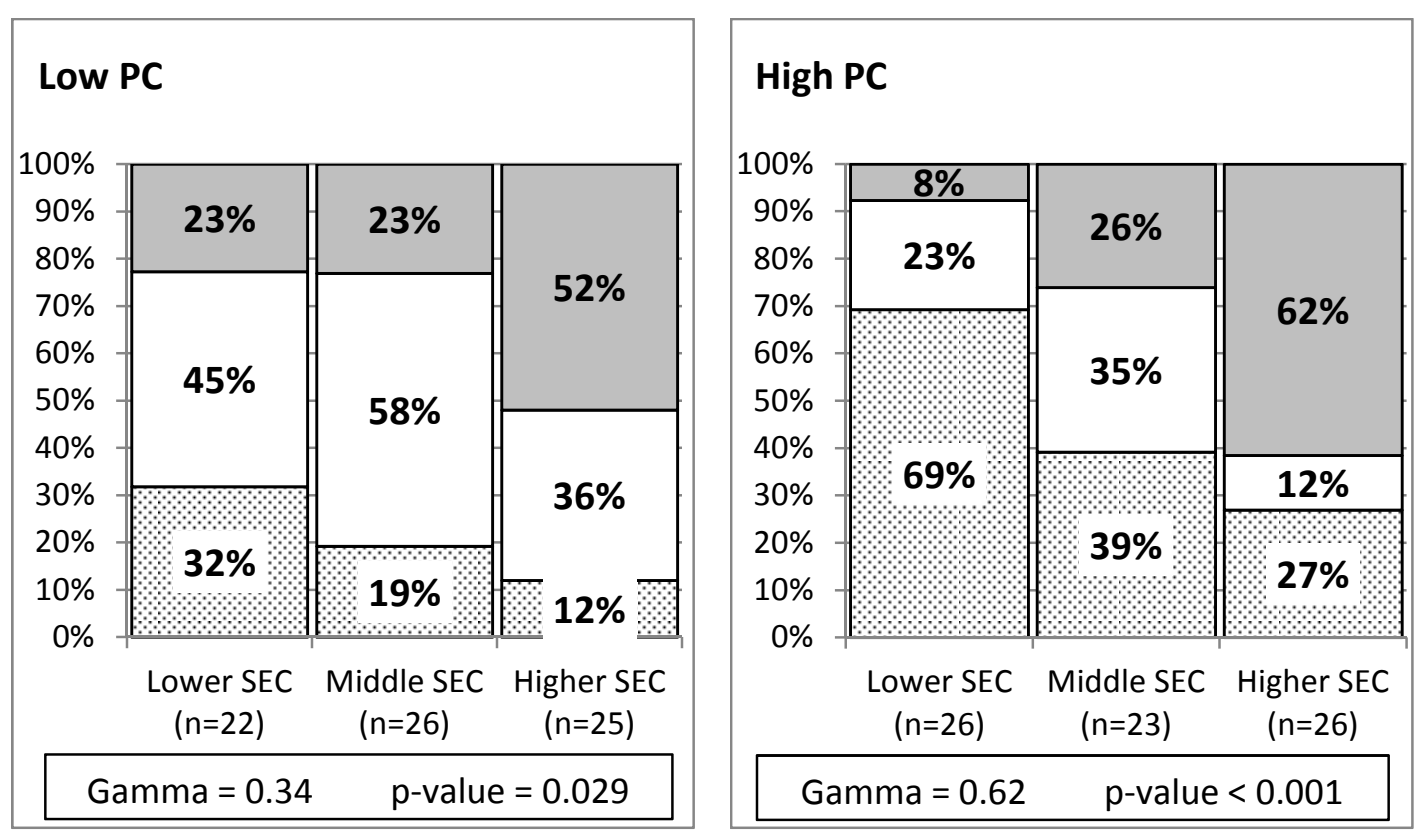

Figure 69: SEC-Total vs. Perf Controlled by PC

In addition to looking at the overall deployment of SE to projects, we examined the specific process groups of SE deployment. Table 9 shows the relationships between project performance and the deployment of SE in various process groups. Table 10 shows the relationships between project performance and other factors. 
Table 9: $\quad$ Summary of Relationships Between SE Deployment and Project Performance

\begin{tabular}{|c|c|c|c|}
\hline \multirow[t]{2}{*}{ Driver } & \multicolumn{3}{|c|}{ Relationship to Performance (Gamma) } \\
\hline & All projects & $\begin{array}{l}\text { Lower challenge } \\
\text { projects }\end{array}$ & $\begin{array}{l}\text { Higher challenge } \\
\text { projects }\end{array}$ \\
\hline SEC-Total - total deployed SE & $\begin{array}{l}+0.49 \Rightarrow \text { Very strong } \\
\text { positive }\end{array}$ & $\begin{array}{l}+0.34 \Rightarrow \text { Strong } \\
\text { positive }\end{array}$ & $\begin{array}{l}+0.62 \Rightarrow \text { Very strong } \\
\text { positive }\end{array}$ \\
\hline $\boldsymbol{S E C - P P}$ - project planning & $\begin{array}{l}+0.46 \Rightarrow \text { Very strong } \\
\text { positive }\end{array}$ & $\begin{array}{l}+0.16 \Rightarrow \text { Weak } \\
\text { positive }\end{array}$ & $\begin{array}{l}+0.65 \Rightarrow \text { Very strong } \\
\text { positive }\end{array}$ \\
\hline $\begin{array}{l}\text { SEC-REQ - requirements } \\
\text { development and management }\end{array}$ & $\begin{array}{l}+0.44 \Rightarrow \text { Very strong } \\
\text { positive }\end{array}$ & $\begin{array}{l}+0.36 \Rightarrow \text { Strong } \\
\text { positive }\end{array}$ & $\begin{array}{l}+0.50 \Rightarrow \text { Very strong } \\
\text { positive }\end{array}$ \\
\hline SEC-VER - verification & $\begin{array}{l}+0.43 \Rightarrow \text { Very strong } \\
\text { positive }\end{array}$ & $\begin{array}{l}+0.27 \Rightarrow \text { Moderate } \\
\text { positive }\end{array}$ & $\begin{array}{l}+0.60 \Rightarrow \text { Very strong } \\
\text { positive }\end{array}$ \\
\hline $\begin{array}{l}S E \boldsymbol{C}-\boldsymbol{A R C H} \text { - product architec- } \\
\text { ture }\end{array}$ & $\begin{array}{l}+0.41 \Rightarrow \text { Very strong } \\
\text { positive }\end{array}$ & $\begin{array}{l}+0.31 \Rightarrow \text { Moderate } \\
\text { positive }\end{array}$ & $\begin{array}{l}+0.49 \Rightarrow \text { Very strong } \\
\text { positive }\end{array}$ \\
\hline $\begin{array}{l}\boldsymbol{S E C} \text { - } \boldsymbol{C M} \text { - configuration } \\
\text { management }\end{array}$ & $\begin{array}{l}+0.38 \Rightarrow \text { Strong } \\
\text { positive }\end{array}$ & $\begin{array}{l}+0.22 \Rightarrow \text { Moderate } \\
\text { positive }\end{array}$ & $\begin{array}{l}+0.53 \Rightarrow \text { Very strong } \\
\text { positive }\end{array}$ \\
\hline SEC-TRD - trade studies & $\begin{array}{l}+0.38 \Rightarrow \text { Strong } \\
\text { positive }\end{array}$ & $\begin{array}{l}+0.29 \Rightarrow \text { Moderate } \\
\text { positive }\end{array}$ & $\begin{array}{l}+0.43 \Rightarrow \text { Very strong } \\
\text { positive }\end{array}$ \\
\hline $\begin{array}{l}S E C-P M C \text { - project monitoring } \\
\text { and control }\end{array}$ & $\begin{array}{l}+0.38 \Rightarrow \text { Strong } \\
\text { positive }\end{array}$ & $\begin{array}{l}+0.27 \Rightarrow \text { Moderate } \\
\text { positive }\end{array}$ & $\begin{array}{l}+0.53 \Rightarrow \text { Very Strong } \\
\text { positive }\end{array}$ \\
\hline SEC-VAL - validation & $\begin{array}{l}+0.33 \Rightarrow \text { Strong } \\
\text { positive }\end{array}$ & $\begin{array}{l}+0.23 \Rightarrow \text { Moderate } \\
\text { positive }\end{array}$ & $\begin{array}{l}+0.48 \Rightarrow \text { Very strong } \\
\text { positive }\end{array}$ \\
\hline $\boldsymbol{S E C - P I}$ - product integration & $\begin{array}{l}+0.33 \Rightarrow \text { Strong } \\
\text { positive }\end{array}$ & $\begin{array}{l}+0.23 \Rightarrow \text { Moderate } \\
\text { positive }\end{array}$ & $\begin{array}{l}+0.42 \Rightarrow \text { Very strong } \\
\text { positive }\end{array}$ \\
\hline SEC-RSKM - risk management & $\begin{array}{l}+0.21 \Rightarrow \text { Moderate } \\
\text { positive }\end{array}$ & $\begin{array}{l}+0.18 \Rightarrow \text { Weak } \\
\text { positive }\end{array}$ & $\begin{array}{l}+0.24 \Rightarrow \text { Moderate } \\
\text { positive }\end{array}$ \\
\hline $\begin{array}{l}\boldsymbol{S E C} \boldsymbol{C} \boldsymbol{I P T} \text { - integrated product } \\
\text { team utilization }\end{array}$ & $\begin{array}{l}+0.18 \Rightarrow \text { Weak } \\
\text { positive }\end{array}$ & $\begin{array}{l}-0.12 \Rightarrow \text { Weak } \\
\text { negative }\end{array}$ & $\begin{array}{l}+0.40 \Rightarrow \text { Very strong } \\
\text { positive }\end{array}$ \\
\hline
\end{tabular}

Table 10: Summary of Relationships Between Other Factors and Project Performance

\begin{tabular}{|l|l|l|l|}
\hline \multirow{2}{*}{ Driver } & \multicolumn{3}{|c|}{ Relationship to Performance } \\
\cline { 2 - 4 } & \multicolumn{1}{|c|}{ All projects } & \multicolumn{1}{|c|}{$\begin{array}{c}\text { Lower challenge } \\
\text { projects }\end{array}$} & $\begin{array}{l}\text { Higher challenge } \\
\text { projects }\end{array}$ \\
\hline $\boldsymbol{P C}$ - Project challenge & $\begin{array}{l}-0.26 \Rightarrow \text { Moderate } \\
\text { negative }\end{array}$ & $\begin{array}{l}-0.26 \Rightarrow \text { Moderate } \\
\text { negative }\end{array}$ & $\begin{array}{l}-0.23 \Rightarrow \text { Moderate } \\
\text { negative }\end{array}$ \\
\hline $\mathbf{E X P}$ - Prior experience & $\begin{array}{l}+0.36 \Rightarrow \text { Strong } \\
\text { positive }\end{array}$ & $\begin{array}{l}+0.51 \Rightarrow \text { Very strong } \\
\text { positive }\end{array}$ & $\begin{array}{l}+0.19 \Rightarrow \text { Weak } \\
\text { positive }\end{array}$ \\
\hline
\end{tabular}

The data in Tables 8 and 9 are illustrated in Figures 70 through 72. 


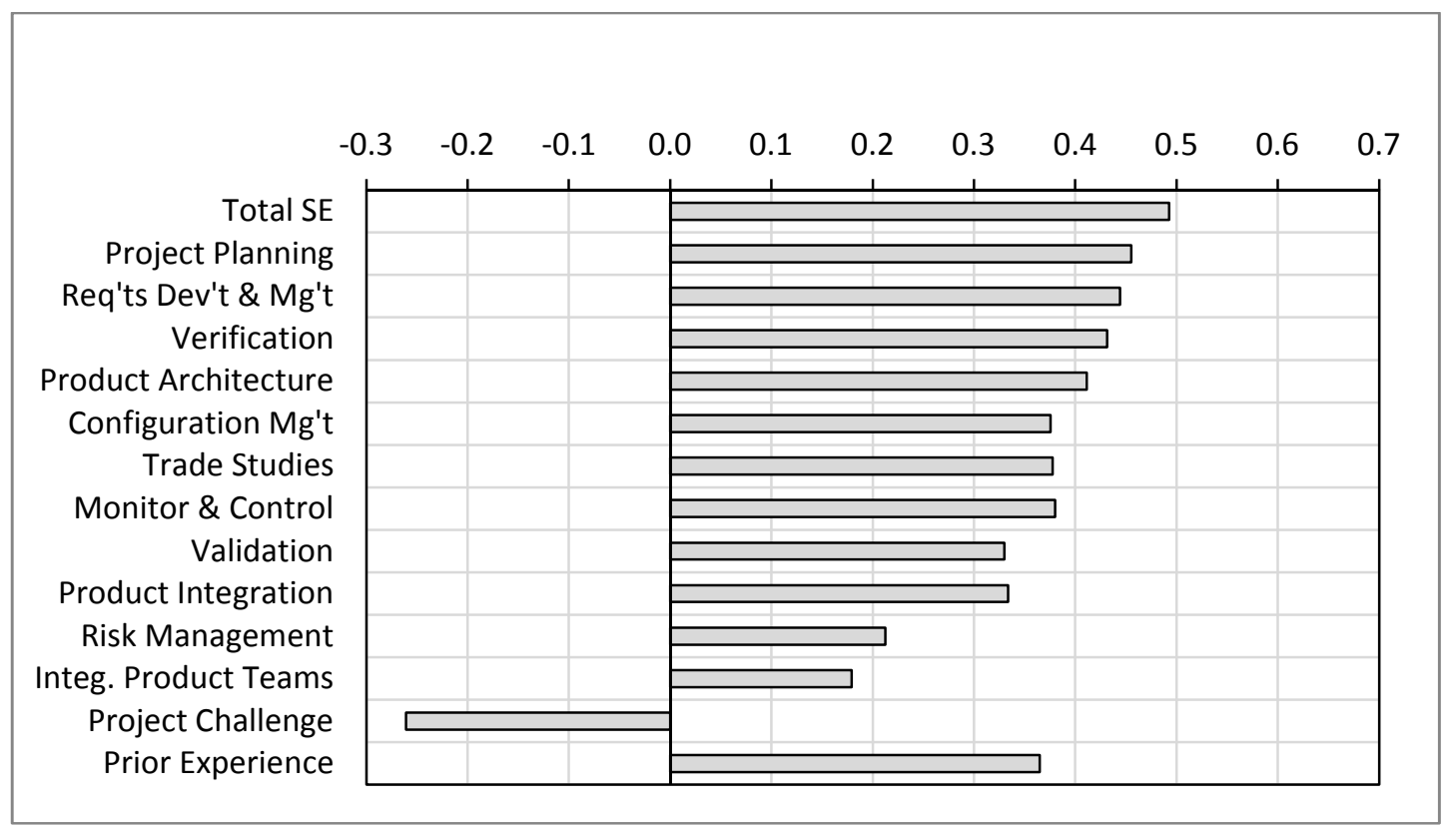

Figure 70: Summary of Relationships for All Projects

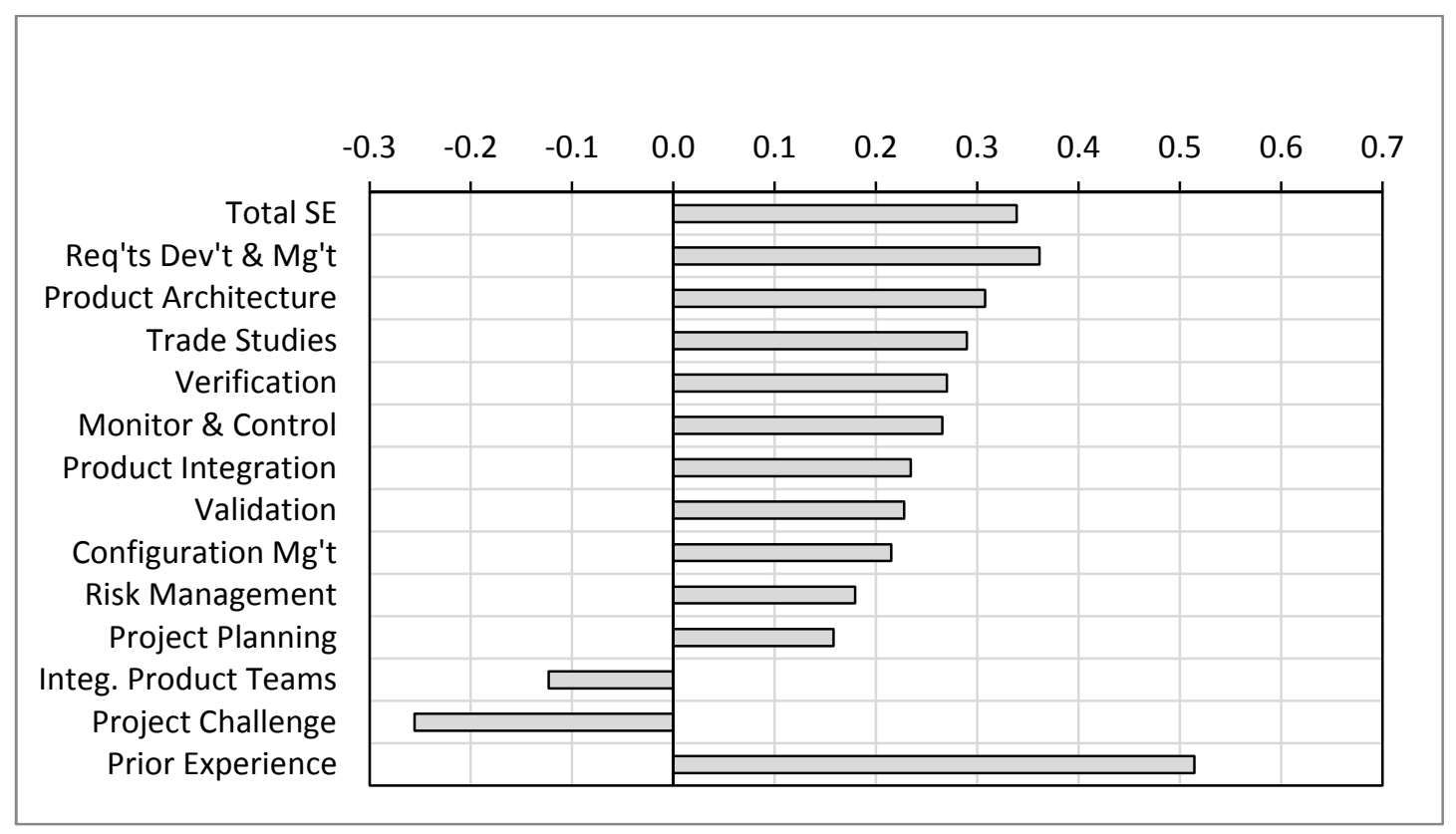

Figure 71: Summary of Relationships for Less Challenging Projects 


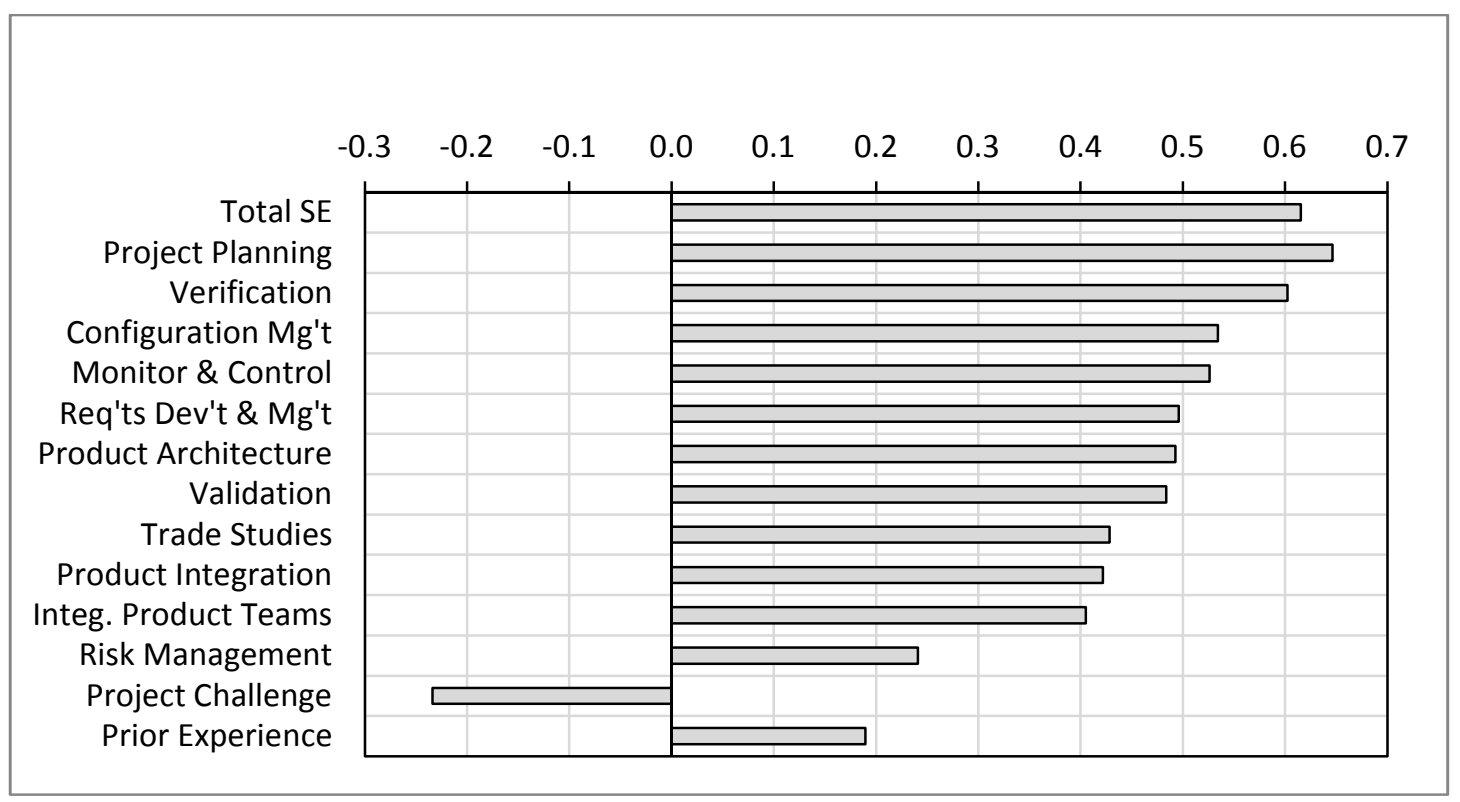

Figure 72: Summary of Relationships for More Challenging Projects

The moderate and strong statistical relationships between systems engineering capabilities and project performance summarized in this report are notable by themselves. Other things being equal, projects deploying better systems engineering capabilities tend to produce better project performance. Of equal interest is the impact of the degree of challenge posed by the projects on the relationships between SE deployment and project performance. Without exception, the relationships between SE and performance are stronger on more challenging projects. These results can be interpreted as

For lower challenge projects, although SE improves the likelihood of project success, success remains somewhat feasible without good SE deployment.

For higher challenge projects, good SE deployment is critical to project success.

The impact of prior experience on project success is also interesting. The success of lower challenge projects is strongly related to prior experience. The success of higher challenge projects is less strongly related. One hypothesis for this difference is that prior experience is helpful but simply insufficient to address the difficulties encountered in the most challenging projects. Deeper understanding of this difference requires more information than is available in this study.

The information presented in this report may be used in several ways:

- System developers can use this knowledge to plan capability improvement efforts for their SE programs. By focusing improvement resources on those SE activities most strongly associated with improved project performance, management may optimize the efficiency and effectiveness of those improvement efforts.

- System developers can use this information as an industry benchmark against which they can compare their organization's SE performance. Projects within the organization can be assessed in a manner consistent with this study and be compared with the results of this study. Weaknesses can then be improved or strengths applied with greater emphasis and leverage. The question-by-question responses are contained in the companion to this report. As prom- 
ised, survey participants have access to the companion report simultaneously with the publication of this report. Others will not have access to the companion report until it is publicly released one year later.

- Systems engineers and SE managers at system developer organizations can use this report as justification for and in defense of their SE estimates.

- Acquirers may use this report to plan contractor evaluations during request for proposal (RFP) development and source selection. Since this survey shows clear statistical relationships between specific SE capabilities and improved project performance, acquirers can structure RFPs and source selection activities to include evaluation and consideration of these capabilities, which thereby may increase the likelihood of project success.

- Throughout the execution of a project, acquirers may employ this survey or similar methods to collect data from suppliers as a means of identifying supplier deficiencies contributing to project risks. 


\section{Next Steps}

The BCSE study is a process intended to produce a sustained and monitored improvement in the acquisition and supply of systems through the application of SE best practices. The SE Effectiveness Survey is the first step in the BCSE Study, as noted in Figure 73.

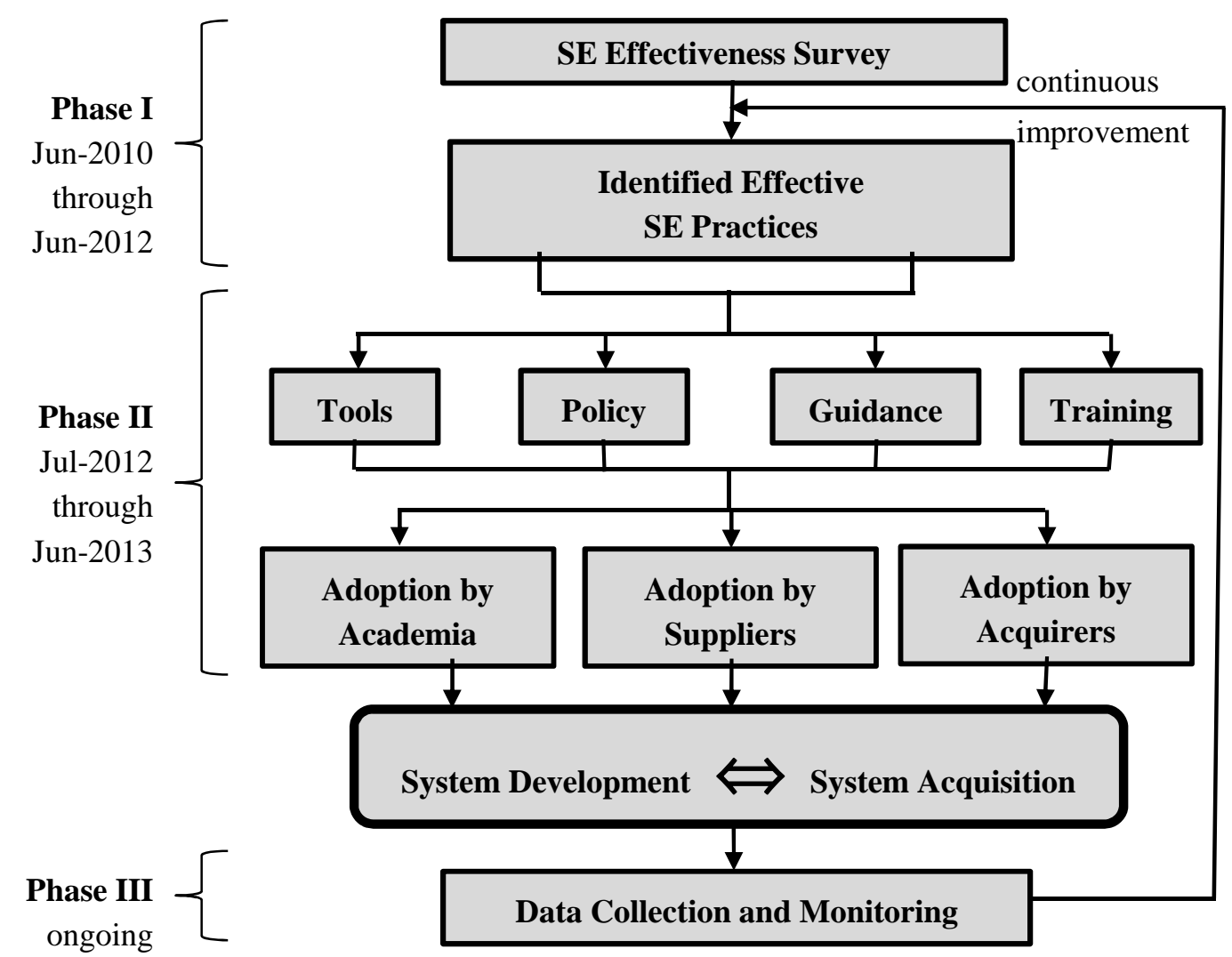

Figure 73: BCSE Process

This report identifies a collection of SE best practices that are shown to have positive impact on project performance. The second phase of the BCSE study is to promote action on the findings of this report.

Working through organizations such as NDIA, IEEE, and INCOSE, we can encourage the SE community to promote and build on the findings of this study. The SE community can use the findings to develop guidance for the use of SE in both acquisition and development programs. Researchers worldwide can use the findings to develop tools that help systems engineers use these best practices. Educators around the world can develop training for systems engineers and others to promote the use of these best practices. The result of these activities will be increased adoption of SE best practices among academics, systems acquirers, and systems suppliers. 
The third and final step is to promote the continuous measurement of the impact of SE best practice adoption. This measurement could be done using periodic repeats of the SE Effectiveness Survey, reverifying the effectiveness of these best practices and/or identifying new ones.

The survey could be administered easily within individual organizations. Each organization would require that ongoing projects periodically complete the SE Effectiveness Survey. Since most organizations already collect project performance data, the questionnaire could be abridged to just the sections addressing SE work products. Completion of these sections could be completed in as little as 15 minutes. The organizations could then perform analyses similar to those defined in this report to monitor and track both the deployment and effectiveness of SE.

The ideal result would be the establishment of a means of continuously monitoring both SE best practice deployment and project performance across many organizations. If the DoD chooses to support this concept, it is in a unique position to support the work. Through the Defense Contract Audit Agency (DCAA) and Defense Contract Management Agency (DCMA), the DoD already collects a large amount of data regarding project performance. The DoD could also require suppliers to report on SE deployment by simply completing the SE assessment questions of the SE Effectiveness Survey. With the combination of performance and SE deployment data, analyses similar to those contained in this report could be performed periodically. This process would reverify the effectiveness of SE best practices and/or identify new ones, but would also provide a means of tracking trends in SE deployment and project performance. All of this information could be used to continually improve and enhance the performance of development projects through the use of SE best practices. 


\section{Appendix A Cross Reference to CMMI}

The survey questions assessing SE deployment were focused on the production of artifacts from what would be considered SE-related activities. The artifacts behind these questions were based on the CMMI for SW/SE/IPPD v1.1 model, which was current when the earlier survey was developed [CMMI Product Team 2002, Elm 2008]. The specific artifacts used in the study were chosen by a panel of systems engineers drawn from industry, government, and academia. Mapping of survey questions to CMMI is shown in this appendix. After a wide-ranging discussion about the nature of systems engineering, the committee settled on CMMI SW/SE/IPPD as the primary source for the survey questions. Questions were derived from other sources on occasion to assure comprehensiveness.

Table 11: Cross Reference to CMMI

\begin{tabular}{|c|c|c|c|c|}
\hline Process Area & Goal & PRACTICE & WORK PRODUCT & $\begin{array}{c}\text { SURVEY } \\
\text { QUESTION }\end{array}$ \\
\hline $\begin{array}{l}\text { Organizational } \\
\text { Process } \\
\text { Definition }\end{array}$ & $\begin{array}{l}\text { SG 1: Establish Organizational } \\
\text { Process Assets - A set of } \\
\text { organizational process assets is } \\
\text { established and maintained. }\end{array}$ & $\begin{array}{l}\text { SP 1.1-1: Establish Standard Processes - } \\
\text { Establish and maintain the organization's } \\
\text { set of standard processes. }\end{array}$ & Organization's set of standard processes & $\mathrm{D} 1$ \\
\hline \multirow{10}{*}{$\begin{array}{l}\text { Project } \\
\text { Planning }\end{array}$} & \multirow{4}{*}{$\begin{array}{l}\text { SG 1: Establish Estimates - } \\
\text { Estimates of project planning } \\
\text { parameters are established and } \\
\text { maintained. }\end{array}$} & \multirow{3}{*}{$\begin{array}{l}\text { SP 1.1-1: Estimate the Scope of the Project } \\
\text { - Establish a top-level work breakdown } \\
\text { structure (WBS) to estimate the scope of } \\
\text { the project. }\end{array}$} & Task descriptions & $\mathrm{D} 2$ \\
\hline & & & Work package descriptions & D2 \\
\hline & & & WBS & D3 \\
\hline & & $\begin{array}{l}\text { SP 1.2-1: Establish Estimates of Work } \\
\text { Product and Task Attributes - Establish and } \\
\text { maintain estimates of the attributes of the } \\
\text { work products and tasks. }\end{array}$ & Technical approach & D6 \\
\hline & \multirow{6}{*}{$\begin{array}{l}\text { SG 2: Develop a Project Plan - } \\
\text { A project plan is established } \\
\text { and maintained as the basis for } \\
\text { managing the project. }\end{array}$} & \multirow{6}{*}{$\begin{array}{l}\text { SP 2.7-1: Establish the Project Plan - } \\
\text { Establish and maintain the overall project } \\
\text { plan content. }\end{array}$} & \multirow[t]{3}{*}{ Integrated master plan } & D9 \\
\hline & & & & D10 \\
\hline & & & & D11 \\
\hline & & & \multirow[t]{3}{*}{ Integrated master schedule } & D12 \\
\hline & & & & D15 \\
\hline & & & & D16 \\
\hline
\end{tabular}




\begin{tabular}{|c|c|c|c|c|}
\hline Process Area & Goal & PRACTICE & WORK PRODUCT & $\begin{array}{c}\text { SURVEY } \\
\text { QUESTION } \\
\end{array}$ \\
\hline & & & Systems engineering management plan & D21 \\
\hline & & & & D22 \\
\hline & & & Systems engineering detailed schedule & D13 \\
\hline & & & & D14 \\
\hline & GG 2: Institutionalize a & GP 2.7: Identify and Involve Relevant & Stakeholders include SE staff & D4 \\
\hline & Managed Process & Stakeholders & & D5 \\
\hline & & & & D7 \\
\hline & & & & D8 \\
\hline & & & & D18 \\
\hline & & & & D19 \\
\hline \multirow{14}{*}{$\begin{array}{l}\text { Project } \\
\text { Monitoring and } \\
\text { Control }\end{array}$} & \multirow{12}{*}{$\begin{array}{l}\text { SG 1: Monitor Project Against } \\
\text { Plan - Actual performance and } \\
\text { progress of the project are } \\
\text { monitored against the project } \\
\text { plan. }\end{array}$} & \multirow{5}{*}{$\begin{array}{l}\text { SP 1.1-1: Monitor Project Planning } \\
\text { Parameters - Monitor the actual values of } \\
\text { the project planning parameters against the } \\
\text { project plan. }\end{array}$} & \multirow[t]{5}{*}{ Records of project performance } & N1 \\
\hline & & & & N2 \\
\hline & & & & N3 \\
\hline & & & & N6 \\
\hline & & & & A14 \\
\hline & & $\begin{array}{l}\text { SP 1.2-1: Monitor Commitments - Monitor } \\
\text { commitments against those identified in the } \\
\text { project plan. }\end{array}$ & Records of commitment reviews & N5 \\
\hline & & \multirow{5}{*}{$\begin{array}{l}\text { SP 1.3-1: Monitor Project Risks - Monitor } \\
\text { risks against those identified in the project } \\
\text { plan. }\end{array}$} & \multirow[t]{5}{*}{ Records of project risk monitoring } & F3 \\
\hline & & & & F4 \\
\hline & & & & F5 \\
\hline & & & & F6 \\
\hline & & & & F7 \\
\hline & & $\begin{array}{l}\text { SP 1.7-1: Conduct Milestone Reviews - } \\
\text { Review the accomplishments and results of } \\
\text { the project at selected project milestones. }\end{array}$ & Documented milestone review results & K9 \\
\hline & \multirow{2}{*}{$\begin{array}{l}\text { SG 2: Manage Corrective } \\
\text { Action to Closure - Corrective }\end{array}$} & \multirow{2}{*}{$\begin{array}{l}\text { SP 2.1-1: Analyze Issues - Collect and } \\
\text { analyze the issues and determine the }\end{array}$} & \multirow[t]{2}{*}{ List of issues needing corrective actions } & N4 \\
\hline & & & & O6 \\
\hline
\end{tabular}




\begin{tabular}{|c|c|c|c|c|}
\hline Process Area & Goal & PRACTICE & WORK PRODUCT & $\begin{array}{l}\text { SURVEY } \\
\text { QUESTION }\end{array}$ \\
\hline & $\begin{array}{l}\text { actions are managed to closure } \\
\text { when the project's performance }\end{array}$ & $\begin{array}{l}\text { corrective actions necessary to address the } \\
\text { issues. }\end{array}$ & & $\mathrm{O} 7$ \\
\hline & $\begin{array}{l}\text { or results deviate significantly } \\
\text { from the plan. }\end{array}$ & $\begin{array}{l}\text { SP 2.3-1: Manage Corrective Action - } \\
\text { Manage corrective actions to closure. }\end{array}$ & Corrective action results & K6 \\
\hline \multirow{5}{*}{$\begin{array}{l}\text { Integrated } \\
\text { Project } \\
\text { Management } \\
\text { for IPPD }\end{array}$} & \multirow{5}{*}{$\begin{array}{l}\text { SG 4: Organize Integrated } \\
\text { Teams for IPPD - The } \\
\text { integrated teams needed to } \\
\text { execute the project are } \\
\text { identified, defined, structured, } \\
\text { and tasked. }\end{array}$} & \multirow{3}{*}{$\begin{array}{l}\text { SP 4.1-1: Determine Integrated Team } \\
\text { Structure for the Project - Determine the } \\
\text { integrated team structure that will best } \\
\text { meet the project objectives and constraints. }\end{array}$} & \multirow{3}{*}{$\begin{array}{l}\text { Integrated team structures based on the } \\
\text { WBS and adaptations }\end{array}$} & E1 \\
\hline & & & & E2 \\
\hline & & & & E3 \\
\hline & & \multirow{2}{*}{$\begin{array}{l}\text { SP 4.3-1: Establish Integrated Teams - } \\
\text { Establish and maintain teams in the } \\
\text { integrated team structure. }\end{array}$} & \multirow{2}{*}{$\begin{array}{l}\text { Responsibilities and authorities for each } \\
\text { integrated team }\end{array}$} & E4 \\
\hline & & & & E5 \\
\hline \multirow{4}{*}{$\begin{array}{l}\text { Risk } \\
\text { Management }\end{array}$} & \multirow[t]{2}{*}{$\begin{array}{l}\text { SG 2: Identify and Analyze } \\
\text { Risks - Risks are identified and } \\
\text { analyzed to determine their } \\
\text { relative importance. }\end{array}$} & \multirow[t]{2}{*}{$\begin{array}{l}\text { SP 2.1-1: Identify Risks - Identify and } \\
\text { document the risks. }\end{array}$} & \multirow[t]{2}{*}{$\begin{array}{l}\text { List of identified risks, including the } \\
\text { context, conditions, and consequences of } \\
\text { risk occurrence }\end{array}$} & F1 \\
\hline & & & & F8 \\
\hline & \multirow{2}{*}{$\begin{array}{l}\text { SG 3: Mitigate Risks - Risks } \\
\text { are handled and mitigated, } \\
\text { where appropriate, to reduce } \\
\text { adverse impacts on achieving } \\
\text { objectives. }\end{array}$} & \multirow{2}{*}{$\begin{array}{l}\text { SP 3.1-1: Develop Risk Mitigation Plans - } \\
\text { Develop a risk mitigation plan for the most } \\
\text { important risks to the project, as defined by } \\
\text { the risk management strategy. }\end{array}$} & Risk mitigation plans & F2 \\
\hline & & & Contingency plans & F2 \\
\hline \multirow{4}{*}{$\begin{array}{l}\text { Requirements } \\
\text { Management }\end{array}$} & \multirow{4}{*}{$\begin{array}{l}\text { SG 1: Manage Requirements - } \\
\text { Requirements are managed and } \\
\text { inconsistencies with project } \\
\text { plans and work products are } \\
\text { identified. }\end{array}$} & \multirow{3}{*}{$\begin{array}{l}\text { SP 1.1-1: Obtain an Understanding of } \\
\text { Requirements - Develop an understanding } \\
\text { with the requirements providers on the } \\
\text { meaning of the requirements. }\end{array}$} & $\begin{array}{l}\text { Lists of criteria for distinguishing } \\
\text { appropriate requirements providers }\end{array}$ & G7 \\
\hline & & & $\begin{array}{l}\text { Criteria for evaluation and acceptance of } \\
\text { requirements }\end{array}$ & G8 \\
\hline & & & An agreed-to set of requirements & G9 \\
\hline & & $\begin{array}{l}\text { SP 1.2-2: Obtain Commitment to } \\
\text { Requirements - Obtain commitment to the } \\
\text { requirements from the project participants. }\end{array}$ & Requirements impact assessments & G10 \\
\hline
\end{tabular}




\begin{tabular}{|c|c|c|c|c|}
\hline Process Area & Goal & PRACTICE & WORK PRODUCT & $\begin{array}{l}\text { SURVEY } \\
\text { QUESTION } \\
\end{array}$ \\
\hline & & $\begin{array}{l}\text { SP 1.4-2: Maintain Bidirectional } \\
\text { Traceability of Requirements - Maintain } \\
\text { bidirectional traceability among the } \\
\text { requirements and the project plans and } \\
\text { work products. }\end{array}$ & Requirements tracking system & G12 \\
\hline & \multirow{2}{*}{$\begin{array}{l}\text { GG 2: Institutionalize a } \\
\text { Managed Process }\end{array}$} & GP 2.6: Manage Configurations & Configuration management records & G13 \\
\hline & & $\begin{array}{l}\text { GP 2.7: Identify and Involve Relevant } \\
\text { Stakeholders }\end{array}$ & $<$ Stakeholders include SE staff $>$ & G14 \\
\hline \multirow{7}{*}{$\begin{array}{l}\text { Requirements } \\
\text { Development }\end{array}$} & $\begin{array}{l}\text { SG 1: Develop Customer } \\
\text { Requirements - Stakeholder } \\
\text { needs, expectations, } \\
\text { constraints, and interfaces are } \\
\text { collected and translated into } \\
\text { customer requirements. }\end{array}$ & $\begin{array}{l}\text { SP 1.1-1: Collect Stakeholder Needs - } \\
\text { Identify and collect stakeholder needs, } \\
\text { expectations, constraints, and interfaces for } \\
\text { all phases of the product lifecycle. }\end{array}$ & Customer requirements & G11 \\
\hline & & $\begin{array}{l}\text { SP 1.2-1: Develop the Customer } \\
\text { Requirements - Transform stakeholder } \\
\text { needs, expectations, constraints, and } \\
\text { interfaces into customer requirements. }\end{array}$ & Customer requirements & G1 \\
\hline & $\begin{array}{l}\text { SG 2: Develop Product } \\
\text { Requirements - Customer } \\
\text { requirements are refined and } \\
\text { elaborated to develop product } \\
\text { and product-component }\end{array}$ & $\begin{array}{l}\text { SP 2.1-1: Establish Product and Product- } \\
\text { Component Requirements - Establish and } \\
\text { maintain product and product-component } \\
\text { requirements, which are based on the } \\
\text { customer requirements. }\end{array}$ & Derived requirements & G2 \\
\hline & requirements. & $\begin{array}{l}\text { SP 2.2-1: Allocate Product-Component } \\
\text { Requirements - Allocate the requirements } \\
\text { for each product component. }\end{array}$ & Requirement allocation sheets & G3 \\
\hline & SG 3: Analyze and Validate & SP 3.1-1: Establish Operational Concepts & Operational concept & G4 \\
\hline & $\begin{array}{l}\text { Requirements - The } \\
\text { requirements are analyzed and }\end{array}$ & $\begin{array}{l}\text { and Scenarios - Establish and maintain } \\
\text { operational concepts and associated }\end{array}$ & $\begin{array}{l}\text { Product installation, operational, } \\
\text { maintenance, and support concepts }\end{array}$ & G6 \\
\hline & $\begin{array}{l}\text { validated, and a definition of } \\
\text { required functionality is } \\
\text { developed. }\end{array}$ & scenarıos. & Use cases & G5 \\
\hline
\end{tabular}




\begin{tabular}{|c|c|c|c|c|}
\hline Process Area & Goal & PRACTICE & WORK PRODUCT & $\begin{array}{l}\text { SURVEY } \\
\text { QUESTION } \\
\end{array}$ \\
\hline \multirow{11}{*}{$\begin{array}{l}\text { Technical } \\
\text { Solution }\end{array}$} & \multirow{4}{*}{$\begin{array}{l}\text { SG 1: Select Product- } \\
\text { Component Solutions - Product } \\
\text { or product-component } \\
\text { solutions are selected from } \\
\text { alternative solutions. }\end{array}$} & \multirow{2}{*}{$\begin{array}{l}\text { SP 1.1-1: Develop Alternative Solutions } \\
\text { and Selection Criteria - Develop alternative } \\
\text { solutions and selection criteria. }\end{array}$} & Alternative solutions & $\mathrm{H} 2$ \\
\hline & & & Selection criteria & $\mathrm{H} 2$ \\
\hline & & \multirow{2}{*}{$\begin{array}{l}\text { SP 1.3-1: Select Product-Component } \\
\text { Solutions - Select the product-component } \\
\text { solutions that best satisfy the criteria } \\
\text { established. }\end{array}$} & $\begin{array}{l}\text { Product-component selection decisions and } \\
\text { rationale }\end{array}$ & H3 \\
\hline & & & $\begin{array}{l}\text { Documented solutions, evaluations, and } \\
\text { rationale }\end{array}$ & H3 \\
\hline & \multirow{5}{*}{$\begin{array}{l}\text { SG 2: Develop the Design - } \\
\text { Product or product-component } \\
\text { designs are developed. }\end{array}$} & \multirow{2}{*}{$\begin{array}{l}\text { SP 2.1-1: Design the Product or Product } \\
\text { Component - Develop a design for the } \\
\text { product or product component. }\end{array}$} & \multirow[t]{2}{*}{ Product architecture } & I3 \\
\hline & & & & I4 \\
\hline & & \multirow{2}{*}{$\begin{array}{l}\text { SP 2.3-1: Establish Interface Descriptions - } \\
\text { Establish and maintain the solution for } \\
\text { product-component interfaces. }\end{array}$} & Interface design & I1 \\
\hline & & & Interface design documents & I1 \\
\hline & & $\begin{array}{l}\text { SP 2.3-3: Design Interfaces Using Criteria - } \\
\text { Design comprehensive product-component } \\
\text { interfaces in terms of established and } \\
\text { maintained criteria. }\end{array}$ & Interface control documents & $\mathrm{I} 2$ \\
\hline & \multirow{2}{*}{$\begin{array}{l}\text { GG 2: Institutionalize a } \\
\text { Managed Process }\end{array}$} & \multirow{2}{*}{$\begin{array}{l}\text { GP 2.7: Identify and Involve Relevant } \\
\text { Stakeholders }\end{array}$} & \multirow[t]{2}{*}{$<$ Stakeholders include SE staff $>$} & H1 \\
\hline & & & & I5 \\
\hline $\begin{array}{l}\text { Product } \\
\text { Integration }\end{array}$ & $\begin{array}{l}\text { SG 1: Prepare for Product } \\
\text { Integration - Preparation for } \\
\text { product integration is } \\
\text { conducted. }\end{array}$ & $\begin{array}{l}\text { SP 1.3-3: Establish Product Integration } \\
\text { Procedures and Criteria - Establish and } \\
\text { maintain procedures and criteria for } \\
\text { integration of the product components. }\end{array}$ & Product integration procedures & $\mathrm{J} 1$ \\
\hline \multirow{4}{*}{ Verification } & \multirow{2}{*}{$\begin{array}{l}\text { SG 1: Prepare for Verification - } \\
\text { Preparation for verification is } \\
\text { conducted. }\end{array}$} & \multirow{2}{*}{$\begin{array}{l}\text { SP 1.3-3: Establish Verification Procedures } \\
\text { and Criteria - Establish and maintain } \\
\text { verification procedures and criteria for the } \\
\text { selected work products. }\end{array}$} & Verification procedures & K1 \\
\hline & & & Verification criteria & K2 \\
\hline & \multirow[t]{2}{*}{$\begin{array}{l}\text { SG 2: Perform Peer Reviews - } \\
\text { Peer reviews are performed on } \\
\text { selected work products. }\end{array}$} & \multirow[t]{2}{*}{$\begin{array}{l}\text { SP 2.1-1: Prepare for Peer Reviews - } \\
\text { Prepare for peer reviews of selected work } \\
\text { products. }\end{array}$} & Peer review schedule & D17 \\
\hline & & & Entry and exit criteria for work products & K3 \\
\hline
\end{tabular}




\begin{tabular}{|c|c|c|c|c|}
\hline Process Area & Goal & PRACTICE & WORK PRODUCT & $\begin{array}{l}\text { SURVEY } \\
\text { QUESTION } \\
\end{array}$ \\
\hline & & & Peer review training material & $\mathrm{K} 4$ \\
\hline & & & Selected work products to be reviewed & K5 \\
\hline & & $\begin{array}{l}\text { SP 2.2-1: Conduct Peer Reviews - Conduct } \\
\text { peer reviews on selected work products and } \\
\text { identify issues resulting from the peer }\end{array}$ & Peer review issues & K7 \\
\hline & & & & K9 \\
\hline & & $\begin{array}{l}\text { SP 2.3-2: Analyze Peer Review Data - } \\
\text { Analyze data about preparation, conduct, } \\
\text { and results of the peer reviews. }\end{array}$ & Peer review action items & K6 \\
\hline \multirow[b]{2}{*}{ Validation } & \multirow{2}{*}{$\begin{array}{l}\text { SG 1: Prepare for Validation - } \\
\text { Preparation for validation is } \\
\text { conducted. }\end{array}$} & \multirow{2}{*}{$\begin{array}{l}\text { SP 1.3-3: Establish Validation Procedures } \\
\text { and Criteria - Establish and maintain } \\
\text { procedures and criteria for validation. }\end{array}$} & Validation procedures & L1 \\
\hline & & & Validation criteria & $\mathrm{L} 2$ \\
\hline \multirow{6}{*}{$\begin{array}{l}\text { Configuration } \\
\text { Management }\end{array}$} & \multirow[t]{4}{*}{$\begin{array}{l}\text { SG 1: Establish Baselines - } \\
\text { Baselines of identified work } \\
\text { products are established. }\end{array}$} & $\begin{array}{l}\text { SP 1.1-1: Identify Configuration Items - } \\
\text { Identify the configuration items, } \\
\text { components, and related work products that } \\
\text { will be placed under configuration } \\
\text { management. }\end{array}$ & Identified configuration items & M1 \\
\hline & & $\begin{array}{l}\text { SP 1.2-1: Establish a Configuration } \\
\text { Management System - Establish and } \\
\text { maintain a configuration management and } \\
\text { change management system for controlling } \\
\text { work products. }\end{array}$ & $\begin{array}{l}\text { Configuration management system access } \\
\text { control procedures }\end{array}$ & M2 \\
\hline & & \multirow{2}{*}{$\begin{array}{l}\text { SP 1.3-1: Create or Release Baselines - } \\
\text { Create or release baselines for internal use } \\
\text { and for delivery to the customer. }\end{array}$} & \multirow[t]{2}{*}{ Baselines } & M4 \\
\hline & & & & N1 \\
\hline & \multirow{2}{*}{$\begin{array}{l}\text { SG 2: Track and Control } \\
\text { Changes - Changes to the work } \\
\text { products under configuration } \\
\text { management are tracked and } \\
\text { controlled. }\end{array}$} & \multirow{2}{*}{$\begin{array}{l}\text { SP 2.2-1: Control Configuration Items - } \\
\text { Control changes to the configuration items. }\end{array}$} & Revision history of configuration items & M3 \\
\hline & & & Archives of the baselines & M3 \\
\hline
\end{tabular}




\begin{tabular}{|l|l|l|l|c|}
\hline Process Area & \multicolumn{1}{|c|}{ Goal } & \multicolumn{1}{|c|}{ PRACTICE } & \multicolumn{1}{c|}{ WORK PRODUCT } \\
& $\begin{array}{l}\text { SG 3: Establish Integrity - } \\
\text { Integrity of baselines is } \\
\text { established and maintained. }\end{array}$ & $\begin{array}{l}\text { SP 3.2-1: Perform Configuration Audits - } \\
\text { Perform configuration audits to maintain } \\
\text { integrity of the configuration baselines. }\end{array}$ & Configuration audit results \\
\hline
\end{tabular}




\title{
Appendix B Questionnaire
}

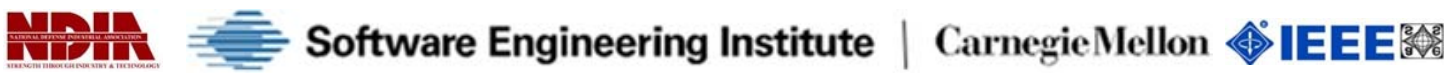

\section{The Effectiveness of Systems Engineering: A Survey}

The National Defense Industrial Association (NDIA), the IEEE Aerospace and Electronic Systems Society (IEEE-AESS) and the Software Engineering Institute (SEI) welcome you to your personalized questionnaire for our survey on "The Effectiveness of Systems Engineering." Our hope is that your participation will help your project and organization evaluate the effectiveness of their Systems Engineering practices relative to the successes and challenges reported by others throughout the industry.

Most of the information necessary to complete the questionnaire should be easily accessible or familiar to you or perhaps an informed designee. It should take about 30 to 45 minutes to complete the questionnaire. Please provide your best estimates if quantitative measurements are unavailable.

Please complete the questionnaire as candidly and completely as you possibly can. The results will be useful to you, us and others only to the extent that all survey participants do so. There is no need to hide weaknesses or embellish strengths. Remember that your response will be anonymous. Neither the SEI nor anyone else will know the person, project, or organization reflected in your response. The information, collected under promise of non disclosure by the SEI, will be held in strict confidence and will not be released in any manner. Survey results will be reported only in summary aggregate form. Individual responses will NOT be exposed. No attribution to people, projects, or organizations will be made.

A detailed summary report of the survey results will be prepared by the SEI. The report will provide a baseline against which you can compare the performance of your project and organization. As a reward for participating in this survey, the report will be initially released only to those who fully complete a survey questionnaire. The report will be not be publicly released until one year later.

Thank you once again for your help with this important activity. Please feel free to contact us at sei-analysis@sei.cmu.edu if you have any difficulty with the questionnaire. 


\section{CHARACTERIZATION OF THE PROJECT, PRODUCT, CONTRACT, AND ORGANIZATION}

\section{A. ABOUT THIS PROJECT}

The information gathered here and in the next few sections will be used by the survey analysts to categorize the participating projects and organizations in order to better understand the responses to subsequent questions about systems, Systems Engineering practices, and project performance.

The terms "Project", and "Program", are used interchangeably throughout this survey. Both refer to any temporary endeavor, having a defined beginning and end, undertaken to meet unique goals and objectives. Such endeavors are characterized by a defined set of objectives, a defined budget or cost estimate, and a defined schedule or period of performance. In crafting your response to this survey, it is important that you keep in mind a clear idea of the scope of the project for which you are responding. This will help to ensure that your responses regarding applied Systems Engineering activities and your responses regarding project performance relate to the same body of work.

Following are several statements that have been used to characterize various development projects. How well do the statements describe this project?

1. The project is challenging because there is no precedent for what is being done. (Please select one)

Strongly disagree

O Disagree

O Agree

O Strongly Agree

2. This project is challenging because significant constraints are placed on the quality attributes (e.g. reliability, scalability, security, supportability, etc.) of the product. (Please select one)

O Strongly disagree

O Disagree

O Agree

O Strongly Agree

3. The project is challenging because the size of the development effort is large. (Please select one)

O Strongly disagree

O Disagree

O Agree

O Strongly Agree

4. The project is challenging because the technology needed for this project is not mature or otherwise poses a high risk. (Please select one)

O Strongly disagree

O Disagree

O Agree

O Strongly Agree 
5. The project is challenging because there are extensive needs for interoperability with other systems (Please select one)

O Strongly disagree

O Disagree

O Agree

O Strongly Agree

6. The project is challenging because there are insufficient resources (e.g. people, funding) available to support the project. (Please select one)

O Strongly disagree

O Disagree

O Agree

O Strongly Agree

7. The project is challenging because there are insufficient skills and subject matter expertise available to support the project. (Please select one)

O Strongly disagree

O Disagree

O Agree

O Strongly Agree

8. The project is challenging for other reasons (Please describe briefly)

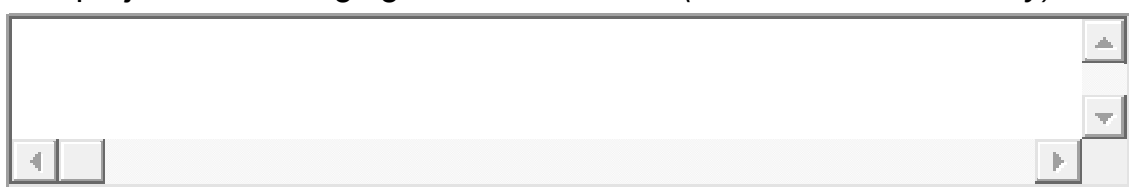

9. In the past, this project team has successfully completed projects of similar scope. (Please select one)

Strongly disagree

O Disagree

O Agree

O Strongly Agree

10. The requirements supplied by the customer for this project are well-defined (Please select one)

O Strongly disagree

O Disagree

O Agree

O Strongly Agree 
11. The requirements supplied by the customer for this project have not changed sufficiently to generate a significant impact on the project. (Please select one)

O Strongly disagree

O Disagree

O Agree

O Strongly Agree

12. What percentage of the customer technical requirements were marked "To Be Determined" or equivalent at time of contract award? (Please specify -- numbers only, without the percentage sign)

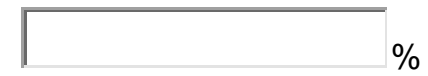

13. What percentage of the customer's technical requirements are currently marked "To Be Determined" or equivalent? (Please specify an approximate percentage -- without the percentage sign)

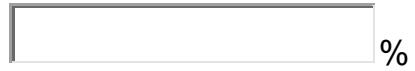

14. Do you separately budget and track Systems Engineering activities? (Please select one)

O Yes

O No

O Don't Know

15. Approximately what percentage of non-recurring engineering (NRE) does Systems Engineering represent? (Please specify an approximate percentage -- without the percentage sign)

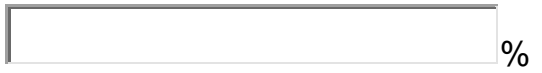

16. How are Systems Engineering activities estimated and budgeted? (Please check all that apply)

$\square \quad$ They are budgeted as a percentage of the total development cost

$\square \quad$ They are estimated using a parametric cost model (e.g., COSYSMO, SEER, SLIM, TruePlanning)

They are estimated on a task-by-task basis

$\square \quad$ Other (please describe)

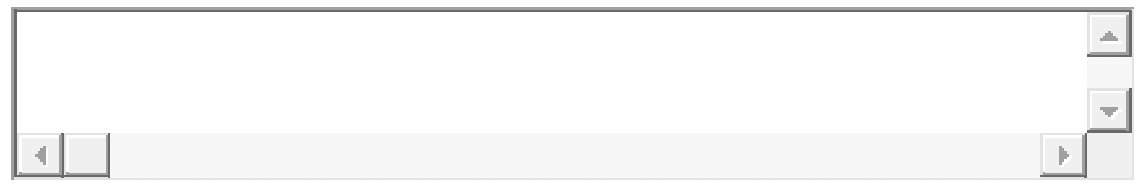


17. Which of the following best describes the ultimate end-user of this product? (Please select one)

O Government (USA) - defense related

O Government (USA) - not defense related

O Government (non-USA) - defense related

O Government (non-USA) - not defense related

O Industrial / Commercial

O Private Consumer

O Other (Please describe)

\begin{tabular}{|l|l|l}
\hline 1 &
\end{tabular}




\section{B. ABOUT THE CONTRACT}

1. What is the current total contract value of this project? (Please specify in US dollars -numbers only, without a dollar sign or commas)

$$
\text { US dollars (\$) }
$$

2. What was the initial contract value of this project? (Please specify in US dollars -- numbers only, without a dollar sign or commas)

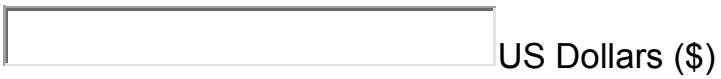

3. The change in contract value is primarily due to: (Please select one)

O Not applicable; contract value has not changed significantly

O Change in the technical scope of the project

O Unplanned increases in the cost of the project

O Other (please explain)

4. What is the current total planned duration of this project or contract? (Please specify in months - numbers only)

\section{Calendar months}

5. What was the initial total planned duration of this project or contract? (Please specify in months - numbers only)

\section{Calendar months}

6. The change in schedule is primarily due to: (Please select one)

O Not applicable; schedule has not changed significantly

O Change in the technical scope of the project

O Unplanned increases in the schedule for executing the project

O Customer driven increases in the schedule for executing the project

O Other (please explain)

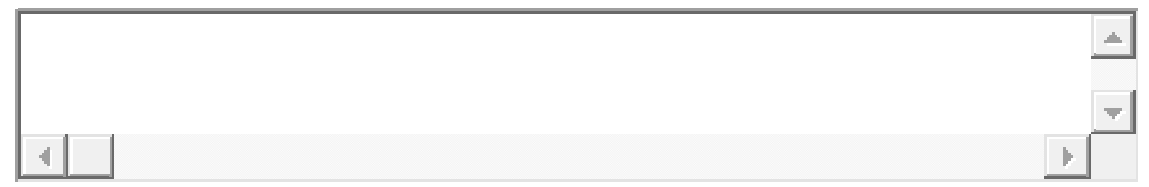

7. What was the initial total budget for this project?

US dollars (\$) 
8. What is the current total budget for this project?

US dollars (\$)

9. The change in budget is primarily due to: (Please select one)

O Not applicable; budget has not changed significantly

Change in the technical scope of the project

Unplanned increases in the cost of executing the project

O Customer driven increases in the cost of executing the project

O Other (please explain)

10. How many contract change orders have been received? (Please specify a number, approximate if necessary)

Change orders

11. This contract, includes provisions for additional payments based on meeting or exceeding cost, schedule, and/or performance targets (e.g., incentive fees, award fees). (Please select one)

Strongly disagree

O Disagree

O Agree

Strongly Agree

12. What is the current completion status of this project? (Please specify an approximate percentage -- without the percentage sign -- e.g., 60 for a project that is $60 \%$ complete)

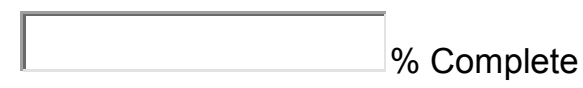

13. What type of contract(s) was awarded for this project? (Please select one)

$O$ This is a fixed-price contract - the total contract value is primarily determined by the initial contract. (e.g., FFP, FPIF, FFP-LOE).

$O$ This is a cost-reimbursable contract - the total contract value is primarily determined by my cost of executing the contract (e.g., CPFF, CPAF, CPIF).

O This contract does not fit the categories listed above. (Please describe) 


\section{ABOUT THE ORGANIZATION}

By "organization" we mean an administrative structure within which (possibly many) projects or similar work efforts are organized under common management and policies.

When thinking about your organization, please answer for the unit to which this project reports administratively, e.g., a site, division or department, not for a larger enterprise of which the organization to which you report may be a part.

Following are several statements that have been used to characterize various development organizations. How well do the statements describe this project's parent organization?

1. This organization has successfully completed projects similar in scope to this one in the past. (Please select one)

Strongly disagree

O Disagree

O Agree

O Strongly Agree

2. Within this organization ... (Please select one)

O Systems Engineering skills and responsibilities are contained in a separate department.

O Systems Engineering skills and responsibilities are distributed throughout other departments.

3. Which of these best describes your industry or service? (Please select one)

O Industrial Manufacturing and Services - Aerospace and Defense

O Industrial Manufacturing and Services - Electronic and Electrical Equipment

O Industrial Manufacturing and Services - Other (please specify)

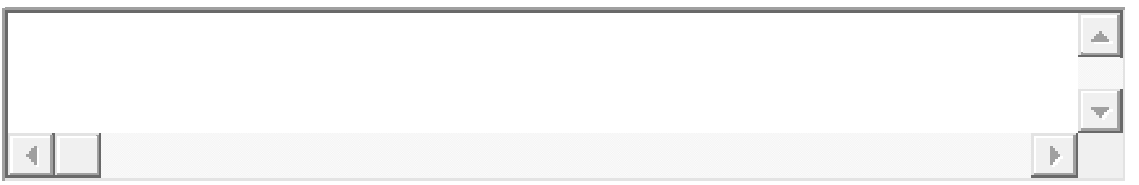

O Transportation

O Energy

O Communications

O Consumer Goods and Services

O Health Care

Other (please specify)

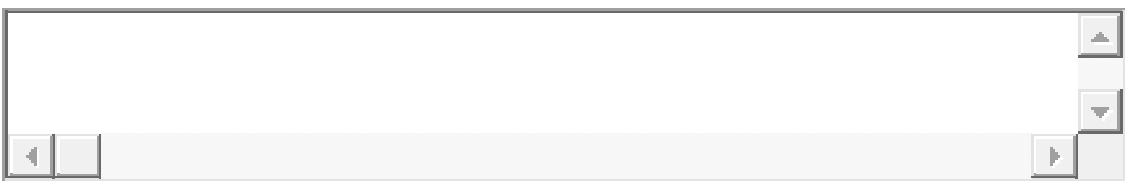

4. Please enter the country in which most of the design and development engineering will be/was performed. 
5. Is anything else particularly important in characterizing your project, product, contract, or organization within which it resides. (Please describe here)

\begin{tabular}{|l|l|l|}
\hline 1 & &
\end{tabular}




\section{SYSTEMS ENGINEERING CAPABILITIES ASSESSMENT}

This and the next few sections ask you about the Systems Engineering activities performed on this project. Most of the questions ask about the existence and quality of tangible work products. Note that the pertinent information often may be distributed throughout multiple documents or other work products; it need not necessarily be located in one particular place.

Following are several statements about work products and activities that are sometimes used for systems development. Please use the following definitions to describe their use on this project:

Strongly Disagree: The work product does not exist or is never used on this project.

Disagree: The work product is of insufficient quality or is not used regularly at appropriate occasions on this project.

Agree: The work product or practice is of good quality and it is used regularly on this project, although not necessarily as often as it could be.

Strongly Agree: The work product or practice is of exceptional quality and it is used at nearly all appropriate occasions on this project.

\section{PROJECT PLANNING}

1. This project utilizes/utilized a documented set of Systems Engineering processes for the planning and execution of the project. (Please select one)

O Strongly disagree

O Disagree

O Agree

S Strongly Agree

2. This project has/had an accurate and up-to-date Work Breakdown Structure (WBS) that included task descriptions and work package descriptions. (Please select one)

O Strongly disagree

O Disagree

O Agree

Strongly Agree

3. This project has/had an accurate and up-to-date Work Breakdown Structure (WBS) that was based upon the product structure. (Please select one)

$\begin{array}{ll}\text { O } & \text { Strongly disagree } \\ \text { O } & \text { Disagree } \\ \text { O } & \text { Agree } \\ \text { O } & \text { Strongly Agree }\end{array}$


4. This project has/had an accurate and up-to-date Work Breakdown Structure (WBS) that was developed with the active participation of those who perform the systems engineering activities. (Please select one)

O Strongly disagree

O Disagree

O Agree

Strongly Agree

5. This project has/had an accurate and up-to-date Work Breakdown Structure (WBS) that was developed and maintained with the active participation of all relevant stakeholders (e.g., developers, maintainers, testers, inspectors, etc.). (Please select one)

S Strongly disagree

O Disagree

O Agree

O Strongly Agree

6. This project's Technical Approach is complete, accurate and up-to-date. (Please select one)

Strongly disagree

O Disagree

O Agree

Strongly Agree

7. This project's Technical Approach is developed and maintained with the active participation of those who perform the Systems Engineering activities. (Please select one)

O Strongly disagree

O Disagree

O Agree

O Strongly Agree

8. This project's Technical Approach is developed and maintained with the active participation of all appropriate functional stakeholders. (Please select one)

Strongly disagree

O Disagree

O Agree

S Strongly Agree

9. This project has a top-level plan, such as an Integrated Master Plan (IMP), that is an event-driven plan (i.e., each accomplishment is tied to a key project event). (Please select one)

O Strongly disagree

O Disagree

O Agree

O Strongly Agree 
10. This project has a top-level plan, such as an Integrated Master Plan (IMP), that documents significant accomplishments with pass/fail accomplishment criteria for both business and technical elements of the project. (Please select one)

O Strongly disagree

O Disagree

O Agree

Strongly Agree

11. This project has a top-level plan, such as an Integrated Master Plan (IMP), that is consistent with the Work Breakdown Structure (WBS). (Please select one)

S Strongly disagree

O Disagree

O Agree

Strongly Agree

12. This project has an integrated event-based schedule that is structured as a networked, multi-layered schedule of project tasks required to complete the work effort. (Please select one)

O Strongly disagree

O Disagree

O Agree

S Strongly Agree

13. This project has an integrated event-based schedule that contains a compilation of key technical accomplishments (e.g., a Systems Engineering Master Schedule). (Please select one)

O Strongly disagree

O Disagree

O Agree

Strongly Agree

14. This project has an integrated event-based schedule that references measurable criteria (usually contained in the Integrated Master Plan) required for successful completion of key technical accomplishments. (Please select one)

O Strongly disagree

O Disagree

O Agree

Strongly Agree

15. This project has an integrated event-based schedule that is consistent with the Work Breakdown Structure (WBS). (Please select one)

O Strongly disagree

O Disagree

O Agree

O Strongly Agree 
16. This project has an integrated event-based schedule that identifies the critical path of the program schedule. (Please select one)

O Strongly disagree

O Disagree

O Agree

O Strongly Agree

17. This project has a plan or plans for the performance of technical reviews with defined entry and exit criteria throughout the life cycle of the project. (Please select one)

Strongly disagree

O Disagree

O Agree

O Strongly Agree

18. The Systems Engineering function actively participates in the development and updates of the project planning. (Please select one)

Strongly disagree

O Disagree

O Agree

O Strongly Agree

19. Those who perform Systems Engineering activities actively participate in tracking/reporting of task progress. (Please select one)

O Strongly disagree

O Disagree

O Agree

O Strongly Agree

20. The acquirer provided this project with a Systems Engineering Plan in a timely manner. (Please select one)

S Strongly disagree

O Disagree

O Agree

O Strongly Agree

21. This project has a plan or plans that include details of the management of the integrated technical effort across the project (e.g., a Systems Engineering Management Plan or a Systems Engineering Plan). (Please select one)

O Strongly disagree

O Disagree

O Agree

O Strongly Agree 
22. The Systems Engineering Management Plan (or equivalent) developed by the project team is aligned and consistent with the Systems Engineering Plan). (or equivalent) provided by the acquirer. (Please select one)

O Strongly disagree

O Disagree

O Agree

O Strongly Agree 


\section{E. INTEGRATED PRODUCT TEAMS}

1. This project makes effective use of integrated product teams (IPTs). (Please select one)

O Strongly disagree

O Disagree

O Agree

O Strongly Agree

2. My acquirer participates in my integrated product teams (IPTs) for this project. (Please select one)

O Strongly disagree

O Disagree

O Agree

O Strongly Agree

3. My suppliers actively participate in my integrated product teams (IPTs). (Please select one)

O Strongly disagree

Disagree

O Agree

O Strongly Agree

4. This project has an integrated product team (IPTs) with assigned responsibility for Systems Engineering. (Please select one)

S Strongly disagree

Disagree

O Agree

O Strongly Agree

5. This project has Systems Engineering representation on each integrated product teams (IPTs). (Please select one)

O Strongly disagree

O Disagree

O Agree

O Strongly Agree 


\section{F. RISK MANAGEMENT}

1. This project has a Risk Management process that creates and maintains an accurate and up-to-date list of risks affecting the project (e.g., risks to cost, risks to schedule, risks to performance) (Please select one)

O Strongly disagree

O Disagree

O Agree

Strongly Agree

2. This project has a Risk Management process that creates and maintains up-to-date documentation of risk mitigation plans and contingency plans for selected risks (Please select one)

Strongly disagree

Disagree

O Agree

O Strongly Agree

3. This project has a Risk Management process that monitors and reports the status of risk mitigation activities and resources. ((Please select one)

Strongly disagree

O Disagree

O Agree

O Strongly Agree

4. This project has a Risk Management process that assesses risk against achievement of an event-based schedule (Please select one)

Strongly disagree

O Disagree

O Agree

Strongly Agree

5. This project's Risk Management process is integrated with project decision-making. (Please select one)

Strongly disagree

O Disagree

O Agree

Strongly Agree

6. This project's Risk Management process is integrated with program cost and/or earned value management. (Please select one)

Strongly disagree

O Disagree

O Agree

O Strongly Agree 
7. This project's Risk Management process is integrated with program scheduling (e.g., risks are incorporated in the program master schedules). (Please select one)

O Strongly disagree

O Disagree

O Agree

O Strongly Agree

8. This project's Risk Management process integrates subcontract or supplier risk management processes. (Please select one)

$\begin{array}{ll}\mathrm{O} & \text { Strongly disagree } \\ \mathrm{O} & \text { Disagree } \\ \mathrm{O} & \text { Agree } \\ \mathrm{O} & \text { Strongly Agree }\end{array}$




\section{G. REQUIREMENTS DEVELOPMENT AND MANAGEMENT}

1. This project maintains an up-to-date and accurate listing of all requirements specified by the customer, to include regulatory, statutory, and certification requirements. (Please select one)

Strongly disagree

O Disagree

O Agree

Strongly Agree

2. This project maintains an up-to-date and accurate listing of all requirements derived from those specified by the customer. (Please select one)

Strongly disagree

O Disagree

O Agree

O Strongly Agree

3. This project maintains up-to-date and accurate documentation clearly reflecting the hierarchical allocation of both customer and derived requirements to each element (subsystem, component, etc.) of the system in the configuration baselines. (Please select one)

O Strongly disagree

O Disagree

O Agree

O Strongly Agree

4. This project documents and maintains accurate and up-to-date descriptions of operational concepts and their associated scenarios. (Please select one)

O Strongly disagree

O Disagree

O Agree

O Strongly Agree

5. This project documents and maintains accurate and up-to-date descriptions of use cases (or their equivalent). (Please select one)

O Strongly disagree

O Disagree

O Agree

O Strongly Agree

6. This project documents and maintains accurate and up-to-date descriptions of product installation, maintenance and support concepts. (Please select one)
S Strongly disagree
O Disagree
O Agree
O Strongly Agree 
7. This project has documented criteria for identifying authorized requirements providers to avoid requirements creep and volatility. (Please select one)

O Strongly disagree

O Disagree

O Agree

O Strongly Agree

8. This project has documented criteria (e.g., cost impact, schedule impact, authorization of source, contract scope, requirement quality) for evaluation and acceptance of requirements. (Please select one)

S Strongly disagree

O Disagree

O Agree

O Strongly Agree

9. The requirements for this project are approved in a formal and documented manner by relevant stakeholders. (Please select one)

O Strongly disagree

O Disagree

O Agree

O Strongly Agree

10. This project performs and documents requirements impact assessments for proposed requirements changes (Please select one)

O Strongly disagree

O Disagree

O Agree

O Strongly Agree

11. This project develops and documents project requirements based upon stakeholder needs, expectations, and constraints. (Please select one)

Strongly disagree

O Disagree

O Agree

O Strongly Agree

12. This project has an accurate and up-to-date requirements management system. (Please select one)

O Strongly disagree

O Disagree

O Agree

O Strongly Agree 
13. For this project, the requirements documents are managed under a configuration control process. (Please select one)

O Strongly disagree

O Disagree

O Agree

O Strongly Agree

14. For this project, the requirements documents are accessible to all relevant project staff. (Please select one)

Strongly disagree

O Disagree

O Agree

O Strongly Agree 


\section{H. TRADE STUDIES}

1. Stakeholders impacted by trade studies are involved in the development and performance of those trade studies. (Please select one)

O Strongly disagree

O Disagree

O Agree

O Strongly Agree

2. This project performs and documents trade studies between alternate solutions in a timely manner, and based upon definitive and documented selection criteria. (Please select one)

O Strongly disagree

O Disagree

O Agree

Strongly Agree

3. Documentation of trade studies is maintained in a defined repository and is accessible to all relevant project staff. (Please select one)
Strongly disagree
O Disagree
O Agree
O Strongly Agree 


\section{PRODUCT ARCHITECTURE}

1. This project maintains accurate and up-to-date descriptions (e.g. interface control documents, models, etc.) defining interfaces in detail. (Please select one)

O Strongly disagree

O Disagree

O Agree

O Strongly Agree

2. Interface definition descriptions are maintained in a designated location, under configuration management, and accessible to all who need them. (Please select one)

O Strongly disagree

O Disagree

O Agree

O Strongly Agree

3. For this project, the product high-level structure is documented, kept up to date, and managed under configuration control. (Please select one)

O Strongly disagree

O Disagree

O Agree

O Strongly Agree

4. For this project, the product high-level structure is documented using multiple views (e.g. functional views, module views, etc.). (Please select one)

S Strongly disagree

O Disagree

O Agree

O Strongly Agree

5. For this project, the product high-level structure is accessible to all relevant project personnel. (Please select one)

O Strongly disagree

O Disagree

O Agree

O Strongly Agree 


\section{J. PRODUCT INTEGRATION}

1. This project has accurate and up-to-date documents defining its product integration process, plans, criteria, etc. throughout the life cycle. (Please select one)

O Strongly disagree

O Disagree

O Agree

O Strongly Agree 


\section{K. VERIFICATION}

1. This project has accurate and up-to-date documents defining the procedures used for the test and verification of systems and system elements. (Please select one)

Strongly disagree

O Disagree

O Agree

Strongly Agree

2. This project has accurate and up-to-date documents defining acceptance criteria used for the verification of systems and system elements. (Please select one)

S Strongly disagree

O Disagree

O Agree

O Strongly Agree

3. This project has a documented and practiced review (e.g. peer reviews, design reviews, etc.) process for work products that defines entry and exit criteria. (Please select one)

O Strongly disagree

O Disagree

O Agree

O Strongly Agree

4. This project has a documented and practiced review (e.g. peer reviews, design reviews, etc.) process that includes training the reviewers to conduct reviews. (Please select one)

Strongly disagree

O Disagree

O Agree

O Strongly Agree

5. This project has a documented and practiced review (e.g. peer reviews, design reviews, etc.) process that defines criteria for the selection of work products (e.g., requirements documents, test plans, system design documents, etc.) for review. (Please select one)

Strongly disagree

O Disagree

O Agree

Strongly Agree

6. This project has a documented and practiced review (e.g. peer reviews, design reviews, etc.) process that tracks action items to closure. (Please select one)

O Strongly disagree

Disagree

O Agree

O Strongly Agree 
7. This project has a documented and practiced review (e.g. peer reviews, design reviews, etc.) process that addresses identified risks and risk mitigation activities during reviews. (Please select one)

S Strongly disagree

O Disagree

O Agree

O Strongly Agree

8. This project has a documented and practiced review (e.g. peer reviews, design reviews, etc.) process that examines completeness of configuration baselines. (Please select one)

O Strongly disagree

O Disagree

O Agree

O Strongly Agree

9. This project conducts non-advocate reviews (e.g. reviews by qualified personnel with no connection to or stake in the project) and documents results, issues, action items, risks, and risk mitigations (Please select one)

O Strongly disagree

O Disagree

O Agree

O Strongly Agree 


\section{VALIDATION}

1. This project has accurate and up-to-date documents defining the procedures used for the validation of systems and system elements. (Please select one)

O Strongly disagree

O Disagree

O Agree

S Strongly Agree

2. This project has accurate and up-to-date documents defining acceptance criteria used for the validation of systems and system elements. (Please select one)

Strongly disagree

O Disagree

O Agree

O Strongly Agree 


\section{CONFIGURATION MANAGEMENT}

1. This project maintains a listing of items managed under configuration control. (Please select one)

O Strongly disagree

O Disagree

O Agree

O Strongly Agree

2. This project has a configuration management system that charters a Change Control Board to disposition change requests. (Please select one)

S Strongly disagree

O Disagree

O Agree

O Strongly Agree

3. This project maintains records of requested and implemented changes to configurationmanaged items. (Please select one)

O Strongly disagree

O Disagree

O Agree

O Strongly Agree

4. This project creates and manages configuration baselines (e.g., functional, allocated, product). (Please select one)

S Strongly disagree

O Disagree

O Agree

O Strongly Agree 


\section{N. PROJECT PERFORMANCE: EARNED VALUE MANAGEMENT}

1. This project creates and manages cost and schedule baselines. (Please select one)

O Strongly disagree

O Disagree

O Agree

O Strongly Agree

2. Earned Value Management System (EVMS) data are available to decision makers in a timely manner (i.e. current within 2 weeks). (Please select one)

O Strongly disagree

O Disagree

O Agree

O Strongly Agree

3. The requirement to track and report Earned Value Management System (EVMS) data is levied upon the project's suppliers. (Please select one)

O Strongly disagree

Disagree

O Agree

O Strongly Agree

4. Variance thresholds for the Cost Performance Index (CPI) and Schedule Performance Index (SPI) are defined, documented, and used to determine when corrective action is needed. (Please select one)

O Strongly disagree

O Disagree

O Agree

O Strongly Agree

5. The Earned Value Management System (EVMS) is linked to the technical effort through the Work Breakdown Structure (WBS), the Integrated Master Plan (IMP), (or equivalent), and the Integrated Master Schedule (IMS) (or equivalent). (Please select one)

Strongly disagree

O Disagree

O Agree

O Strongly Agree 
6. When is the Earned Value Management System (EVMS) baseline updated? (Please select as many as apply)

Only at contract initiation

Whenever a contract change order or renewal is received

Incrementally in rolling wave planning

Whenever the project is reprogrammed due to a pre-determined cost or schedule variance

At periodic intervals

Other (Please describe briefly)

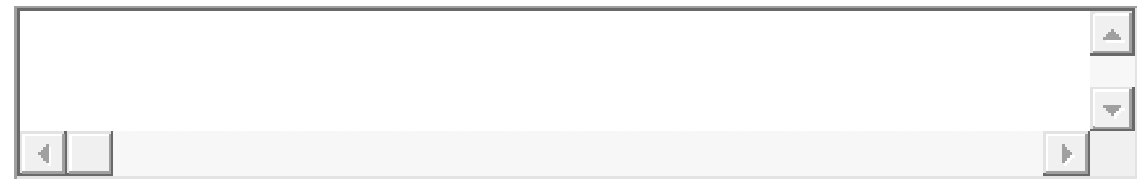

7. What is the projected cost variance at completion for the current contract baseline? (Please specify an amount in US Dollars (\$), using + signs for any overruns and - signs for any underruns)

\section{US Dollars (\$)}

8. What is the projected schedule variance at completion for the current contract baseline? (Please specify in months, using + signs for any late delivery and - signs for early delivery)

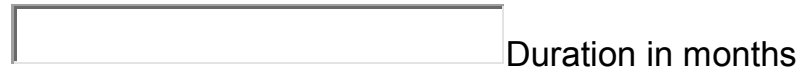

9. What is the current cumulative (or final) EVMS Cost Performance Index (CPI) for this project? (Please specify a number)

10. What is the current cumulative (or final) EVMS Schedule Performance Index (SPI) for this project? (Please specify a number) 


\section{O. OTHER PERFORMANCE INDICATORS}

1. What percentage of available Award Fees have been received by this project in the current period of performance? (Please specify an approximate percentage -- without the percentage sign. Enter "n/a" if this contract does not include Award Fees.)

2. What percentage of available Award Fees have been received by this project to date (i.e., in all periods)? (Please specify an approximate percentage -- without the percentage sign. Enter "n/a" if this contract does not include Award Fees.)

3. Requirements are being satisfied and remain on track to be satisfied in the product releases as originally planned; they are not being deleted or deferred to later releases. (Please select one)

Strongly disagree

O Disagree

O Agree

O Strongly Agree

4. Overall, this project is performing per the schedule established in the current Integrated Master Schedule (IMS) approved by the acquirer. (Please select one)

Strongly disagree

O Disagree

O Agree

O Strongly Agree

5. The schedule of this project's critical path, when compared to the current Integrated Master Schedule (IMS) approved by the acquirer is ... (Please select one)

O Greater than 6 months late

O 3 to 6 months late

O 1 to 3 months late

Within plus or minus 1 month

O 1 to 3 months early

O 3 to 6 months early

6. This project collects and tracks (or will collect and track) reports of problems from fielded items. (Please select one)

O Strongly disagree

O Disagree

O Agree

O Strongly Agree 
7. This project conducts (or will conduct) engineering assessments of all field trouble reports. (Please select one)

O Strongly disagree

O Disagree

O Agree

O Strongly Agree

8. I believe that my customer is satisfied with this project's performance with respect to the schedule. (Please select one)

Strongly disagree

O Disagree

O Agree

O Strongly Agree

9. I believe that my customer is satisfied with this project's performance with respect to cost. (Please select one)

O Strongly disagree

O Disagree

O Agree

Strongly Agree

10. I believe that my customer is satisfied with this project's performance with respect to satisfaction of requirements. (Please select one)

Strongly disagree

O Disagree

O Agree

O Strongly Agree

11. What performance indicators (beyond cost and schedule) have been particularly useful for managing your project? (Please describe here)

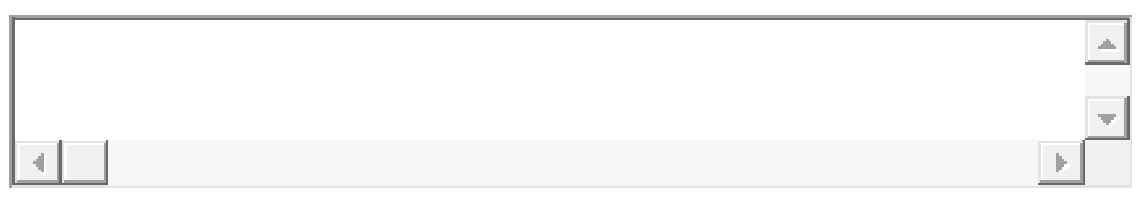

12. What other kinds of performance related information would have been helpful for your project or program, but was unavailable? (Please describe here)

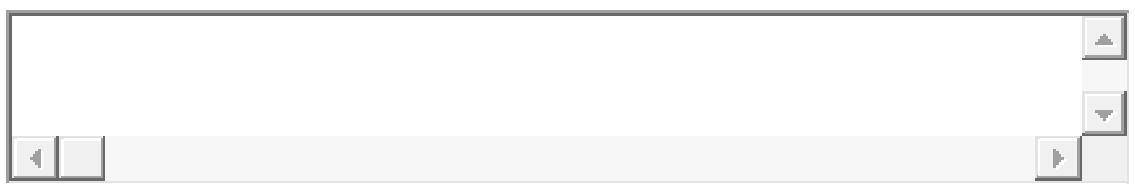


13. What indicators do you use in your project or organization to determine Systems Engineering effectiveness? (Please describe here)

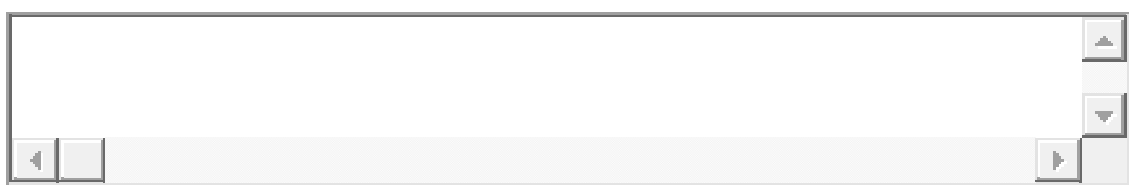

14. What indicators of Systems Engineering effectiveness are regularly reviewed across projects by higher level management? (Please describe here)

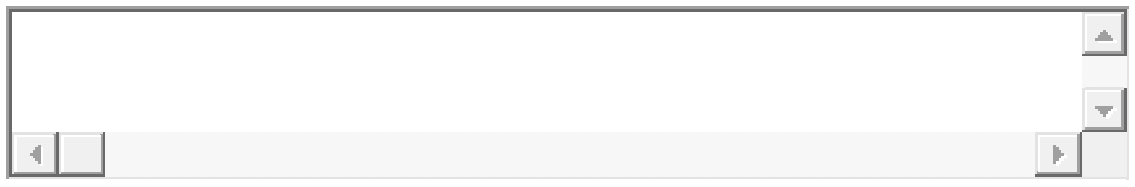




\section{P. IN CONCLUSION}

1. Is there anything else that you would like to tell us about your project or this survey? (Please describe here)

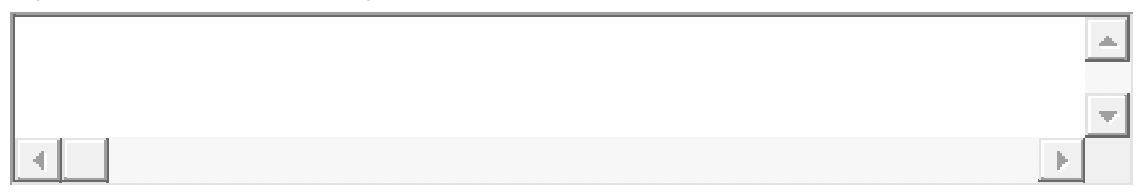

Thank you very much for your time and effort!

Please be sure to use the Save button. That will take you to the final page where you may SUBMIT your response.

Copyright 2012, Carnegie Mellon University. 


\title{
Appendix C Solicitation of an Invitation to Respondents
}

\author{
Sample solicitation email
}

\section{Business Case for Systems Engineering}

From: Business Case for Systems Engineering

Sent: Wednesday, October 26, 2011 11:17 AM

To: <member's email address>

Subject: NDIA / IEEE Systems Engineering Effectiveness Study - Participation inquiry AccessDataCollection:\{<Access ID Code $>$ \}

NOTE: This study is being performed by the National Defense Industrial Association (NDIA) and the IEEE Aerospace and Electronic Systems Society (IEEE-AESS). If you are a member of more than one of these organizations, you may receive multiple copies of this email. We apologize for any inconvenience.

\section{Dear Colleague}

The Systems Engineering Effectiveness Committee - a joint committee of the National Defense Industrial Association (NDIA). the IEEE Aerospace and Electronic Systems Society (IEEE-AESS), and the Software Engineering Institute (SEI) is conducting a study of Systems Engineering Effectiveness to build a stronger "BUSINESS CASED FOR SYSTEMS ENGINEERING" (BCSE). Our intent is to provide quantitative information on the impact of SE activities on project performance. This information will aid organizations and individuals utilizing SE to focus their efforts on activities that produce measureable benefits. We would like your organization to participate in this study by completing a CONFIDENTIAL and ANONYMOUS survey.

In 2006, the SE Effectiveness Committee of the NDIA Systems Engineering Division conducted the Systems Engineering Effectiveness Study (SEES). Using survey techniques, this study identified statistical relationships between the application of specific SE practices to development projects and the performance of those projects, as measured by satisfaction of budget, schedule, and requirements. The results clearly demonstrated the benefits of SE, showing that projects applying the least SE performed measurably worse than projects applying the most SE. The study also identified relationships between specific SE practices (e.g., requirements development, trade study performance, architecture development) and project performance. For more information about the SEES, you may download several reports, papers, and presentations from the BCSE web site at wnw.sei.cmu.edu/go/bcsel.

Based on the success of the prior study, in 2010 the NDIA embarked on the BCSE project to update and enhance it by gathering data from a larger and more diverse population. The BCSE Project Team is comprised of members of defense, industry, and academia working through the NDIA, the IEEE-AESS, and the SEI. This project has been coordinated with the Office of the Secretary of Defense through the Deputy Assistant Secretary of Defense, Systems Engineering (DASD(SE)). This study will survey individual product-producing projects to assess the 1) characteristics of the project, 2) the SE activities applied to the project, and 3 ) the resulting project performance. Completion of the survey will require approximately 30 minutes for each project. Like the prior survey, data security and confidentiality will be paramount. ALL DATA WILL BE COLLCTED ANONYMOUSLY. No information identifying the project, organization, or respondent will be requested. The Software Engineering Institute, a DoD-sponsored FFRDC, will do the data collection and analysis. Only they will see your responses, and only statistical summaries of the aggregated data, untraceable to any project, organization, or person, will be released.

Similar to the original study, those who participate will be rewarded with early access to more detailed levels of aggregated data and analysis for one year prior to these results being published for everyone. This will allow you to assess your organization/project results relative to the rest on the industry. showing your strengths and areas of weaknesses that should be addressed.

\section{OUR REQUEST TO YOU:}

By this inquiry, we wish to reach out to relevant organizations to invite them to participate in this study. If your organization executes projects that produce delivered products, we ask you to participate in this study. By providing the data requested below, you will enable us to contact the appropriate decision makers within your organization to 1) explain this important study. 2) discuss the value of this study to your organization, and 3) request the participation of your organization in the study. 
Please take just a minute to answer the following six questions that will assist us in reaching out to potential respondents for the survey. Based upon the information that you provide, we will contact the designated person to discuss this study. If they

authorize your organization to participate, an invitation will be sent to your organization, enabling the submission of

ANONYMOUS AND CONFIDENTIAL responses to the survey.

If you have any questions, please feel to contact the undersigned.

Thank you.

William F. Lyons

IEEE AESS Board of Governors

253-657-5984

william.f.hons/abseing.com.

Alan R. Brown

NDIA SE Effectiveness Committee Chair

314-234-2337

alan.r.brown2@aboeing.com

Joseph P. Elm

Software Engineering Institute

412-268-9132

ielmareicmuedu

Robert C. Rassa

NDIA SE Division Chair

$310-985-4962$

RCRassa@Qraytheon.com

Note: Type only in the areas designated for data entry. Your reply will be automatically processed, so it is important that the form or the message is not altered in any other way.

\section{NDIA / IEEE Systems Engineering Effectiveness Study - Participation inquiry}

Type only in the areas deslanated for data entry. Your reply wil be automatcally processed. Therefore, it is important that the form or the message is not aliered in any other way. For more irformation about niling out this form see the folowing

Email_Address: $\quad$ member's email address;

Type any combination of numbers and letters up to 255 characters.

Member_Name: $\quad$-member's name

Type any combinaton of numbers and letters up to 255 characters.

What is the name of your

organization: 


\section{Type any combinaton of numbers and letters up to 255 characters.}

Segment/Division of your organization (if applicable)

Type any combinaton of numbers and lefters up to 255 characters.

Name (of the individual who should be approached):

Title (of the individual who should be approached):

Type any combinaton of numbers and letters up to 255 characters.

Done? Click Send to submit your information. 


\section{Business Case for Systems Engineering}

From: Business Case for Systems Engineering

Sent: Tuesdary, November 22, 2011 11:49 AM

To: <invitee's email address>

Subject: SE Effectiveness Study
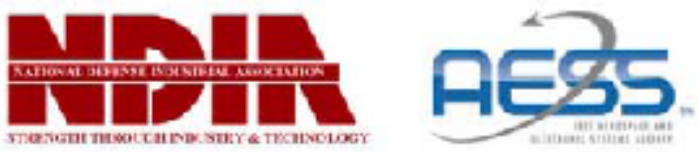

Software Engineering Institute | Carnegie Mellon

FROM:

The Systems Engineering Effectiveness Committee

TO:

<invitee name>

<invitee organization>

Welcome to the Systems Engineering Effectiveness Study, a component of the "Business Case for Systems Engineering" (BCSE) project. Through inquiries to the memberships of the National Defense Industrial Association (NDIA), the Institute of Electrical and Electronic Engineers Aerospace and Electronic Systems Society (IEEEIAESS), and the International Council on Systems Engineering (INCOSE), you have been nominated as a potential respondent to the SE Effectiveness Survey.

The BCSE Project Team is comprised of members of defense, industry, and academia working through the NDIA the IEEEIAESS, and the Software Engineering Institute (SEI) of Carnegie Mellon University. INCOSE is also promoting this project to its members. This project has been coordinated with the Office of the Secretary of Defense through the Deputy Assistant Secretary of Defense, Systems Engineering (DASD(SE)).

This study is an extension of the 2006 NDIA Systems Engineering Division conducted the Systems Engineering Effectiveness Study (SEES), which was successful at identifying statistical relationships between the application of specific SE practices to development projects and the performance of those projects through anonymous and confidential survey techniques. The results of this prior study clearly demonstrated the benefits of SE, showing that:

- in the set of projects applying the least SE, only $15 \%$ delivered the highest levels of performance

- in the set of projects applying the most SE, $56 \%$ delivered the highest levels of performance. 


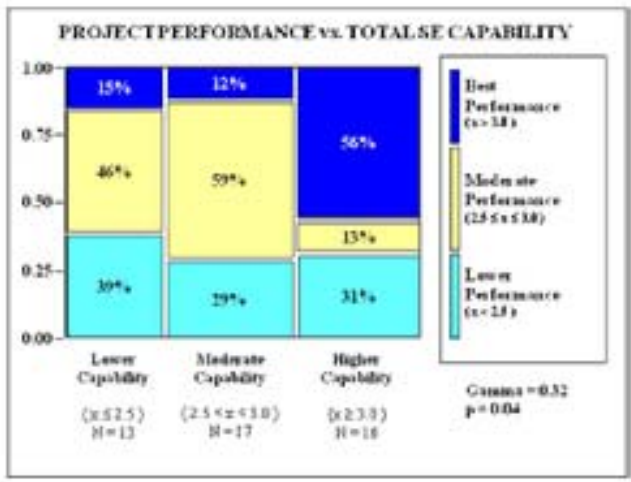

The study also identified relationships between specific SE practices (e.g., requirements development and management, trade study performance, architecture development) and project performance. For more information about the SEES, you may download several reports, papers, and presentations from the BCSE web site at www.sei.cmu.edu/go/bcsel.

We are asking for your participation in extension and expansion of the previous study

This new study will survey individual projects within organizations like yours to assess

- key characteristics of the project,

- the SE activities applied to the project, and

- the resulting project performance.

Like the previous study, data security and confidentiality are paramount. All data will be collected anonymously. No information identifying the project, organization, or respondent will be requested or collected. The Software Engineering Institute, a DoD-sponsored FFRDC, will do the data collection and analysis. Only they will see your responses, and only aggregated data, untraceable to any project, organization, or person, will be released. Similar to the original study, those who participate will be rewarded with early access to more detailed levels of aggregated data and analysis for one year prior to these results being published for everyone. This will allow you to assess your organization/project results relative to the rest on the industry, showing your strengths and areas of weaknesses that should be addressed.

We ask that you randomly select one or more product-producing projects within your organization and complete a survey for each of them. Please do not attempt to select the only the best (or only the worst performing projects; we seek a randomized sample. Projects need not be totally completed, but should be substantially ( $>50 \%$ )

complete. Completion of the survey will require approximately 30 minutes for each project. In preparation for completing the survey, it will be helpful to assemble the following data regarding your project

- Initial and current contract value

- Initial and current project budget

- Initial and current project schedule

- Earned value data (SPI and CPI)

Once you have assembled this data, please go to

\section{https://feedback.sei.cmu.edu/2011 SE Eff} ectiveness Portal.asp

to access a copy of the survey questionnaire. At this site, you will receive a randomized account name that will enable you to submit an anonymous response. 
Thank you for your participation in this study. Your efforts will contribute to the creation of a business case that will encourage the application of sound SE practices to produce better products more efficiently and effectively.

If you have any questions, please feel to contact the undersigned.

Thank you.

William F. Lyons Alan R. Brown Joseph P. Elm Robert C. Rassa
IEEE AESS Board of Governors NDIA SE Effectiveness Committee Chair Software Engineering Institute NDIA SE Division Chair
253-657-5984

314-234-2337

412-268-9132

$310-985-4962$ william.f.lvons:@boeing.com

alan.r.brown2@boeing.com

ielm@sei.cmu.edu

RCRassa@raytheon.com 


\section{Appendix D Details of the Analysis Process}

\section{Project Performance (Perf)}

This section provides a summary of the process used to develop Perf, PerfC, PerfD, and PerfS. A detailed discussion of this process is provided in The Business Case for Systems Engineering Study: Assessing Project Performance from Sparse Data [Elm 2012].

Project performance (Perf) is assessed using the survey questions shown in Table 12.

\section{Table 12: Project Performance (Perf) Assessment}

\begin{tabular}{|c|c|c|}
\hline Q\# & Question & Response range \\
\hline B1. & What is the current total contract value of this project? & U.S.\$ \\
\hline B2. & What was the initial contract value of this project? & U.S.\$ \\
\hline B3. & The change in contract value is primarily due to & $\begin{array}{l}\text { 1=N/A; No change } \\
2=\text { Change in tech. scope } \\
3=\text { Unplanned increases } \\
\text { 4=Other }\end{array}$ \\
\hline B7. & What was the initial total budget for this project? & U.S.\$ \\
\hline B8. & What is the current total budget for this project? & U.S.\$ \\
\hline N7 & $\begin{array}{l}\text { What is the projected cost variance at completion for the } \\
\text { current contract baseline? }\end{array}$ & U.S.\$ \\
\hline B9. & The change in budget is primarily due to & $\begin{array}{l}1=\mathrm{N} / \mathrm{A} \text {; No change } \\
2=\text { Change in tech. scope } \\
3=\text { Unplanned increases } \\
4=\text { Customer driven increases } \\
5=\text { Other }\end{array}$ \\
\hline N6 & When is the EVMS baseline updated? & $\begin{array}{l}\text { - Only at contract initiation } \\
\text { - Whenever a contract change order or } \\
\text { renewal is received } \\
\text { - Incrementally in rolling wave planning } \\
\text { - Whenever the project is reprogrammed } \\
\text { due to a pre-determined cost or } \\
\text { schedule variance } \\
\text { - At periodic intervals } \\
\text { - Other }\end{array}$ \\
\hline N9 & $\begin{array}{l}\text { What is the current cumulative (or final) EVMS CPI for } \\
\text { this project? }\end{array}$ & $\mathrm{n}$ \\
\hline O9 & $\begin{array}{l}\text { I believe that my customer is satisfied with this project's } \\
\text { performance with respect to cost. }\end{array}$ & $\begin{array}{l}1=\text { Strongly disagree } \\
2=\text { Disagree } \\
3=\text { Agree } \\
4=\text { Strongly Agree }\end{array}$ \\
\hline B4. & $\begin{array}{l}\text { What is the current total planned duration of this project } \\
\text { or contract? }\end{array}$ & Months \\
\hline B5. & $\begin{array}{l}\text { What was the initial total planned duration of this } \\
\text { project or contract? }\end{array}$ & Months \\
\hline
\end{tabular}




\begin{tabular}{|c|c|c|}
\hline Q\# & Question & Response range \\
\hline B6. & The change in schedule is primarily due to & $\begin{array}{l}1=\mathrm{N} / \mathrm{A} ; \text { No change } \\
2=\text { Change in tech. scope } \\
3=\text { Unplanned increases } \\
4=\text { Cust. driven increases } \\
5=\text { Other }\end{array}$ \\
\hline N8 & $\begin{array}{l}\text { What is the projected schedule variance at completion } \\
\text { for the current contract baseline? }\end{array}$ & Months \\
\hline N10 & $\begin{array}{l}\text { What is the current cumulative (or final) EVMS SPI for } \\
\text { this project? }\end{array}$ & $\mathrm{n}$ \\
\hline $\mathrm{O} 4$ & $\begin{array}{l}\text { Overall, this project is performing per the schedule } \\
\text { established in the current IMS approved by the acquirer. }\end{array}$ & $\begin{array}{l}1=\text { Strongly disagree } \\
2=\text { Disagree } \\
3=\text { Agree } \\
4=\text { Strongly Agree }\end{array}$ \\
\hline O5 & $\begin{array}{l}\text { The schedule of this project's critical path, when } \\
\text { compared to the current IMS approved by the acquirer is }\end{array}$ & $\begin{array}{l}>6 \text { months late } \\
3 \text { - } 6 \text { months late } \\
1-3 \text { months late } \\
\text { Within }+/-1 \text { month } \\
1 \text { - } 3 \text { months early } \\
3 \text { - } 6 \text { months early }\end{array}$ \\
\hline O8 & $\begin{array}{l}\text { I believe that my customer is satisfied with this project's } \\
\text { performance with respect to the schedule. }\end{array}$ & $\begin{array}{l}1=\text { Strongly disagree } \\
2=\text { Disagree } \\
3=\text { Agree } \\
4=\text { Strongly Agree }\end{array}$ \\
\hline $\mathrm{O} 3$ & $\begin{array}{l}\text { Requirements are being satisfied and remain on track to } \\
\text { be satisfied in the product releases as originally planned; } \\
\text { they are not being deleted or deferred to later releases. }\end{array}$ & $\begin{array}{l}1=\text { Strongly disagree } \\
2=\text { Disagree } \\
3=\text { Agree } \\
4=\text { Strongly Agree }\end{array}$ \\
\hline $\mathrm{O} 10$ & $\begin{array}{l}\text { I believe that my customer is satisfied with this project's } \\
\text { performance with respect to satisfaction of requirements. }\end{array}$ & $\begin{array}{l}1=\text { Strongly disagree } \\
2=\text { Disagree } \\
3=\text { Agree } \\
4=\text { Strongly Agree }\end{array}$ \\
\hline
\end{tabular}

Project performance (Perf) can be measured and decomposed into
Cost performance
(PerfC)
Schedule performance
(PerfS )
Technical performance
(PerfT )

Each of these factors is calculated independently. The three factors are then combined into a weighted summed index to create a measure of project performance (Perf) scaled from 1 (very poor performance) to 5 (very good performance). ${ }^{13}$

13 A description of the calculation of weighted summed indices can be found in Section 4.1 on page 10 . 


\section{Project Cost Performance (PerfC)}

PerfC is assessed based on evaluations of three factors:

1. estimated cost at completion (ECAC) vs. project budget

2. EVMS CPI

3. perception of customer satisfaction with the cost performance of the project

Executing a project within its budget is generally considered to be an element of a successful project. Thus, comparing the ECAC to the project budget is a reasonable measure of project performance. However, the following modifying factors must be considered.

In some organizations, the budget may be changed to reflect significant cost overruns or project replanning. In these cases, comparison of the ECAC with budget is no longer a valid measure of project performance. To remedy this defect, we derived the project performance assessment as

$$
\text { Cost ratio }=\frac{E C A C}{\text { initial project budget }}
$$

Sometimes the customer issues a contract change order that modifies the project scope, contract value (CV), and/or project schedule. In response to such a change, most organizations will amend the budget to reflect the change in the expected project cost. In these cases, comparison of the ECAC and initial budget is no longer a valid measure of project performance. Comparison of the ECAC with the revised budget could be a valid measure, unless the budget revision reflects incurred or anticipated cost overruns as previously noted. To tease apart these issues, we derive the project performance assessment from

$$
\text { Cost ratio }=\frac{E C A C / \text { initial budget }}{\text { revised } C V / \text { initial } C V}
$$

The cost ratio is then assessed as shown in Table 13.

Table 13: Budget-Based Cost Performance Assessment

\begin{tabular}{|cc|}
\hline $\begin{array}{c}\text { Cost Performance Assessment } \\
\text { (Cost_Perf2) }\end{array}$ & Criteria \\
\hline 1 & $($ Cost Ratio $) \geq 1.1$ \\
\hline 2 & $1.1>($ Cost Ratio $) \geq 1.05$ \\
\hline 3 & $1.05>($ Cost Ratio $) \geq 0.95$ \\
\hline 4 & $0.95>($ Cost Ratio $) \geq 0.90$ \\
\hline 5 & $0.90>($ Cost Ratio $)$ \\
\hline
\end{tabular}

An assessment of EVMS data is also incorporated into the measure of the project's cost performance. CPI appears to be an ideal measure of project performance, but again, there are some modifying factors to consider.

EVMS is calculated from variances from a baseline; therefore, it is highly sensitive to revisions in those baselines. The questionnaire asks when the EVMS baseline is updated. The response, as shown in Table 14, defines how CPI data are used. 
Table 14: CPI Data Disposition

\begin{tabular}{|c|c|c|}
\hline The EVMS Baseline is updated & Other conditions & Disposition \\
\hline \multirow[t]{2}{*}{ Only at contract initiation } & Project scope has not changed & Use CPI, SPI \\
\hline & Project scope has changed & Discard CPI, SPI \\
\hline \multirow[t]{2}{*}{$\begin{array}{l}\text { Whenever a contract change order } \\
\text { or renewal is received }\end{array}$} & $\begin{array}{l}\text { Change order reflects change in } \\
\text { scope }\end{array}$ & Use CPI, SPI \\
\hline & $\begin{array}{l}\text { Change order reflects only } \\
\text { recognition of cost overrun }\end{array}$ & Discard CPI, SPI \\
\hline $\begin{array}{l}\text { Incrementally in rolling wave } \\
\text { planning }\end{array}$ & & Discard CPI, SPI \\
\hline $\begin{array}{l}\text { Whenever the project is } \\
\text { reprogrammed due to a pre- } \\
\text { determined cost or schedule } \\
\text { variance }\end{array}$ & & Discard CPI, SPI \\
\hline At periodic intervals & & Discard CPI, SPI \\
\hline Other & & Per analyst evaluation \\
\hline
\end{tabular}

If CPI data are used, they are assessed as shown in Table 15.

Table 15: CPI-Based Cost Performance

\begin{tabular}{|c|c|}
\hline $\begin{array}{c}\text { Cost Performance Assessment } \\
\text { (Cost_Perf 1) }\end{array}$ & Criteria \\
\hline 1 & $0.90>(C P I)$ \\
\hline 2 & $0.95>(C P I) \geq 0.90$ \\
\hline 3 & $1.05>(C P I) \geq 0.95$ \\
\hline 4 & $1.1>(C P I) \geq 1.05$ \\
\hline 5 & $(C P I) \geq 1.1$ \\
\hline
\end{tabular}

The final factor evaluated for assessment of project cost performance is the perception of the customer's satisfaction with the cost performance of the project, assessed as shown in Table 16.

Table 16: Customer-Satisfaction-Based Cost Performance Assessment

\begin{tabular}{|c|l|}
\hline $\begin{array}{c}\text { Cost Performance Assessment } \\
\text { (Cost_Perf 3) }\end{array}$ & $\begin{array}{l}\text { I believe that my customer is satisfied with this project's } \\
\text { performance with respect to cost } \\
1.00\end{array}$ \\
\hline 2.33 & Strongly disagree \\
\hline 3.67 & Disagree \\
\hline 5.00 & Agree \\
\hline
\end{tabular}

These three assessment factors are combined into a weighted summed index, PerfC, to provide an assessment of project cost performance scaled from 1 (very poor performance) to 5 (very good performance). 


\section{Project Schedule Performance (PerfS)}

PerfS is assessed based on evaluations of four factors:

1. the difference between the initial completion date and the current estimated completion date

2. the Schedule Performance Index (SPI) from an Earned Value Management System (EVMS)

3. variance from the approved integrated master schedule (IMS)

4. the respondent's impression of the degree of customer satisfaction with the project cost

In comparing the initial and current estimated completion dates, we encountered the same challenge seen with the cost data discussed in the Project Cost Performance (PerfC) section on page 133 - changes in the scope of the project. For cases where the scope of the project has remained stable, we calculated a schedule performance assessment as

$$
\text { Schedule ratio }=\frac{\text { Sched_current }+E C D \_v a r i a n c e}{\text { Sched_initial }}
$$

For projects with a scope modified by a contract change order, we used the change in contract value (CV) as a correction factor for our schedule performance assessment:

$$
\text { Schedule ratio }=\frac{\text { Scched_current }+E C D \_ \text {variance }}{\text { Sched_initial }} \div \frac{C V_{-} \text {current }}{C V \_ \text {initial }}
$$

The schedule ratio is then assessed as shown in Table 17.

Table 17: Project-Duration-Based Schedule Performance Assessment

\begin{tabular}{|cc|}
\hline $\begin{array}{c}\text { Schedule Performance Assessment } \\
\text { (Sched_Perf2a) }\end{array}$ & Criteria \\
\hline 1 & $($ Schedule Ratio $) \geq 1.1$ \\
\hline 2 & $1.1>($ Schedule Ratio $) \geq 1.05$ \\
\hline 3 & $1.05>($ Schedule Ratio $) \geq 0.95$ \\
\hline 4 & $0.95>($ Schedule Ratio $) \geq 0.90$ \\
\hline 5 & $0.90>($ Schedule Ratio $)$ \\
\hline
\end{tabular}

Our second assessment of schedule performance is derived from EVMS data using the SPI. Again, as discussed in the Project Cost Performance (PerfC) section on page 133, the validity of the SPI data is affected by the criteria used to manage the EVMS baselines. Table 14 illustrates the validity and the disposition of SPI data. If the SPI data are acceptable, they are assessed as shown in Table 18.

Table 18: SPI-Based Schedule Performance

\begin{tabular}{|cc|}
$\begin{array}{c}\text { Schedule Performance Assessment } \\
\text { (Sched_Perf 1) }\end{array}$ & Criteria \\
\hline 1 & $0.90>(S P I)$ \\
\hline 2 & $0.95>(S P I) \geq 0.90$ \\
\hline 3 & $1.05>(S P I) \geq 0.95$ \\
\hline 4 & $1.1>(S P I) \geq 1.05$ \\
\hline 5 & $(S P I) \geq 1.1$ \\
\hline
\end{tabular}


Our third assessment of schedule performance is based on deviation from the customer-approved IMS, based on the question in Table 19.

Table 19: IMS-Based Schedule Performance Assessment

\begin{tabular}{|c|c|c|c|}
\hline Q\# & Question & Response & Assessment \\
\hline O5. & $\begin{array}{l}\text { The schedule of this project's critical path, } \\
\text { when compared to the current IMS ap- } \\
\text { proved by the acquirer is ... }\end{array}$ & $\begin{array}{l}\text { Degree of } \\
\text { deviation }\end{array}$ & $\begin{array}{l}1=>6 \text { months late } \\
2=3-6 \text { months late } \\
3=1-3 \text { months late } \\
4=\text { Within }+/-1 \text { month } \\
5=1-3 \text { months early } \\
6=3-6 \text { months early }\end{array}$ \\
\hline
\end{tabular}

The final factor evaluated for the assessment of project schedule performance is the perception of the customer's satisfaction with the schedule performance of the project, assessed as shown in Table 20.

Table 20: Customer-Satisfaction-Based Schedule Performance Assessment

\begin{tabular}{|c|l|}
\hline $\begin{array}{c}\text { Schedule Performance Assessment } \\
\text { (Sched_Perf 4) }\end{array}$ & $\begin{array}{l}\text { I believe that my customer is satisfied with this project's } \\
\text { performance with respect to schedule }\end{array}$ \\
\hline 1.00 & Strongly disagree \\
\hline 2.33 & Disagree \\
\hline 3.67 & Agree \\
\hline 5.00 & Strongly Agree \\
\hline
\end{tabular}

These four assessment factors are combined into a weighted summed index, PerfS, to provide an assessment of project schedule performance scaled from 1 (very poor performance) to 5 (very good performance).

\section{Project Technical Performance (PerfT)}

PerfT is assessed based on evaluations of two factors:

1. satisfaction of requirements

2. perception of customer satisfaction with the technical performance of the project

PerfT is assessed based on the questions in Table 21.

\section{Table 21: PerfT Assessment}

\begin{tabular}{|c|c|c|c|}
\hline Q\# & Question & Response & Assessment \\
\hline $\mathrm{O} 3$ & $\begin{array}{l}\text { Requirements are being satisfied and re- } \\
\text { main on track to be satisfied in the product } \\
\text { releases as originally planned; they are not } \\
\text { being deleted or deferred to later releases. }\end{array}$ & $\begin{array}{l}\text { Degree of } \\
\text { agreement }\end{array}$ & $\begin{array}{l}1=\text { Strongly disagree } \\
2.33=\text { Disagree } \\
3.67=\text { Agree } \\
5=\text { Strongly Agree }\end{array}$ \\
\hline O10 & $\begin{array}{l}\text { I believe that my customer is satisfied with } \\
\text { this project's performance with respect to } \\
\text { satisfaction of requirements. }\end{array}$ & $\begin{array}{l}\text { Degree of } \\
\text { agreement }\end{array}$ & $\begin{array}{l}1=\text { Strongly disagree } \\
2.33=\text { Disagree } \\
3.67=\text { Agree } \\
5=\text { Strongly Agree }\end{array}$ \\
\hline
\end{tabular}

These responses are combined into a weighted summed index, PerfT, to provide an assessment of project technical performance scaled from 1 (very poor performance) to 5 (very good performance). 


\section{PROJECT CHALLENGE (PC)}

PC information was collected through responses to the questions shown in Table 22. The response to each question was assessed as shown in the Assessment column.

\section{Table 22: PC Assessment}

\begin{tabular}{|c|c|c|c|}
\hline Q\# & Question & Response & Assessment \\
\hline A1. & $\begin{array}{l}\text { The project is challenging because there is } \\
\text { no precedent for what is being done. }\end{array}$ & $\begin{array}{l}\text { Degree of } \\
\text { agreement }\end{array}$ & $\begin{array}{l}1=\text { Strongly disagree } \\
2=\text { Disagree } \\
3=\text { Agree } \\
4=\text { Strongly Agree }\end{array}$ \\
\hline A2. & $\begin{array}{l}\text { This project is challenging because } \\
\text { significant constraints are placed on the } \\
\text { quality attributes of the product. }\end{array}$ & $\begin{array}{l}\text { Degree of } \\
\text { agreement }\end{array}$ & $\begin{array}{l}1=\text { Strongly disagree } \\
2=\text { Disagree } \\
3=\text { Agree } \\
4=\text { Strongly Agree }\end{array}$ \\
\hline A3. & $\begin{array}{l}\text { The project is challenging because the size } \\
\text { of the development effort is large. }\end{array}$ & $\begin{array}{l}\text { Degree of } \\
\text { agreement }\end{array}$ & $\begin{array}{l}1=\text { Strongly disagree } \\
2=\text { Disagree } \\
3=\text { Agree } \\
4=\text { Strongly Agree }\end{array}$ \\
\hline A4. & $\begin{array}{l}\text { The project is challenging because the } \\
\text { technology needed for this project is not } \\
\text { mature or otherwise poses a high risk. }\end{array}$ & $\begin{array}{l}\text { Degree of } \\
\text { agreement }\end{array}$ & $\begin{array}{l}1=\text { Strongly disagree } \\
2=\text { Disagree } \\
3=\text { Agree } \\
4=\text { Strongly Agree }\end{array}$ \\
\hline A5. & $\begin{array}{l}\text { The project is challenging because there } \\
\text { are extensive needs for interoperability with } \\
\text { other systems. }\end{array}$ & $\begin{array}{l}\text { Degree of } \\
\text { agreement }\end{array}$ & $\begin{array}{l}1=\text { Strongly disagree } \\
2=\text { Disagree } \\
3=\text { Agree } \\
4=\text { Strongly Agree }\end{array}$ \\
\hline A6. & $\begin{array}{l}\text { The project is challenging because there } \\
\text { are insufficient resources available to } \\
\text { support the project. }\end{array}$ & $\begin{array}{l}\text { Degree of } \\
\text { agreement }\end{array}$ & $\begin{array}{l}1=\text { Strongly disagree } \\
2=\text { Disagree } \\
3=\text { Agree } \\
4=\text { Strongly Agree }\end{array}$ \\
\hline A7. & $\begin{array}{l}\text { The project is challenging because there } \\
\text { are insufficient skills and subject matter } \\
\text { expertise available to support the project. }\end{array}$ & $\begin{array}{l}\text { Degree of } \\
\text { agreement }\end{array}$ & $\begin{array}{l}1=\text { Strongly disagree } \\
2=\text { Disagree } \\
3=\text { Agree } \\
4=\text { Strongly Agree }\end{array}$ \\
\hline A9. & $\begin{array}{l}\text { In the past, this project team has NOT } \\
\text { successfully completed projects of similar } \\
\text { scope. }\end{array}$ & $\begin{array}{l}\text { Degree of } \\
\text { agreement }\end{array}$ & $\begin{array}{l}1=\text { Strongly disagree } \\
2=\text { Disagree } \\
3=\text { Agree } \\
4=\text { Strongly Agree }\end{array}$ \\
\hline A10. & $\begin{array}{l}\text { The requirements supplied by the customer } \\
\text { for this project are NOT well-defined. }\end{array}$ & $\begin{array}{l}\text { Degree of } \\
\text { agreement }\end{array}$ & $\begin{array}{l}1=\text { Strongly disagree } \\
2=\text { Disagree } \\
3=\text { Agree } \\
4=\text { Strongly Agree }\end{array}$ \\
\hline A11. & $\begin{array}{l}\text { The requirements supplied by the customer } \\
\text { for this project have NOT changed } \\
\text { sufficiently to generate a significant impact } \\
\text { on the project. }\end{array}$ & $\begin{array}{l}\text { Degree of } \\
\text { agreement }\end{array}$ & $\begin{array}{l}1=\text { Strongly disagree } \\
2=\text { Disagree } \\
3=\text { Agree } \\
4=\text { Strongly Agree }\end{array}$ \\
\hline $\mathrm{C} 1$ & $\begin{array}{l}\text { This organization has NOT successfully } \\
\text { completed projects similar in scope to this } \\
\text { one in the past. }\end{array}$ & $\begin{array}{l}\text { Degree of } \\
\text { agreement }\end{array}$ & $\begin{array}{l}1=\text { Strongly disagree } \\
2=\text { Disagree } \\
3=\text { Agree } \\
4=\text { Strongly Agree }\end{array}$ \\
\hline D20 & $\begin{array}{l}\text { The acquirer HAS NOT provided this } \\
\text { project with a SE Plan in a timely manner. }\end{array}$ & $\begin{array}{l}\text { Degree of } \\
\text { agreement }\end{array}$ & $\begin{array}{l}1=\text { Strongly disagree } \\
2=\text { Disagree } \\
3=\text { Agree } \\
4=\text { Strongly Agree }\end{array}$ \\
\hline
\end{tabular}




\begin{tabular}{|c|c|c|c|}
\hline Q\# & Question & Response & Assessment \\
\hline A12. & $\begin{array}{l}\text { What percentage of the customer technical } \\
\text { requirements were marked "TBD" or equiv. } \\
\text { at time of contract award? }\end{array}$ & $0-100 \%$ & $\begin{array}{l}1 \leftarrow 5 \%>\text { (undef reqts }) \\
2 \leftarrow 10 \%>(\text { undef reqts }) \geq 5 \% \\
3 \leftarrow 20 \%>(\text { undef reqts }) \geq 10 \% \\
4 \leftarrow(\text { undef reqts }) \geq 20 \%\end{array}$ \\
\hline A13. & $\begin{array}{l}\text { What percentage of the customer's } \\
\text { technical requirements are currently } \\
\text { marked "TBD" or equiv? }\end{array}$ & $0-100 \%$ & $\begin{array}{l}1 \leftarrow 5 \%>\text { (undef reqts }) \\
2 \leftarrow 10 \%>(\text { undef reqts }) \geq 5 \% \\
3 \leftarrow 20 \%>(\text { undef reqts }) \geq 10 \% \\
4 \leftarrow(\text { undef reqts }) \geq 20 \%\end{array}$ \\
\hline B1. & $\begin{array}{l}\text { What is the current total contract value of } \\
\text { this project? }\end{array}$ & U.S.\$ & $\begin{array}{l}1 \leftarrow \$ 1 e 6>(C V) \\
2 \leftarrow \$ 1 e 7>(C V) \geq \$ 1 e 6 \\
3 \leftarrow \$ 1 e 8>(C V) \geq \$ 1 e 7 \\
4 \leftarrow(C V) \geq \$ 1 e 8\end{array}$ \\
\hline B2. & $\begin{array}{l}\text { What was the initial contract value of this } \\
\text { project? }\end{array}$ & U.S.\$ & $\begin{array}{l}1 \leftarrow \$ 1 e 6>(C V) \\
2 \leftarrow \$ 1 e 7>(C V) \geq \$ 1 e 6 \\
3 \leftarrow \$ 1 e 8>(C V) \geq \$ 1 e 7 \\
4 \leftarrow(C V) \geq \$ 1 e 8\end{array}$ \\
\hline B4. & $\begin{array}{l}\text { What is the current total planned duration } \\
\text { of this project or contract? }\end{array}$ & Months & $\begin{array}{l}1 \leftarrow 30>(\text { Duration }) \\
2 \leftarrow 60>(\text { Duration }) \geq 30 \\
3 \leftarrow 120>(\text { Duration }) \geq 60 \\
4 \leftarrow(\text { Duration }) \geq 120\end{array}$ \\
\hline B5. & $\begin{array}{l}\text { What was the initial total planned duration } \\
\text { of this project or contract? }\end{array}$ & Months & $\begin{array}{l}1 \rightarrow 30>(\text { Duration }) \\
2 \rightarrow 60>(\text { Duration }) \geq 30 \\
3 \rightarrow 120>(\text { Duration }) \geq 60 \\
4 \rightarrow(\text { Duration }) \geq 120\end{array}$ \\
\hline B7. & $\begin{array}{l}\text { What was the initial total budget for this } \\
\text { project? }\end{array}$ & U.S.\$ & $\begin{array}{l}1 \leftarrow \$ 1 e 6>(\text { budget }) \\
2 \leftarrow \$ 1 e 7>(\text { budget }) \geq \$ 1 e 6 \\
3 \leftarrow \$ 1 e 8>(\text { budget }) \geq \$ 1 e 7 \\
4 \leftarrow(\text { budget }) \geq \$ 1 e 8\end{array}$ \\
\hline B8. & $\begin{array}{l}\text { What is the current total budget for this } \\
\text { project? }\end{array}$ & U.S.\$ & $\begin{array}{l}1 \leftarrow \$ 1 e 6>(\text { budget }) \\
2 \leftarrow \$ 1 e 7>(\text { budget }) \geq \$ 1 e 6 \\
3 \leftarrow \$ 1 e 8>(\text { budget }) \geq \$ 1 e 7 \\
4 \leftarrow(\text { budget }) \geq \$ 1 e 8\end{array}$ \\
\hline B10. & $\begin{array}{l}\text { How many contract change orders have } \\
\text { been received? }\end{array}$ & $\mathrm{N}$ & \\
\hline
\end{tabular}

All assessments were scaled from 1 to 4 . The results of all assessments were then combined into a weighted summed index, $\boldsymbol{P C}$, to create an overall assessment of project challenge scaled from 1 (very low challenge) to 4 (very high challenge).

\section{SYSTEMS ENGINEERING CAPABILITY (SEC)}

SEC is a measure of the SE activities applied to each project. In addition to assessing the total SE activities (SEC-Total) applied, we also are able to assess the SE activities applied in each of the SE process groups shown in Table 6 . For each of these process groups, this section identifies the questions and criteria that produce the assessment. 


\section{Integrated Product Team Capability (SEC-IPT)}

The project's use of integrated product teams was assessed through the questions shown in Table 23.

\section{Table 23: SEC-IPT Assessment}

\begin{tabular}{|c|c|c|c|}
\hline Q\# & Question & Response & Assessment criteria \\
\hline E1 & This project makes effective use of IPTs. & $\begin{array}{l}\text { Degree of } \\
\text { agreement }\end{array}$ & $\begin{array}{l}1=\text { Strongly disagree } \\
2=\text { Disagree } \\
3=\text { Agree } \\
4=\text { Strongly Agree }\end{array}$ \\
\hline E2 & $\begin{array}{l}\text { My acquirer participates in my IPTs for this } \\
\text { project. }\end{array}$ & $\begin{array}{l}\text { Degree of } \\
\text { agreement }\end{array}$ & $\begin{array}{l}1=\text { Strongly disagree } \\
2=\text { Disagree } \\
3=\text { Agree } \\
4=\text { Strongly Agree }\end{array}$ \\
\hline E3 & My suppliers actively participate in my IPTs. & $\begin{array}{l}\text { Degree of } \\
\text { agreement }\end{array}$ & $\begin{array}{l}1=\text { Strongly disagree } \\
2=\text { Disagree } \\
3=\text { Agree } \\
4=\text { Strongly Agree }\end{array}$ \\
\hline Q\# & Question & Response & Assessment criteria \\
\hline E4 & $\begin{array}{l}\text { This project has an IPT with assigned } \\
\text { responsibility for SE. }\end{array}$ & $\begin{array}{l}\text { Degree of } \\
\text { agreement }\end{array}$ & $\begin{array}{l}1=\text { Strongly disagree } \\
2=\text { Disagree } \\
3=\text { Agree } \\
4=\text { Strongly Agree }\end{array}$ \\
\hline E5 & $\begin{array}{l}\text { This project has SE representation on each } \\
\text { IPT. }\end{array}$ & $\begin{array}{l}\text { Degree of } \\
\text { agreement }\end{array}$ & $\begin{array}{l}1=\text { Strongly disagree } \\
2=\text { Disagree } \\
3=\text { Agree } \\
4=\text { Strongly Agree }\end{array}$ \\
\hline
\end{tabular}

The assessed values are combined into a weighted summed index to create the assessment for SEC-IPT scaled from 1 (very low capability) to 4 (very high capability).

\section{Project Planning Capability (SEC-PP)}

The project's application of best practices in Project Planning was assessed through the questions shown in Table 24.

\section{Table 24: SEC-PP Assessment}

\begin{tabular}{|c|c|c|c|}
\hline Q\# & Question & Response & Assessment criteria \\
\hline A14 & $\begin{array}{l}\text { Do you separately budget and track } \\
\text { Systems Engineering activities? }\end{array}$ & $\begin{array}{l}\text { Yes, No, Don't } \\
\text { Know }\end{array}$ & $\begin{array}{l}4=\text { Yes } \\
1=\text { No } \\
1=\text { Don't Know }\end{array}$ \\
\hline D1 & $\begin{array}{l}\text { This project utilizes/utilized a documented } \\
\text { set of Systems Engineering processes for } \\
\text { the planning and execution of the project. }\end{array}$ & $\begin{array}{l}\text { Degree of } \\
\text { agreement }\end{array}$ & $\begin{array}{l}1=\text { Strongly disagree } \\
2=\text { Disagree } \\
3=\text { Agree } \\
4=\text { Strongly Agree }\end{array}$ \\
\hline D2 & $\begin{array}{l}\text { This project has/had an accurate and up-to- } \\
\text { date WBS that included task descriptions } \\
\text { and work package descriptions. }\end{array}$ & $\begin{array}{l}\text { Degree of } \\
\text { agreement }\end{array}$ & $\begin{array}{l}1=\text { Strongly disagree } \\
2=\text { Disagree } \\
3=\text { Agree } \\
4=\text { Strongly Agree }\end{array}$ \\
\hline D3 & $\begin{array}{l}\text { This project has/had an accurate and up-to- } \\
\text { date WBS that was based on the product } \\
\text { structure. }\end{array}$ & $\begin{array}{l}\text { Degree of } \\
\text { agreement }\end{array}$ & $\begin{array}{l}1=\text { Strongly disagree } \\
2=\text { Disagree } \\
3=\text { Agree } \\
4=\text { Strongly Agree }\end{array}$ \\
\hline
\end{tabular}




\begin{tabular}{|c|c|c|c|}
\hline Q\# & Question & Response & Assessment criteria \\
\hline D4 & $\begin{array}{l}\text { This project has/had an accurate and up-to- } \\
\text { date WBS that was developed with the } \\
\text { active participation of those who perform } \\
\text { the systems engineering activities. }\end{array}$ & $\begin{array}{l}\text { Degree of } \\
\text { agreement }\end{array}$ & $\begin{array}{l}\text { 1=Strongly disagree } \\
2=\text { Disagree } \\
\text { 3=Agree } \\
\text { 4=Strongly Agree }\end{array}$ \\
\hline D5 & $\begin{array}{l}\text { This project has/had an accurate and up-to- } \\
\text { date WBS that was developed and } \\
\text { maintained with the active participation of } \\
\text { all relevant stakeholders. }\end{array}$ & $\begin{array}{l}\text { Degree of } \\
\text { agreement }\end{array}$ & $\begin{array}{l}1=\text { Strongly disagree } \\
2=\text { Disagree } \\
3=\text { Agree } \\
4=\text { Strongly Agree }\end{array}$ \\
\hline D6 & $\begin{array}{l}\text { This project's Technical Approach is } \\
\text { complete, accurate and up-to-date. }\end{array}$ & $\begin{array}{l}\text { Degree of } \\
\text { agreement }\end{array}$ & $\begin{array}{l}1=\text { Strongly disagree } \\
2=\text { Disagree } \\
3=\text { Agree } \\
4=\text { Strongly Agree }\end{array}$ \\
\hline D7 & $\begin{array}{l}\text { This project's Technical Approach is } \\
\text { developed and maintained with the active } \\
\text { participation of those who perform the } \\
\text { Systems Engineering activities. }\end{array}$ & $\begin{array}{l}\text { Degree of } \\
\text { agreement }\end{array}$ & $\begin{array}{l}1=\text { Strongly disagree } \\
2=\text { Disagree } \\
3=\text { Agree } \\
4=\text { Strongly Agree }\end{array}$ \\
\hline D8 & $\begin{array}{l}\text { This project's Technical Approach is } \\
\text { developed and maintained with the active } \\
\text { participation of all appropriate functional } \\
\text { stakeholders. }\end{array}$ & $\begin{array}{l}\text { Degree of } \\
\text { agreement }\end{array}$ & $\begin{array}{l}1=\text { Strongly disagree } \\
2=\text { Disagree } \\
3=\text { Agree } \\
4=\text { Strongly Agree }\end{array}$ \\
\hline D9 & $\begin{array}{l}\text { This project has a top-level plan, such as } \\
\text { an IMP, that is an event-driven plan (i.e., } \\
\text { each accomplishment is tied to a key } \\
\text { project event). }\end{array}$ & $\begin{array}{l}\text { Degree of } \\
\text { agreement }\end{array}$ & $\begin{array}{l}1=\text { Strongly disagree } \\
2=\text { Disagree } \\
3=\text { Agree } \\
4=\text { Strongly Agree }\end{array}$ \\
\hline D10 & $\begin{array}{l}\text { This project has a top-level plan, such as } \\
\text { an IMP, that documents significant } \\
\text { accomplishments with pass/fail } \\
\text { accomplishment criteria for both business } \\
\text { and technical elements of the project. }\end{array}$ & $\begin{array}{l}\text { Degree of } \\
\text { agreement }\end{array}$ & $\begin{array}{l}1=\text { Strongly disagree } \\
2=\text { Disagree } \\
3=\text { Agree } \\
4=\text { Strongly Agree }\end{array}$ \\
\hline D11 & $\begin{array}{l}\text { This project has a top-level plan, such as } \\
\text { an IMP, that is consistent with the WBS. }\end{array}$ & $\begin{array}{l}\text { Degree of } \\
\text { agreement }\end{array}$ & $\begin{array}{l}1=\text { Strongly disagree } \\
2=\text { Disagree } \\
3=\text { Agree } \\
4=\text { Strongly Agree }\end{array}$ \\
\hline D12 & $\begin{array}{l}\text { This project has an integrated event-based } \\
\text { schedule that is structured as a networked, } \\
\text { multi-layered schedule of project tasks } \\
\text { required to complete the work effort. }\end{array}$ & $\begin{array}{l}\text { Degree of } \\
\text { agreement }\end{array}$ & $\begin{array}{l}1=\text { Strongly disagree } \\
2=\text { Disagree } \\
3=\text { Agree } \\
4=\text { Strongly Agree }\end{array}$ \\
\hline D13 & $\begin{array}{l}\text { This project has an integrated event-based } \\
\text { schedule that contains a compilation of key } \\
\text { technical accomplishments (e.g., a SE } \\
\text { Master Schedule). }\end{array}$ & $\begin{array}{l}\text { Degree of } \\
\text { agreement }\end{array}$ & $\begin{array}{l}1=\text { Strongly disagree } \\
2=\text { Disagree } \\
3=\text { Agree } \\
4=\text { Strongly Agree }\end{array}$ \\
\hline D14 & $\begin{array}{l}\text { This project has an integrated event-based } \\
\text { schedule that references measurable } \\
\text { criteria (usually contained in the IMP) } \\
\text { required for successful completion of key } \\
\text { technical accomplishments. }\end{array}$ & $\begin{array}{l}\text { Degree of } \\
\text { agreement }\end{array}$ & $\begin{array}{l}1=\text { Strongly disagree } \\
2=\text { Disagree } \\
3=\text { Agree } \\
4=\text { Strongly Agree }\end{array}$ \\
\hline D15 & $\begin{array}{l}\text { This project has an integrated event-based } \\
\text { schedule that is consistent with the WBS. }\end{array}$ & $\begin{array}{l}\text { Degree of } \\
\text { agreement }\end{array}$ & $\begin{array}{l}1=\text { Strongly disagree } \\
2=\text { Disagree } \\
3=\text { Agree } \\
4=\text { Strongly Agree }\end{array}$ \\
\hline D16 & $\begin{array}{l}\text { This project has an integrated event-based } \\
\text { schedule that identifies the critical path of } \\
\text { the program schedule. }\end{array}$ & $\begin{array}{l}\text { Degree of } \\
\text { agreement }\end{array}$ & $\begin{array}{l}1=\text { Strongly disagree } \\
2=\text { Disagree } \\
3=\text { Agree } \\
4=\text { Strongly Agree }\end{array}$ \\
\hline
\end{tabular}




\begin{tabular}{|c|c|c|c|}
\hline Q\# & Question & Response & Assessment criteria \\
\hline D17 & $\begin{array}{l}\text { This project has a plan or plans for the } \\
\text { performance of technical reviews with } \\
\text { defined entry and exit criteria throughout } \\
\text { the lifecycle of the project. }\end{array}$ & $\begin{array}{l}\text { Degree of } \\
\text { agreement }\end{array}$ & $\begin{array}{l}\text { 1=Strongly disagree } \\
2=\text { Disagree } \\
3=\text { Agree } \\
4=\text { Strongly Agree }\end{array}$ \\
\hline D18 & $\begin{array}{l}\text { The SE function actively participates in the } \\
\text { development and updates of the project } \\
\text { planning. }\end{array}$ & $\begin{array}{l}\text { Degree of } \\
\text { agreement }\end{array}$ & $\begin{array}{l}1=\text { Strongly disagree } \\
2=\text { Disagree } \\
3=\text { Agree } \\
4=\text { Strongly Agree }\end{array}$ \\
\hline D19 & $\begin{array}{l}\text { Those who perform SE activities actively } \\
\text { participate in tracking/reporting of task } \\
\text { progress. }\end{array}$ & $\begin{array}{l}\text { Degree of } \\
\text { agreement }\end{array}$ & $\begin{array}{l}1=\text { Strongly disagree } \\
2=\text { Disagree } \\
3=\text { Agree } \\
4=\text { Strongly Agree }\end{array}$ \\
\hline D20 & $\begin{array}{l}\text { The acquirer provided this project with a SE } \\
\text { Plan in a timely manner. }\end{array}$ & $\begin{array}{l}\text { Degree of } \\
\text { agreement }\end{array}$ & $\begin{array}{l}1=\text { Strongly disagree } \\
2=\text { Disagree } \\
3=\text { Agree } \\
4=\text { Strongly Agree }\end{array}$ \\
\hline D21 & $\begin{array}{l}\text { This project has a plan or plans that include } \\
\text { details of the management of the integrated } \\
\text { technical effort across the project (e.g., a } \\
\text { SE Mgt. Plan or a SE Plan). }\end{array}$ & $\begin{array}{l}\text { Degree of } \\
\text { agreement }\end{array}$ & $\begin{array}{l}1=\text { Strongly disagree } \\
2=\text { Disagree } \\
3=\text { Agree } \\
4=\text { Strongly Agree }\end{array}$ \\
\hline D22 & $\begin{array}{l}\text { The SEMP developed by the project team } \\
\text { is aligned and consistent with the SE Plan } \\
\text { provided by the acquirer. }\end{array}$ & $\begin{array}{l}\text { Degree of } \\
\text { agreement }\end{array}$ & $\begin{array}{l}1=\text { Strongly disagree } \\
2=\text { Disagree } \\
3=\text { Agree } \\
4=\text { Strongly Agree }\end{array}$ \\
\hline
\end{tabular}

The assessed values are combined into a weighted summed index to create the assessment for SEC-PP scaled from 1 (very low capability) to 4 (very high capability).

\section{Project Monitoring and Control Capability (SEC-PMC)}

The project's application of best practices in Project Monitoring and Control was assessed through the questions shown in Table 25.

\section{Table 25: SEC-PMC Assessment Questions}

\begin{tabular}{|c|c|c|c|}
\hline Q\# & Question & Response & Assessment criteria \\
\hline K6 & $\begin{array}{l}\text { This project has a documented and } \\
\text { practiced review process that tracks action } \\
\text { items to closure. }\end{array}$ & $\begin{array}{l}\text { Degree of } \\
\text { agreement }\end{array}$ & $\begin{array}{l}1=\text { Strongly disagree } \\
2=\text { Disagree } \\
3=\text { Agree } \\
4=\text { Strongly Agree }\end{array}$ \\
\hline N1 & $\begin{array}{l}\text { This project creates and manages cost and } \\
\text { schedule baselines. }\end{array}$ & $\begin{array}{l}\text { Degree of } \\
\text { agreement }\end{array}$ & $\begin{array}{l}1=\text { Strongly disagree } \\
2=\text { Disagree } \\
3=\text { Agree } \\
4=\text { Strongly Agree }\end{array}$ \\
\hline N2 & $\begin{array}{l}\text { EVMS data are available to decision } \\
\text { makers in a timely manner. }\end{array}$ & $\begin{array}{l}\text { Degree of } \\
\text { agreement }\end{array}$ & $\begin{array}{l}1=\text { Strongly disagree } \\
2=\text { Disagree } \\
3=\text { Agree } \\
4=\text { Strongly Agree }\end{array}$ \\
\hline N3 & $\begin{array}{l}\text { The requirement to track and report EVMS } \\
\text { data is levied on the project's suppliers. }\end{array}$ & $\begin{array}{l}\text { Degree of } \\
\text { agreement }\end{array}$ & $\begin{array}{l}1=\text { Strongly disagree } \\
2=\text { Disagree } \\
3=\text { Agree } \\
4=\text { Strongly Agree }\end{array}$ \\
\hline
\end{tabular}




\begin{tabular}{|c|c|c|c|}
\hline Q\# & Question & Response & Assessment criteria \\
\hline N4 & $\begin{array}{l}\text { Variance thresholds for the CPI and SPI are } \\
\text { defined, documented, and used to } \\
\text { determine when corrective action is } \\
\text { needed. }\end{array}$ & $\begin{array}{l}\text { Degree of } \\
\text { agreement }\end{array}$ & $\begin{array}{l}\text { 1=Strongly disagree } \\
2=\text { Disagree } \\
3=\text { Agree } \\
4=\text { Strongly Agree }\end{array}$ \\
\hline N5 & $\begin{array}{l}\text { The EVMS is linked to the technical effort } \\
\text { through the WBS, and the IMS. }\end{array}$ & $\begin{array}{l}\text { Degree of } \\
\text { agreement }\end{array}$ & $\begin{array}{l}1=\text { Strongly disagree } \\
2=\text { Disagree } \\
3=\text { Agree } \\
4=\text { Strongly Agree }\end{array}$ \\
\hline N6 & When is the EVMS baseline updated? & & $\begin{array}{l}3 \leftarrow \text { Only at contract initiation } \\
4 \leftarrow \text { Whenever a contract change order } \\
\text { or renewal is received } \\
1 \leftarrow \text { Incrementally in rolling wave } \\
\text { planning } \\
1 \leftarrow \text { Whenever the project is } \\
\text { reprogrammed due to a pre-determined } \\
\text { cost or schedule variance } \\
1 \leftarrow \text { At periodic intervals } \\
\text { Per analyst evaluation } \leftarrow \text { Other }\end{array}$ \\
\hline A14. & $\begin{array}{l}\text { Do you separately budget and track } \\
\text { Systems Engineering activities? }\end{array}$ & $\begin{array}{l}\text { Yes, No, Don't } \\
\text { Know }\end{array}$ & $\begin{array}{l}4 \leftarrow \text { Yes } \\
1 \leftarrow \text { No } \\
1 \leftarrow \text { Don't Know }\end{array}$ \\
\hline D19 & $\begin{array}{l}\text { Those who perform SE activities actively } \\
\text { participate in tracking/reporting of task } \\
\text { progress. }\end{array}$ & $\begin{array}{l}\text { Degree of } \\
\text { agreement }\end{array}$ & $\begin{array}{l}1=\text { Strongly disagree } \\
2=\text { Disagree } \\
3=\text { Agree } \\
4=\text { Strongly Agree }\end{array}$ \\
\hline $\mathrm{O} 6$ & $\begin{array}{l}\text { This project collects and tracks (or will } \\
\text { collect and track) reports of problems from } \\
\text { fielded items. }\end{array}$ & $\begin{array}{l}\text { Degree of } \\
\text { agreement }\end{array}$ & $\begin{array}{l}1=\text { Strongly disagree } \\
2=\text { Disagree } \\
3=\text { Agree } \\
4=\text { Strongly Agree }\end{array}$ \\
\hline $\mathrm{O} 7$ & $\begin{array}{l}\text { This project conducts (or will conduct) } \\
\text { engineering assessments of all field trouble } \\
\text { reports. }\end{array}$ & $\begin{array}{l}\text { Degree of } \\
\text { agreement }\end{array}$ & $\begin{array}{l}1=\text { Strongly disagree } \\
2=\text { Disagree } \\
3=\text { Agree } \\
4=\text { Strongly Agree }\end{array}$ \\
\hline
\end{tabular}

The assessed values are combined into a weighted summed index to create the assessment for SEC-PMC scaled from 1 (very low capability) to 4 (very high capability).

\section{Risk Management Capability (SEC-RSKM)}

The project's application of best practices in Risk Management was assessed through the questions shown in Table 26.

\section{Table 26: SEC-RSKM Assessment Questions}

\begin{tabular}{|c|c|c|c|}
\hline Q\# & Question & Response & Assessment criteria \\
\hline $\mathrm{F} 1$ & $\begin{array}{l}\text { This project has a Risk Management } \\
\text { process that creates and maintains an } \\
\text { accurate and up-to-date list of risks } \\
\text { affecting the project. }\end{array}$ & $\begin{array}{l}\text { Degree of } \\
\text { agreement }\end{array}$ & $\begin{array}{l}\text { 1=Strongly disagree } \\
2=\text { Disagree } \\
3=\text { Agree } \\
4=\text { Strongly Agree }\end{array}$ \\
\hline $\mathrm{F} 2$ & $\begin{array}{l}\text { This project has a Risk Management } \\
\text { process that creates and maintains up-to- } \\
\text { date documentation of risk mitigation plans } \\
\text { and contingency plans for selected risks. }\end{array}$ & $\begin{array}{l}\text { Degree of } \\
\text { agreement }\end{array}$ & $\begin{array}{l}1=\text { Strongly disagree } \\
2=\text { Disagree } \\
3=\text { Agree } \\
4=\text { Strongly Agree }\end{array}$ \\
\hline
\end{tabular}




\begin{tabular}{|c|c|c|c|}
\hline Q\# & Question & Response & Assessment criteria \\
\hline F3 & $\begin{array}{l}\text { This project has a Risk Management } \\
\text { process that monitors and reports the } \\
\text { status of risk mitigation activities and } \\
\text { resources. }\end{array}$ & $\begin{array}{l}\text { Degree of } \\
\text { agreement }\end{array}$ & $\begin{array}{l}1=\text { Strongly disagree } \\
2=\text { Disagree } \\
3=\text { Agree } \\
4=\text { Strongly Agree }\end{array}$ \\
\hline $\mathrm{F} 4$ & $\begin{array}{l}\text { This project has a Risk Management } \\
\text { process that assesses risk against } \\
\text { achievement of an event-based schedule. }\end{array}$ & $\begin{array}{l}\text { Degree of } \\
\text { agreement }\end{array}$ & $\begin{array}{l}1=\text { Strongly disagree } \\
2=\text { Disagree } \\
3=\text { Agree } \\
4=\text { Strongly Agree }\end{array}$ \\
\hline F5 & $\begin{array}{l}\text { This project's Risk Management process is } \\
\text { integrated with project decision-making. }\end{array}$ & $\begin{array}{l}\text { Degree of } \\
\text { agreement }\end{array}$ & $\begin{array}{l}1=\text { Strongly disagree } \\
2=\text { Disagree } \\
3=\text { Agree } \\
4=\text { Strongly Agree }\end{array}$ \\
\hline F6 & $\begin{array}{l}\text { This project's Risk Management process is } \\
\text { integrated with program cost and/or earned } \\
\text { value management. }\end{array}$ & $\begin{array}{l}\text { Degree of } \\
\text { agreement }\end{array}$ & $\begin{array}{l}1=\text { Strongly disagree } \\
2=\text { Disagree } \\
3=\text { Agree } \\
4=\text { Strongly Agree }\end{array}$ \\
\hline F7 & $\begin{array}{l}\text { This project's Risk Management process is } \\
\text { integrated with program scheduling. }\end{array}$ & $\begin{array}{l}\text { Degree of } \\
\text { agreement }\end{array}$ & $\begin{array}{l}1=\text { Strongly disagree } \\
2=\text { Disagree } \\
3=\text { Agree } \\
4=\text { Strongly Agree }\end{array}$ \\
\hline F8 & $\begin{array}{l}\text { This project's Risk Management process } \\
\text { integrates subcontract or supplier risk } \\
\text { management processes. }\end{array}$ & $\begin{array}{l}\text { Degree of } \\
\text { agreement }\end{array}$ & $\begin{array}{l}1=\text { Strongly disagree } \\
2=\text { Disagree } \\
3=\text { Agree } \\
4=\text { Strongly Agree }\end{array}$ \\
\hline
\end{tabular}

The assessed values are combined into a weighted summed index to create the assessment for SEC-RSKM scaled from 1 (very low capability) to 4 (very high capability).

\section{Requirements Development and Management Capability (SEC-REQ)}

The project's application of best practices in Requirements Development and Requirements Management was assessed through the questions shown in Table 27.

Table 27: SEC-REQ Assessment Questions

\begin{tabular}{|c|c|c|c|}
\hline Q\# & Question & Response & Assessment criteria \\
\hline G1 & $\begin{array}{l}\text { This project maintains an up-to-date and } \\
\text { accurate listing of all requirements specified } \\
\text { by the customer, to include regulatory, } \\
\text { statutory, and certification requirements. }\end{array}$ & $\begin{array}{l}\text { Degree of } \\
\text { agreement }\end{array}$ & $\begin{array}{l}1=\text { Strongly disagree } \\
2=\text { Disagree } \\
3=\text { Agree } \\
4=\text { Strongly Agree }\end{array}$ \\
\hline G2 & $\begin{array}{l}\text { This project maintains an up-to-date and } \\
\text { accurate listing of all requirements derived } \\
\text { from those specified by the customer. }\end{array}$ & $\begin{array}{l}\text { Degree of } \\
\text { agreement }\end{array}$ & $\begin{array}{l}1=\text { Strongly disagree } \\
2=\text { Disagree } \\
3=\text { Agree } \\
4=\text { Strongly Agree }\end{array}$ \\
\hline G3 & $\begin{array}{l}\text { This project maintains up-to-date and } \\
\text { accurate documentation clearly reflecting } \\
\text { the hierarchical allocation of both customer } \\
\text { and derived requirements to each element } \\
\text { (subsystem, component, etc.) of the system } \\
\text { in the configuration baselines. }\end{array}$ & $\begin{array}{l}\text { Degree of } \\
\text { agreement }\end{array}$ & $\begin{array}{l}1=\text { Strongly disagree } \\
2=\text { Disagree } \\
3=\text { Agree } \\
4=\text { Strongly Agree }\end{array}$ \\
\hline G4 & $\begin{array}{l}\text { This project documents and maintains } \\
\text { accurate and up-to-date descriptions of } \\
\text { operational concepts and their associated } \\
\text { scenarios. }\end{array}$ & $\begin{array}{l}\text { Degree of } \\
\text { agreement }\end{array}$ & $\begin{array}{l}1=\text { Strongly disagree } \\
2=\text { Disagree } \\
3=\text { Agree } \\
4=\text { Strongly Agree }\end{array}$ \\
\hline
\end{tabular}




\begin{tabular}{|c|c|c|c|}
\hline Q\# & Question & Response & Assessment criteria \\
\hline G5 & $\begin{array}{l}\text { This project documents and maintains } \\
\text { accurate and up-to-date descriptions of use } \\
\text { cases (or their equivalent). }\end{array}$ & $\begin{array}{l}\text { Degree of } \\
\text { agreement }\end{array}$ & $\begin{array}{l}1=\text { Strongly disagree } \\
2=\text { Disagree } \\
3=\text { Agree } \\
4=\text { Strongly Agree }\end{array}$ \\
\hline G6 & $\begin{array}{l}\text { This project documents and maintains } \\
\text { accurate and up-to-date descriptions of } \\
\text { product installation, maintenance and } \\
\text { support concepts. }\end{array}$ & $\begin{array}{l}\text { Degree of } \\
\text { agreement }\end{array}$ & $\begin{array}{l}1=\text { Strongly disagree } \\
2=\text { Disagree } \\
3=\text { Agree } \\
4=\text { Strongly Agree }\end{array}$ \\
\hline G7 & $\begin{array}{l}\text { This project has documented criteria for } \\
\text { identifying authorized requirements } \\
\text { providers to avoid requirements creep and } \\
\text { volatility. }\end{array}$ & $\begin{array}{l}\text { Degree of } \\
\text { agreement }\end{array}$ & $\begin{array}{l}1=\text { Strongly disagree } \\
2=\text { Disagree } \\
3=\text { Agree } \\
4=\text { Strongly Agree }\end{array}$ \\
\hline G8 & $\begin{array}{l}\text { This project has documented criteria (e.g., } \\
\text { cost impact, schedule impact, authorization } \\
\text { of source, contract scope, requirement } \\
\text { quality) for evaluation and acceptance of } \\
\text { requirements. }\end{array}$ & $\begin{array}{l}\text { Degree of } \\
\text { agreement }\end{array}$ & $\begin{array}{l}1=\text { Strongly disagree } \\
2=\text { Disagree } \\
3=\text { Agree } \\
4=\text { Strongly Agree }\end{array}$ \\
\hline G9 & $\begin{array}{l}\text { The requirements for this project are } \\
\text { approved in a formal and documented } \\
\text { manner by relevant stakeholders. }\end{array}$ & $\begin{array}{l}\text { Degree of } \\
\text { agreement }\end{array}$ & $\begin{array}{l}1=\text { Strongly disagree } \\
2=\text { Disagree } \\
3=\text { Agree } \\
4=\text { Strongly Agree }\end{array}$ \\
\hline G10 & $\begin{array}{l}\text { This project performs and documents } \\
\text { requirements impact assessments for } \\
\text { proposed requirements changes. }\end{array}$ & $\begin{array}{l}\text { Degree of } \\
\text { agreement }\end{array}$ & $\begin{array}{l}1=\text { Strongly disagree } \\
2=\text { Disagree } \\
3=\text { Agree } \\
4=\text { Strongly Agree }\end{array}$ \\
\hline G11 & $\begin{array}{l}\text { This project develops and documents } \\
\text { project requirements based on stakeholder } \\
\text { needs, expectations, and constraints. }\end{array}$ & $\begin{array}{l}\text { Degree of } \\
\text { agreement }\end{array}$ & $\begin{array}{l}1=\text { Strongly disagree } \\
2=\text { Disagree } \\
3=\text { Agree } \\
4=\text { Strongly Agree }\end{array}$ \\
\hline G12 & $\begin{array}{l}\text { This project has an accurate and up-to-date } \\
\text { requirements management system. }\end{array}$ & $\begin{array}{l}\text { Degree of } \\
\text { agreement }\end{array}$ & $\begin{array}{l}1=\text { Strongly disagree } \\
2=\text { Disagree } \\
3=\text { Agree } \\
4=\text { Strongly Agree }\end{array}$ \\
\hline G13 & $\begin{array}{l}\text { For this project, the requirements } \\
\text { documents are managed under a } \\
\text { configuration control process. }\end{array}$ & $\begin{array}{l}\text { Degree of } \\
\text { agreement }\end{array}$ & $\begin{array}{l}1=\text { Strongly disagree } \\
2=\text { Disagree } \\
3=\text { Agree } \\
4=\text { Strongly Agree }\end{array}$ \\
\hline G14 & $\begin{array}{l}\text { For this project, the requirements } \\
\text { documents are accessible to all relevant } \\
\text { project staff. }\end{array}$ & $\begin{array}{l}\text { Degree of } \\
\text { agreement }\end{array}$ & $\begin{array}{l}1=\text { Strongly disagree } \\
2=\text { Disagree } \\
3=\text { Agree } \\
4=\text { Strongly Agree }\end{array}$ \\
\hline
\end{tabular}

The assessed values are combined into a weighted summed index to create the assessment for SEC-REQ scaled from 1 (very low capability) to 4 (very high capability). 


\section{Trade Studies Capability (SEC-TRD)}

The project's application of best practices in Trade Studies was assessed through the questions shown in Table 28.

\section{Table 28: SEC-TRD Assessment Questions}

\begin{tabular}{|c|c|c|c|}
\hline Q\# & Question & Response & Assessment criteria \\
\hline $\mathrm{H} 1$ & $\begin{array}{l}\text { Stakeholders impacted by trade studies are } \\
\text { involved in the development and } \\
\text { performance of those trade studies. }\end{array}$ & $\begin{array}{l}\text { Degree of } \\
\text { agreement }\end{array}$ & $\begin{array}{l}1=\text { Strongly disagree } \\
2=\text { Disagree } \\
3=\text { Agree } \\
4=\text { Strongly Agree }\end{array}$ \\
\hline $\mathrm{H} 2$ & $\begin{array}{l}\text { This project performs and documents trade } \\
\text { studies between alternate solutions in a } \\
\text { timely manner, and based on definitive and } \\
\text { documented selection criteria. }\end{array}$ & $\begin{array}{l}\text { Degree of } \\
\text { agreement }\end{array}$ & $\begin{array}{l}1=\text { Strongly disagree } \\
2=\text { Disagree } \\
3=\text { Agree } \\
4=\text { Strongly Agree }\end{array}$ \\
\hline $\mathrm{H} 3$ & $\begin{array}{l}\text { Documentation of trade studies is } \\
\text { maintained in a defined repository and is } \\
\text { accessible to all relevant project staff. }\end{array}$ & $\begin{array}{l}\text { Degree of } \\
\text { agreement }\end{array}$ & $\begin{array}{l}1=\text { Strongly disagree } \\
2=\text { Disagree } \\
3=\text { Agree } \\
4=\text { Strongly Agree }\end{array}$ \\
\hline
\end{tabular}

The assessed values are combined into a weighted summed index to create the assessment for SEC-TRD scaled from 1 (very low capability) to 4 (very high capability).

\section{Architecture Capability (SEC-ARCH)}

The project's application of best practices in Product Architecture was assessed through the questions shown in Table 29.

Table 29: SEC-ARCH Assessment Questions

\begin{tabular}{|c|c|c|c|}
\hline Q\# & Question & Response & Assessment criteria \\
\hline 11 & $\begin{array}{l}\text { This project maintains accurate and up-to- } \\
\text { date descriptions (e.g. interface control } \\
\text { documents, models, etc.) defining } \\
\text { interfaces in detail. }\end{array}$ & $\begin{array}{l}\text { Degree of } \\
\text { agreement }\end{array}$ & $\begin{array}{l}\text { 1=Strongly disagree } \\
2=\text { Disagree } \\
\text { 3=Agree } \\
4=\text { Strongly Agree }\end{array}$ \\
\hline 12 & $\begin{array}{l}\text { Interface definition descriptions are } \\
\text { maintained in a designated location, under } \\
\text { configuration management, and accessible } \\
\text { to all who need them. }\end{array}$ & $\begin{array}{l}\text { Degree of } \\
\text { agreement }\end{array}$ & $\begin{array}{l}1=\text { Strongly disagree } \\
2=\text { Disagree } \\
3=\text { Agree } \\
4=\text { Strongly Agree }\end{array}$ \\
\hline 13 & $\begin{array}{l}\text { For this project, the product high-level } \\
\text { structure is documented, kept up to date, } \\
\text { and managed under configuration control. }\end{array}$ & $\begin{array}{l}\text { Degree of } \\
\text { agreement }\end{array}$ & $\begin{array}{l}1=\text { Strongly disagree } \\
2=\text { Disagree } \\
3=\text { Agree } \\
4=\text { Strongly Agree }\end{array}$ \\
\hline 14 & $\begin{array}{l}\text { For this project, the product high-level } \\
\text { structure is documented using multiple } \\
\text { views (e.g. functional views, module views, } \\
\text { etc.). }\end{array}$ & $\begin{array}{l}\text { Degree of } \\
\text { agreement }\end{array}$ & $\begin{array}{l}1=\text { Strongly disagree } \\
2=\text { Disagree } \\
3=\text { Agree } \\
4=\text { Strongly Agree }\end{array}$ \\
\hline 15 & $\begin{array}{l}\text { For this project, the product high-level } \\
\text { structure is accessible to all relevant project } \\
\text { personnel. }\end{array}$ & $\begin{array}{l}\text { Degree of } \\
\text { agreement }\end{array}$ & $\begin{array}{l}1=\text { Strongly disagree } \\
2=\text { Disagree } \\
3=\text { Agree } \\
4=\text { Strongly Agree }\end{array}$ \\
\hline
\end{tabular}

The assessed values are combined into a weighted summed index to create the assessment for SEC-ARCH scaled from 1 (very low capability) to 4 (very high capability). 


\section{Product Integration Capability (SEC-PI)}

The project's application of best practices in Product Integration was assessed through the questions shown in Table 30.

\section{Table 30: SEC-PI Assessment Questions}

\begin{tabular}{|l|l|l|l|}
\hline Q\# & Question & Response & Assessment criteria \\
\hline J1 & $\begin{array}{l}\text { This project has accurate and up-to-date } \\
\text { documents defining its product integration } \\
\text { process, plans, criteria, etc. throughout the } \\
\text { lifecycle. }\end{array}$ & $\begin{array}{l}\text { Degree of } \\
\text { agreement }\end{array}$ & $\begin{array}{l}\text { 1=Strongly disagree } \\
\text { 2=Disagree } \\
\text { 3=Agree } \\
\text { 4=Strongly Agree }\end{array}$ \\
\hline
\end{tabular}

The assessed values are combined into a weighted summed index to create the assessment for SEC-PI scaled from 1 (very low capability) to 4 (very high capability).

\section{Verification Capability (SEC-VER)}

The project's application of best practices in Verification was assessed through the questions shown in Table 31.

\section{Table 31: SEC-VER Assessment Questions}

\begin{tabular}{|c|c|c|c|}
\hline Q\# & Question & Response & Assessment criteria \\
\hline K1 & $\begin{array}{l}\text { This project has accurate and up-to-date } \\
\text { documents defining the procedures used for } \\
\text { the test and verification of systems and } \\
\text { system elements. }\end{array}$ & $\begin{array}{l}\text { Degree of } \\
\text { agreement }\end{array}$ & $\begin{array}{l}1=\text { Strongly disagree } \\
2=\text { Disagree } \\
3=\text { Agree } \\
4=\text { Strongly Agree }\end{array}$ \\
\hline K2 & $\begin{array}{l}\text { This project has accurate and up-to-date } \\
\text { documents defining acceptance criteria used } \\
\text { for the verification of systems and system } \\
\text { elements. }\end{array}$ & $\begin{array}{l}\text { Degree of } \\
\text { agreement }\end{array}$ & $\begin{array}{l}1=\text { Strongly disagree } \\
2=\text { Disagree } \\
3=\text { Agree } \\
4=\text { Strongly Agree }\end{array}$ \\
\hline K3 & $\begin{array}{l}\text { This project has a documented and practiced } \\
\text { review process for work products that } \\
\text { defines entry and exit criteria. }\end{array}$ & $\begin{array}{l}\text { Degree of } \\
\text { agreement }\end{array}$ & $\begin{array}{l}1=\text { Strongly disagree } \\
2=\text { Disagree } \\
3=\text { Agree } \\
4=\text { Strongly Agree }\end{array}$ \\
\hline K4 & $\begin{array}{l}\text { This project has a documented and practiced } \\
\text { review process that includes training the } \\
\text { reviewers to conduct reviews. }\end{array}$ & $\begin{array}{l}\text { Degree of } \\
\text { agreement }\end{array}$ & $\begin{array}{l}1=\text { Strongly disagree } \\
2=\text { Disagree } \\
3=\text { Agree } \\
4=\text { Strongly Agree }\end{array}$ \\
\hline K5 & $\begin{array}{l}\text { This project has a documented and practiced } \\
\text { review process that defines criteria for the } \\
\text { selection of work products for review. }\end{array}$ & $\begin{array}{l}\text { Degree of } \\
\text { agreement }\end{array}$ & $\begin{array}{l}1=\text { Strongly disagree } \\
2=\text { Disagree } \\
3=\text { Agree } \\
4=\text { Strongly Agree }\end{array}$ \\
\hline K6 & $\begin{array}{l}\text { This project has a documented and practiced } \\
\text { review process that tracks action items to } \\
\text { closure. }\end{array}$ & $\begin{array}{l}\text { Degree of } \\
\text { agreement }\end{array}$ & $\begin{array}{l}1=\text { Strongly disagree } \\
2=\text { Disagree } \\
3=\text { Agree } \\
4=\text { Strongly Agree }\end{array}$ \\
\hline K7 & $\begin{array}{l}\text { This project has a documented and practiced } \\
\text { review process that addresses identified } \\
\text { risks and risk mitigation activities during } \\
\text { reviews. }\end{array}$ & $\begin{array}{l}\text { Degree of } \\
\text { agreement }\end{array}$ & $\begin{array}{l}1=\text { Strongly disagree } \\
2=\text { Disagree } \\
3=\text { Agree } \\
4=\text { Strongly Agree }\end{array}$ \\
\hline K8 & $\begin{array}{l}\text { This project has a documented and practiced } \\
\text { review process that examines completeness } \\
\text { of configuration baselines. }\end{array}$ & $\begin{array}{l}\text { Degree of } \\
\text { agreement }\end{array}$ & $\begin{array}{l}1=\text { Strongly disagree } \\
2=\text { Disagree } \\
3=\text { Agree } \\
4=\text { Strongly Agree }\end{array}$ \\
\hline
\end{tabular}




\begin{tabular}{|l|l|l|l|}
\hline Q\# & Question & Response & Assessment criteria \\
\hline K9 & This project conducts non-advocate reviews & Degree of & 1=Strongly disagree \\
& and documents results, issues, action items, & agreement & 2=Disagree \\
& risks, and risk mitigations. & & 3=Agree \\
& & & 4=Strongly Agree \\
\hline
\end{tabular}

The assessed values are combined into a weighted summed index to create the assessment for

SEC-VER scaled from 1 (very low capability) to 4 (very high capability).

\section{Validation Capability (SEC-VAL)}

The project's application of best practices in Validation was assessed through the questions shown in Table 32.

Table 32: SEC-VAL Assessment Questions

\begin{tabular}{|l|l|l|l|}
\hline Q\# & Question & Response & Assessment criteria \\
\hline L1 & $\begin{array}{l}\text { This project has accurate and up-to-date } \\
\text { documents defining the procedures used for } \\
\text { the validation of systems and system } \\
\text { elements. }\end{array}$ & $\begin{array}{l}\text { Degree of } \\
\text { agreement }\end{array}$ & $\begin{array}{l}\text { 1=Strongly disagree } \\
\text { 2=Disagree } \\
\text { 3=Agree } \\
\text { 4=Strongly Agree }\end{array}$ \\
\hline L2 & $\begin{array}{l}\text { This project has accurate and up-to-date } \\
\text { documents defining acceptance criteria used } \\
\text { for the validation of systems and system } \\
\text { elements. }\end{array}$ & $\begin{array}{l}\text { Degree of } \\
\text { agreement }\end{array}$ & $\begin{array}{l}\text { 1=Strongly disagree } \\
\text { 2=Disagree } \\
\text { 3=Agree }\end{array}$ \\
\hline
\end{tabular}

The assessed values are combined into a weighted summed index to create the assessment for

SEC-VAL scaled from 1 (very low capability) to 4 (very high capability).

\section{Configuration Management Capability (SEC-CM)}

The project's application of best practices in Configuration Management was assessed through the questions shown in Table 33.

Table 33: SEC-CM Assessment Questions

\begin{tabular}{|c|c|c|c|}
\hline Q\# & Question & Response & Assessment criteria \\
\hline G13 & $\begin{array}{l}\text { For this project, the requirements documents } \\
\text { are managed under a configuration control } \\
\text { process. }\end{array}$ & $\begin{array}{l}\text { Degree of } \\
\text { agreement }\end{array}$ & $\begin{array}{l}1=\text { Strongly disagree } \\
2=\text { Disagree } \\
3=\text { Agree } \\
4=\text { Strongly Agree }\end{array}$ \\
\hline M1 & $\begin{array}{l}\text { This project maintains a listing of items } \\
\text { managed under configuration control. }\end{array}$ & $\begin{array}{l}\text { Degree of } \\
\text { agreement }\end{array}$ & $\begin{array}{l}1=\text { Strongly disagree } \\
2=\text { Disagree } \\
3=\text { Agree } \\
4=\text { Strongly Agree }\end{array}$ \\
\hline M2 & $\begin{array}{l}\text { This project has a configuration management } \\
\text { system that charters a CCB to disposition } \\
\text { change requests. }\end{array}$ & $\begin{array}{l}\text { Degree of } \\
\text { agreement }\end{array}$ & $\begin{array}{l}1=\text { Strongly disagree } \\
2=\text { Disagree } \\
3=\text { Agree } \\
4=\text { Strongly Agree }\end{array}$ \\
\hline M3 & $\begin{array}{l}\text { This project maintains records of requested } \\
\text { and implemented changes to configuration- } \\
\text { managed items. }\end{array}$ & $\begin{array}{l}\text { Degree of } \\
\text { agreement }\end{array}$ & $\begin{array}{l}1=\text { Strongly disagree } \\
2=\text { Disagree } \\
3=\text { Agree } \\
4=\text { Strongly Agree }\end{array}$ \\
\hline M4 & $\begin{array}{l}\text { This project creates and manages } \\
\text { configuration baselines. }\end{array}$ & $\begin{array}{l}\text { Degree of } \\
\text { agreement }\end{array}$ & $\begin{array}{l}1=\text { Strongly disagree } \\
2=\text { Disagree } \\
3=\text { Agree } \\
4=\text { Strongly Agree }\end{array}$ \\
\hline
\end{tabular}


The assessed values are combined into a weighted summed index to create the assessment for SEC-CM scaled from 1 (very low capability) to 4 (very high capability).

\section{Total Systems Engineering Capability (SEC-Total)}

The capability subcategories of D3.1 through D3.11 were combined into a weighted summed index to produce a measure of total systems engineering capability (SEC-Total) scaled from 1 (very low capability) to 4 (very high capability).

\section{OTHER FACTORS}

Factors other than project challenge may also influence project performance. Factors considered in the survey included:

- Prior Experience - the degree of experience that the organization had with similar projects

- Contract Type — fixed price, cost reimbursable, or other contract type governing the project

- SE Organization-SE organized as a separate department or distributed throughout the organization

- Percentage Complete - the percentage of the project that has been complete

- SE Content - the percentage of the non-recurring engineering effort dedicated to systems engineering

\section{Prior Experience (EXP)}

The project's prior experience with similar projects was assessed through the questions shown in

Table 34.

\section{Table 34: EXP Assessment Questions}

\begin{tabular}{|l|l|l|l|}
\hline Q\# & Question & \multicolumn{2}{|l|}{ Response } \\
A9. & $\begin{array}{l}\text { In the past, this project team has } \\
\text { successfully completed projects of similar } \\
\text { scope. }\end{array}$ & $\begin{array}{l}\text { Degree of } \\
\text { agreement }\end{array}$ & $\begin{array}{l}\text { 1=Strongly disagree } \\
\text { 2=Disagree } \\
\text { 3=Agree } \\
\text { 4=Strongly Agree }\end{array}$ \\
\hline C1 & $\begin{array}{l}\text { This organization has successfully } \\
\text { completed projects similar in scope to this } \\
\text { one in the past. }\end{array}$ & $\begin{array}{l}\text { Degree of } \\
\text { agreement }\end{array}$ & $\begin{array}{l}\text { 1=Strongly disagree } \\
\text { 2=Disagree }\end{array}$ \\
& & & $\begin{array}{l}\text { 3=Agree } \\
4=\text { Strongly Agree }\end{array}$ \\
\hline
\end{tabular}

The assessed values are combined into a weighted summed index to create the assessment for $\boldsymbol{E X P}$ scaled from 1 (very low experience) to 4 (very high experience). 


\section{Contract Type}

The type of contract governing the project was assessed through the question shown in Table 35.

Table 35: Contract Type Question

\begin{tabular}{|l|l|l|}
\hline Q\# & Question & Response \\
B13. & $\begin{array}{l}\text { What type of contract(s) was awarded for } \\
\text { this project? }\end{array}$ & $\begin{array}{l}\text { This is a fixed-price contract - the total contract value is primarily } \\
\text { determined by the initial contract. (e.g., FFP, FPIF, FFP-LOE). }\end{array}$ \\
& & $\begin{array}{l}\text { This is a cost-reimbursable contract - the total contract value is } \\
\text { primarily determined by my cost of executing the contract (e.g., } \\
\text { CPFF, CPAF, CPIF). } \\
\text { This contract does not fit the categories listed above. }\end{array}$ \\
\hline
\end{tabular}

The response is used to categorize projects and segment the data set to assess the impact of contract type.

\section{SE Organization}

The structure of the SE operations within the organization was assessed through the question shown in Table 36.

\section{Table 36: SE Organization Question}

\begin{tabular}{|c|c|c|}
\hline Q\# & Question & Response \\
\hline $\mathrm{C} 2$. & Within this organization & $\begin{array}{l}\text { Systems engineering skills and responsibilities are contained in a } \\
\text { separate department. } \\
\text { Systems engineering skills and responsibilities are distributed } \\
\text { throughout other departments. }\end{array}$ \\
\hline
\end{tabular}

The response is used to categorize projects and segment the data set to assess the impact of the structure of SE operations.

\section{Percentage Complete}

The degree of completion of the project was assessed through the question shown in Table 37.

Table 37: Percentage Complete Question

\begin{tabular}{|l|l|l|}
\hline Q\# & Question & Response \\
\hline B12. & $\begin{array}{l}\text { What is the current completion status of this } \\
\text { project? }\end{array}$ & $0-100 \%$ \\
\hline
\end{tabular}

The response is used to categorize projects and segment the data set to assess the impact of percentage complete. 


\section{SE Content}

The magnitude of the SE effort, as a percentage of the total project non-recurring engineering effort, was assessed through the question shown in Table 38.

Table 38: Percentage SE Question

Q\# Question Response

\begin{tabular}{|l|l|l} 
B12. Approximately what percentage of non- & $0-100 \%$
\end{tabular}

recurring engineering (NRE) does Systems

Engineering represent?

The response is used to categorize projects and segment the data set to assess the impact of percentage SE. 


\section{Acronyms and Abbreviations}

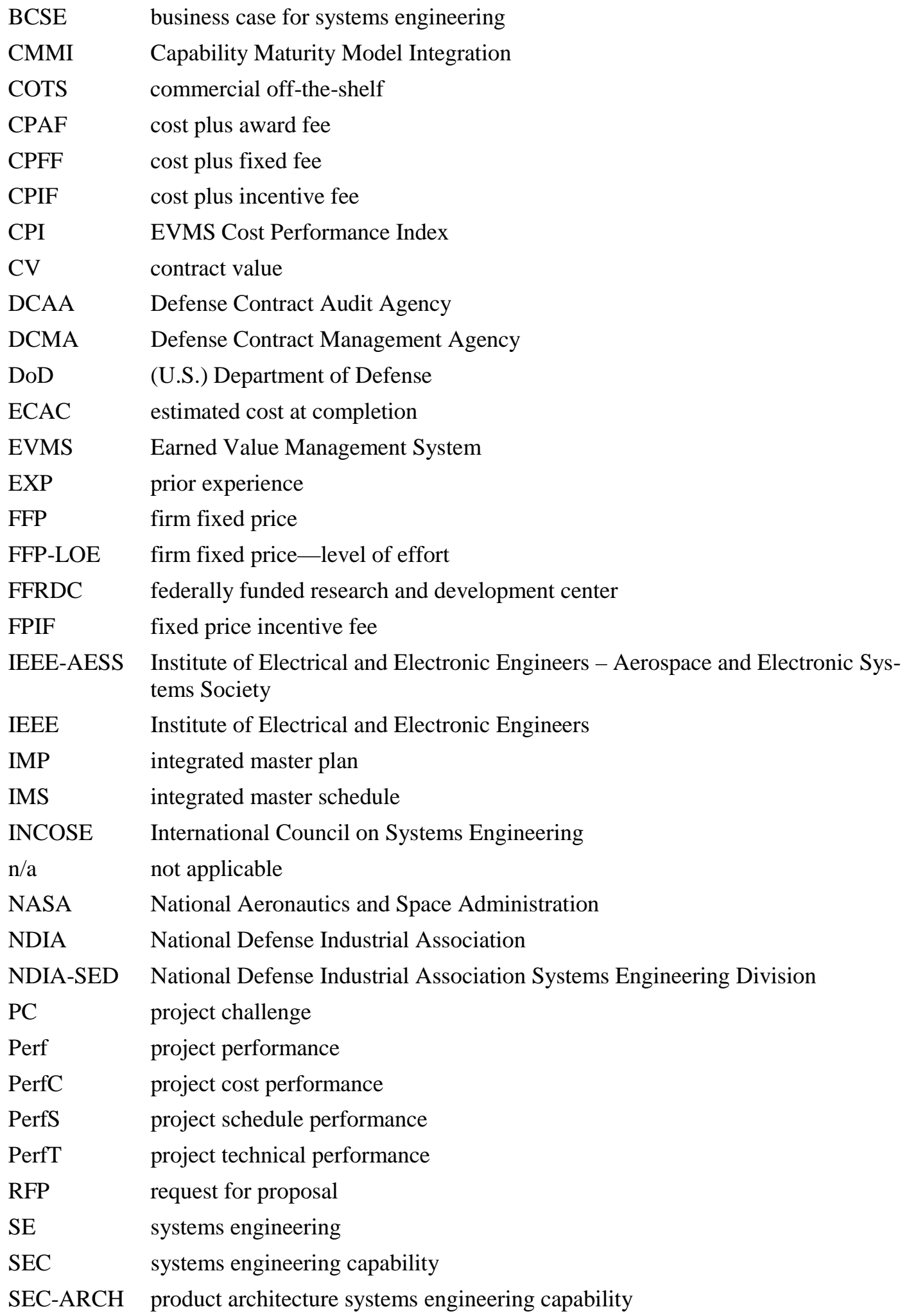




$\begin{array}{ll}\text { SEC-CM } & \text { configuration management systems engineering capability } \\ \text { SEC-IPT } & \text { integrated project team systems engineering capability } \\ \text { SEC-PI } & \text { product integration systems engineering capability } \\ \text { SEC-PMC } & \text { project monitoring and control systems engineering capability } \\ \text { SEC-PP } & \text { project planning systems engineering capability } \\ \text { SEC-REQ } & \text { requirements development and management systems engineering capability } \\ \text { SEC-RSKM } & \text { risk management systems engineering capability } \\ \text { SEC-Total } & \text { total SE capability applied to a project } \\ \text { SEC-TRD } & \text { trade study systems engineering capability } \\ \text { SEC-VAL } & \text { validation systems engineering capability } \\ \text { SEC-VER } & \text { verification systems engineering capability } \\ \text { SEI } & \text { Software Engineering Institute } \\ \text { SEMP } & \text { systems engineering master plan } \\ \text { SoS } & \text { system of systems } \\ \text { SPI } & \text { EVMS Schedule Performance Index } \\ \text { WBS } & \text { work breakdown structure }\end{array}$




\section{References}

URLs are valid as of the publication date of this document.

[CMMI Product Team 2002]

CMMI Product Team. CMMI for Systems Engineering/Software Engineering/Integrated Product and Process Development/Supplier Sourcing, Version 1.1, Continuous Representation (CMMISE/SW/IPPD/SS, V1.1, Continuous) (CMU/SEI-2002-TR-011). Software Engineering Institute, Carnegie Mellon University, 2002. http://www.sei.cmu.edu/library/abstracts/reports/02tr011.cfm

\section{[Coleman 1964]}

Coleman, J. S. Models of Change and Response Uncertainty. Prentice-Hall, 1964.

\section{[Elm 2008]}

Elm, J.; Goldenson, D.; El Emam, K.; Donatelli, \& N.; Neisa, A. A Survey of Systems Engineering Effectiveness - Initial Results (CMU/SEI-2008-SR-034). Software Engineering Institute, Carnegie Mellon University, 2008. http://www.sei.cmu.edu/library/abstracts/reports/08sr034.cfm

\section{[EIm 2012]}

Elm, J. The Business Case for Systems Engineering Study: Assessing Project Performance from Sparse Data. (CMU/SEI-2012-SR-010). Software Engineering Institute, Carnegie Mellon University, 2012. http://www.sei.cmu.edu/library/abstracts/reports/12sr010.cfm

\section{[Elm 2013]}

Elm, J. \& Goldenson, D. The Business Case for Systems Engineering Study: Detailed Response Data. (CMU/SEI-2012-SR-011). Software Engineering Institute, Carnegie Mellon University, 2013. http://www.sei.cmu.edu/library/abstracts/reports/12sr011.cfm

\section{[Freeman 1965]}

Freeman, Linton C. Elementary Applied Statistics: For Students in Behavior Science. J. Wiley \& Sons, 1965.

\section{[Goldenson 2008]}

Goldenson, Dennis; McCurley, James; \& Stoddard, Robert. Use and Organizational Effects of Measurement and Analysis in High Maturity Organizations: Results from the 2008 SEI State of Measurement and Analysis Practice Surveys (CMU/SEI-2008-TR-024). Software Engineering Institute, Carnegie Mellon University, 2008.

http://www.sei.cmu.edu/library/abstracts/reports/08tr024.cfm

\section{[Guilford 1954]}

Guilford, J. P. Psychometric Methods, 2nd ed. McGraw-Hill Inc., 1954.

\section{[Hill 2006]}

Hill, T. \& Lewicki, P. Statistics: Methods and Applications: a Comprehensive Reference for Science, Industry, and Data Mining. StatSoft, Inc., 2006. 
[Honour 2004]

Honour, E. Understanding the Value of Systems Engineering.

http://www.incose.org/secoe/0103/ValueSE-INCOSE04.pdf (2004).

\section{[McCurley 2010]}

McCurley, James \& Goldenson, Dennis. Performance Effects of Measurement and Analysis: Perspectives from CMMI High Maturity Organizations and Appraisers (CMU/SEI-2010-TR-022). Software Engineering Institute, Carnegie Mellon University, 2010.

http://www.sei.cmu.edu/library/abstracts/reports/10tr022.cfm

\section{[Stoddard 2010]}

Stoddard, Robert \& Goldenson, Dennis. Approaches to Process Performance Modeling: A Summary from the SEI Series of Workshops on CMMI High Maturity Measurement and Analysis

(CMU/SEI-2009-TR-021). Software Engineering Institute, Carnegie Mellon University, January 2010. http://www.sei.cmu.edu/library/abstracts/reports/09tr021.cfm 


\section{REPORT DOCUMENTATION PAGE \\ Form Approved \\ OMB No. 0704-0188}

Public reporting burden for this collection of information is estimated to average 1 hour per response, including the time for reviewing instructions, searching existing data sources, gathering and maintaining the data needed, and completing and reviewing the collection of information. Send comments regarding this burden estimate or any other aspect of this collection of information, including suggestions for reducing this burden, to Washington Headquarters Services, Directorate for information Operations and Reports, 1215 Jefferson Davis Highway, Suite 1204, Arlington, VA 22202-4302, and to the Office of Management and Budget, Paperwork Reduction Project (0704-0188), Washington, DC 20503.

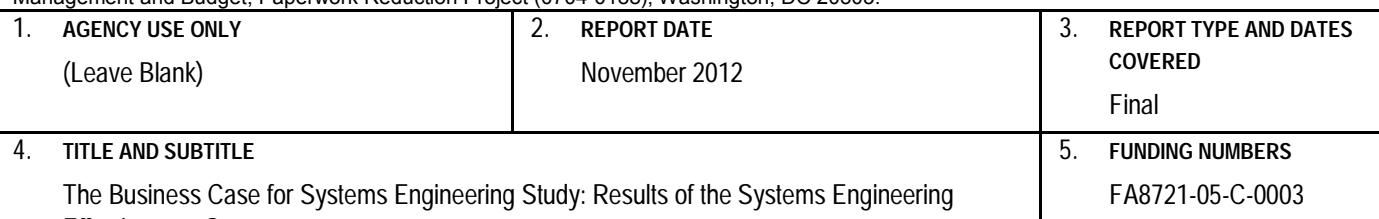
Effectiveness Survey

6. AUTHOR(S)

Joseph P. Elm and Dennis R. Goldenson

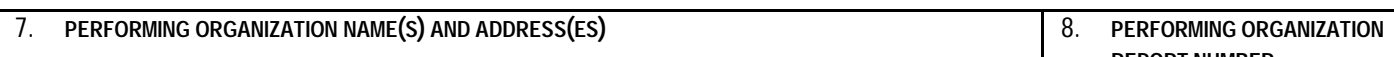

Software Engineering Institute

Carnegie Mellon University REPORT NUMBER

Pittsburgh, PA 15213

9. SPONSORING/MONTORING AGENCY NAME(S) AND ADDRESS(ES)

AFLCMC/PZE/Hanscom

CMU/SEI-2012-SR-009

Enterprise Acquisition Division

20 Schilling Circle

Building 1305

Hanscom AFB, MA 01731-2116

11. SUPPLEMENTARY NOTES

\begin{tabular}{l|l}
\hline 12A DISTRIBUTIONAVAILABIUTY STATEMENT & 12B DISTRIBUTIONCODE \\
Unclassified/Unlimited, DTIC, NTIS &
\end{tabular}

13. ABSTRACT (MAXIMUM 200 WORDS)

This report summarizes the results of a survey that had the goal of quantifying the connection between the application of systems engineering (SE) best practices to projects and programs and the performance of those projects and programs. The survey population consisted of projects and programs executed by system developers reached through the National Defense Industrial Association Systems Engineering Division (NDIA-SED), the Institute of Electrical and Electronics Engineers Aerospace and Electronic Systems Society (IEEE-AESS), and the International Council on Systems Engineering (INCOSE). Analysis of survey responses revealed strong statistical relationships between project performance and several categories of specific SE best practices. The survey results show notable differences in the relationship between SE best practices and performance between more challenging and less challenging projects. The statistical relationship with project performance is quite strong for survey data of this kind when both SE capability and project challenge are considered together.

\section{SUBJECT TERMS}

systems engineering, performance, project performance

\section{PRICE CODE}

\begin{tabular}{|c|c|c|c|}
\hline $\begin{array}{l}\text { 17. SECURITY CLASSIFCATION OF } \\
\text { REPORT } \\
\text { Unclassified }\end{array}$ & $\begin{array}{l}\text { 18. SECURITY CLASSIFCATION } \\
\text { OFTHISPAGE } \\
\text { Unclassified }\end{array}$ & $\begin{array}{l}\text { 19. SECURITY CLASSIFCATION } \\
\text { OF ABSTRACT } \\
\text { Unclassified }\end{array}$ & $\begin{array}{l}\text { 20. } \text { UMTATION OF } \\
\text { ABSTRACT } \\
\text { UL }\end{array}$ \\
\hline
\end{tabular}

